\title{
Blockchain and Cryptocurrencies
}

Edited by Saralees Nadarajah, Stephen Chan, Jeffrey Chu and Yuanyuan Zhang Printed Edition of the Special Issue Published in Journal of Risk and Financial Management 


\section{Blockchain and Cryptocurrencies}





\section{Blockchain and Cryptocurrencies}

Editors

Saralees Nadarajah

Stephen Chan

Jeffrey Chu

Yuanyuan Zhang 
Editors

Saralees Nadarajah

School of Mathematics,

University of Manchester

UK

Yuanyuan Zhang

School of Mathematics,

University of Manchester

UK
Stephen Chan

Department of Mathematics

and Statistics,

American University of Sharjah

$\mathrm{UAE}$
Jeffrey Chu

Department of Statistics,

Universidad Carlos III de Madrid

Spain

\section{Editorial Office}

MDPI

St. Alban-Anlage 66

4052 Basel, Switzerland

This is a reprint of articles from the Special Issue published online in the open access journal Journal of Risk and Financial Management (ISSN 1911-8074) (available at: https://www.mdpi.com/ journal/jrfm/special_issues/Blockchain).

For citation purposes, cite each article independently as indicated on the article page online and as indicated below:

LastName, A.A.; LastName, B.B.; LastName, C.C. Article Title. Journal Name Year, Article Number, Page Range.

ISBN 978-3-03943-533-3 (Hbk)

ISBN 978-3-03943-534-0 (PDF)

(c) 2020 by the authors. Articles in this book are Open Access and distributed under the Creative Commons Attribution (CC BY) license, which allows users to download, copy and build upon published articles, as long as the author and publisher are properly credited, which ensures maximum dissemination and a wider impact of our publications.

The book as a whole is distributed by MDPI under the terms and conditions of the Creative Commons license CC BY-NC-ND. 


\section{Contents}

About the Editors $\ldots \ldots \ldots \ldots \ldots \ldots \ldots \ldots \ldots$ vii

Stephen Chan, Jeffrey Chu, Yuanyuan Zhang and Saralees Nadarajah

Blockchain and Cryptocurrencies

Reprinted from: J. Risk Financial Manag. 2020, 13, 227, doi:10.3390/jrfm13100227 . . . . . . . . . . 1

Nader Trabelsi

Are There Any Volatility Spill-Over Effects among Cryptocurrencies and Widely Traded Asset Classes?

Reprinted from: J. Risk Financial Manag. 2018, 11, 66, doi:10.3390/jrfm11040066 _ . . . . . . . . 5

Toan Luu Duc Huynh

Spillover Risks on Cryptocurrency Markets: A Look from VAR-SVAR Granger Causality and Student's-t Copulas

Reprinted from: J. Risk Financial Manag. 2019, 12, 52, doi:10.3390/jrfm12020052 _ . . . . . . . . 23

Nikolaos A. Kyriazis

A Survey on Efficiency and Profitable Trading Opportunities in Cryptocurrency Markets

Reprinted from: J. Risk Financial Manag. 2019, 12, 67, doi:10.3390/jrfm12020067 . . . . . . . . . 43

Ziaul Haque Munim, Mohammad Hassan Shakil and Ilan Alon

Next-Day Bitcoin Price Forecast

Reprinted from: J. Risk Financial Manag. 2019, 12, 103, doi:10.3390/jrfm12020103 . . . . . . . . . 61

Paulo Ferreira and Éder Pereira

Contagion Effect in Cryptocurrency Market

Reprinted from: J. Risk Financial Manag. 2019, 12, 115, doi:10.3390/jrfm12030115 . . . . . . . . . . 77

Nikolaos A. Kyriazis and Paraskevi Prassa

Which Cryptocurrencies Are Mostly Traded in Distressed Times?

Reprinted from: J. Risk Financial Manag. 2019, 12, 135, doi:10.3390/jrfm12030135 . . . . . . . . . 85

Yuanyuan Zhang, Stephen Chan, Jeffrey Chu and Hana Sulieman

On the Market Efficiency and Liquidity of High-FrequencyCryptocurrencies in a Bull and Bear Market

Reprinted from: J. Risk Financial Manag. 2020, 13, 8, doi:10.3390/jrfm13010008 . . . . . . . . . . 97

Mircea Constantin Șcheau, Simona Liliana Crăciunescu, Iulia Brici and Monica Violeta Achim

A Cryptocurrency Spectrum Short Analysis

Reprinted from: J. Risk Financial Manag. 2020, 13, 184, doi:10.3390/jrfm13080184 . . . . . . . . . 111

Ahmed Ibrahim, Rasha Kashef, Menglu Li, Esteban Valencia and Eric Huang

Bitcoin Network Mechanics: Forecasting the BTC Closing Price Using Vector Auto-Regression

Models Based on Endogenous and Exogenous Feature Variables

Reprinted from: J. Risk Financial Manag. 2020, 13, 189, doi:10.3390/jrfm13090189 . . . . . . . . . 127 



\section{About the Editors}

Saralees Nadarajah is a Senior Lecturer at the School of Mathematics, University of Manchester, UK. His research interests include climate modeling, extreme value theory, distribution theory, information theory, sampling and experimental designs, and reliability. He is an author/co-author of four books and has over 600 papers published or accepted. He has held positions in Florida, California, and Nebraska.

Stephen Chan was awarded the EPSRC Doctoral Prize Fellowship in 2016 at the University of Manchester, UK. His research areas include extreme value analysis and distribution theory in analyzing financial commodities data and cryptocurrency data. He co-developed and co-wrote an $\mathrm{R}$ package, entitled 'VaRES', for computing value at risk and expected shortfall. He is a co-author of the book Extreme Events in Finance: A Handbook of Extreme Value Theory and its Applications.

Jeffrey Chu is an assistant professor at Universidad Carlos III de Madrid, Spain. He holds a $\mathrm{PhD}$ in Financial Mathematics from the University of Manchester UK, where he also undertook postdoctoral research funded by the U.S. Army Research Laboratory. His current research interests cover statistical modeling and distribution theory, graphs and networks, and cryptocurrencies, and financial technology.

Yuanyuan Zhang is a Data Scientist at the Centre for Epidemiology at the University of Manchester. Her research interests are focused on statistical methods and distribution theory, with applications to cryptocurrencies, and big data. Among some of her accomplishments are publications as an author and guest editor of leading journals, such as Computational Statistics and Data Analysis and the Journal of Risk and Financial Management; and winning the Institute of Mathematical Statistics (IMS) New Researcher Travel Award 2019. 



\title{
Editorial
}

\section{Blockchain and Cryptocurrencies}

\author{
Stephen Chan ${ }^{1, *}$, Jeffrey Chu ${ }^{2}$, Yuanyuan Zhang ${ }^{3}$ and Saralees Nadarajah ${ }^{3}$ \\ 1 Department of Mathematics and Statistics, American University of Sharjah, Sharjah 26666, UAE \\ 2 School of Statistics, Renmin University of China, No. 59 Zhongguancun Street, Haidian District, \\ Beijing 100872, China; jeffrey.jchu@outlook.com \\ 3 School of Mathematics, University of Manchester, Manchester M13 9PL, UK; \\ yuanyuan.zhang@manchester.ac.uk (Y.Z.); saralees.nadarajah@manchester.ac.uk (S.N.) \\ * Correspondence: schan@aus.edu
}

Received: 24 September 2020; Accepted: 24 September 2020; Published: 26 September 2020

\begin{abstract}
Cryptocurrencies are essentially digital currencies that use blockchain technology and cryptography to facilitate secure and anonymous transactions. Many institutions and countries are starting to understand and implement the idea of cryptocurrencies in their business models. With this recent surge in interest, we believe that now is the time to start studying these areas as a key piece of financial technology. The aim of this Special Issue is to provide a collection of papers from leading experts in the area of blockchain and cryptocurrencies. The topics covered in this Special Issue includes the economics, financial analysis and risk management with cryptocurrencies.
\end{abstract}

Keywords: Blockchain; Cryptocurrencies; Digital Currencies; Risk management; Bitcoin; Financial analysis

Blockchain and cryptocurrencies have recently captured the interest of academics and those in industry.

Cryptocurrencies are essentially digital currencies that use blockchain technology and cryptography to facilitate secure and anonymous transactions. The cryptocurrency market is worth over USD 500 billion. Many institutions and countries are starting to understand and implement the idea of cryptocurrencies in their business models. The aim of this Special Issue is to provide a collection of papers from leading experts in the area of blockchain and cryptocurrencies. This volume includes a wide variety of theoretical and empirical contributions that address a range of issues and topics related to blockchain and cryptocurrencies. Short abstracts of the articles in this Special Issue are presented below:

Trabelsi (2018) investigates the connectedness of the cryptocurrency markets, with other traditional currencies, stock market indices, and commodities using the spill over index approach. The results show no significant spillover effects between the cryptocurrencies and other financial markets. This suggests that cryptocurrencies pose no danger to the stability of financial systems and is seen as an independent financial instrument.

Luu Duc Huynh (2019) analyses the spillover risks among cryptocurrency markets using the VAR (Vector Autoregressive Model)-SVAR (Structural Vector Autoregressive Model) Granger causality and Student's-t Copulas. The results show that Ethereum is likely to be the independent coin in this market, while Bitcoin tends to be the spillover effect recipient. Furthermore, the study sheds light on investigating the contagion risks among cryptocurrencies by employing Student's-t Copulas for modelling the joint distribution. The result suggests that all coins negatively change in terms of extreme value and the investors are advised to pay more attention to 'bad news' and moving patterns in order to make timely decisions.

Kyriazis (2019) provides a systematic survey on whether the pricing behavior of cryptocurrencies is predictable, through centering the investigation on the Efficient Market Hypothesis. It is observed 
that the majority of academic papers provide evidence for the inefficiency of Bitcoin and other digital currencies. Furthermore, studies over the past few years have shown market efficiency in cryptocurrencies, which suggests less profitable trading strategies for speculators.

Munim et al. (2019) provide forecasts of Bitcoin prices using the autoregressive integrated moving average (ARIMA) and neural network auto regression (NNAR) models. The forecast provides next-day Bitcoin price predictions both with and without re-estimation of the forecast model for each step. Training and testing samples are implemented to cross-validate the forecast results. The results show, in the first training sample, that NNAR performs better than ARIMA, while ARIMA outperforms NNAR in the second training sample. Furthermore, the superiority of forecast results from the ARIMA model over NNAR in the test-sample periods is confirmed by the Diebold Mariano test. Despite the sophistication of NNAR, this paper demonstrates ARIMA's enduring power of volatile Bitcoin price prediction.

Ferreira and Pereira (2019) evaluate the contagion effect between Bitcoin and other major cryptocurrencies, using the Detrended Cross-Correlation Analysis correlation coefficient $(\triangle \rho D C C A)$, and compare the periods before and after the crash. The results find evidence of a contagion effect, with the market being more integrated now than in the past.

(Kyriazis and Prassa 2019) investigate the level of liquidity of digital currencies during the intense bearish phase (April 2018 until January 2019) in their markets. The Amihud's illiquidity ratio is employed in order to measure the liquidity of these digital assets. The results indicate that the most popular cryptocurrencies exhibit higher levels of liquidity during periods of market stress. Furthermore, the results support the findings of relevant literature about strong and persistent positive or negative herding behavior of investors based on Bitcoin, Ethereum and highly capitalized cryptocurrencies in general.

Zhang et al. (2020) provide the first high-frequency analysis of cryptocurrencies in terms of bull and bear markets. Algorithms are implemented for detecting the turning points to identify bull and bear phases in cryptocurrencies, and during these periods the market efficiency and liquidity are investigated. The findings show that the hourly returns of cryptocurrencies during a bull market indicate market efficiency when using the detrended-fluctuation-analysis (DFA) method to analyze the Hurst exponent with a rolling window approach. However, when conditions turn and there is a bear-market period, we see signs of a more inefficient market. Furthermore, the results indicated differences between the cryptocurrencies in terms of their liquidity during the two market states. Moving from a bull to a bear market, Ethereum and Litecoin appear to become more illiquid, as opposed to Bitcoin, which appears to become more liquid.

Șcheau et al. (2020) provide a literature review on empirical studies related to the interferences between cryptocurrency and cybercrime.

Ibrahim et al. (2020) investigate the Bitcoin market mechanics through using the vector autoregression (VAR) and the Bayesian vector autoregression (BVAR) prediction models. The analysis provides an in-depth understanding of what drives Bitcoin price and capitalize on market movement and identifies the significant price drivers, including stakeholders impacted, effects of time, as well as supply, demand, and other characteristics. The experimental results show that the vector-autoregression-based models achieved better performance compared to the traditional autoregression models and the Bayesian regression models.

Funding: This research received no external funding.

Conflicts of Interest: The authors declare no conflict of interest.

\section{References}

Ferreira, Paulo, and Éder Pereira. 2019. Contagion effect in cryptocurrency market. Journal of Risk and Financial Management 12: 115. [CrossRef] 
Ibrahim, Ahmed, Rasha Kashef, Menglu Li, Esteban Valencia, and Eric Huang. 2020. Bitcoin Network Mechanics: Forecasting the BTC Closing Price Using Vector Auto-Regression Models Based on Endogenous and Exogenous Feature Variables. Journal of Risk and Financial Management 13: 189. [CrossRef]

Kyriazis, Nikolaos A. 2019. A survey on efficiency and profitable trading opportunities in cryptocurrency markets. Journal of Risk and Financial Management 12: 67. [CrossRef]

Kyriazis, Nikolaos A., and Paraskevi Prassa. 2019. Which Cryptocurrencies Are Mostly Traded in Distressed Times? Journal of Risk and Financial Management 12: 135. [CrossRef]

Luu Duc Huynh, Toan. 2019. Spillover risks on cryptocurrency markets: A look from VAR-SVAR granger causality and student'st copulas. Journal of Risk and Financial Management 12: 52. [CrossRef]

Munim, Ziaul Haque, Mohammad Hassan Shakil, and Ilan Alon. 2019. Next-day bitcoin price forecast. Journal of Risk and Financial Management 12: 103. [CrossRef]

Șcheau, Mircea Constantin, Simona Liliana Crăciunescu, Iulia Brici, and Monica Violeta Achim. 2020. A Cryptocurrency Spectrum Short Analysis. Journal of Risk and Financial Management 13: 184. [CrossRef]

Trabelsi, Nader. 2018. Are there any volatility spill-over effects among cryptocurrencies and widely traded asset classes? Journal of Risk and Financial Management 11: 66. [CrossRef]

Zhang, Yuanyuan, Stephen Chan, Jeffrey Chu, and Hana Sulieman. 2020. On the Market Efficiency and Liquidity of High-Frequency Cryptocurrencies in a Bull and Bear Market. Journal of Risk and Financial Management 13: 8. [CrossRef]

(C) 2020 by the authors. Licensee MDPI, Basel, Switzerland. This article is an open access article distributed under the terms and conditions of the Creative Commons Attribution (CC BY) license (http://creativecommons.org/licenses/by/4.0/). 

Article

\title{
Are There Any Volatility Spill-Over Effects among Cryptocurrencies and Widely Traded Asset Classes?
}

\author{
Nader Trabelsi ${ }^{1,2}$ \\ 1 Department of Finance and Investment, College of Economics and Administrative Sciences, Al Imam \\ Mohammad Ibn Saud Islamic University (IMSIU), Riyadh 5701, Saudi Arabia \\ 2 LARTIGE, University of Sfax, Sfax 3018, Tunisia; nhtrabelsi@imamu.edu.sa
}

Received: 4 September 2018; Accepted: 18 October 2018; Published: 23 October 2018

\begin{abstract}
In the present paper, we investigate connectedness within cryptocurrency markets as well as across the Bitcoin index (hereafter, BPI) and widely traded asset classes such as traditional currencies, stock market indices and commodities, such as gold and Brent oil. A spill over index approach with the spectral representation of variance decomposition networks, is employed to measure connectedness. Results show no significant spillover effects between the nascent market of cryptocurrencies and other financial markets. We suggest that cryptocurrencies are real independent financial instruments that pose no danger to financial system stability. Concerning the connectedness within the cryptocurrency markets, we report a time-frequency-dynamics connectedness nature. Moreover, the decomposition of the total spill over index is mostly dominated by a short frequency component (2-4 days) leading to the conclusion that this nascent market is highly speculative at present. These findings provide insights for regulators and potential international investors.
\end{abstract}

Keywords: cryptocurrencies; connectedness; spill overs; spectral analysis; time-frequency-dynamic

\section{Introduction}

Since the systemic failure of the global equity markets during the recent financial crisis in 2008, the public at large has lost confidence in the traditional monetary system. This situation has made non-traditional currency exchange (i.e., digital currency or cryptocurrency) encroach on our daily lives and has become part of the new world economy in this century. ${ }^{1}$ Bitcoin ${ }^{2}$ is a digital currency that has triggered the interest of many users (e.g., companies, merchants, investors, etc.) due to its decentralization, anonymity and freedom, combined with lower fees than those exacted by incumbent payment systems (Joshi 2017). The cryptocurrency markets (popularized by Bitcoin) have arguably been a panacea for the global economic system (Kerner 2014).

Despite that, many economies have been less welcoming of cryptocurrencies, with regulators issuing some of the strongest warnings. It is no secret that the cryptocurrency nature provides a high level of anonymity from the gazing eyes of states, which can therefore facilitate money laundering, tax evasion and terrorist financing. ${ }^{3}$ The controversial opinions about this nascent market have drawn significant attention from the mainstream press and various financial blogs, as well as a wide range of people, which indicates the vital importance of this phenomenon.

Despite its sharp popularity and its huge volatility that occurred from time to time, there are still fewer academic works assessing cryptocurrencies from the economic-finance perspectives ${ }^{4}$.

\footnotetext{
This has given rise also to Islamic products and services (see Trabelsi and Naifar 2017).

Bitcoin is usually labelled as a digital coin or virtual currency, which is BY the people, For the people, Of the people.

Please see document requested by the European Parliament's Special Committee on Financial Crimes, Tax Evasion and Tax Avoidance, July 2018.

4 The other existing studies relating to Bitcoins deal with the legalities and technical details associated with Bitcoins.
} 
Prior studies are concentrated on understanding their moneyless properties, according to gold and traditional currency or compared to a well-known asset such as stocks, bonds, etc. (Barber et al. 2012; Bell 2013; Glaser et al. 2014). As most findings show, Bitcoin is neither a convertible tangible asset (such as gold) nor a fiat currency (such as dollar). There exist other studies focusing on the determinants of bitcoin prices (Buchholz et al. 2012; Kristoufek 2013; van Wijk 2013; Dyhrberg 2015a). Their research results suggest multiple factors that may play important roles in explaining its evolution (e.g., supply-demand fundamentals, the attractiveness for investors, popularity in the media, transaction volume, etc.). The past few years have witnessed considerable research concerning the importance of adding cryptocurrency to a portfolio with equity and with other assets classes (Briere et al. 2013; Eisel et al. 2015; Bouri et al. 2017a). A comparative analysis of different results (see Section 3) shows that no definitive conclusions can be reached in regard to key functions of the Bitcoins for the global economic system. This paper does not lead to any of these research areas. The aim here is to provide empirical insights on the direction and intensity of information transmission within Bitcoins, and between Bitcoins and the global economic system.

A substantial body of literature has investigated the volatility spillover between the same type of asset classes, e.g., stock, bond, commodity and FX markets, between oil and stock markets, between FX and stock market, among other Aftab et al. (2015) and Tiwari et al. (2018). The absence of empirical works addressing spillover effects within the Bitcoin markets, and across Bitcoins and other asset classes, is the motive for this study.

In a recent show of the acceptance of cryptocurrencies by the financial world, several Bitcoin derivatives exchanges opened ${ }^{5}$. In 2016, Chicago Mercantile Exchange (CME) group and Crypto Facilities Ltd. have launched two Bitcoin pricing products: BRR (Bitcoin Reference Rate) and BRTI (a real-time index of the US dollars of one Bitcoin). Therefore, the growing range of acceptance on the various fronts of cryptocurrencies and their started integration with more traditional financial markets may make them develop more relationships, create information flows and induce shocks. This study attempts to explore these features, by evaluating their connectedness with each other, and with other markets such as traditional currencies, stocks and commodities, using the spill over index approach and extensions. These markets are selected for two major reasons. The major reason is the great interest of these asset classes for financial analysts and investors, who use them for risk hedging alternatives or as investment opportunities. The second one is that the number and intensity of crises in these markets in recent decades have sharpened. This seeks to provide a valuable insight for investors about the influences they have on one another and on the stability of Bitcoin markets.

The spill over index approach has been proposed by Diebold and Yilmaz (2009). The basic spill over index idea is simple but often effective in ranking assets by their systemic importance. Following the original method of Diebold and Yilmaz (2009), the Forecast Error Variance Decomposition (hereafter, FEVD) networks associated with an n-variable vector auto-regressive model (VAR) is used to define weighted and directed networks from market data. In Diebold and Yilmaz (2012), authors proposed the generalized variance decompositions of Pesaran and Shin (1998) (GFEVD hereafter), which are invariant to variable ordering, to identify uncorrelated structural shocks from correlated reduced form shocks. More recently, Baruník and Křehlik (2017) have been interested in frequency origins of connectedness variables. Using the spectral technique, Baruník and Křehlík (2017) document that such frequency domains are important for a deep understanding of the different sources of risk spill over, that remain hidden when time domain measures are used (i.e., the effects are simply aggregated through frequencies). In this paper, we follow these extensions to assess volatility spill overs within cryptocurrencies and from BPI to several currencies and stock market indices, as well as commodities, and vice versa.

Our underlying data are daily and cover the period 7 October 2010 to 8 February 2018. The data includes the return of BPI made by Coindesk. Moreover, our data covers the daily return of five

5 e.g., CME group has launched in 2017 cryptocurrencies futures contracts. 
popular stock indexes (i.e., SP500, NASDAQ, FTSE100, HangSeng and Nikkei225) and currencies (i.e., EUR/USD, GBP/USD, USD/JPY, USD/CHF and USD/CAD). For commodity markets, we limit our attention to the daily return of gold and Brent futures contracts. We calculate return as the change in the $\log$ closed prices. Then, the volatility is expressed as the absolute value of these changes. This approach dates back at least to Davidian and Carroll (1987), who argue that absolute return volatility is more robust against symmetric and non-normality variables.

Our results exhibit a time-varying pattern of connectedness within cryptocurrencies. The decomposition of the total spill over index (TSI) is dominated by a short frequency component (2-4 days). This shows that the market is mostly controlled by speculative behavior. We have shown also that volatility shocks in the cryptocurrency market may not propagate to other financial markets and vice versa.

The remainder of this paper proceeds as follows: we begin by presenting a background and a literature review on cryptocurrencies. Then, we describe our methodology on how we calculate the average (i.e., total) spill overs and to identify connectedness frequency. Afterwards, we present our data and substantive results in Sections 5 and 6, respectively. To finish, we conclude in Section 7.

\section{Brief Background on Cryptocurrencies}

The most popular virtual currency is Bitcoin, with a market capitalization of about $40 \%$ of the entire cryptocurrency market. ${ }^{6}$ In its purest form, a digital coin is a peer-to-peer payment cash system and an unregulated currency introduced in 2008 without legal tender status. ${ }^{7}$ The proposed protocol is related to a decentralized system to confirm transactions and to assure that the supply of Bitcoins is, and remains, limited. This system functions without the backing of a central bank or any other monitoring authority. It allows any two willing parties to transact directly with each other without the need for a trusted third party. ${ }^{8}$ The record in the system is secured through cryptography by allowing the protection of data from theft or alteration. The cryptography can be also used for user authentication.

Once confirmed, every transaction is recorded in a "block chain" which is a tamper-proof public ledger technology. Every payment is validated by each network node. While this ecosystem provides an effective protection against "counterfeiting" and ownership disputes, it is still vulnerable to theft. Owners require a cryptographic key pair (i.e., private and public keys). Each owner [trader] transfers coin [bitcoin] to the next [owner] by digitally signing a hash of the previous transaction and the public key of the next owner and adding these to the end of the block chain ${ }^{9}$. A payee can verify the signatures to verify the chain of ownership. Thereby, Bitcoin can be defined as a chain of digital signatures.

On 2 October 2013, the U.S. government followed by China regulators shut down websites involved in that activity, thus creating a bigger shock in this market. Despite this action, Bitcoin price has continued to climb with the undetermined rate. For instance, Bitcoin started in 2017 at less than $\$$ US1000 then in December it went up to around $\$$ US20,000, which meant that it notched up a gain of $1318 \%$ for the year 2017. This certainly looked like speculative hysteria. In February 2018 , cryptocurrencies also reached a record $\$ 600$ billion in market value after the recovery; with the inevitable $\$ 700$ billion marks right around the corner (i.e., will happen very soon)..$^{10}$ Even though it has soared in market capitalization this year, the cryptocurrency market remains small compared to other traditional financial markets.

\footnotetext{
Market capitalization, price, volume and other Crypto-currency info can be listed on coinmarketcap.com.

Unlike conventional currencies that are designed and controlled by a governing body.

The Bitcoin foundation is a private association that was formed in late 2012, after bitcoin had earned a reputation for criminality and fraud. "The mission of this foundation is to coordinate the efforts of the members of the Bitcoin community, helping to create awareness of the benefits of Bitcoin, how to use it and its related technology requirements, for technologists, regulators, the media and everyone else globally" (see foundation's global policy). Thus, this association cannot be a legal or a financial regulatory authority responsible for supervising and controlling Law and legal transactions.

9 Hashing means converting a string of characters of arbitrary length into a fixed length string.

10 Source: statistic predictions by medium.com.
} 
To date, there are 1400 digital currencies in the world and many countries (at least 32 countries) authorize the use of them. It is possible also to convert Bitcoin into all major currencies, but $90 \%$ of the daily trading volume is processed in Chinese Yuan and $6 \%$ in US dollars. ${ }^{11}$

Due to this mysterious rise of trading volume, the Bitcoin phenomenon demands a deeper investigation, which is the main objective of this study.

\section{Literature Review}

Although Bitcoins have been of interest in law and computer science for a long time, it has not significantly attracted the focus of economic and financial researchers. First of all, we mention the study of Nakamoto (2008), as the elusive creator of bitcoin. Following its proposal, Bitcoin was originally presented as a purely peer-to-peer version of electronic cash that allows online payments directly from one party to another without going through any monitoring institution. After that, the sharp spike in bitcoin price, and its huge volatility from time to time, has steered debate amongst economists.

Some papers have concentrated on the characteristics of cryptocurrencies following different forms of money and other well-known assets; among others Grinberg (2011), Wu and Pandey (2014), Barber et al. (2012), Whelan (2013) and Glaser et al. (2014). For example, Grinberg (2011) shows that bitcoin has a competitive advantage to make micropayments. However, Wu and Pandey (2014) finds that bitcoin does not have the key attributes of a currency and it should be regarded as a very illiquid financial asset. Whelan (2013) argues that bitcoin might look like the dollar. The main difference is that the dollar is backed by a government entity, while bitcoin is created and managed by non-government entities. Moreover, users' intentions to participate in the Bitcoin ecosystems are described by Glaser et al. (2014), finding that new users tend to trade Bitcoin on a speculative investment intention basis rather than as a means of paying for goods or services. Likewise, Yermack (2015) claims that Bitcoins closely resemble speculative investments, and their trading style demonstrates characteristics similar to stock trading.

Other papers have concentrated on the price formation of cryptocurrencies; among others Buchholz et al. (2012), Kristoufek (2013), van Wijk (2013), Dyhrberg (2015a). As for the case of any other assets, these authors argued that the price of Bitcoin is determined by several factors such as demand-supply fundamentals, investor's speculative behavior and global financial indicators related to equity markets, foreign exchange rate or crude oil and gold. Ali et al. (2014) also include other factors that influence the value of virtual currencies, such as risk-return trade-offs, transaction costs or relative benefits, and habit formation.

Briere et al. (2013) provide a tentative first look at how Bitcoin might be a suitable instrument for diversification. The researchers concluded that Bitcoin delivers high diversification benefits as it correlates negatively with most of the analyzed stock market indices. More recently, Gangwal (2016) wrote about the effect of including Bitcoin to the portfolio of an international investor. Using mean-variance analysis, the author argued that adding Bitcoin to portfolios always yields a diversification benefit (i.e., a higher Sharpe ratio). This means that Bitcoin return offsets its volatility risk. Due to the non-normal nature of Bitcoin return, Eisel et al. (2015) do not propose the classic mean-variance approach applied by Briere et al. (2013), but adopt a Conditional Value-at-Risk framework (CVaR). The results indicate that an investment in Bitcoin increases the CVaR of a portfolio. Nonetheless, this additional risk is overcompensated by high return, leading to better risk-return ratios. This last issue is further extended by Dyhrberg (2015b) who explores the financial asset capabilities of bitcoin using the Generalized Auroregressive Conditional Heteroskedasticity (GARCH) model. Results show that Bitcoins have a few aspects that are similar to gold and the dollar, indicating hedging capabilities and advantages as a medium of exchange. The asymmetric GARCH show that bitcoin may be useful in risk management and ideal for risk-averse investors in anticipation of negative shocks to the market. Overall, one can conclude that Bitcoin has a place in the

11 Please see the article "Bitcoin Regulation in china still unclear, but Chinese exchanges thrive overseas" by Leonhard Weese. Published on forbes.com. 
financial markets and in portfolio management, as it can be considered as something between a fiat currency and a commodity. Conversely, Baur et al. (2018), using the same sample and econometric models of Dyhrberg (2015b), showed that Bitcoin exhibits distinctively different return, volatility and correlation characteristics compared to gold and the US dollar. On the other hand, Baur et al. (2015) argue that Bitcoin is a hybrid between precious metals and conventional currencies. They also highlight its role as a useful diversifier (i.e., uncorrelated with traditional assets) and an investment asset. In another interesting study, Bouri et al. (2017b) investigate the relationship between Bitcoin and commodities by assessing the ability of Bitcoin to act as a diversifier, hedge, or safe haven against daily movements in commodities in general, and energy commodities in particular. Through the use of an Asymmetric Dynamic Conditional Correlation (DCC) model, results show that Bitcoin is a strong hedge and a safe-haven against movements of commodity indices, including energy commodities. Furthermore, when taking in account the December 2013 Bitcoin price crash, results reveal that Bitcoin hedge and safe-haven properties against movements of commodity indices are only present in the pre-crash period, whereas in the post-crash period, Bitcoin is no more than a diversifier. However, Bouoiyour and Selmi (2015) using global macroeconomic and financial indicators and technical drivers, provide insightful evidence that Bitcoin may be used for economic reasons. Furthermore, there is not any sign of being a safe haven or a long-term promise. Our study differs from the previously mentioned studies. In fact, the global financial crisis of 2007-2009 (the "Great Recession") has simulated considerable interest in defining, measuring and monitoring connectedness among asset classes, markets and countries. As illustrated by this crisis, an important aspect of systemic risk is the propagation of adverse shocks throughout the whole system. As a consequence, a strand of literature that aims at evaluating systemic risk importance and interconnectedness has emerged. In the respective literature, there are many studies done by, among others, Kaul and Sapp (2006), Meurers and Diekmann (2007), Baur and McDermott (2010), Baur and Lucey (2010), Beckmann et al. (2015), Bouoiyour and Selmi (2017), Ranaldo and Söderlind (2010), Grisse and Nitschka (2013), Botman et al. (2013), and Morley (2014), that account for spillover effects and interconnectedness, but only among traditional assets classes. According to this strand of research, our paper builds on and contributes to extending the literature on Bitcoins by assessing interconnectedness within the cryptocurrency market and between Bitcoin price changes and the volatility of traditional asset classes, using within the group of measures in the literature on the spillover index approach.

\section{Methodology}

Besides assessing the overall error variation in an asset " $k$ " due to shock arising in other asset " $j$ " or leading to shocks to other asset classes, we are also interested in assessing shares of forecast error variation in an asset " $k$ " due to shock to an asset " $j$ " at a specific frequency band. To achieve this, we follow the generalized forecast error variance decomposition methodology by Diebold and Yilmaz (2012) and the Baruník and Křehlík (2017).

Let us describe the $n$-variate stationary process $Y_{t}=\left(y_{t, 1}, \ldots, y_{t, n}\right)$ by structural VAR(p) at $t=1, \ldots$, T as:

$$
\Phi(\mathrm{L}) \mathrm{Y}_{\mathrm{t}}=\varepsilon_{\mathrm{t}}
$$

In this equation and below, we define the asset volatility as $y_{t, n}=\left|\ln P_{t, n}-\ln P_{t-1, n}\right|$, where $P_{t, n}$ is the daily closing value of the $n$th asset in the system (e.g., in intra-cryptocurrency market connectedness $n=4$ ) on day . $^{12}$

12 For other advantages of absolute returns one can see Forsberg and Ghysels (2007), Antonakakis and Vergos (2013) and Wang et al. (2016). Indeed, it is well documented in the literature that the use of absolute returns in modeling volatility has some advantages. First of all, absolute returns are more robust than the standard-deviation in the presence of large movements (Davidian and Carroll 1987). In this framework, the standard-deviation may not be investors' most appropriate measure of risk because it rewards the desirable upside movements as hard as it punishes the undesirable downside movements. Furthermore, absolute return modeling is more reliable than the standard-deviation for the non-existence of a fourth moment commonly associated with financial returns (Mikosch 2000). 
We assume that the roots of $|\Phi(z)|$ lie outside the unit-circle. Under this assumption the VAR process has following $\mathrm{MA}(\infty)$ representation:

$$
\mathrm{Y}_{\mathrm{t}}=\Psi(\mathrm{L}) \varepsilon_{\mathrm{t}}
$$

where $\Psi(\mathrm{L})$ is an $\mathrm{n} \times \mathrm{n}$ infinite lag polynomial matrix of coefficients.

Let us define the own variance shares as the fractions of the $H$-step-ahead error variances in forecasting $\mathrm{y}_{j}$ that are due to shocks to $\mathrm{y}_{j}$, for $j=1,2 \ldots, \mathrm{n}$, and across variance shares, or spill over, as the fractions of the $H$-step-ahead error variances in forecasting $\mathrm{y}_{j}$ that are due to shocks to $\mathrm{y}_{k}$, for $k=1,2, \ldots, \mathrm{n}$, such that $j \neq k$. This can be written in the form:

$$
\left(\theta_{H}\right)_{j, k}=\left((\Sigma)_{k, k}\right)^{-1} \sum_{h=0}^{H-1}\left(\left(\Psi_{h} \Sigma\right)_{j, k}\right)^{2} / \sum_{h=0}^{H-1}\left(\Psi_{h} \Sigma \Psi_{h}^{\prime}\right)_{j, j}
$$

where $\Psi_{h}$ is an $\mathrm{n} \times \mathrm{n}$ matrix of coefficients corresponding to lag $h$, and $\sigma_{k k}=(\Sigma)_{k, k}$.

The $\left(\theta_{H}\right)_{j, k}$ captures the Pearson-Shin GFEVD partial contribution from asset class $\mathrm{k}$ to asset class $j$.

Given that the effect does not add up to one $\left(\sum_{h=0}^{H} \theta_{j, k} \neq 1\right)$ within columns by definition in generalized VAR process of FEVDs, we propose measuring pairwise-directional connectedness $\complement_{j \leftarrow k}(H)$, to standardize the effects $\left(\widetilde{\theta}_{H}\right)_{j, k}$ by:

$$
\left(\widetilde{\theta}_{H}\right)_{j, k}=\left(\theta_{H}\right)_{j, k} / \sum_{k}\left(\theta_{H}\right)_{j, k}
$$

The total directional connectedness from a variable $k$ to the other variables is then defined as:

$$
\complement_{j \leftarrow}(H)=100 \times \sum_{j \neq k, j=1}^{\mathrm{n}} \mathrm{C}_{j, k}(H) / \sum_{j, k=1}^{\mathrm{n}} \mathrm{C}_{j, k}(H)
$$

Similarly, the total directional connectedness of other variables to $j$ is given by:

$$
\complement_{\leftarrow k}(H)=100 \times \sum_{j \neq k, k=1}^{n} \mathrm{C}_{j, k}(H) / \sum_{j, k=1}^{n} \mathrm{C}_{j, k}(H)
$$

The connectedness of the whole system is then defined as the share variances in the forecasts contributed by other than own errors, or equally as the ratio of the sum of the diagonal elements to the sum of the entire matrix:

$$
\complement_{H}=100 \times \frac{\sum_{j \neq k}\left(\widetilde{\theta}_{H}\right)_{j, k}}{\sum\left(\widetilde{\theta}_{H}\right)_{j, k}}=100 \times\left(1-\frac{\operatorname{Tr}\left\{\widetilde{\theta}_{h}\right\}}{\sum \widetilde{\theta}_{h}}\right)
$$

$\operatorname{Tr}\{$.$\} is the trace operator.$

After assessing overall error variation in asset $\mathrm{j}$ due to shock arising in an asset $k$, we now follow Barunik et al. (2017) to evaluate connectedness in the frequency domain. We know that GFEVD is the central part of connectedness, hence we consider a frequency response function $\Psi\left(e^{-i \omega}\right)=\sum_{h} e^{-\omega h} \Psi_{h}$ that can be obtained from Fourier transform of the coefficients $\Psi$, with $i=\sqrt{-1}$.

Formally, let us have a frequency band $d=(a, b): a, b \in(-\pi, \pi), a<b$. The generalized variance decompositions on frequency band " $d$ " are defined as:

$$
\left(\theta_{d}\right)_{j, k}=\frac{1}{2 \pi} \int_{-\pi}^{\pi} \Gamma(\omega)(f(\omega))_{j, k}
$$

where $(f(\omega))_{j, k}$, denotes the generalized causation spectrum over frequencies $\omega \in(-\pi, \pi)$, and $\Gamma(\omega)$ is a weighting function. In fact, to obtain a natural decomposition of original GFEVD to frequencies, we can simply weight the $(f(\omega))_{j, k}$ by the frequency share of the variance of variable $j$. (Please see Baruník and Křehlík (2017) for more detail). 
Denote by " $d_{s}$ " an interval on the real line from the set of intervals $\mathcal{D}$ that form a partition of the interval $(-\pi, \pi)$, such that $\cap_{d_{s} \in \mathcal{D}} d_{s}=\varnothing$ and $\cup_{d_{s} \in \mathcal{D}} d_{s}=(-\pi, \pi)$. Due to the linearity of integral and the construction of $d_{s}$, we have:

$$
\left(\theta_{\infty}\right)_{j, k}=\sum_{d_{s} \in \mathcal{D}}\left(\theta_{d_{s}}\right)_{j, k}
$$

The natural way to describe the time-varying frequency of the connectedness is to consider the spectral representation of GFEVD. ${ }^{13}$ For that, let us define the scaled generalized variance decomposition on the frequency band $d=(a, b): a, b \in(-\pi, \pi), a<b$ as:

$$
\left(\widetilde{\theta}_{d}\right)_{j, k}=\left(\theta_{d}\right)_{j, k} / \sum_{k}\left(\theta_{\infty}\right)_{j, k}
$$

The within connectedness on the frequency band $d$ can be then defined as:

$$
C_{d}^{\mathcal{W}}=100\left(\frac{\sum \widetilde{\theta}_{d}}{\sum \widetilde{\theta}_{\infty}}-\frac{\operatorname{Tr}\left\{\widetilde{\theta}_{d}\right\}}{\sum \widetilde{\theta}_{d}}\right)
$$

The frequency connectedness on the frequency band $d$ is also defined as:

$$
C_{d}^{\mathcal{F}}=100\left(1-\frac{\operatorname{Tr}\left\{\tilde{\theta}_{d}\right\}}{\sum\left(\tilde{\theta}_{d}\right)_{j, k}}\right)=C_{d}^{\mathcal{W}} \cdot \frac{\sum \tilde{\theta}_{d}}{\sum \tilde{\theta}_{\infty}}
$$

It is important to note that the within connectedness gives us the connectedness effect that happens within the frequency band and is weighted by the power of the series on the given frequency band exclusively. Moreover, the frequency connectedness decomposes the overall connectedness defined in Equation (3) into distinct parts that, when summed, give the original connectedness measure $\complement_{\infty}$.

\section{Data and Descriptive Statistics}

In this paper, we investigate whether or not cryptocurrencies are in co-movement over time with each other, and with other markets. For the cryptocurrency market, we use data of four successful cryptocurrencies: Bitcoin (BTC), Ethereum (ETH), Ripple (XRP) and Litecoin (LTC). We also use data of the most active Bitcoin-USD index, a simple average of global Bitcoin/USD exchange prices, produced by Coindesk. Moreover, our data covers the daily return of five popular stock indexes (i.e., SP500, NASDAQ, FTSE100, Hang Seng and Nikkei225) and another five major Forex currencies (i.e., EUR/USD, GBP/USD, USD/JPY, USD/CHF and USD/CAD). For commodity markets, we limit our attention to the daily return of gold and Brent futures contracts launched by COMEX and the London International Petroleum Exchange (IPE), respectively. The data spans the period 7 October, 2010 to 8 February, 2018, with a total of 1918 daily observations. For the computation of volatility, we restrict the analysis to daily absolute returns. The summary statistics of the data can be found in Table 1 .

13 The spectral representation of $Y_{\mathrm{t}}$ at frequency d can be defined as a Fourier transform of MA $(\infty)$ filtered series as: $\mathrm{S}_{\mathrm{y}}(d)=$ $\sum_{h=-\infty}^{\infty} \mathrm{E}\left(\mathrm{y}_{\mathrm{t}} \mathrm{y}_{\mathrm{t}-\mathrm{h}}^{\prime}\right) e^{i d h}=\Psi\left(e^{-i d}\right) \Sigma \Psi^{\prime}\left(e^{+i d}\right)$. The power spectrum $S_{\mathrm{y}}(d)$ is a key quantity for understanding frequency dynamics, since it describes how the variance of the $Y_{t}$ is distributed over the frequency components $d$. 


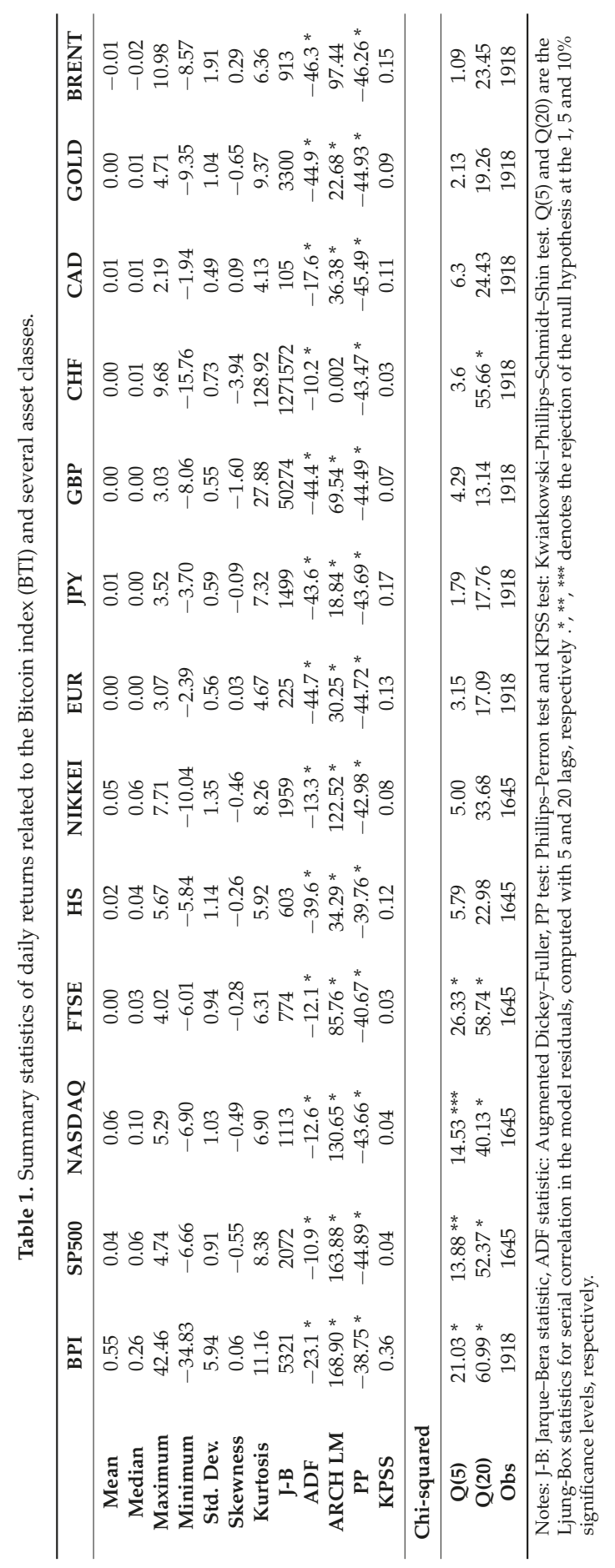


Following Table 1 , the daily mean return is $0.55 \%$ for BPI and thus it is the largest average daily return. At the same time, it is observed that its volatility (represented by the standard deviation) is also higher than the volatility of traditional currencies, equities, or commodities. Therefore, this high volatility may prevent the use of cryptocurrency as a currency (Yermack 2015). The direction of skewness is given by the sign. The positive sign is perceived to have a long tail to the right of the distribution, while the negative sign is perceived to have a long tail to the left. From Table 1, the larger positive value of skewness is associated with $\mathrm{CAD}$, followed by BPI. However, the larger negative value is associated with $\mathrm{CHF}$, followed by GBP. This means that there is a great chance that BPI return goes ups more than downs, during our sample period. Note that rational investors value this positively skewed return, which comes from BPI. On the other hand, all volatility series showed a coefficient of kurtosis significantly in excess of the normal distribution reference value. This means that data has a heavy tail. This departure from normality is confirmed by the Jarque-Bera (J-B) test.

The Augmented Dickey-Fuller (ADF) test indicates that the time series of returns are stationary because we reject the null hypothesis of a unit root at $1 \%$ level of significance in all cases. The Phillips-Perron (PP) and Kwiatkowski-Phillips-Schmidt-Shin (KPSS) tests also confirm this stationarity. Furthermore, the results of the Lagrange multiplier (LM) test for autoregressive conditional heteroskedastic (ARCH) errors ( $\mathrm{LM}-\mathrm{ARCH}$ test) prove that there is an $\mathrm{ARCH}$ effect for almost all series, except the CHF series. Finally, the $\mathrm{Q}$ statistics and the $p$-value reveal the absence of the autocorrelation in the residuals from an AR(1) regression model for BPI and US stock indices.

The descriptive statistics in Table 2 show that the average daily return of the four top cryptocurrencies is positive. The XRP gives the greatest average of daily return. It has also the very high average of daily volatility measured by standard deviation. The XRP followed by LTC seems the riskier digital currencies. More interestingly, we can observe that the skewness is positive for all cryptocurrencies. This led to our precedent notification on BPI that a "rational investor" always prefers a positively skewed distribution to negative distribution. In another term, this result can be probably part of the reason for the latest trend involving using cryptocurrencies to raise money.

Table 2. Summary statistics of daily returns related to four top cryptocurrencies.

\begin{tabular}{lcccc}
\hline & BTC & ETH & LTC & XRP \\
\hline Mean & 0.66 & 1.07 & 1.08 & 1.61 \\
Median & 0.57 & 0.27 & 0.00 & -0.12 \\
Maximum & 26.77 & 29.51 & 83.49 & 184.64 \\
Minimum & -18.44 & -23.40 & -26.50 & -49.36 \\
Std. Dev. & 4.79 & 6.68 & 8.45 & 12.89 \\
Skewness & 0.17 & 0.67 & 3.45 & 6.44 \\
Kurtosis & 6.85 & 5.57 & 27.65 & 81.39 \\
J-B & 331 & 186 & 14478 & 139375 \\
ADF & $-23.18^{*}$ & $-22.16^{*}$ & $-7.48^{*}$ & $-10.72 *$ \\
ARCH LM & $13.96^{*}$ & $40.03^{*}$ & $7.32 *$ & 1.39 \\
PP & $-23.20 *$ & $-22.26^{*}$ & $-22.47 *$ & $-24.49 *$ \\
KPSS & 0.11 & 0.17 & 0.18 & 0.11 \\
\hline Chi-squared test & \multicolumn{5}{c}{} \\
\hline Q(5) & 6.21 & 3.34 & 3.5 & $22.73 *$ \\
Q(20) & 21.83 & 25.88 & $35.42 * *$ & $40.93 *$ \\
Observations & 530 & 530 & 530 & 530 \\
\hline
\end{tabular}

Note: J-B: Jarque-Bera statistic, ADF statistic: Augmented Dickey-Fuller, PP test: Phillips-Perron test and KPSS test: Kwiatkowski-Phillips-Schmidt-Shin test. Q(5) and Q(20) are the Ljung-Box statistics for serial correlation in the model residuals, computed with 5 and 20 lags, respectively. ${ }^{*}, * *$ denotes the rejection of the null hypothesis at the 1 and $5 \%$ significance levels, respectively.

Notice that the Kurtosis value of all cryptocurrencies is above 3. This is consistent with the presence of fat tails in data series and all are not normally distributed. 
The results for the ADF test indicate that series are stationary. The PP and KPSS tests confirm also this stationarity. Additionally, the ARCH (LM) test indicates that there is an ARCH effect in almost all series, except the XRP series. Finally, the $\mathrm{Q}$ statistics and the $p$-value show that there is no autocorrelation in the residuals from an AR(1) model for BTC and ETH series.

\section{Empirical Results}

To explain the dependence of cryptocurrencies on other markets, we investigate here the connectedness among volatility forecasting errors using Diebold and Yilmaz (2012) and Baruník and Křehlík (2017). We begin by characterizing volatility spill overs over the digital market as represented by BPI and other financial markets (i.e., Forex, stocks and commodities). Subsequently, we will track volatility spill overs within top digital currencies. Lastly, we report TSI in the lower right corner of Table 3.

\subsection{Directional spill over index}

We use VAR (2) approach with 10-days ahead forecasting horizon (h) to construct Table 3. We call this table spill over table. It provides an "input-output" decomposition of the spill over index. For example, the ij-th entry is the estimated contributions to the forecast error variance of index $\mathrm{i}$ coming from innovations to index $j$. Hence, the off-diagonal column sums (labelled contributions to others) and row sums (contributions from others), expressed the directional spill overs.

Table 3. Spill over effects between BTI, foreign currencies, stock markets and commodities.

\begin{tabular}{|c|c|c|c|c|c|c|c|}
\hline \multicolumn{8}{|c|}{ Panel a. Foreign Currencies } \\
\hline & BTI & EUR/USD & USD/JPY & GBP/USD & $\mathrm{USD} / \mathrm{CHF}$ & USD/CAD & From \\
\hline BTI & 98.16 & 0.95 & 0.02 & 0.01 & 0.65 & 0.09 & 1.83 \\
\hline EUR/USD & 0.39 & 66.17 & 4.14 & 7.98 & 15.20 & 6.08 & 33.82 \\
\hline USD/JPY & 0.01 & 5.15 & 84.64 & 4.71 & 3.41 & 2.05 & 15.35 \\
\hline GBP/USD & 0.13 & 9.85 & 5.52 & 75.76 & 2.76 & 5.95 & 24.23 \\
\hline $\mathrm{USD} / \mathrm{CHF}$ & 1.22 & 16.69 & 2.98 & 2.65 & 73.80 & 2.63 & 26.19 \\
\hline $\mathrm{USD} / \mathrm{CAD}$ & 0.19 & 6.57 & 2.13 & 6.37 & 2.57 & 82.14 & 17.85 \\
\hline To & 1.96 & 39.23 & 14.80 & 21.83 & 24.62 & 16.83 & TSI $=19.88$ \\
\hline \multicolumn{8}{|c|}{ Panel b. Stock Markets } \\
\hline & BTI & SP500 & NASDAQ & FTSE100 & HangSeng & Nikkei225 & From \\
\hline BTI & 97.51 & 0.44 & 0.56 & 0.79 & 0.61 & 0.05 & 2.48 \\
\hline SP500 & 0.21 & 42.43 & 33.25 & 11.65 & 8.56 & 3.87 & 57.56 \\
\hline Nasdaq & 0.20 & 36.46 & 42.60 & 10.54 & 7.27 & 2.90 & 57.39 \\
\hline FTSE100 & 0.23 & 14.41 & 11.01 & 60.76 & 9.47 & 4.09 & 39.23 \\
\hline Hang Seng & 0.62 & 5.94 & 4.89 & 8.34 & 73.14 & 7.04 & 26.85 \\
\hline Nikkei225 & 0.05 & 2.68 & 1.57 & 3.94 & 8.21 & 83.52 & 16.47 \\
\hline To & 1.34 & 59.95 & 51.30 & 35.28 & 34.14 & 17.97 & $\mathrm{TSI}=33.33$ \\
\hline \multicolumn{8}{|c|}{ Panel c. Commodities } \\
\hline & BTI & Gold & Brent & & & & From \\
\hline BTI & 98.28 & 1.40 & 0.30 & & & & 1.71 \\
\hline Gold & 0.81 & 97.94 & 1.24 & & & & 2.05 \\
\hline Brent & 0.21 & 1.28 & 98.49 & & & & 1.50 \\
\hline To & 1.03 & 2.68 & 1.55 & & & & $\mathrm{TSI}=1.75$ \\
\hline
\end{tabular}

Panel "a" of Table 3 shows the spill over index for the daily return volatilities among traditional currencies and BPI. Panel " $\mathrm{b}$ " is, however, relative to the spill over index between stock indexes and BPI. Concerning Panel c, it reports directional spill overs between the two wide range commodity markets (i.e., gold and Brent oil), and BPI. The TSI in panel " $\mathrm{b}$ " appears to have been relatively larger, which indicates that, on average, roughly $30 \%$ of the forecast error variance across stock indexes and BPI comes from spill overs. BPI appears as being obviously the tiny and negligible spill over 
transmitter and recipient of shock channels (i.e., directional spill overs from and to BPI have varied between $0 \%$ and $1 \%$ over our sample period). Like many analysts, this low connectedness is due to different drivers of returns in the crypto markets (e.g., investor adoption, legal and regulatory developments) versus the stock and bond markets, which are driven more by factors such as economic growth, interest rates and corporate profits. Since cryptocurrency markets are relatively small and lack of economic forces, beside speculations, they will be less connected to the conventional markets.

A comparison of panel " $b$ " with panel "a" or " $c$ " shows that BPI spillover effects are equivalent, ranging mostly from $0 \%$ to $1 \%$. For instance, we can learn from panel "a" that innovations to USD/CHF are responsible for 15.20 of the error variance in forecasting 10-days-ahead EUR/USD error variance, but only 0.39 of the error variance in the forecasting 10-days ahead EUR/USD comes from innovations to BPI. That is, volatility spill overs from CHF to EUR are larger than the BPI to EUR. As another example, we see that total volatility spill over from SP500 and NASDAQ to others is much larger than the total return spill overs from BPI to others, and vice versa. The latter suggests that US markets are more transmitters and recipients of shock channels, whereas BPI is less susceptible to global shocks, which indicates that the integration of the digital currency market with other financial markets, is still low for the last decade overall. These findings seem crucial to international investors and portfolio managers, given that uncertainty and investment risks can be reduced significantly by investing in digital currencies.

Table 4 reports the spill over index for the daily return volatilities among the top four cryptocurrencies using VAR (2). For the estimate equation of VAR (2), we suppose that deterministic regressors can be constant ("const"), the trend ("trend") or "both". There are also values of forecast error variance to 10 and 50 days ahead. We can see that TSI has a weak value estimated at around 15\%. It seems in most cases (i.e., type and number of days ahead) are similar in magnitude. For instance, we can learn from panel "a" that with type "const". TSI is 17.23 and 15.46 using type "both", which indicates that these markets are not closely linked with each other. In addition, one can see from Table 4 that BTC hits more other cryptocurrencies. At the same time, it also appears to be the most influenced by shocks of other cryptocurrencies.

Table 4. Spillover effects within the cryptocurrency market.

\begin{tabular}{|c|c|c|c|c|c|c|c|}
\hline \multicolumn{8}{|c|}{ Panel a. Foreign Currencies } \\
\hline & BTI & EUR/USD & USD/JPY & GBP/USD & USD/CHF & USD/CAD & From \\
\hline BTI & 98.16 & 0.95 & 0.02 & 0.01 & 0.65 & 0.09 & 1.83 \\
\hline EUR/USD & 0.39 & 66.17 & 4.14 & 7.98 & 15.20 & 6.08 & 33.82 \\
\hline USD/JPY & 0.01 & 5.15 & 84.64 & 4.71 & 3.41 & 2.05 & 15.35 \\
\hline GBP/USD & 0.13 & 9.85 & 5.52 & 75.76 & 2.76 & 5.95 & 24.23 \\
\hline $\mathrm{USD} / \mathrm{CHF}$ & 1.22 & 16.69 & 2.98 & 2.65 & 73.80 & 2.63 & 26.19 \\
\hline USD/CAD & 0.19 & 6.57 & 2.13 & 6.37 & 2.57 & 82.14 & 17.85 \\
\hline To & 1.96 & 39.23 & 14.80 & 21.83 & 24.62 & 16.83 & $\mathrm{TSI}=19.88$ \\
\hline \multicolumn{8}{|c|}{ Panel b. Stock Markets } \\
\hline & BTI & SP500 & NASDAQ & FTSE100 & HangSeng & Nikkei225 & From \\
\hline BTI & 97.51 & 0.44 & 0.56 & 0.79 & 0.61 & 0.05 & 2.48 \\
\hline SP500 & 0.21 & 42.43 & 33.25 & 11.65 & 8.56 & 3.87 & 57.56 \\
\hline Nasdaq & 0.20 & 36.46 & 42.60 & 10.54 & 7.27 & 2.90 & 57.39 \\
\hline FTSE100 & 0.23 & 14.41 & 11.01 & 60.76 & 9.47 & 4.09 & 39.23 \\
\hline Hang Seng & 0.62 & 5.94 & 4.89 & 8.34 & 73.14 & 7.04 & 26.85 \\
\hline Nikkei225 & 0.05 & 2.68 & 1.57 & 3.94 & 8.21 & 83.52 & 16.47 \\
\hline To & 1.34 & 59.95 & 51.30 & 35.28 & 34.14 & 17.97 & $\mathrm{TSI}=33.33$ \\
\hline \multicolumn{8}{|c|}{ Panel c. Commodities } \\
\hline & BTI & Gold & Brent & & & & From \\
\hline BTI & 98.28 & 1.40 & 0.30 & & & & 1.71 \\
\hline Gold & 0.81 & 97.94 & 1.24 & & & & 2.05 \\
\hline Brent & 0.21 & 1.28 & 98.49 & & & & 1.50 \\
\hline To & 1.03 & 2.68 & 1.55 & & & & $\mathrm{TSI}=1.75$ \\
\hline
\end{tabular}


We now turn to estimate volatility dynamic connectedness among the top four cryptocurrencies using 50-days rolling window samples. The resulting time series of spill over index are presented in Figure 1. Our first observation reveals that the spill over shape clearly shows that, while there are periods of increased and decreased market interdependence, there are also sudden spikes and dips during our short sample period. This shows that connectedness between cryptocurrencies is dynamic and rises during turmoil periods.

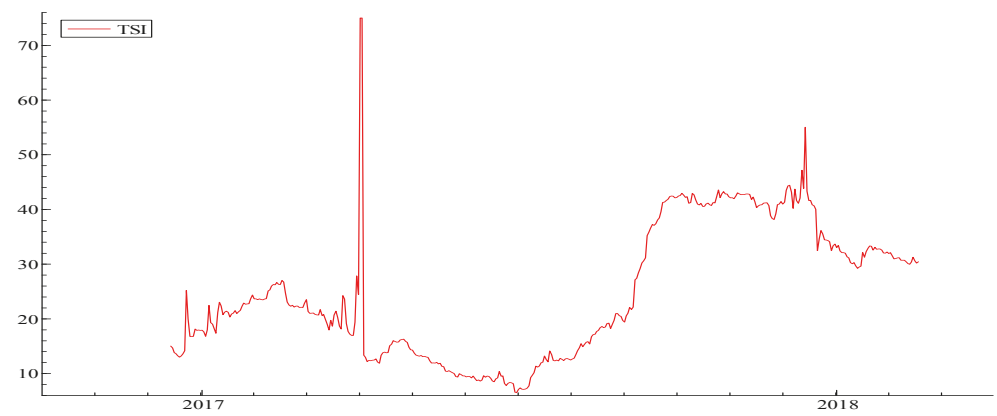

Figure 1. Dynamic of cryptocurrency spill over indexes: 100-days rolling window.

A natural way to define the frequency dependent connectedness measures is to consider the spectral representation of variance decompositions based on frequency, instead of impulse-responses of shocks. The frequency domain is the natural place to study the long-run, medium-run, or short-run connectedness shifts. In this study, we retain three frequency domains: Freq1: (pi/2, pi), which roughly corresponds to less than 4 days, Freq2: (pi/4, pi/2), which roughly corresponds to 4 days to 10 days and Freq3: (0, pi/4), which roughly corresponds to more than 10 days. Figure 2 presents the results of this frequency-domain analysis.

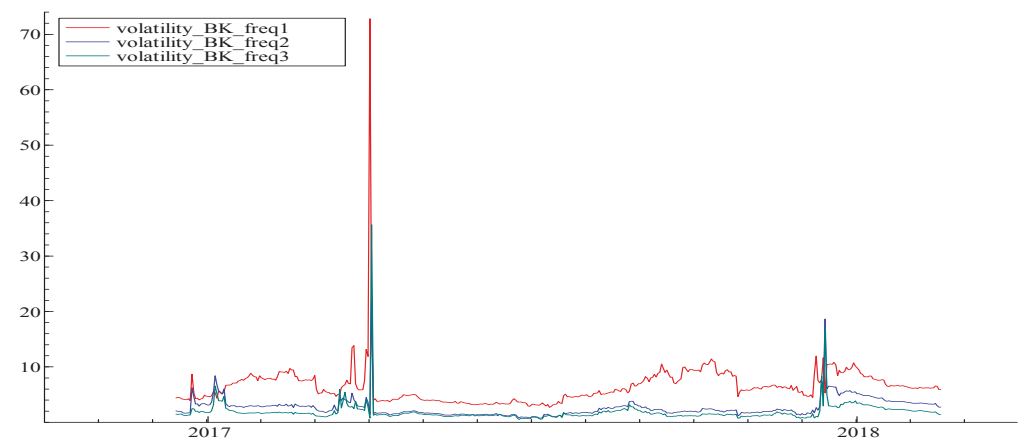

Figure 2. Time frequency-dynamic of cryptocurrency spill over indexes: window $=100$ days and $\mathrm{n}$. ahead $=100$ days.

We can see from Figure 2 that the response to return volatility shocks is distributed unevenly over frequency domains. Looking at how the global system is connected at these different frequency domains, we find that the largest total connectedness of cryptocurrencies comes from the short-run frequency (i.e., Freq1). These findings are obviously important and one could not have obtained this with the simple Diebold and Yilmaz (2012) method, and it thus highlights the importance of different frequencies that are considered for the analysis.

Referring also to Figure 2, we can show the possible importance of the long and medium run connectedness among cryptocurrencies just during two extreme jambs. As Baruník and Křehlík (2017) 
shows, the following increases in the long-term connectedness and the declines in short term connectedness can be attributed to change in market participants' beliefs in created information. In fact, when market participants understand that the information has generated a return shock that would quickly propagate and impact the stability of the system, this can create short-term connectedness. Moreover, the belief in surge volatility persistence can amplify the uncertainty and therefore enhances long term connectedness. These results are in line with the conclusions of Baur et al. (2015), showing that the value of Bitcoin (and "cryptocurrencies" in general) is primarily forced by speculative investors who want to gain experience in new markets and exploit the high return possible because of high volatility.

\subsection{Robustness Check}

Numerous dependence measures exist in the literature (cf., Joe 1997; Nelsen 2006). To explore the robustness of the results, we simply use Pearson's product moment coefficient, which indicates the strength and direction of a linear relationship between two random variables. Then, we implement Granger causality tests.

Following Table 5 (panel a), it is found that the correlation coefficients between the major Forex exchange rate and BPI over the sample period are extremely low. In contrast, all other correlation coefficients exhibit a relatively strong relationship with only some exceptions mainly for JPY return with both CAD and GBP return. A similar result is also observed between BPI and stock indexes (panel b) as well as between BPI and gold or Brent oil (panel c). Hence, this analysis shows that Bitcoin does not correlate with the other asset classes mentioned. This can tell us that overall cryptocurrencies do not conform to economic fundamentals, which can reinforce the conclusion that the value of cryptocurrency is mainly based on speculation and betting. Furthermore, bitcoin correlation with core asset classes (i.e., currencies, equities and commodities) is extremely low, implying that it is a favorable diversification instrument. This result is also provided by Dyhrberg (2015b).

Table 5. Correlation between BTI and other asset classes.

\begin{tabular}{|c|c|c|c|c|c|c|}
\hline \multicolumn{7}{|c|}{ Panel a. Correlation between BTI and Top Foreign Currencies } \\
\hline & BTI & EUR & JPY & GBP & $\mathrm{CHF}$ & CAD \\
\hline BTI & 1 & & & & & \\
\hline EUR & 0.04 & 1 & & & & \\
\hline JPY & -0.00 & -0.29 & 1 & & & \\
\hline GBP & 0.00 & 0.55 & -0.14 & 1 & & \\
\hline $\mathrm{CHF}$ & -0.07 & -0.56 & 0.35 & -0.34 & 1 & \\
\hline CAD & -0.03 & -0.43 & 0.10 & -0.42 & 0.25 & 1 \\
\hline \multicolumn{7}{|c|}{ Panel b. Correlation between BTI and Commodities } \\
\hline & \multicolumn{2}{|c|}{ BTI } & \multicolumn{2}{|c|}{ GOLD } & \multicolumn{2}{|c|}{ BRENT } \\
\hline BTI & \multicolumn{2}{|c|}{1} & & & & \\
\hline GOLD & \multirow{2}{*}{\multicolumn{2}{|c|}{$\begin{array}{l}0.01 \\
0.02\end{array}$}} & \multicolumn{2}{|c|}{1} & \multirow{2}{*}{\multicolumn{2}{|c|}{1}} \\
\hline BRENT & & & \multicolumn{2}{|c|}{0.13} & & \\
\hline \multicolumn{7}{|c|}{ Panel c. Correlation between BTI and Top Stock Indexes } \\
\hline & BTI & SP500 & NASDAQ & FTSE100 & HANGSENG & NIKKEI225 \\
\hline BTI & 1 & & & & & \\
\hline SP500 & 0.03 & 1 & & & & \\
\hline NASDAQ & 0.02 & 0.95 & 1 & & & \\
\hline FTSE100 & 0.01 & 0.59 & 0.55 & 1 & & \\
\hline HANGSENG & -0.05 & 0.20 & 0.22 & 0.41 & 1 & \\
\hline NIKKEI225 & -0.01 & 0.15 & 0.15 & 0.26 & 0.51 & 1 \\
\hline
\end{tabular}

We have observed some interesting patterns in the above analysis. A natural question to ask is whether movements in the return of traditional markets 'predict' future changes in returns of digital currencies, and vice versa. For that, we restrict testing the predictability or causality to the Granger 
causality test as performed by Granger (1969) and Sims (1980). In this interpretation, a variable x causes $\mathrm{y}$ if lagged values of $\mathrm{x}$ are significant in explaining $\mathrm{y}$ in a regression in which lagged values of $\mathrm{y}$ are also explanatory variables. It is, of course, possible that causality can exist in both directions. This test can be performed using VAR. Table 6 reports the results of F-statistic for the no Granger causality restrictions imposed on a linear vector autoregressive model (i.e., VAR (2)) under the null hypothesis.

Table 6. Pairwise Granger causality.

\begin{tabular}{|c|c|c|}
\hline \multicolumn{3}{|c|}{ Panel a. Foreign Currencies } \\
\hline \multicolumn{2}{|c|}{$\mathrm{H}_{0}$ : Foreign currencies do not Granger cause BTI } & $\mathrm{H}_{0}$ : BTI does not Granger cause Foreign currencies \\
\hline EUR & 0.61 & 0.20 \\
\hline JPY & 0.23 & 0.32 \\
\hline GBP & 0.27 & 0.11 \\
\hline $\mathrm{CHF}$ & 0.43 & $2.40^{* * *}$ \\
\hline CAD & $2.53 * * *$ & 0.28 \\
\hline \multicolumn{3}{|c|}{ Panel b. Stock Markets } \\
\hline \multicolumn{2}{|c|}{$\mathrm{H}_{0}$ : stock returns do not Granger cause BTI } & \multirow{2}{*}{$\begin{array}{c}\mathrm{H}_{0} \text { : BTI does not Granger cause stock returns } \\
1.54\end{array}$} \\
\hline SP500 & 1.85 & \\
\hline NASDAQ & $2.55^{* * *}$ & $2.57^{* * *}$ \\
\hline FTSE100 & 1.56 & $2.41^{* * *}$ \\
\hline HangSeng & 1.97 & 1.16 \\
\hline Nikkei225 & 1.78 & 0.24 \\
\hline \multicolumn{3}{|c|}{ Panel c. Commodities } \\
\hline \multicolumn{2}{|c|}{$\mathrm{H}_{0}$ : Commodities do not Granger cause BTI } & $\mathrm{H}_{0}$ : BTI does not Granger cause commodities \\
\hline Gold & $3.99 * *$ & 1.19 \\
\hline Brent & 0.59 & 0.81 \\
\hline \multicolumn{3}{|c|}{ Panel d. Cryptocurrencies } \\
\hline $\mathrm{H}_{0}:$ crypto $1 \mathrm{do}$ & cause crypto 2 & $\mathrm{H}_{0}$ : Crypto 2 does not Granger cause crypto 1 \\
\hline $\mathrm{XRP} / \mathrm{BTC}$ & 0.35 & 1.53 \\
\hline $\mathrm{BTC} / \mathrm{XRP}$ & 2.04 & 1.42 \\
\hline $\mathrm{XRP} / \mathrm{ETH}$ & 0.62 & 1.24 \\
\hline $\mathrm{LTC} / \mathrm{ETH}$ & 1.69 & 0.54 \\
\hline $\mathrm{LTC} / \mathrm{XRP}$ & 0.65 & $4.45 * *$ \\
\hline
\end{tabular}

Notes: This table reports the F-statistic for the no Granger causality restrictions imposed on a linear vector autoregressive (VAR) model under the null hypotheses $\mathrm{H}_{0}$. ${ }^{* * *}$ The asterisks indicate a rejection of the null of no Granger causality at the $10 \%$ levels of significance. ${ }^{* *}$ The asterisks indicate a rejection of the null of no Granger causality at the $5 \%$ levels of significance. Lag $=2$.

Following Panel "a", one can show that traditional currencies "do not Granger cause BPI", except for CAD currency (at a significance level of 10\%). In addition, "BPI does not Granger cause" any top traditional currencies with the exception of CHF currency. In regard to panel b of Table 6, we can also see that the hypothesis of stock return that "does not Granger cause BPI" is not statistically satisfied except for the NASDAQ index. As for the causality from BPI to stock return, it is also rejected, except for NASDAQ and FTSE100. Similarly, there is on average no Granger causality between BPI and gold or Brent oil for all cases, except from gold to BPI. From these results, we report that the predictability of many asset classes from BPI is minimal, and vice versa. Turning now to the causality among the four successful cryptocurrencies, (i.e., BTC, ETF, LTC and XRP), the results exhibit that all casual flows are not evident, except the Granger casual flow from XRP to LTC (at a significance level of 5\%).

The Granger causality tests also suggest-like the earlier TSI and correlation data-that there is no significant interaction within the nascent market of cryptocurrencies, as well as between BPI and the daily return of different asset classes. 


\section{Conclusions}

In this paper, we have investigated connectedness within the cryptocurrency market, and across BPI and other asset classes such as traditional currencies, stocks and gold or Brent oil. We have used the spill over index approach with the spectral representation of variance decomposition networks as proposed by Diebold and Yilmaz (2012) and Baruník and Křehlík (2017). We have shown no significant spillover effects between the nascent market of cryptocurrencies and other asset classes. Hence, we suggest that cryptocurrencies are weakly integrated into the global financial market. They can be interpreted as independent financial instruments that pose little to no systematic risk, which may add to its attractiveness for investors. Concerning the connectedness within the cryptocurrency market, we report a time-frequency-dynamics connectedness nature of the course of the considered period. Moreover, the decomposition of TSI is mostly dominated by short frequency component (2-4 days) leading to the conclusion that this nascent market is highly speculative at present. These findings provide insights for regulators and potential international investors.

As the literature grows, there are different valuation procedures or techniques to model and analyze changes in the volatility of financial assets. The most popular is the Multivariate ARCH type (GARCH) model with DCC correlation or the Spline-GARCH model. Therefore, in the future, we will use one of these methods with the aim of uncovering the connection of assets within other regional and global markets, or industry, and provide grounds for further research in risk management.

Funding: This research received no external funding.

\section{References}

Aftab, Muhammad, Rubi Ahmad, and Izlin Ismail. 2015. Dynamics between currency and equity in Chinese markets. Chinese Management Studies 9: 333-54. [CrossRef]

Ali, Robleh, John Barrdear, Roger Clews, and James Southgate. 2014. The Economics of Digital Currencies. Bank of England Quarterly Bulletin, Q3. Available online: http:/ /www.bankofengland.co.uk/publications/ Documents / quarterlybulletin/2014/qb14q3digitalcurrenciesbitcoin1.pdf (accessed on 9 November 2015).

Antonakakis, Nikolaos, and Konstantinos Vergos. 2013. Sovereign bond yield spillovers in the Euro zone during the financial and debt crisis. Journal of International Financial Markets 26: 258-72. [CrossRef]

Tiwari, Aviral Kumar, Juncal Cunado, Rangan Gupta, and Mark E. Wohar. 2018. Volatility spillovers across Global Asset Classes: Evidence from time and Frequency Domains. The Quarterly Review of Economics and Finance. [CrossRef]

Barber, Simon, Xavier Boyen, Elaine Shi, and Ersin Uzun. 2012. Bitter to Better-How to Make BitCoin a Better Currency. In Financial Cryptography and Data Security. Berlin/Heidelberg: Springer.

Baruník, Jozef, and Tomáš Křehlík. 2017. Measuring the Frequency Dynamics of Financial Connectedness and Systemic Risk. Journal of Financial Econometrics 16: 271-96. [CrossRef]

Baur, Dirk, KiHoon Hong, and Adrian Lee. 2015. Bitcoin: Currency or Asset? Available online: https:/ / papers. ssrn.com/sol3 / papers.cfm?abstract_id=2736020 (accessed on 22 February 2016).

Baur, Dirk G., and Brian M. Lucey. 2010. Is Gold a Hedge or a Safe Haven? An Analysis of stocks, Bonds and Gold. Financial Review 45: 217-29. [CrossRef]

Baur, Dirk G., and Thomas K. McDermott. 2010. Is gold a safe haven? International evidence. Journal of Banking \& Finance 34: 1886-98.

Baur, Dirk G., Thomas Dimpfl, and Konstantin Kuck. 2018. Bitcoin, gold and the US dollar-A replication and extension. Finance Research Letters 25: 103-10. [CrossRef]

Beckmann, Joscha, Theo Berger, and Robert Czudaj. 2015. Does gold act as a hedge or a safe haven for stocks? A smooth transition approach. Economic Modeling 48: 16-24. [CrossRef]

Bell, Claes. 2013. Bitcoin: Virtual Money or Risky Investment? Available online: https://www.bankrate.com/ investing/bitcoin-virtual-money-or-risky-investment/ (accessed on 25 September 2013).

Botman, Dennis P. J., Irineu E. Carvalho Filho, and Raphael W. Lam. 2013. The Curious Case of the Yen as a Safe Haven Currency: A Forensic Analysis. Available online: https://www.imf.org/external/pubs/ft/wp/2013/ wp13228.pdf (accessed on 6 November 2013). 
Bouoiyour, Jamal, and Refk Selmi. 2015. Bitcoin Price: Is it really that New Round of Volatility can be on way? Economics Bulletin 36: 3.

Bouoiyour, Jamal, and Refk Selmi. 2017. Ether: Bitcoin's Competitor or Ally? Available online: https://arxiv.org/ abs/1707.07977 (accessed on 25 July 2017).

Bouri, Elie, Peter Molnár, Georges Azzi, David Roubaud, and Lars Ivar Hagfors. 2017a. On the hedge and safe haven properties of Bitcoin: Is it really more than a diversifier? Finance Research Letters 20: 192-98. [CrossRef]

Bouri, Elie, Naji Jalkh, Peter Molnár, and David Roubaud. 2017b. Bitcoin for energy commodities before and after the December 2013 crash: diversifier, hedge or a safe haven? Applied Economics 49: 5063-73. [CrossRef]

Briere, Marie, Kim Oosterlinck, and Ariane Szafarz. 2013. Virtual Currency, Tangible Return: Portfolio Diversification with Bitcoins. Journal of Assessment Management 16: 365-73. [CrossRef]

Buchholz, Martis, Jess Delaney, Joseph Warren, and Jeff Parker. 2012. Bits and Bets, Information, Price Volatility, and Demand for BitCoin. Economics. 312. Available online: http:/ /www.bitcointrading.com/pdf/ bitsandbets.pdf (accessed on 5 May 2012).

Morley, Ciara. 2014. Three Essays on Identifying Safe Haven for Equity Investors. National University of Ireland Maynooth (NUIM), Maynooth, Co. Kildare, Ireland. Available online: http://rian.ie/en/item/view/98385. html (accessed on 8 April 2014).

Davidian, Marie, and Raymond J. Carroll. 1987. Variance Function Estimation. Journal of the American Statistical Association 82: 1079-91. [CrossRef]

Diebold, Francis X., and Kamil Yilmaz. 2009. Measuring financial asset return and volatility spillovers, with application to global equity markets. The Economic Journal 119: 158-71. [CrossRef]

Diebold, Francis X., and Kamil Yilmaz. 2012. Better to give than to receive: Predictive directional measurement of volatility spillovers. International Journal of Forecasting 28: 57-66. [CrossRef]

Dyhrberg, Anne Haubo. 2015a. Hedging capabilities of Bitcoin. Is it the virtual gold? Finance Research Letters 16: 139-144. [CrossRef]

Dyhrberg, Anne Haubo. 2015b. Bitcoin, gold and the dollar-A GARCH volatility analysis. Finance Research Letters 16: 85-92. [CrossRef]

Eisel, Alexander, Stephan Gasser, and Karl Weinmayer. 2015. Caveat Emptor: Does Bitcoin Improve Portfolio Diversification? Available online: https:/ / ssrn.com/abstract=2408997 (accessed on 3 June 2015).

Forsberg, Lars, and Eric Ghysels. 2007. Why Do absolute Returns Predict Volatility so well? Journal of Financial Econometrics 5: 31-67. [CrossRef]

Glaser, Florian, Martin Haferkorn, Moritz Weber, and Kai Zimmermann. 2014. How to price a digital currency? Empirical insights on the influence of media coverage on the Bitcoin bubble. Banking and Information Technology 15: 21-32.

Granger, Clive. 1969. Investigating Causal Relationships by Econometric Models and Cross-Spectral Methods. Econometica 37: 424-38. [CrossRef]

Grinberg, Reuben. 2011. BitCoin: An Innovative Alternative Digital Currency. Hastings Science \& Technology Law Journal 4: 159-208.

Grisse, Christian, and Thomas Nitschka. 2013. On Financial Risk and the Safe Haven Characteristics of Swiss Franc Exchange Rates. Swiss National Bank Working Papers. Available online: https: / www.sciencedirect. com/science/article/pii/S0927539815000249?via\%3Dihub (accessed on 22 March 2015).

Joe, Harry. 1997. Multivariate Models and Dependence Concepts. London: Chapman \& Hall.

Joshi, Leela. 2017. Bitcoin: Real or virtual currency? International Journal of Recent Scientific Research 8: 22354-57.

Kaul, Aditya, and Stephen Sapp. 2006. Y2K fears and safe haven trading of the U.S. dollar. Journal of International Money and Finance 25: 760-79. [CrossRef]

Kerner, Sean Michael. 2014. Why Marc Andreessen is Bullish on Bitcoin. Available online: http:/ /www.eweek. com/cloud/why-marc-andreessen-is-bullish-on-bitcoin (accessed on 2 February 2014).

Kristoufek, Ladislav. 2013. BitCoin meets Google Trends and Wikipedia: Quantifying the relationship between phenomena of the Internet era. Scientific Reports 3: 1-7. [CrossRef] [PubMed]

Meurers, Martin, and Berend Diekmann. 2007. The US Dollar: Safe Haven, Despite Rising US Current Account Defecit. Deutsche Bank Working Paper Series. Available online: https://www.econstor.eu/dspace/ bitstream/10419/21888/1/PROD0000000000214099.pdf (accessed on 6 August 2007).

Nakamoto, Satoshi. 2008. Bitcoin: A Peer-to-Peer Electronic Cash System. Available online: https:// nakamotoinstitute.org/literature/bitcoin/ (accessed on 31 October 2008). 
Nelsen, Roger B. 2006. An Introduction to Copulas, 2nd ed. New York: Springer.

Pesaran, H. Hashem, and Yongcheol Shin. 1998. Generalized impulse response analysis in linear multivariate models. Economics Letters 58: 17-29. [CrossRef]

Ranaldo, Angelo, and Paul Söderlind. 2010. Safe haven currencies. Review of Finance 14: 385-407. [CrossRef]

Gangwal, Shashwat. 2016. Analyzing the Effects of Adding Bitcoin to Portfolio. International Journal of Economics and Management Engineering 10: 3519-32.

Sims, Christopher A. 1980. Macroeconomics and reality. Econometrica 48: 1-48. [CrossRef]

Mikosch, Thomas. 2000. Limit theory for the sample autocorrelations and extremes of a GARCH $(1,1)$ process. Annals of Statistics 28: 1427-51.

Trabelsi, Nader, and Nader Naifar. 2017. Are Islamic stock indexes exposed to systemic risk? Multivariate GARCH estimation of CoVaR. Research in International Business and Finance 42: 727-44. [CrossRef]

van Wijk, Dennis. 2013. What Can be Expected from the BitCoin? Available online: https://thesis.eur.nl/pub/ 14100 / Final-version-Thesis-Dennis-van-Wijk.pdf (accessed on 18 July 2013).

Wang, Gang-Jin, Chi Xie, Zhi-Qiang Jiang, and H. Eugene Stanley. 2016. Who are the net senders and recipients of volatility spillovers in China's financial markets? Finance Research Letters 18: 255-62. [CrossRef]

Whelan, Karl. 2013. How Is Bitcoin Different From The Dollar? Available online: https://www.forbes.com/sites/ karlwhelan/2013/11/19/how-is-bitcoin-different-from-the-dollar (accessed on 19 November 2013).

Wu, Chen Y., and Vivek K. Pandey. 2014. The Value of Bitcoin in Enhancing the Efficiency of an Investor's Portfolio. Journal of Financial Planning 27: 44-52.

Yermack, David. 2015. Is Bitcoin a Real Currency? An Economic Appraisal. NBER Working Paper N. 19747, National Bureau of Economic Research. Available online: https:/ /www.sciencedirect.com/science/article/ pii/B9780128021170000023?via\%3Dihub (accessed on 5 May 2015).

(C) 2018 by the author. Licensee MDPI, Basel, Switzerland. This article is an open access article distributed under the terms and conditions of the Creative Commons Attribution (CC BY) license (http:/ / creativecommons.org/licenses/by/4.0/). 



\title{
Spillover Risks on Cryptocurrency Markets: A Look from VAR-SVAR Granger Causality and Student's-t Copulas
}

\author{
Toan Luu Duc Huynh ${ }^{1,2}$ \\ 1 School of Banking, University of Economics Ho Chi Minh City, Ho Chi Minh City 700000, Vietnam; \\ toanhld@ueh.edu.vn or toan.huynh@whu.edu \\ 2 WHU-Otto Beisheim School of Management, Burgplatz 2, D-56179 Vallendar, Germany
}

Received: 1 March 2019; Accepted: 21 March 2019; Published: 1 April 2019

\begin{abstract}
This paper contributes a shred of quantitative evidence to the embryonic literature as well as existing empirical evidence regarding spillover risks among cryptocurrency markets. By using VAR (Vector Autoregressive Model)-SVAR (Structural Vector Autoregressive Model) Granger causality and Student's-t Copulas, we find that Ethereum is likely to be the independent coin in this market, while Bitcoin tends to be the spillover effect recipient. Our study sheds further light on investigating the contagion risks among cryptocurrencies by employing Student's-t Copulas for joint distribution. This result suggests that all coins negatively change in terms of extreme value. The investors are advised to pay more attention to 'bad news' and moving patterns in order to make timely decisions on three types (buy, hold, and sell).
\end{abstract}

Keywords: Bitcoin; cryptocurrency; spillover risks; Copulas; Student's-t

JEL Classification: C46; F38; G01

When you do physics you are playing against God; in finance, you are playing against God's creatures.

(Emanuel Derman)

\section{Introduction}

One of the financial decisions is to determine the interconnection among assets because these relationships are relative reference sources to portfolio management and hedging strategies. This matter has attracted many scholars' attention in both literature and empirical fields. Notably, in the volatile world, there are many events, which not only foster, but also restrict the financial markets, financialization economies, or financial technologies. For instance, the constraints imposed by the trade war between the United States and China, the booming of many Fintech companies, the boom and bust of the Bitcoin lifecycle, etc.

The development of cryptocurrencies is an irresistible process. With the presence of Bitcoin and the rest of coins in market (referring to Altcoins, which are established for alternative investment after the commencement of Bitcoin), many investors paid close attention to them as a potential market for earning money. Unbelievably, Bitcoin returns used to climb up by $1358 \%$ in 2017 alone (Bouri et al. 2018a). Afterwards, numerous financial institutions, such as the Chicago Mercantile Exchange (CME) Group and the Chicago Board Options Exchange's (CBOE), accepted this coin as a part of their playground in derivatives. Bitcoin became a 'financial phenomenon' due to being continuously mentioned on the Internet and social media. Suddenly, the collapse of Bitconnect caused a 'huge crash' in the total market. Many coins are likely to go "back to the drawing board" from zero. More explicitly, this shock makes the investors more afraid to invest their money. 
Concomitantly, there are many controversial studies regarding economic characteristics of Bitcoin and these cryptocurrencies. It is undeniable that if there is a shock in cryptocurrency market, it might be a spillover for other coins (Huynh et al. 2018; Koutmos 2018a, 2018b). This concern is just a beginning because some studies explored the relationship between Bitcoin and other financial assets such as currencies (Dyhrberg 2016), global macroscopic determinants (Ciaian et al. 2016), macroeconomics news (Al-Khazali et al. 2018), energy assets (Bouri et al. 2017a), uncertainties (Bouri et al. 2017b), other assets (Bouri et al. 2018b), etc. However, there is a shortage gap in bridging the relationships specializing in spillover risks among cryptocurrencies.

There are also several studies that examine the contagion risks and spillover effects in cryptocurrencies, such as the studies of Fry and Cheah (2016), Yi et al. (2018), Ji et al. (2018b), Katsiampa (2018) and Catania and Sandholdt (2019), etc. However, these papers are initial exploiters of quantitative techniques for contagion risks among cryptocurrencies. In the following parts, we will discuss them to point out why we started working using the VAR-SVAR and Copulas approach. Therefore, this study contributes to the existing literature and empirical evidence different kinds of quantitative techniques that estimate the spillover risks among cryptocurrencies. To be more precise, this study has three main contributions: Firstly, in this study, we drew the updated data before and after the 'Bitcoin crash', which might capture the spillover effect clearly. Secondly, we employed a rich set of quantitative techniques including the linear approaches (Pearson correlation and VAR) and structural approaches (Structural VAR). Thirdly, we also introduce the cutting-edge viewpoint in using t-Student's Copulas, mainly based on the Student's-t distribution to estimate the dependence structure for extreme value events, which is considered our major contribution.

In this study, we attempt to employ the different econometric methods to answer the following research questions. (i) Are there spillover effects among the cryptocurrency market from empirical data? (ii) Is there any coin which is dependent on the other movements? (iii) Are there spillover effects in extreme events? In order to achieve this research contribution and to answer these research questions, we employed four main econometric models, namely Pearson correlation, VAR causality, SVAR causality, and t-Student's Copulas.

The remainder of this paper is structured as follows. Section 2 acknowledges the existing literature review regarding Bitcoin and spillover methodology measurement. Section 3 describes our data collection and briefly summarizes our methodologies. Section 4 illustrates our findings and results. Finally, Section 5 will conclude and deliver some implications.

\section{Literature Review}

In this section, thanks to the previous theoretical and empirical studies, we will review them as three categories: cryptocurrency markets, spillover risks, and relevant fields.

\subsection{Terminology and Basic Concepts}

The digital era has gradually changed monetary regimes. Regarding the terms of the 'cryptocurrency market', there is the digital exchange, which provides the platform for nonphysical coins or notes. Therefore, the exchange status exists in online form. Noticeably, the transactions have continued with the innovative terminology 'cryptography' ${ }^{1}$. This work should be conducted to secure the previous transactions, which are required to record as well as update the electronic ledger-known as a 'blockchain'.

'Cryptocurrency' refers to the 'digital coin' which operates in the previous aforementioned context. In this following part, we will focus on summarizing characteristics of some typical cryptocurrencies in our studies. One of the coins worth mentioning is Bitcoin, first introduced in 2009 by Satoshi Nakamoto. Especially, there were many skeptics that the Bitcoin price climbed up after its ten-year existence.

1 It becomes one of popular practices to perform the verification for historical online confirmation among trading parties. 
Afterwards, Ethereum came to the market with new functions and differences to Bitcoin. For instance, Ethereum demonstrates a decentralized platform which supports smart contracts to save trading time as well as transaction cost. Therefore, technically different from Bitcoin, Ethereum allows the users to program without any possibilities of third-party intervention, fraud, etc. Meanwhile, Ripple was born for the purpose of a real-time gross settlement system. Therefore, Ripple is likely to generate the currency and remittance network, which freely enables trading transactions. In addition, Litecoin is also known as the 'peer-to-peer network'. This coin is also built on the fundamental concept of Bitcoin but it is also an open-source without any central authorization. Similarly with Ethereum, Stellar has some noticeable features such as an open-source, decentralized protocol. In addition, this coin gradually fosters the transferring process with cross-border transactions of many cryptocurrencies. In brief, there are some commonly shared technical characteristics among these cryptocurrencies, such as (i) decentralized platform, (ii) the usage of cryptography for security, (iii) anonymous transactions, and (iv) quick confirmation.

Time after time Bitcoin and its sequential coins (Ethereum, Ripple, Litecoin, Stellar, etc.) have attracted the investors' attention. Therefore, these coins have gradually become the emerging financial asset class (Brandvold et al. 2015; Polasik et al. 2015). In terms of 'cryptocurrency market', we would like to address some concerns. First, contradictory to traditional monetary regimes, these cryptocurrency prices are wholly depended on perception as well as willingness to pay by investors. It is very intuitive to consider that all investors are 'peer-to-peer' participants in the market having no central control Sovbetov (2018). Second, the majority of cryptocurrencies represents the limitation in mining or producing new ones. This means that the limited supply is one of important traits. Coin miners tend to consume large amounts of energy as well as computer memory to generate a 'reward', meaning a new coin. Thus, it is deterministic, meaning that the coin stake can be generated in this way, not depending on the wealth. Therefore, the increase in prices can be explained by the supply-demand of trading investors. Thus, the movement of this market mainly depends on investor behavior. Third, the hashes of current blocks for one coin (which mainly influences the current price) are the mathematical function deriving from Nakamoto (2008):

$$
\text { Hash of current block }=f\left(\theta_{t-1}, \phi, \Phi\right)
$$

In which, $\theta$ is the hash, $\phi$ is the difficulty level of mining the coin, and $\Phi$ is the random key generated in the current process ( $\Phi$ is uniquely specific for one stage). This cryptocurrency market has past memories, difficulties in market, and typical characteristics in each transaction stage.

Furthermore, based on the aforementioned characteristics, this market is quite different from the stock market. We will discuss the three distinct features of these differences. First, the cryptocurrency market is traded 24/7, while the stock market is off during holidays, Saturday, and Sunday. Second, some stock exchanges regulate the upper lower bound for trading, whereas the cryptocurrency market is free to trade. This means that the cryptocurrency has high volatility which allows for an increase in price of up to 100 times. Third, the stock has intrinsic value, which is mainly based on the operating income or financial activities. Meanwhile, the cryptocurrencies have no intrinsic or tangible value. This kind of asset is mainly based on the fundamental concept of 'hash of current block', which is aforementioned by determinants in the previous function.

\subsection{Bitcoin and Cryptocurrency Markets}

From the policy-makers' perspective, there is an opposite view to criticize cryptocurrencies, which impedes the stability and development of financial markets. It derives from the studies of Gandal et al. (2018), Lo and Wang (2014), and Velde (2013). However, the development of Bitcoin, as well as other cryptocurrencies, still happens with many warnings and restrictions.

When it comes to economic characteristics, many studies doubted whether Bitcoin is a kind of currency or not. Bouri et al. (2017b) admitted that Bitcoin is considered as a 'peer-to-peer' environment 
that allows the alternative financial asset to be easily traded. However, Yermack (2015) disagreed with previous studies. This study claimed that Bitcoin should be not used as money, whereas Polasik et al. (2015) looked at Bitcoin as a mean of exchange, not reflected entirely as a monetary currency. On the other hand, Selgin (2015) supposed that Bitcoin is a kind of counterfeit commodity money.

There are also inconclusive findings regarding investors' behaviors in cryptocurrency markets, especially Bitcoin, in terms of forecasting their prices. Cheah et al. (2018) emphasized that Bitcoin shows an uncertain cointegration relationship with other assets. Mainly, this study indicated the inefficiency and informational nonhomogeneity in Bitcoin markets. These results are similar to the studies of Ciaian et al. (2016), Katsiampa (2017), and Urquhart (2017). Interestingly, there are some researches that have evaluated the microscopic structure in the Bitcoin market. In more detail, while Dyhrberg et al. (2018) initially examined the transaction costs as well as liquidity from market structures, Li and Wang (2017) conducted an empirical study to examine the technological and economic determinants of cryptocurrency exchange rates. These studies provided insights of large factors such as news public interest (Google search, Wiki views, Twitter, Facebook, and Forum), user volume trading (volume and frequency), Bitcoin amount, hash rate, difficulty in other markets (Gold and stocks), financial stress, and economy fundamentals. Moreover, Koutmos (2018b) and Wei (2018) also employed the bivariate VAR models to further investigation regarding transaction activity as well as growing microstructure in cryptocurrency markets. Also, Li and Wang (2017) pointed out the role of attention in Bitcoin returns. Nasir et al. (2019) contributed to the existing literature stating that Google search engines could be used to forecast Bitcoin returns in one-week shock. However, this element failed to explain why Bitcoin is volatile.

Regarding the interconnection between Bitcoin and other financial indices, Kristoufek (2015) used wavelet functions to prove that Chinese market indexes are likely to be a determinant of Bitcoin returns. This conclusion is also similar to the study of Bouoiyour and Selmi (2015). Meanwhile, Briere et al. (2015) figured out that Bitcoin has high volatility but it can be taken as a hedged instrument due to their relationship with conventional assets and unconventional assets. This study suggested the optimal ratio of Bitcoin in the portfolio is $\sim 3$ percent. By using the quantitative graphs, Ji et al. (2018a) confirmed that Bitcoin is useful for hedging purposes. In addition, Dyhrberg (2016) tested this characteristic of Bitcoin by univariate GARCH models (Generalized Autoregressive Conditionally Heteroscedastic models). Afterwards, this type of investment seems effective to hedge against the volatility of U.K. currency and equities. Interestingly, the following studies also supported the previous findings such as Bouri et al. (2017b), Balcilar et al. (2017), etc.

One of Bitcoin's features that has attracted many scholars' attention is 'bubble and speculation'. Cheah and Fry (2015) argued that Bitcoin is an only speculative asset because it does not convey any economic value. Moreover, Cheung et al. (2015) indicated that Bitcoin has speculative bubble features, which many investors use to exploit Bitcoin returns. This shares the same result with the study of Corbet et al. (2018).

In the scope of this study, we briefly summarize Bitcoin and cryptocurrencies studies based on five main points: (i) legal and policy-makers; (ii) currency or not; (iii) behaviors in markets; (iv) interconnection between cryptocurrency and other financial assets; and (v) speculative and bubble.

\subsection{General Spillover Risks}

First and foremost, the connectedness between decentralization policy and spillover effects is mentioned in study of Ogawa and Wildasin (2009) as well as Feder (2018). In these researches, the authors emphasized that decentralization might lead to spillovers among heterogeneous status. Second, when it comes to the decentralization in cryptocurrency market mentioned before, this means that these cryptocurrencies have a 'peer-to-peer' position in purchasing, selling, and trading without central control or concentrated authorization. Thus, the spillover effects might easily happen in terms of a decentralized context with unrestricted transactions. 
The test of spillover risks is usually to test for many different stocks, equity markets, as well as different kinds of financial assets. In this subsection, we will acknowledge the previous studies regarding the extent of relevant models to our study. Primarily, there is also an empirical study regarding contagion risk through the Structural Vector Autoregression (SVAR) model. Dungey et al. (2011) asserted that the liquidity and volatility of JP Morgan indices measured by credit risk with spread ${ }^{2}$, as well as a country risk by idiosyncratic shocks. Therefore, this study also emphasized the role of SVAR in identifying contagion risk through transmission of shocks from one country to another country. In the previous period, Diebold and Yilmaz (2008) suggested a method to measure the interdependent features among many assets. It is based on "own variance shares", which are estimated by error variances in forecasting. Latter, Yilmaz (2010) applied this method for measuring risks and volatility among East Asian stock markets. Similarly, there are plenty of works using Granger causality on the VAR basis to indicate the spillover risks such as Zhang et al. (2010). This study used Granger causality tests to indicate that change in the Dow Jones Industrial Average Index significantly causes changes in the Shanghai Stock Exchange Composite Index. This is one of the fundamental concepts for us to employ Granger causality for further investigation. Besides, the work of Shabri Abd. Majid et al. (2009) integrated the Generalized Method of Moments (GMM) in panel data to test contagion risks in 5 emerging markets among ASEAN countries. Additionally, Ding (2010) also checked the co-movements with Granger causality for the US and the Asia Pacific stock markets, while Central and Eastern Europe are the scope of study by Tudor (2011). Then, there is also a country research, employing this methodology of Vinh (2014) and Su (2017).

In order to observe the spillover risks, Christodoulakis and Satchell (2002), Engle (2002), as well as Tse and Tsui (2002) proposed the methodology of time-varying conditional correlations to examine whether the spillover risks happen in the market or not. There are many innovations from the previous traditional model. For example, Kundu and Sarkar (2016) introduced the STVAR-BTGARCH-M model for examining contagion risks. Afterward, Bouri et al. (2018a) built on previous studies, investigating the spillover risks between Bitcoin and financial assets (such as MSCI indices, commodity, energy, gold, US dollar, and US Treasury). One of the most impressive points in this study is to divide the sample into two regimes, for instance, bull and bear market. Additionally, Cong et al. (2008) employed multivariate VAR to indicate the transmission between oil price shocks and the equity market in China. Afterward, the study of Narayan and Narayan (2010) reexamined this approach for country research in Vietnam. Interestingly, Park and Ratti (2008) expanded their sample to the US and European countries by using Johnson and Juselius' cointegration tests before the empirical findings of Maghyereh and Al-Kandari (2007) by nonlinear cointegration analysis for Gulf Cooperation Council (GCC) countries. Another country research is from Hammoudeh and Aleisa (2004), who used VAR, likelihood ratio, and cointegration tests to examine the equity markets and New York Mercantile Exchange (NYMEX) oil futures.

One of the modern methodologies to measure the dependence structure is Copulas. Noticeably, in the equity market, Nguyen and Bhatti (2012) took advantage of the characteristics of marginal distribution and bivariate analysis to estimate the dependence structure, which is also known as spillover risks. In the early period, Bae et al. (2003) and Boyson et al. (2010) shed new light on estimating tail (or extreme) events of market returns as contagion risks. Later, the study of Luo et al. (2011) approached this methodology to explain how Chinese stock markets transmitted their risks to the other equity markets. Interestingly, Hiang Liow (2012) presented the results of the co-movements in securitized real estate and stock markets by Copulas. Following this work, Boubaker and Sghaier (2013) also implemented their Copulas results with portfolio management implications for the US financial assets, whereas Ghorbel and Trabelsi (2014) contributed a piece of empirical evidence for energy portfolio using Copulas. Besides, the research of Al Rahahleh and Bhatti (2017)

2 It was measured by the gap between the US industrial yields and the US Treasury bond. 
demonstrated that there is a relationship between the information transmission and international stock markets in co-movements by Copulas.

To sum up, our literature review regarding spillover effects only focuses on three main points: (i) Granger causality test to estimate spillover risks; (ii) other time-varying models to examine contagion phenomenon; and (iii) the applications of Copulas in spillover risks.

\subsection{Relevant Studies in Terms of Spillover Risks on the Cryptocurrency Markets}

The study of Koutmos (2018a) investigated the relationship among cryptocurrencies by employing a multivariable vector autoregression (VAR). These findings suggest that there exists the spillover pattern in cryptocurrency markets, which represents interdependencies among these coins. However, this study only examines the covariates rather than joint distribution between each pair of cryptocurrencies. Therefore, it is encouraged to have further researches in distribution characteristics.

By using the value-at-risk and expected shortfall, the study of Gkillas and Katsiampa (2018) investigated tail behaviors among the five largest coins in the exchange market. This study shares some similarities in findings with Brauneis and Mestel (2018) regarding tail risks. Interestingly, the study of Brauneis and Mestel (2018) uses a rich set of quantitative techniques, such as the Ljung and Box (1978) test for autocorrelation, Wald and Wolfowitz (1940) test for random order, bootstrapped variance ratio by Chow and Denning (1993), etc. Nevertheless, these studies might miss capturing the tail dependence structure among these cryptocurrencies. In brief, the findings are quite consistent in that there exist spillover risks among these kinds of assets.

Interestingly, Corbet et al. (2017) examined the idiosyncratic characteristics of Bitcoin and came into conclusion that there exist the spillover effects among cryptocurrencies. However, this study applied the GARCH approach to investigate the volatility spillovers. Later, by using LASSO-VAR ${ }^{3}$ approach, Yi et al. (2018) indicated that there is interconnection among cryptocurrencies in terms of returns and volatilities. This study failed to confirm that Bitcoin is the dominant element for this transmission. Therefore, Yi et al. (2018) confirmed that the spillover effects happen in cryptocurrency markets; however, this study does not emphasize the tail dependence structure. Recently, Bouri et al. (2018a, 2018b) applied the test from Phillips et al. (2015) called generalized sup Augmented Dickey-Fuller (GSADF) test for proving the multiple bubbles as well as co-explosivity in the cryptocurrency market. Once again, this study skipped the tail structure in capturing the extreme value, which might cause spillover risks. The study of Tu and Xue (2018) is entirely new, and employs Granger causality to check interrelationship between Bitcoin and Litecoin. However, this study limits two coins without more expansion for many coins. Finally, Huynh et al. (2018) asserted that there exist the contagion risks among cryptocurrency markets by using nonparametric (chi-plots and Kendall-plots) and parametric (Copulas with Normal, Clayton, and Gumbel) approaches. This study is one of the fundamental concepts for us to develop to use further quantitative techniques in examining the spillover risks.

Recently, Trabelsi (2018) investigated the volatility spillover effects among cryptocurrencies with a time-frequency-dynamic connectedness nature. The results are quite interesting to the readers because it contributes to the empirical evidences regarding connectedness within the cryptocurrency markets. Especially, this study also introduces the time of decomposition of the total spillover index, emphasized in 2-4 days. However, Trabelsi (2018) employed VAR methodology, which is good to forecast in linear shape rather structural dependence or complex structures of asset distribution. Although this study is a review, we would like to investigate insights by using quantitative techniques specifically structural VAR and Copulas for further estimation.

To the best of our knowledge, there was no further investigation among cryptocurrencies using Granger causality on the theme of VAR and SVAR. Furthermore, the previous studies only took normal

3 Least Absolute Shrinkage and Selection Operator and Vector Autoregressive Model. 
Copulas with a normal distribution to capture the left-tail dependence and fail to explain the extreme value, which only Student's-t Copulas fits. Therefore, our research will bridge the shortage of previous studies on the three following main points. (i) Review the previous studies in cryptocurrencies in terms of spillover or contagion risks; (ii) contribute to new approach of Granger causality on the theme of VAR (or linear) and SVAR (or structural dependence); and (iii) reexamine the joint distribution between each pair of cryptocurrencies with Gaussian and Student's-t Copulas allowing to capture the extreme value.

\section{Data and Methodology}

\subsection{Data}

Our daily data covered five coins—-bitcoin, ethereum, xrp, litecoin, and stellar-over the period from 8 September 2015 to 4 January 2019. The main reason to choose this period is to ensure the balanced availability of dataset without missing observations. Although there were some coins having higher market capitalization-EOS, Bitcoin Cash, etc.-we also eliminated them in our sample due to the shortage of dataset in comparison with altcoins. In addition, the market capitalization on 20 February 2019 was USD 134,776,251,887; these five coins at the same date were occupied by USD $103,483,837,488$. Therefore, the percentage of our research samples is $76.78 \%$. Next, we performed the statistics description test to initially evaluate how these variables distributions are.

As in Table 1, except for Bitcoin experiencing the left-skewed trait, all variables are skewed to the right side. Noticeably, the Ripple (XRP) has the heaviest value on the fat tail, and the others have a fat tail. Interestingly, we also figure out that the average return per day is between $0.1 \%$ and $0.4 \%$. Also, it is seen that ' $x r p^{\prime}$ has the highest loss value in $\min (-61.627 \%)$ as well as the largest gain in $\max (102.7356 \%)$. While the Bitcoin movements attract many attentions, the other coins (ethereum, $\mathrm{xrp}$, litecoin, and stellar) are likely to have extreme loss or gain values, which should be considered carefully. In this market, the transaction costs seem to be less than the other financial markets, which means that investors sell coins faster and more recklessly then they buy another coin. Hence, it might happen the spillover risk phenomenon, which needs to examine in different quantitative techniques.

Table 1. Descriptive statistics.

\begin{tabular}{ccccccc}
\hline Variable & Mean & Std. Dev. & Min & Max & Skewness & Kurtosis \\
\hline bitcoin & 0.002163 & 0.040021 & -0.20753 & 0.225119 & -0.2623099 & 7.720781 \\
ethereum & 0.004276 & 0.068703 & -0.31547 & 0.412337 & 0.4963407 & 7.554288 \\
xrp & 0.003004 & 0.075708 & -0.61627 & 1.027356 & 2.987435 & 41.54075 \\
litecoin & 0.001711 & 0.057338 & -0.39515 & 0.510348 & 1.271329 & 15.6589 \\
stellar & 0.003104 & 0.083676 & -0.36636 & 0.723102 & 2.030118 & 18.3531 \\
\hline
\end{tabular}

\subsection{Methodology}

In this paper, we employ a rich set of quantitative techniques such as Pearson correlation, VAR Granger causality, SVAR Granger causality, and Copulas with two specific kinds (Gaussian and Student's-t). Importantly, Huynh et al. (2018) indicated that there are contagion risks among cryptocurrencies by using three kinds of Copulas (Normal, Clayton, and Gumbel). This study also indicated that these pairs capture the Clayton Copulas (for the left-tail dependence). However, this study fails to evaluate the extreme values, which is one of the characteristics in financial returns data. Therefore, we further investigation on Gaussian Copulas (normally known as normal) and Student's-t Copulas (for extreme value in tail dependence) (Chen and Fan 2006). Therefore, we focused on the Gaussian and Student's-t Copulas for further investigation. Lastly, this paper also takes a closer look in this market by the Pearson, VAR, and SVAR Granger causality employed by Zhang et al. (2010), Shabri Abd. Majid et al. (2009), Ding (2010), Tudor (2011), Vinh (2014), Su (2017) for an explanation of 
spillover effects, to understand which coin influences another one. We will present the basic framework of our methodologies to use in the following sections.

\subsubsection{Pearson Correlation}

This is the traditional approach to investigate the relationship between two variables. There are numerous studies regarding these parameters: Stigler (1986), Snedecor and Cochran [1980] 1989, Galton (1889), etc. In this paper, we briefly acknowledge the relevant formula as well as the confidence level for testing. The parameter $\rho$ represents the product-moment correlation coefficient.

$$
\hat{\rho}=\frac{\sum_{i=1}^{n} w_{i}\left(x_{i}-\bar{x}\right)\left(y_{i}-\bar{y}\right)}{\sqrt{\sum_{i=1}^{n} w_{i}\left(x_{i}-\bar{x}\right)^{2}} \sqrt{\sum_{i=1}^{n} w_{i}\left(y_{i}-\bar{y}\right)^{2}}}
$$

In which, $w_{i}$ denotes weight and $\bar{x}$ and $\bar{y}$ are the means of $x$ and $y$, respectively. Then, we also demonstrate the unadjusted significance level for testing significance level.

$$
\rho=2 * \operatorname{ttail}\left(\mathrm{n}-2,|\hat{\rho}| \frac{\sqrt{n-2}}{1-\hat{\rho}^{2}}\right)
$$

One of Pearson correlation benefits is that it is easy to calculate; however, it only supports linear dependence between two variables. Therefore, we also employ further investigation.

\subsubsection{Vector Autoregressive Model (VAR)}

We refer to the studies of Lütkepohl (2005) and Greene (2008) to briefly explain the VAR model in terms of linear regression without constraint placed on the coefficients. The VAR(p) model with exogenous variables is statistically written in form as

$$
y_{t}=A Y_{t-1}+B_{0} \chi_{t}+u_{t}
$$

In which $y_{t}$ is the matrix with $(K \times 1)$ of endogenous variables; $A$ is a matrix with $\left(K \times K_{p}\right)$ of coefficients of lagged values of $Y\left(Y_{t-1}\right) ; B_{0}$ is matrix with coefficients of matrix $\chi_{;} \chi_{t}$ is the matrix $(M$ $\times 1)$ of exogenous variables; and $u_{t}$ is the matrix $(K \times 1)$ of white noise innovations. Finally, $Y_{t}$ is the $\operatorname{matrix}\left(K_{p} \times 1\right)$ matrix with $Y_{t}=\left(\begin{array}{c}y_{t} \\ \vdots \\ y_{t-p+1}\end{array}\right)$.

The matrix $\chi_{t}$ also includes intercept terms in VAR model. Therefore, $\chi_{t}$ will be empty when it includes no exogenous variables and no intercept terms in the model. In summary, VAR is a model with $K$ variables regressed in linear functions. In this estimation, there are $(p)$ own lagged values of variables and $(\mathrm{p})$ lags of other $(K-1)$ variables, and possibly exogenous variables. Therefore, a VAR model with $\mathrm{p}$ lags denotes as $\operatorname{VAR}(\mathrm{p})$.

\subsubsection{Structural Vector Autoregressive Model (SVAR)}

In this study, we briefly introduced the theoretical framework of Structural Vector Autoregressive Model (SVAR) by Amisano and Giannini (2012). Assume that we have the full system of variables of interactions as follows

$$
\begin{aligned}
& y_{t}=\delta_{1}+b_{12} \vartheta_{1}+\gamma_{11} y_{t-1}+\gamma_{12} \vartheta_{t-1}+\varepsilon_{1 t} \\
& \vartheta_{1}=\delta_{2}+b_{21} y_{1}+\gamma_{21} y_{t-1}+\gamma_{22} \vartheta_{t-1}+\varepsilon_{2 t}
\end{aligned}
$$


Therefore, we can capture the mutual interaction between these variables in our model. When it comes to matrix notation, we have

$$
\left[\begin{array}{cc}
1 & -b_{12} \\
-b_{21} & 1
\end{array}\right]\left[\begin{array}{l}
y_{t} \\
\vartheta_{1}
\end{array}\right]=\left[\begin{array}{l}
\delta_{1} \\
\delta_{2}
\end{array}\right]+\left[\begin{array}{ll}
\gamma_{11} & \gamma_{12} \\
\gamma_{21} & \gamma_{22}
\end{array}\right]\left[\begin{array}{l}
y_{t-1} \\
\vartheta_{t-1}
\end{array}\right]+\left[\begin{array}{l}
\varepsilon_{1 t} \\
\varepsilon_{2 t}
\end{array}\right]
$$

Compactly, $\xi$ denotes the matrix in Equation (6).

$$
B \xi_{t}=\Delta+\Gamma \xi_{t-1}+\varepsilon_{t}
$$

This SVAR can be rewritten in a VAR form by premultiplication by $B^{-1}$

$$
\xi_{t}=\mathrm{A}_{0}+\mathrm{A}_{1} \xi_{t-1}+u_{t}
$$

In which, $u_{t}=B^{-1} \varepsilon_{t}, \mathrm{~A}_{0}=B^{-1} \Delta$, and $\mathrm{A}_{1}=B^{-1} \Gamma$, then the $\varepsilon_{t}$ is assumed that SVAR generates white noise and i.i.d, the $u_{t}$ from VAR has the following characteristics; (i) zero mean, (ii) fixed variance, (iii) not individually autocorrelated and, most importantly, (iv) the correlation between $b_{12}$ and $b_{21}$ is different to 0. Finally, our calculation will examine: $u_{t}=B^{-1} \varepsilon_{t}=\left\{\begin{array}{l}\frac{\left(\varepsilon_{1 t}-b_{12} \varepsilon_{2 t}\right)}{1-b_{12} b_{21}} \\ \frac{\left(\varepsilon_{2 t}-b_{21} \varepsilon_{1 t}\right)}{1-b_{12} b_{21}}\end{array}\right.$.

There are also two types of SVAR estimation such as short-run and long-run restrictions. For the short run one, the Cholesky decomposition is followed by a study of Sims (1980), whereas Amisano and Giannini (2012) adapted long run SVAR to the methodology of checking local identification.

\subsubsection{Granger Causality}

One variable, $x$, is defined as having Granger causality on variable $y$ if the given previous information of $y$, as well as the past values of $x$, enable to forecast the current value of $y$. This is the fundamental concept of Granger causality of these variables. Therefore, the null hypothesis is to test that the joint coefficients equal zero, including the lagged values of $x$ in the regression between $y$, the lagged values of $y$ and $x$. Therefore, Granger (1969) employed the Wald statistics for the hypothesis. Especially, the procedure for the Granger causality test is to store all values in VAR (or SVAR) regression first. Afterwards, they calculate and report small sample F statistics or large sample $\chi^{2}$ statistics for the null hypotheses.

\subsubsection{Copulas Approaches}

According to Gudendorf and Segers (2010), Copulas refers to specific multivariate distribution functions, in which the distribution function $H$ of a n-dimensional random vector $X=\left(X_{1}, \ldots, X_{d}\right)$ is the function defined by

$$
H(x)=P(X \leq x)=P\left(X_{1} \leq x_{1}, \ldots, X_{d} \leq x_{d}\right)
$$

with $x=\left(x_{1}, \ldots, x_{d}\right) \in \mathbb{R}^{d}$.

The distribution function $F_{j}$ of $X_{j}$ with $j \in\{1, \ldots, d\}$ can be recalled by the multivariate distribution function $H$ by $F_{j}\left(x_{j}\right)=H\left(\infty, \ldots, \infty, x_{j}, \infty, \ldots, \infty\right), x_{j} \in \mathbb{R}$. Therefore, $F_{j}, \ldots, F_{d}$ is also known as univariate margins of $H$ (or called as marginal distribution functions of $X$ ). One of the concise Copulas definitions is a multivariate distribution function with standard uniform univariate margins, that is, $\mathrm{U}(0,1)$ margins.

- Gaussian Copulas 
Malevergne and Sornette (2006) also asserted that the parameter for dependence structure $R_{g}$ can be estimated as follows

$$
\hat{R_{g}}=\underset{R_{g}}{\operatorname{argmax}} \sum_{i=1}^{n} \log c_{g}\left(\widetilde{x}_{i} ; R_{g}\right)
$$

In which, $\tilde{x}$ is considered as increasing transformations of variable $x$. Then, random vector $\tilde{x}$ and $x$ share the same Copulas function. The method of maximum likelihood estimates this parameter in Equation (5). To be more specific, $c_{g}\left(\widetilde{x}, R_{g}\right)$ denotes the density function of the Gaussian Copulas with parameter $R_{g}$.

- Student's-t Copulas

The parameter of dependence structure $R_{t}$ and the degree of freedom $v$ can be estimated by maximum likelihood:

$$
\left(\hat{R_{t}} ; \hat{v}\right)=\underset{\left(R_{t} ; v\right)}{\operatorname{argmax}} \sum_{i=1}^{n} \log c_{t}\left(\widetilde{x_{i}} ; R_{t} ; v\right)
$$

In which, $c_{t}\left(\tilde{x}, R_{t} ; v\right)$ denotes the density function of the Student's-t Copulas with parameter $\left(R_{t} ; v\right)$. This refers to the study of Kotz and Nadarajah (2004).

\section{Empirical Findings}

\subsection{Correlation Matrix}

One of the basic analyses from these coins' return is to test these correlations. We perform the Pearson method (Pearson 1896) for estimating the product-moment correlation coefficient with testing under unadjusted significance level. There is a correlation matrix after testing at this significance level.

As seen in Table 2, all pairs of coins have a strong correlation at the $1 \%$ significance level. It displays that these coins returns have the dependence of linearity. This is the initial stage to investigate their structural dependence. This suggests that any positive change at one coin return might lead to positive change in other coins' returns (ethereum, xrp, litecoin, and stellar) due to the positive signs. However, we also need the further quantitative investigation to conclude the spillover phenomenon in this market.

\begin{tabular}{|c|c|c|c|c|c|}
\hline & Bitcoin & Ethereum & xrp & Litecoin & Stellar \\
\hline bitcoin & 1 & & & & \\
\hline ethereum & $0.3992^{* * *}$ & 1 & & & \\
\hline xrp & $0.3043^{* * *}$ & $0.2587^{* * *}$ & 1 & & \\
\hline litecoin & $0.6113^{* * *}$ & $0.3871^{* * *}$ & $0.3609^{* * *}$ & 1 & \\
\hline stellar & $0.3661 * * *$ & $0.2789 * * *$ & $0.5488^{* * *}$ & $0.3857^{* * *}$ & 1 \\
\hline
\end{tabular}

Table 2. Correlation matrix.

\subsection{Test of Stationary}

In order to ensure that our further findings and results are unbiased and not spurious, we tested the stationary of our variables first. For our test, we employed ADF (Dickey and Fuller 1979) and PP (Phillips and Perron 1988) unit root tests in the initial stage. In addition, we also further employed Zivot and Andrews (2002) test for Structural Break of Stationary to our variables. Table 3 will represent the results of test of stationary for these variables. 
Table 3. Test of stationary.

\begin{tabular}{cccc}
\hline Variables & Augmented Dickey-Fuller & Phillips-Perron & Zivot-Andrews \\
\hline bitcoin & $-34.983^{* * *}$ & $-35.005^{* * * *}$ & $-13.900^{* * *}$ \\
ethereum & $-33.161^{* * *}$ & $-33.288^{* * *}$ & $-18.966^{* * *}$ \\
xrp & $-35.585^{* * *}$ & $-35.934^{* * *}$ & $-13.027^{* * *}$ \\
litecoin & $-34.731^{* * *}$ & $-34.809^{* * *}$ & $-12.725^{* * *}$ \\
stellar & $-32.703^{* * *}$ & $-32.760^{* * *}$ & $-14.925^{* * *}$ \\
\hline
\end{tabular}

We find that all variables are stationary at the $1 \%$ significance level. This indicates that our variables are integrated at $\mathrm{I}(0)$, which allows us to conduct further empirical estimation. Then, we also perform the Lütkepohl (2005) ${ }^{4}$ test to choose the most appropriate lag order. We refer to the study of Ivanov and Kilian (2001) to choose the best-fit lag order (current value) for our Granger causality models.

\subsection{VAR Granger Causality Findings}

One variable (origin) has VAR Granger causality with another variable (receiver) when the past and current information of the origin can be statistically used to predict for the receiver. As the results stated in Table 4, there are some contagion effects among cryptocurrency markets. There is no contagion effect from the other coins on Bitcoin or Ethereum. Meanwhile, xrp is likely to bear spillover risk from bitcoin, litecoin, and stellar at significance levels of $1 \%, 10 \%$, and $5 \%$, respectively. There is weak evidence that Stellar influences on Litecoin in the Granger causality at $10 \%$ significance level. In addition, xrp significantly causes in Granger relationship to stellar at $1 \%$ level. To be more specific, there is a considerably conclusive point on bidirectional Granger causality. The only pair of two coins-'xrp-stellar' - shows the bilateral relationship on Granger causality test.

However, the Granger causality test introduces the spillover effect among these cryptocurrencies, but it fails to indicate the risk structure in each distribution of these coins. This is also a drawback of Granger causality test methodology. Therefore, we suggest further quantitative techniques capture the dependence structure among these coins. Table 4 will demonstrate the findings in VAR Granger causality test.

Table 4. VAR Granger causality results ${ }^{5}$.

\begin{tabular}{cccccc}
\hline \multirow{2}{*}{ Receiver } & \multicolumn{5}{c}{ Origin } \\
\cline { 2 - 6 } & Bitcoin & Ethereum & xrp & Litecoin & Stellar \\
\hline bitcoin & & 0.55163 & 4.489 & 1.7486 & 5.5009 \\
ethereum & 0.14445 & & 0.74868 & 0.44237 & 1.7673 \\
xrp & $9.6048^{* * *}$ & 2.4533 & & $8.5096^{* *}$ & $5.3684^{*}$ \\
litecoin & 1.0108 & 0.2165 & 2.0288 & & $5.0043^{*}$ \\
stellar & 1.359 & 1.5335 & $29.199^{* * *}$ & 3.2276 & \\
\hline
\end{tabular}

The symbols $* * *$, and $* *$ denote the significance at the $10 \%, 5 \%$, and $1 \%$ levels, respectively.

4 Selection-order criteria based on rich set of parameters such as the Log-Likelihood (LL), the Likelihood ratio (LR), the Prediction Error (FPE), the Akaike's Information Criterion (AIC), the Schwarz's Bayesian Information Criterion (SBIC), and the Hannan and Quinn Information Criterion (HQIC).

5 The VAR model estimation for VAR Granger causality is based on the suggested lag by Lütkepohl (2005) with the L(3) term and we also employed the multivariate VAR (all of the cryptocurrencies) in our models to test the spillover effects rather than bivariable (it might be omitted the effects from other cryptocurrencies). 


\subsection{SVAR Granger Causality Results}

In the previous part, we employ VAR for Granger causality to estimate the relationship among these cryptocurrencies. However, after the crash of Bitcoin in 2017, many coins plunged. Afterward, they gradually covered. Therefore, we employed Structural Vector Autoregression for Granger causality estimation. The more advantageously quantitative results are (i) capturing the structural break of the dataset and (ii) dynamic stochastic models with a minimum of identifying assumptions. Table 5 will summarize the results of Structural Vector Autoregression (SVAR) Granger causality test.

Table 5. Structural Vector Autoregression (SVAR) Granger causality results.

\begin{tabular}{cccccc}
\hline \multirow{2}{*}{ Receiver } & \multicolumn{5}{c}{ Origin } \\
\cline { 2 - 6 } & Bitcoin & Ethereum & xrp & Litecoin & Stellar \\
\hline bitcoin & & 0.8461 & $6.029^{* * *}$ & 0.71176 & $6.6254^{* * *}$ \\
ethereum & 044158 & & 1.792 & 0.37347 & 2.2796 \\
xrp & 0.26372 & 1.7793 & & $3.1169^{*}$ & 3.3771 \\
litecoin & 0.58286 & 0.22677 & 0.06153 & & 1.8682 \\
stellar & 1.6201 & 1.6 & $16.003^{* * *}$ & $3.528^{* *}$ & \\
\hline
\end{tabular}

The symbols $* * *$, and ${ }^{* * *}$ denote the significance at the $10 \%, 5 \%$, and $1 \%$ levels, respectively.

Interestingly, the results are similar to VAR Granger causality in terms of two pars 'xrp-stellar' and 'litecoin-stellar'. In which, the changes of xrp and litecoin are likely to cause the changes of stellar at significance levels of $1 \%$ and $5 \%$, respectively. When it comes to structural break, bitcoin seems to be sensitive. Both xrp and stellar cause a change in Bitcoin at a significance level of $1 \%$. There is also weak evidence that litecoin influences xrp at 10\% significance level. However, in the SVAR Granger causality context, there is not the existence of a bidirectional relationship among these cryptocurrencies. Moreover, the differences between VAR Granger causality and SVAR Granger causality findings suggest having further quantitative techniques to investigate the dependence structure among these variables.

\subsection{Copulas Approach}

In this part, we performed the Copulas approach to test whether these pairs of cryptocurrencies have a dependence structure at the tail or not. Hence, our work tests two types of Copulas-Frank (normal) and t-Copulas (t-student Copulas)—for the dependence structure of these cryptocurrencies. Before choosing the appropriate Copulas, we need to test the dependence structure first. The Kendall parameter is one of our estimations for statistical evaluation.

As results are represented in Table 6, it can be seen that all cryptocurrency pairs have strong dependence structure through Kendall tau $(\tau)$ parameters at the $1 \%$ significance level. Therefore, we employed further Copulas estimation, which detects an interpretable dependence structure for these cryptocurrencies returns. Malevergne and Sornette (2003) also indicated that the Copulas approaches (including Gaussian and the Student's-t) are taken into consideration for testing correlation in terms of structural dependence among currencies. The Tables 6 and 7 will demonstrate the results of Kendall parameters as well as Copulas test, respectively. 
Table 6. Kendall $\tau$ parameter for dependence structure.

\begin{tabular}{cccccc}
\hline & Bitcoin & Ethereum & xrp & Litecoin & Stellar \\
\hline bitcoin & & & & \\
ethereum & $0.282^{* * *}$ & & & \\
xrp & $0.287^{* * *}$ & $0.288^{* * *}$ & & \\
litecoin & $0.523^{* * *}$ & $0.316^{* * *}$ & $0.356^{* * *}$ & & \\
stellar & $0.283^{* * *}$ & $0.280^{* * *}$ & $0.409^{* * *}$ & $0.336^{* * *}$ & \\
\hline
\end{tabular}

The symbols*,**, and *** denote the significance at the $10 \%, 5 \%$, and $1 \%$ levels, respectively.

Table 7. Gaussian Copula and Student's-t Copulas estimation.

\begin{tabular}{ccc}
\hline Pairs & Gaussian Copula & Student's-t Copulas \\
\hline \multirow{2}{*}{ bitcoin-ethereum } & 0.4148 & 0.4334 \\
& {$[115.7]$} & {$[\mathbf{1 6 0 . 1}]$} \\
\hline \multirow{2}{*}{ bitcoin-xrp } & 0.4135 & 0.4389 \\
bitcoin-litecoin & {$[114.9]$} & {$[\mathbf{1 6 2 . 6}]$} \\
\hline \multirow{2}{*}{ bitcoin-stellar } & 0.6894 & 0.7367 \\
& {$[397.5]$} & {$[525.5]$} \\
\hline \multirow{2}{*}{ ethereum-xrp } & 0.4217 & 0.4328 \\
& {$[120]$} & {$[\mathbf{1 6 1 . 8}]$} \\
\hline \multirow{2}{*}{ ethereum-litecoin } & 0.3958 & 0.4467 \\
& {$[104.4]$} & {$[\mathbf{1 4 5 . 5 ]}$} \\
\hline \multirow{2}{*}{ ethereum-stellar } & 0.4484 & 0.4793 \\
& {$[137.7]$} & {$[\mathbf{1 7 3 . 5}]$} \\
\hline \multirow{2}{*}{ xrp-litecoin } & 0.3842 & 0.4284 \\
& {$[97.8]$} & {$[\mathbf{1 3 2 . 4}]$} \\
\hline \multirow{2}{*}{ xrp-stellar } & 0.4872 & 0.5453 \\
& {$[166.3]$} & {$[\mathbf{2 6 8 . 4 ]}$} \\
\hline \multirow{2}{*}{ litecoin-stellar } & 0.5921 & 0.6001 \\
& {$[265.5]$} & {$[330.2]$} \\
\hline
\end{tabular}

The maximized log-likelihood of the corresponding coefficients $\rho_{0}$ is shown in square brackets.

Our findings demonstrated that these pairs of cryptocurrencies have strong dependence structure on Student's-t Copulas, which should be preferred to the Gaussian one. Based on maximized log-likelihood results, we came to the conclusion that the Student's-t is a better fit for our data than its counterpart. As many previous studies evaluated that the Student's-t Copulas offers deep insights in interpreting asymptotic dependence in the tail. Therefore, it is clear to witness that these pairs of cryptocurrencies joint symmetric tail dependence. Moreover, it also represents that the spillover risks happen among these cryptocurrencies through joint fat tails mechanism (at Student's-t Copulas estimation). To be more precise, the network of contagion risks among these cryptocurrencies (including bitcoin, ethereum, xrp, litecoin, and stellar) increased the probability of joint extreme values. Clearly, this approach offers us the precise nature of correlation among these kinds of coins in terms of structural distribution. Regarding the goodness-of-fit for Copulas, Embrechts (2009) also pointed out that up to $99.9 \%$ of Copulas approach will pass through the goodness-of-fit. Therefore, we focused on choosing the Copulas family for parametric figures as Genest et al. (1995) suggest. 


\subsection{Summary of Findings}

Before stating conclusions and implications, we will summarize our findings for the estimation above. Firstly, the Pearson correlation showed strong evidence about each pair of cryptocurrencies at the $1 \%$ significance level. One of significant findings to point out is that all cryptocurrencies have linear correlations. However, this approach fails to explain the dependence structure as well as extreme value. Our findings are similar to the study of Brauneis and Mestel (2018). Secondly, VAR and SVAR Granger causalities demonstrated inconsistent findings. Regarding the linear dependence through VAR estimation, ethereum is the only element that has an independent feature. This coin does not cause or receive any effect. Meanwhile, all the remaining cryptocurrencies cause spillover for another one. Especially, Ripple (xrp) is quite sensitive to changes because it receives all effects from these cryptocurrencies. When it comes to structural dependence, Bitcoin is likely to incur spillover effects, whereas Ripple (xrp), Litcoin, and Stellar tend to cause the change of the other cryptocurrencies. Our findings are quite similar to Tu and Xue (2018) regarding spillover effects. However, we cannot conclude that Bitcoin dominates the market to cause contagion risks. Thirdly, by using further investigation in quantitative techniques as Gaussian and Student's-t Copulas, we figured out that all cryptocurrencies have strong evidence independence structure. Previously, the findings of Huynh et al. (2018), who employed the three kinds of Copulas—Normal, Clayton, and Gumbel—are consistent to choose left-tail dependence structure. Our results contribute to the investigation of Student's-t Copulas in terms of spillover risks with extreme value to the existing literature. Clearly, the cryptocurrency markets with all coins have spillover effects in the structural tail dependence context with an extreme value. Therefore, when a market event happens, it might cause a downside trend for these cryptocurrencies at the same time. This quantitative result demonstrates that there is a contagion risk among the cryptocurrency markets as regards to the extreme value when using Student's-t Copulas for testing.

\section{Conclusions and Implications}

This paper sheds further light on investigating the spillover effects in the cryptocurrency market by various quantitative techniques such as VAR and SVAR Granger causality as well as Copulas with types of Gaussian and Student's-t. We found that the Ethereum is likely to be an independent relationship compared to the other coins from our sample in VAR and SVAR Granger causality approaches. Previously, when using the same methodology, Bitcoin tends to have a sensitive recipient, influenced by the other coins (ethereum, xrp, litecoin, and stellar). This suggests that the investors can use Ethereum for portfolio diversification or a hedging instrument in this kind of market. Nevertheless, we would advise caution when choosing Bitcoin as one of the investment types. The Student's-t Copulas, once again, implicates that all cryptocurrencies have joint distribution in extreme value, which might cause simultaneous downside trend with 'bad news'. Therefore, the investors or portfolio managers should pay more attention to their moving patterns as well as information in order to immediately take any actions (if needed).

Based on the previous findings and results, we make some recommendations for investors as follows. First, investors should be pay attention to moving signals in the markets. This means that any current and past changes in one coin might negatively cause the movement of the other coins. Second, Ethereum is likely to be independent part in this market. Therefore, investors are able to diversify their portfolios by adding Ethereum as a hedging instrument. Third, when extreme value happens, the investors especially concern the left-tail movement, which means the spillover risks phenomenon. These suggestions are also our contributions to current literature novelty and answers for the research questions, which are mentioned in the beginning of this paper.

However, there are some limitations of the VAR-SVAR Granger causality and Student's-t Copulas methods. When it comes to VAR-SVAR Granger causality, one of disadvantages of VAR-SVAR causality is unknown asymptotic distribution of the parameters. In addition, the hypothesis is only constructed under several restricted assumptions. Finally, this approach is not able to measure nonlinear functions 
of parameters of the model, such as the exponential, inversed functions (Droumaguet et al. 2015). Therefore, we also suggest the need for further research in integrating more econometric techniques into VAR-SVAR causality such as Posterior Odds Ratio or Bayesian analysis. Regarding t-Student's Copulas limitations, although the t-Student's Copulas is better than the Gaussian Copulas, it skips the serial dependence error, which will be corrected by Value-at-Risk (VaR) and Extreme-Value-Theory (EVT). Furthermore, the t-Student's Copulas does not capture the time varying changes in dependence structure. Hence, we suggest the time-varying Copulas to fix this error.

Our research also has some limitations for further researches, which are possible to outperform. First, this study only examines the whole sample without dividing into two subsamples (before and after the crash) to estimate the spillover effects. Second, there are some further Copulas for estimation such as time-varying (which estimates one dependence structure parameter for each period) or other bivariate Copulas such as Ali-Mikhail-Haq, Joe, etc.). Third, this study does not capture the spatial spillover effects, which asserts that a shock in Bitcoin (or other coins) is more likely to affect the neighboring countries than countries which are far. We also suggest the further research in DCC-GARCH integrated Bayesian or Markov-Switching to measure this purpose. Lastly, one of the practical applications for using Copulas is to construct portfolio optimization. We suggest further study to indicate the proportions of each coin for investors to put their money in.

Funding: This research was funded by School of Banking, University of Economics Ho Chi Minh City (Vietnam) and Chair of Behavioral Finance, WHU-Otto Beisheim School of Management (Germany).

Acknowledgments: We are grateful for the anonymous referees and guest editors for their remarks. Any remaining errors are my own responsibilities. The author thanks Duy Duong for excellent research assistance.

Conflicts of Interest: The author declares no conflict of interest.

\section{References}

Al Rahahleh, Naseem, and M. Ishaq Bhatti. 2017. Co-movement measure of information transmission on international equity markets. Physica A: Statistical Mechanics and its Applications 470: 119-31. [CrossRef]

Al-Khazali, Osamah, Bouri Elie, and David Roubaud. 2018. The impact of positive and negative macroeconomic news surprises: Gold versus Bitcoin. Economics Bulletin 38: 373-82.

Amisano, Gianni, and Carlo Giannini. 2012. Topics in Structural VAR Econometrics. Berlin: Springer Science \& Business Media.

Bae, Kee-Hong, G. Andrew Karolyi, and Reneé M. Stulz. 2003. A new approach to measuring financial contagion. The Review of Financial Studies 16: 717-63. [CrossRef]

Balcilar, Mehmet, Elie Bouri, Rangan Gupta, and David Roubaud. 2017. Can volume predict Bitcoin returns and volatility? A quantiles-based approach. Economic Modelling 64: 74-81. [CrossRef]

Boubaker, Heni, and Nadia Sghaier. 2013. Portfolio optimization in the presence of dependent financial returns with long memory: A copula based approach. Journal of Banking \& Finance 37: 361-77.

Bouoiyour, Jamal, and Refk Selmi. 2015. What does Bitcoin look like? Annals of Economics E Finance 16: 449-92.

Bouri, Elie, Rangan Gupta, Aviral Kumar Tiwari, and David Roubaud. 2017a. Does Bitcoin hedge global uncertainty? Evidence from wavelet-based quantile-in-quantile regressions. Finance Research Letters 23: 87-95. [CrossRef]

Bouri, Elie, Naji Jalkh, Peter Molnár, and David Roubaud. 2017b. Bitcoin for energy commodities before and after the December 2013 crash: diversifier, hedge or safe haven? Applied Economics 49: 5063-73. [CrossRef]

Bouri, Elie, Mahamitra Das, Rangan Gupta, and David Roubaud. 2018a. Spillovers between Bitcoin and other assets during bear and bull markets. Applied Economics 50: 5935-49. [CrossRef]

Bouri, Elie, Syed Jawad Hussain Shahzad, and David Roubaud. 2018b. Co-explosivity in the cryptocurrency market. Finance Research Letters. forthcoming. [CrossRef]

Boyson, Nicole M., Christof W. Stahel, and Rene M. Stulz. 2010. Hedge fund contagion and liquidity shocks. The Journal of Finance 65: 1789-816. [CrossRef]

Brandvold, Morten, Peter Molnár, Kristian Vagstad, and Ole Christian Andreas Valstad. 2015. Price discovery on Bitcoin exchanges. Journal of International Financial Markets, Institutions and Money 36: 18-35. [CrossRef] 
Brauneis, Alexander, and Roland Mestel. 2018. Price discovery of cryptocurrencies: Bitcoin and beyond. Economics Letters 165: 58-61. [CrossRef]

Briere, Marie, Kim Oosterlinck, and Ariane Szafarz. 2015. Virtual currency, tangible return: Portfolio diversification with bitcoin. Journal of Asset Management 16: 365-73. [CrossRef]

Catania, Leopoldo, and Mads Sandholdt. 2019. Bitcoin at High Frequency. Journal of Risk and Financial Management 12: 36. [CrossRef]

Cheah, Eng-Tuck, and John Fry. 2015. Speculative bubbles in Bitcoin markets? An empirical investigation into the fundamental value of Bitcoin. Economics Letters 130: 32-36. [CrossRef]

Cheah, Eng-Tuck, Tapas Mishra, Mamata Parhi, and Zhuang Zhang. 2018. Long memory interdependency and inefficiency in Bitcoin markets. Economics Letters 167: 18-25. [CrossRef]

Chen, Xiaohong, and Yanqin Fan. 2006. Estimation and model selection of semiparametric copula-based multivariate dynamic models under copula misspecification. Journal of Econometrics 135: 125-54. [CrossRef]

Cheung, Adrian, Eduardo Roca, and Jen-Je Su. 2015. Crypto-currency bubbles: An application of the Phillips-Shi-Yu (2013) methodology on Mt. Gox bitcoin prices. Applied Economics 47: 2348-58. [CrossRef]

Chow, K. Victor, and Karen C. Denning. 1993. A simple multiple variance ratio test. Journal of Econometrics 58: 385-401. [CrossRef]

Christodoulakis, George A., and Stephen E. Satchell. 2002. Correlated ARCH (CorrARCH): Modelling the time-varying conditional correlation between financial asset returns. European Journal of Operational Research 139: 351-70. [CrossRef]

Ciaian, Pavel, Miroslava Rajcaniova, and d'Artis Kancs. 2016. The economics of BitCoin price formation. Applied Economics 48: 1799-815. [CrossRef]

Cong, Rong-Gang, Yi-Ming Wei, Jian-Lin Jiao, and Ying Fan. 2008. Relationships between oil price shocks and stock market: An empirical analysis from China. Energy Policy 36: 3544-53. [CrossRef]

Corbet, Shaen, Charles James Larkin, Brian M. Lucey, Andrew Meegan, and Larisa Yarovaya. 2017. Cryptocurrency Reaction to FOMC Announcements: Evidence of Heterogeneity Based on Blockchain Stack Position. Available online: https://papers.ssrn.com/sol3/papers.cfm?abstract_id=3073727 (accessed on 26 March 2019).

Corbet, Shaen, Brian Lucey, and Larisa Yarovaya. 2018. Datestamping the Bitcoin and Ethereum bubbles. Finance Research Letters 26: 81-88. [CrossRef]

Dickey, David A., and Wayne A. Fuller. 1979. Distribution of the estimators for autoregressive time series with a unit root. Journal of the American Statistical Association 74: 427-31.

Diebold, Francis X., and Kamil Yilmaz. 2008. Measuring financial asset return and volatility spillovers, with application to global equity markets. The Economic Journal 119: 158-71. [CrossRef]

Ding, Liang. 2010. US and Asia Pacific equity markets causality test. International Journal of Business and Management 5: 38. [CrossRef]

Droumaguet, Matthieu, Anders Warne, and Tomasz Wozniak. 2015. Granger causality and regime inference in bayesian markov-switching vars. Journal of Applied Economtrics 32: 802-18. [CrossRef]

Dungey, Mardi, Renée A. Fry, Brenda González-Hermosillo, and Vance L. Martin. 2011. Transmission of Financial Crises and Contagion: A Latent Factor Approach. Oxford: Oxford University Press.

Dyhrberg, Anne Haubo. 2016. Hedging capabilities of bitcoin. Is it the virtual gold? Finance Research Letters 16: 139-44. [CrossRef]

Dyhrberg, Anne H., Sean Foley, and Jiri Svec. 2018. How investible is Bitcoin? Analyzing the liquidity and transaction costs of Bitcoin markets. Economics Letters 171: 140-43. [CrossRef]

Embrechts, Paul. 2009. Copulas: A personal view. Journal of Risk and Insurance 76: 639-50. [CrossRef]

Engle, Robert. 2002. Dynamic conditional correlation: A simple class of multivariate generalized autoregressive conditional heteroskedasticity models. Journal of Business \& Economic Statistics 20: 339-50.

Feder, Christophe. 2018. Decentralization and spillovers: A new role for transportation infrastructure. Economics of Transportation 13: 36-47. [CrossRef]

Fry, John, and Eng-Tuck Cheah. 2016. Negative bubbles and shocks in cryptocurrency markets. International Review of Financial Analysis 47: 343-52. [CrossRef]

Galton, Francis. 1889. I. Co-relations and their measurement, chiefly from anthropometric data. Proceedings of the Royal Society of London 45: 135-45. 
Gandal, Neil, J. T. Hamrick, Moore Tyler, and Oberman Tali. 2018. Price manipulation in the Bitcoin ecosystem. Journal of Monetary Economics 95: 86-96. [CrossRef]

Genest, Christian, Kilani Ghoudi, and L.-P. Rivest. 1995. A semiparametric estimation procedure of dependence parameters in multivariate families of distributions. Biometrika 82: 543-52. [CrossRef]

Ghorbel, Ahmed, and Abdelwahed Trabelsi. 2014. Energy portfolio risk management using time-varying extreme value copula methods. Economic Modelling 38: 470-85. [CrossRef]

Gkillas, Konstantinos, and Paraskevi Katsiampa. 2018. An application of extreme value theory to cryptocurrencies. Economics Letters 164: 109-11. [CrossRef]

Granger, Clive W. J. 1969. Investigating causal relations by econometric models and cross-spectral methods. Econometrica: Journal of the Econometric Society 37: 424-38. [CrossRef]

Greene, William H. 2008. Econometric Analysis, 6th ed.Upper Saddle River: Prentice Hall.

Gudendorf, Gordon, and Johan Segers. 2010. Extreme-value copulas. In Copula Theory and Its Applications. Berlin and Heidelberg: Springer, pp. 127-45.

Hammoudeh, Shawkat, and Eisa Aleisa. 2004. Dynamic relationships among GCC stock markets and NYMEX oil futures. Contemporary Economic Policy 22: 250-69. [CrossRef]

Hiang Liow, Kim. 2012. Co-movements and correlations across Asian securitized real estate and stock markets. Real Estate Economics 40: 97-129. [CrossRef]

Huynh, Toan Luu Duc, Sang Phu Nguyen, and Duy Duong. 2018. Contagion risk measured by return among cryptocurrencies. In International Econometric Conference of Vietnam. Cham: Springer, pp. 987-98.

Ivanov, Ventzislav, and Lutz Kilian. 2001. A Practitioner's Guide to Lag-Order Selection for Vector Autoregressions. CEPR Discussion Paper No. 2685. London: Centre for Economic Policy Research, Available online: http: / / www.cepr.org/pubs/dps/DP2685.asp (accessed on 26 March 2019).

Ji, Qiang, Bouri Elie, Gupta Rangan, and Roubaud David. 2018a. Network causality structures among Bitcoin and other financial assets: A directed acyclic graph approach. The Quarterly Review of Economics and Finance 70: 203-13. [CrossRef]

Ji, Qiang, Bouri Elie, Lau Chi Keung Macro, and Roubaud David. 2018b. Dynamic connectedness and integration in cryptocurrency markets. International Review of Financial Analysis. [CrossRef]

Katsiampa, Paraskevi. 2017. Volatility estimation for Bitcoin: A comparison of GARCH models. Economics Letters 158: 3-6. [CrossRef]

Katsiampa, Paraskevi. 2018. An Empirical Investigation of volatility Dynamics in the Cryptocurrency Market. Available online: https://papers.ssrn.com/sol3/papers.cfm?abstract_id=3202317 (accessed on 26 March 2019).

Kotz, Samuel, and Saralees Nadarajah. 2004. Multivariate t-Distributions and Their Applications. Cambridge: Cambridge University Press.

Koutmos, Dimitrios. 2018a. Bitcoin returns and transaction activity. Economics Letters 167: 81-85. [CrossRef]

Koutmos, Dimitrios. 2018b. Return and volatility spillovers among cryptocurrencies. Economics Letters 173: 122-27. [CrossRef]

Kristoufek, Ladislav. 2015. What are the main drivers of the Bitcoin price? Evidence from wavelet coherence analysis. PLoS ONE 10: e0123923. [CrossRef]

Kundu, Srikanta, and Nityananda Sarkar. 2016. Return and volatility interdependences in up and down markets across developed and emerging countries. Research in International Business and Finance 36: 297-311. [CrossRef]

Li, Xin, and Chong Alex Wang. 2017. The technology and economic determinants of cryptocurrency exchange rates: The case of Bitcoin. Decision Support Systems 95: 49-60. [CrossRef]

Ljung, Greta M., and George E. P. Box. 1978. On a measure of lack of fit in time series models. Biometrika 65: 297-303. [CrossRef]

Lo, Stephanie, and J. Christina Wang. 2014. Bitcoin as Money? Current Policy Perspectives. Boston: Federal Reserve Bank of Boston.

Luo, Weiwei, Robert D. Brooks, and Param Silvapulle. 2011. Effects of the open policy on the dependence between the Chinese 'A'stock market and other equity markets: An industry sector perspective. Journal of International Financial Markets Institutions and Money 21: 49-74. [CrossRef]

Lütkepohl, Helmut. 2005. New Introduction to Multiple time Series Analysis. Berlin: Springer Science \& Business Media. 
Maghyereh, Aktham, and Ahmad Al-Kandari. 2007. Oil prices and stock markets in GCC countries: New evidence from nonlinear cointegration analysis. Managerial Finance 33: 449-60. [CrossRef]

Malevergne, Yannick, and Didier Sornette. 2003. Testing the Gaussian copula hypothesis for financial assets dependences. Quantitative Finance 3: 231-50. [CrossRef]

Malevergne, Yannick, and Didier Sornette. 2006. Extreme Financial Risks: From Dependence to Risk Management. Berlin: Springer Science \& Business Media.

Nakamoto, Satoshi. 2008. Bitcoin: A Peer-to-Peer Electronic Cash System. Unpublished Manuscript. Available online: http:/ / pdos.csail.mit.edu/6.824/papers/bitcoin.pdf (accessed on 26 March 2019).

Narayan, Paresh Kumar, and Seema Narayan. 2010. Modelling the impact of oil prices on Vietnam's stock prices. Applied Energy 87: 356-61. [CrossRef]

Nasir, Muhammad Ali, Toan Luu Duc Huynh, Sang Phu Nguyen, and Duy Duong. 2019. Forecasting cryptocurrency returns and volume using search engines. Financial Innovation 5: 2. [CrossRef]

Nguyen, Cuong C., and M. Ishaq Bhatti. 2012. Copula model dependency between oil prices and stock markets: Evidence from China and Vietnam. Journal of International Financial Markets Institutions and Money 22: 758-73. [CrossRef]

Ogawa, Hikaru, and David E. Wildasin. 2009. Think locally, act locally: Spillovers, spillbacks, and efficient decentralized policymaking. American Economic Review 99: 1206-17. [CrossRef]

Park, Jungwook, and Ronald A. Ratti. 2008. Oil price shocks and stock markets in the US and 13 European countries. Energy Economics 30: 2587-608. [CrossRef]

Pearson, Karl. 1896. VII. Mathematical contributions to the theory of evolution.-III. Regression, heredity, and panmixia. Philosophical Transactions of the Royal Society of London. Series A, containing papers of a mathematical or physical character. Royal Society 187: 253-318.

Phillips, Peter C. B., and Pierre Perron. 1988. Testing for a unit root in time series regression. Biometrika 75: 335-46. [CrossRef]

Phillips, Peter C. B., Shuping Shi, and Jun Yu. 2015. Testing for multiple bubbles: Historical episodes of exuberance and collapse in the S\&P 500. International Economic Review 56: 1043-78.

Polasik, Michal, Anna Iwona Piotrowska, Tomasz Piotr Wisniewski, Radoslaw Kotkowski, and Geoffrey Lightfoot. 2015. Price fluctuations and the use of Bitcoin: An empirical inquiry. International Journal of Electronic Commerce 20: 9-49. [CrossRef]

Selgin, George. 2015. Synthetic commodity money. Journal of Financial Stability 17: 92-99. [CrossRef]

Shabri Abd. Majid, M., Ahamed Kameel Mydin Meera, Mohd Azmi Omar, and Hassanuddeen Abdul Aziz. 2009. Dynamic linkages among ASEAN-5 emerging stock markets. International Journal of Emerging Markets 4: 160-84. [CrossRef]

Sims, Christopher A. 1980. Macroeconomics and reality. Econometrica: Journal of the Econometric Society 48: 1-48. [CrossRef]

Snedecor, George W., and William G. Cochran. 1989. Statistical Methods. Ames: Iowa State College Press Ames. First published 1980.

Sovbetov, Yhlas. 2018. Factors influencing cryptocurrency prices: Evidence from bitcoin, ethereum, dash, litcoin, and monero. Journal of Economics and Financial Analysis 2: 1-27.

Stigler, Stephen M. 1986. The History of Statistics: The Measurement of Uncertainty Before 1900. Cambridge: Harvard University Press.

Su, EnDer. 2017. Measuring and testing tail dependence and contagion risk between major stock markets. Computational Economics 50: 325-51. [CrossRef]

Trabelsi, Nader. 2018. Are There Any Volatility Spill-Over Effects among Cryptocurrencies and Widely Traded Asset Classes? Journal of Risk and Financial Management 11: 66. [CrossRef]

Tse, Yiu K., and Albert K. C. Tsui. 2002. A multivariate generalized autoregressive conditional heteroscedasticity model with time-varying correlations. Journal of Business \& Economic Statistics 20: 351-62.

Tu, Zhiyong, and Changyong Xue. 2018. Effect of bifurcation on the interaction between Bitcoin and Litecoin. Finance Research Letters. forthcoming. [CrossRef]

Tudor, Cristiana. 2011. Changes in stock markets interdependencies as a result of the global financial crisis: Empirical investigation on the CEE region. Panoeconomicus 58: 525-43. [CrossRef]

Urquhart, Andrew. 2017. Price clustering in Bitcoin. Economics Letters 159: 145-48. [CrossRef] 
Velde, François R. 2013. Bitcoin Is a Digital Currency That Was Launched in 2009, and It Has Attracted Much Attention Recently. This Article Reviews the Mechanics of the Currency and Offers Some Thoughts on Its Characteristics. Chicago Fed Letter 317: 1.

Vinh, Vo Xuan. 2014. An empirical investigation of factors affecting stock prices in Vietnam. Journal of Economics and Development 16: 74-89.

Wald, Abraham, and Jacob Wolfowitz. 1940. On a test whether two samples are from the same population. The Annals of Mathematical Statistics 11: 147-62. [CrossRef]

Wei, Wang Chun. 2018. Liquidity and market efficiency in cryptocurrencies. Economics Letters 168: 21-24. [CrossRef]

Yermack, David. 2015. Is Bitcoin a real currency? An economic appraisal. In Handbook of Digital Currency. Cambridge: Academic Press, pp. 31-43.

Yi, Shuyue, Zishuang Xu, and Gang-Jin Wang. 2018. Volatility connectedness in the cryptocurrency market: Is Bitcoin a dominant cryptocurrency? International Review of Financial Analysis 60: 98-114. [CrossRef]

Yilmaz, Kamil. 2010. Return and volatility spillovers among the East Asian equity markets. Journal of Asian Economics 21: 304-13. [CrossRef]

Zhang, Bing, Zhizhen Fan, and Xindan Li. 2010. Comovement between China and US's stock markets. Economic Research Journal 11: 141-51.

Zivot, Eric, and Donald W. K. Andrews. 2002. Further evidence on the great crash, the oil-price shock, and the unit-root hypothesis. Journal of Business E Economic Statistics 20: 25-44.

(C) 2019 by the author. Licensee MDPI, Basel, Switzerland. This article is an open access article distributed under the terms and conditions of the Creative Commons Attribution (CC BY) license (http://creativecommons.org/licenses/by/4.0/). 



\title{
A Survey on Efficiency and Profitable Trading Opportunities in Cryptocurrency Markets
}

\author{
Nikolaos A. Kyriazis \\ Laboratory of Economic Policy and Strategic Planning, Department of Economics, University of Thessaly, \\ 28th October 78 Street, P.C. 38333 Volos, Greece; knikolaos@uth.gr
}

Received: 2 April 2019; Accepted: 15 April 2019; Published: 18 April 2019

\begin{abstract}
This study conducts a systematic survey on whether the pricing behavior of cryptocurrencies is predictable. Thus, the Efficient Market Hypothesis is rejected and speculation is feasible via trading. We center interest on the Rescaled Range (R/S) and Detrended Fluctuation Analysis (DFA) as well as other relevant methodologies of testing long memory in returns and volatility. It is found that the majority of academic papers provides evidence for inefficiency of Bitcoin and other digital currencies of primary importance. Nevertheless, large steps towards efficiency in cryptocurrencies have been traced during the last years. This can lead to less profitable trading strategies for speculators.
\end{abstract}

Keywords: survey; bitcoin; cryptocurrency; efficient market hypothesis

JEL Classification: G11; G12; G15; E4

\section{Introduction}

Since its introduction by Nakamoto (2008), the exponential growth of Bitcoin and other digital currencies has aroused sparkling interest concerning governments, academics, investors, traders and portfolio managers. This very new type of money carries characteristics both of commodity and money (Selgin 2015; Ammous 2018) and is tagged with the all-encompassing label of "cryptocurrency". Bitcoin, the most popular among cryptocurrencies, has aroused a proliferating bulk of academic work studying its returns and volatility characteristics, such as in Dyhrberg (2016a, 2016b), Fry and Cheah (2016), Katsiampa (2017), Urquhart (2016, 2017), Corbet et al. (2018, 2019), Bouri et al. (2017a, 2017b), Baur et al. (2018a, 2018b) and Beneki et al. (2019). One of the fundamental aspects of digital currencies that has attracted increasing attention is whether such markets are consistent with the Efficient Markets Hypothesis (EMH).

One of the most radical perspectives of modelling financial data are the three forms of the Efficient Markets Hypothesis, as has been expressed by Fama (1970), in order to detect the existence of any predictable patterns that could form the basis for profitable trading strategies. The Efficient Market Hypothesis constitutes the cornerstone of financial economics and is based on the seminal work of Bachelier in the early 20th century and Fama (1970). Fama defines informational efficiency in a market as the status when "prices reflect full information" in this market.

These are the main forms of informational efficiency most commonly expressed. Firstly, weak-form efficiency in quotes of assets depict all the information inhibited in past prices of these assets. Secondly, semi-strong efficiency stands for present prices reflecting all information easily accessible to public. Thirdly, strong-form efficiency represents the situation where quotes nowadays reflect all public and private information.

Among the three forms of the EMH, the most commonly employed is the weak-form EMH, which represents the inability of interested investors to take advantage of information about past quotes of investible assets in order to envision the future values of these assets. When the Efficient 
Markets Hypothesis is valid, there cannot be long memory in time series concerning financial assets. Therefore, no abnormal returns can be achieved by investors should they try to follow a profitable investing strategy with minimum risk. Differently said, speculation based on long-range dependence in returns is not applicable when EMH holds.

To the best of our knowledge, no study until now has investigated the full spectrum of academic literature on profitable trading based on cryptocurrencies. Differently said, the present study is the first one to conduct a thorough and integrated review of the existing empirical work on whether cryptocurrency markets can outperform the market, thereby leading to abnormal profit-making by investors. A small but upcoming number of important papers such as Urquhart (2016), Nadarajah and Chu (2017) and Bariviera (2017) have paved the way for a more mature viewpoint in the efficiency of digital coin markets.

The remainder of this paper is structured as follows. Section 2 lays out the studies about efficiency in Bitcoin markets. Section 3 provides an overview of the nascent but already very informative domain of Efficient Market Hypothesis testing in a broader spectrum of cryptocurrencies. In Section 4, the conclusions are discussed.

\section{Studies about Efficiency in Bitcoin Markets}

An important number of academic papers have investigated long-range dependence and whether this could co-exist with the Efficient Market Hypothesis. A battery of tests have been employed in order to measure whether weak-form efficiency in the Bitcoin market is valid. Empirical findings by the great majority of papers about Bitcoin provide evidence of inefficiency, thereby profitable trading opportunities. It should be emphasized though that the capacity to outperform the market by investing in Bitcoin fades out as the Bitcoin market renders more mature. Table 1 provides the prestigious studies with examination of the Efficient Market Hypothesis in cryptocurrency markets that have been conducted so far, the relevant data sources as well as the methodologies adopted and whether they detect inefficiency or not.

Table 1. Studies about EMH in cryptocurrency markets with data sources, methodology and conclusions about level of inefficiency.

\begin{tabular}{|c|c|c|c|}
\hline Study & Data Source & Methodology & Efficiency or Not \\
\hline Aggarwal (2019) & www.coindesk.com & $\begin{array}{c}\text { Augmented Dickey-Fuller test based on } \\
\text { Dickey and Fuller (1979) } \\
\text { Phillips-Perron test in Phillips (1987) } \\
\text { Kwiatkowski et al. (1992) test } \\
\text { Zivot and Andrews (2002) structural } \\
\text { breakpoint test } \\
\text { Lo and MacKinlay (1988) multiple variance } \\
\text { ratio (MVR) test } \\
\text { BDS test by Brock et al. (1996) } \\
\text { ARCH by Engle (1982) } \\
\text { GARCH by Bollerslev (1986) } \\
\text { E-GARCH by Nelson (1991) } \\
\text { TARCH by Zakoian (1994) }\end{array}$ & Inefficiency \\
\hline Almudhaf (2018) & $\begin{array}{l}\text { http://grayscale.co/ } \\
\text { bitcoin-investment- } \\
\text { trust }\end{array}$ & OLS with Newey-West's covariance estimator & Inefficiency \\
\hline $\begin{array}{l}\text { Alvarez-Ramirez et } \\
\quad \text { al. (2018) }\end{array}$ & www.coindesk.com & $\begin{array}{l}\text { Detrended Fluctuation Analysis (DFA) } \\
\text { Scaling Exponent over Sliding Window } \\
\text { Asymmetric Scaling Exponent }\end{array}$ & Inefficiency \\
\hline $\begin{array}{l}\text { Al-Yahyaee et al. } \\
\qquad(2018)\end{array}$ & $\begin{array}{c}\text { Datastream } \\
\text { Coindesk Price Index } \\
\text { website }\end{array}$ & $\begin{array}{l}\text { Multifractal Detrended Fluctuation Analysis } \\
\text { (MF-DFA) }\end{array}$ & Inefficiency \\
\hline
\end{tabular}


Table 1. Cont.

\begin{tabular}{|c|c|c|c|}
\hline Study & Data Source & Methodology & Efficiency or Not \\
\hline Bariviera (2017) & Datastream & $\begin{array}{c}\text { Hurst (1951) exponent } \\
\text { Detrended Fluctuation Analysis (DFA) }\end{array}$ & $\begin{array}{l}\text { Inefficiency but } \\
\text { decreasing }\end{array}$ \\
\hline $\begin{array}{l}\text { Bariviera et al. } \\
\quad(2017)\end{array}$ & Datastream & $\begin{array}{c}\text { Hurst (1951) exponent } \\
\text { Detrended Fluctuation Analysis (DFA) }\end{array}$ & $\begin{array}{l}\text { Inefficiency/ } \\
\text { Efficiency }\end{array}$ \\
\hline Bouri et al. (2019) & $\begin{array}{c}\text { Bitstamp } \\
\text { Coindesk Price Index } \\
\text { website }\end{array}$ & $\begin{array}{l}\text { ARIMA (parametric, semiparametric d } \\
\text { estimations) } \\
\text { Bai and Perron (2003) structural break tests }\end{array}$ & Inefficiency \\
\hline Bouri et al. (2018) & $\begin{array}{l}\text { www.coinmarketcap. } \\
\text { com }\end{array}$ & $\begin{array}{l}\text { Copula-Granger Causality in Distribution } \\
\text { (CGCD) by Lee and Yang (2014) }\end{array}$ & Inefficiency \\
\hline $\begin{array}{l}\text { Brauneis and } \\
\text { Mestel (2018) }\end{array}$ & Coinmarketcap.com & $\begin{array}{c}\text { Ljung and Box (1978) test } \\
\text { Wald and Wolfowitz (1940) runs-test } \\
\text { Variance ratio test by Lo and MacKinlay } \\
\text { (1988) } \\
\text { Kim (2009) wild bootstrap automatic variance } \\
\text { ratio test based on Chow and Denning (1993) } \\
\text { Bartels (1982) test } \\
\text { Hurst (1951) exponent }\end{array}$ & $\begin{array}{l}\text { Higher efficiency in } \\
\text { Bitcoin }\end{array}$ \\
\hline $\begin{array}{l}\text { Caporale et al. } \\
\text { (2018) }\end{array}$ & Coinmarketcap.com & $\begin{array}{c}\mathrm{R} / \mathrm{S} \text { analysis } \\
\text { Fractional integration }\end{array}$ & Inefficiency \\
\hline $\begin{array}{c}\text { Chaim and Laurini } \\
\text { (2018) }\end{array}$ & $\begin{array}{l}\text { Coinmetrics.io } \\
\text { FRED database }\end{array}$ & Laurini et al. (2016) model & Inefficiency \\
\hline $\begin{array}{l}\text { Chaim and Laurini } \\
\text { (2019) }\end{array}$ & Coinmetrics.io & Laurini et al. (2016) model & Inefficiency \\
\hline
\end{tabular}

\begin{tabular}{|c|c|c|c|}
\hline $\begin{array}{l}\text { Charfeddine and } \\
\text { Maouchi (2018) }\end{array}$ & Coinmarketcap.com & $\begin{array}{c}\text { Geweke and Porter-Hudak (1983) (GHP) test } \\
\text { Gaussian semi parametric (GSP) test of } \\
\text { Robinson (1995a) } \\
\text { Local Whittle (LW) of Robinson (1995b) } \\
\text { Exact Local Whittle (ELW) of Shimotsu and } \\
\text { Phillips (2005) } \\
\text { R/S test of Lo (1991) } \\
\text { Rescaled Variance (V/S) test of Giraitis et al. } \\
\text { (2003) }\end{array}$ & $\begin{array}{c}\text { Inefficiency, } \\
\text { Efficiency (ETH) }\end{array}$ \\
\hline Cheah et al. (2018) & $\begin{array}{l}\text { www.bitcoincharts. } \\
\text { com }\end{array}$ & FCVAR by Johansen and Nielsen (2012) & Inefficiency \\
\hline $\begin{array}{l}\text { El Alaoui et al. } \\
\text { (2018) }\end{array}$ & $\begin{array}{c}\text { www. } \\
\text { cryptocompare.com }\end{array}$ & $\begin{array}{l}\text { Multifractal Detrended Cross-correlations } \\
\text { Analysis (MF-DCCA) by Zhou (2008) }\end{array}$ & Inefficiency \\
\hline $\begin{array}{l}\text { Hattori and Ishida } \\
\text { (2019) }\end{array}$ & Bloomberg & Regression & Inefficiency \\
\hline Ji et al. (2018) & www.coindesk.com & $\begin{array}{c}\text { Directed Acyclical Graph (DAG) by Spirtes et } \\
\text { al. (2000) } \\
\text { Vector Autoregression (VAR) } \\
\text { Error Correction Model (ECM) } \\
\text { Forecast Error Variance Decomposition } \\
\text { (FEVD) }\end{array}$ & $\begin{array}{l}\text { Very weak } \\
\text { inefficiency }\end{array}$ \\
\hline Jiang et al. (2018) & $\begin{array}{l}\text { www.bitcoinaverage. } \\
\text { com }\end{array}$ & $\begin{array}{c}\text { Hurst (1951) exponent and rolling windows } \\
\text { Ljung -Box test } \\
\text { AVR test }\end{array}$ & Inefficiency \\
\hline Kaiser (2018) & Coinmarketcap.com & $\begin{array}{c}\text { Bid-ask spread estimation as by Abdi and } \\
\text { Ranaldo (2017) } \\
\text { Volatility estimation as by Rogers and } \\
\text { Satchell (1991) } \\
\text { GARCH by Bollerslev (1986) }\end{array}$ & Efficiency \\
\hline $\begin{array}{c}\text { Khuntia and } \\
\text { Pattanayak (2018) }\end{array}$ & www.coindesk.com & $\begin{array}{l}\text { Dominguez- Lobato (DL) test } \\
\text { Generalized Spectral (GS) test }\end{array}$ & $\begin{array}{c}\text { Efficiency } \\
\text { evolving-(Adaptive } \\
\text { Market) }\end{array}$ \\
\hline
\end{tabular}


Table 1. Cont.

\begin{tabular}{|c|c|c|c|}
\hline Study & Data Source & Methodology & Efficiency or Not \\
\hline $\begin{array}{l}\text { Köchling et al. } \\
\text { (2018) }\end{array}$ & $\begin{array}{l}\text { www.bitcoinaverage. } \\
\text { com }\end{array}$ & $\begin{array}{c}\text { Ljung and Box (1978) test } \\
\text { Escanciano and Lobato (2009) automatic } \\
\text { portmanteau test } \\
\text { Wald and Wolfowitz (1940) runs-test } \\
\text { Bartels (1982) } \\
\text { Durlauf (1991) spectral shape test } \\
\text { Escanciano and Velasco (2006) generalized } \\
\text { spectral test } \\
\text { Kim (2009) wild bootstrap automatic variance } \\
\text { ratio test } \\
\text { Brock et al. (1996) BDS test } \\
\text { Hurst (1951) exponent }\end{array}$ & $\begin{array}{l}\text { Inefficiency but } \\
\text { decreasing }\end{array}$ \\
\hline $\begin{array}{l}\text { Köchling et al. } \\
\text { (2019) }\end{array}$ & Coimarketcap.com & $\begin{array}{l}3 \text { delay measures by Hou and Moskowitz } \\
(2005)\end{array}$ & $\begin{array}{l}\text { Inefficiency but } \\
\text { decreasing }\end{array}$ \\
\hline Kristoufek (2018) & www.coindesk.com & $\begin{array}{l}\text { Efficiency Index of Kristoufek and Vosvrda } \\
\qquad(2013)\end{array}$ & $\begin{array}{c}\text { Inefficiency } \\
\text { Efficiency only } \\
\text { after cooling down } \\
\text { of bubbles }\end{array}$ \\
\hline $\begin{array}{c}\text { Kurihara and } \\
\text { Fukushima (2017) }\end{array}$ & $\begin{array}{l}\text { www.bitcoinaverage. } \\
\text { com }\end{array}$ & $\begin{array}{l}\text { Ordinary Least Squares (OLS) } \\
\text { Robust Least Squares (RLS) }\end{array}$ & Inefficiency \\
\hline $\begin{array}{l}\text { Lahmiri and } \\
\text { Bekiros (2018) }\end{array}$ & www.coindesk.com & $\begin{array}{c}\text { Largest Lyapunov Exponent (LLE) } \\
\text { Shannon entropy (SE) } \\
\text { Multi-fractal Detrended Fluctuation Analysis } \\
\text { (MF-DFA) }\end{array}$ & Inefficiency \\
\hline $\begin{array}{l}\text { Lahmiri et al. } \\
\qquad(2018)\end{array}$ & data.Bitcoinity.org & $\begin{array}{c}\text { Fractionally integrated GARCH (FIGARCH) } \\
\text { by Baillie et al. (1996) } \\
\text { Shannon entropy by Shannon (1948) }\end{array}$ & Inefficiency \\
\hline Mbanga (2018) & $\begin{array}{l}\text { www.bitcoincharts. } \\
\text { com }\end{array}$ & Huber (1964) M estimations & Inefficiency \\
\hline $\begin{array}{l}\text { Nadarajah and Chu } \\
\qquad(2017)\end{array}$ & $\begin{array}{l}\text { www.bitcoinaverage. } \\
\text { com }\end{array}$ & $\begin{array}{c}\text { Ljung and Box (1978) test } \\
\text { Runs test by Wald and Wald and Wolfowitz } \\
\qquad(1940) \\
\text { Bartels (1982) test } \\
\text { Wild-bootstrapped AVR test by Kim (2009) } \\
\text { Spectral shape tests by Durlauf (1991) and } \\
\text { Choi (1999) } \\
\text { BDS test by Brock et al. (1996) } \\
\text { Portmanteau test by Escanciano and Lobato } \\
\text { (2009) } \\
\text { Generalized spectral test by Escanciano and } \\
\text { Velasco (2006) }\end{array}$ & Inefficiency \\
\hline Phillip et al. (2018a) & $\begin{array}{l}\text { Brave New Coin } \\
\text { (BNC) Digital } \\
\text { Currency indices }\end{array}$ & $\begin{array}{c}\text { Ljung and Box (1978) test } \\
\text { Kolmogorov-Smirnov test by Massey (1951) } \\
\text { Generalized long-term memory by Gray et al. } \\
\text { (1989) } \\
\text { Generalized long memory (GLM)- stochastic } \\
\text { volatility (SV)- leverage (LVG) and heavy } \\
\text { tails (HT) model }\end{array}$ & Inefficiency \\
\hline $\begin{array}{l}\text { Phillip et al. } \\
\text { (2018b) }\end{array}$ & $\begin{array}{l}\text { Brave New Coin } \\
\text { (BNC) Digital } \\
\text { Currency indices }\end{array}$ & $\begin{array}{l}\text { Jump BAR SV Gegenbauer Log Range } \\
\text { (JBAR-SV-GLR) model, as combination of } \\
\text { Zhu et al. (2014) and Taylor (2007) }\end{array}$ & Inefficiency \\
\hline Sensoy (2018) & 64 Bitcoin exchanges & $\begin{array}{c}\text { Matilla-García and Marín (2008) } \\
\text { López et al. (2010) }\end{array}$ & $\begin{array}{c}\text { Inefficiency } \\
\text { More efficient since } \\
2016\end{array}$ \\
\hline $\begin{array}{l}\text { Takaishi and } \\
\text { Adachi (2018) }\end{array}$ & $\begin{array}{l}\text { www.coindesk.com } \\
\text { Histdata.com }\end{array}$ & Autocorrelation tests & Inefficiency \\
\hline
\end{tabular}


Table 1. Cont.

\begin{tabular}{|c|c|c|c|}
\hline Study & Data Source & Methodology & Efficiency or Not \\
\hline Tiwari et al. (2018) & www.coindesk.com & $\begin{array}{c}\text { Hurst (1951) exponent } \\
\text { DFA } \\
\text { CMA-1 and CMA-2 by Bashan et al. (2008) } \\
\text { Periodogram-LAD and Periodogram-LS by } \\
\text { Taqqu et al. (1995) } \\
\text { GPH by Geweke and Porter-Hudak (1983) } \\
\text { MLE estimators by Haslett and Raftery (1989) }\end{array}$ & Inefficiency \\
\hline Urquhart (2016) & $\begin{array}{l}\text { www.bitcoinaverage. } \\
\text { com }\end{array}$ & $\begin{array}{c}\text { Ljung and Box (1978) test } \\
\text { Runs test by Wald and Wolfowitz (1940) } \\
\text { Automatic variance test (AVR) } \\
\text { Wild-bootstrapped AVR test by Kim (2009) } \\
\text { BDS test by Brock et al. (1996) } \\
\text { Hurst (1951) exponent }\end{array}$ & Inefficiency \\
\hline Urquhart (2017) & $\begin{array}{l}\text { www.bitcoincharts. } \\
\text { com }\end{array}$ & $\begin{array}{l}\text { Clustering test } \\
\text { Probit model }\end{array}$ & Inefficiency \\
\hline $\begin{array}{l}\text { Vidal-Tomás and } \\
\text { Ibañez (2018) }\end{array}$ & Bitstamp and Mt.Gox & CGARCH, AR-CGARCH-M & $\begin{array}{c}\text { Inefficiency but } \\
\text { decreasing }\end{array}$ \\
\hline Wei (2018) & $\begin{array}{l}\text { www.coinmarketcap. } \\
\text { com }\end{array}$ & $\begin{array}{c}\text { Ljung and Box (1978) test } \\
\text { Runs test by Wald and Wolfowitz (1940) } \\
\text { Bartels test } \\
\text { Automatic variance test (AVR) } \\
\text { Wild-bootstrapped AVR test by Kim (2009) } \\
\text { BDS test by Brock et al. (1996) } \\
\text { Hurst (1951) exponent } \\
\text { Amihud (2002) illiquidity ratio } \\
\end{array}$ & Inefficiency \\
\hline $\begin{array}{l}\text { Zargar and Kumar } \\
\qquad(2019 a)\end{array}$ & Bloomberg & $\begin{array}{c}\text { Variance ratio (VR) test by Lo and MacKinlay } \\
(1988) \\
\text { Multiple Variance Ratio (MVR) test by Chow } \\
\text { and Denning (1993) } \\
\text { Automatic Variance Ratio (AVR) test by Choi } \\
(1999) \\
\text { Joint Variance Ratio (JVR) test by Chen and } \\
\text { Deo (2006) } \\
\text { Kuan and Lee (2004) (KL) test }\end{array}$ & $\begin{array}{l}\text { Inefficiency at } \\
\text { higher data } \\
\text { frequencies }\end{array}$ \\
\hline $\begin{array}{l}\text { (Zargar and Kumar } \\
(2019 b)\end{array}$ & Bloomberg & $\begin{array}{c}\text { Local Whittle (LW) estimator } \\
\text { Exact Local Whittle (ELW) estimator } \\
\text { ARFIMA }\end{array}$ & Inefficiency \\
\hline Zhang et al. (2018) & Coinmarketcap.com & $\begin{array}{l}\text { Autocorrelation tests, GARCH by Bollerslev } \\
\text { (1986), GJR model by Glosten et al. (1993), } \\
\text { Detrended Fluctuation Analysis (DFA) by } \\
\text { Peng et al. (1995), Detrended Moving } \\
\text { Average Correlation Analysis (DMCA) by He } \\
\text { and Chen (2011) } \\
\text { Hurst (1951) exponent }\end{array}$ & Inefficiency \\
\hline
\end{tabular}

Among the initial important studies testing about efficiency in the Bitcoin market are Urquhart (2016, 2017), Nadarajah and Chu (2017) and Bariviera (2017). Urquhart (2016) adopted daily data in order to examine the informational efficiency of Bitcoin during the period from 1 August 2010 to 31 July 2016. He examined two nine-year subperiods with the end of July as 2013 separating them. The author employs a battery of tests such as the Ljung and Box (1978) test, the runs test (Wald and Wolfowitz 1940), the Bartels (1982) test, the variance ratio of Lo and Lo and MacKinlay (1988), the wild-bootstrapped test of Kim (2009), the BDS test of Brock et al. (1996) and the Hurst (1951) exponent for testing long memory. These tests reject randomness and the Hurst exponent advocates the existence of strong anti-persistence. Thereby, findings lead to the conclusion that no efficiency in Bitcoin market exists though there is a tendency towards a valid EMH since August 2013. Furthermore, 
Urquhart (2017) adopts data of various Bitcoin exchanges from 1 May 2012 to 30 April 2017 in order to investigate price clustering in Bitcoin markets. Evidence indicated that clustering takes place at round numbers as over one tenth of prices end with 00 decimals. Furthermore, there is weaker evidence of clustering around the 50 digit and the 99 digit. It was found that 1, 2, 3, 5 and 10 days before a round number from increasing prices returns indicate a positive sign, whereas afterwards returns are negative and not statistically significant. Overall, findings abide by the negotiation hypothesis of Harris (1991) because price clustering is linked to quotes and trading volume of Bitcoin.

In a similar perspective, Nadarajah and Chu (2017) employ data from 1 August 2010 to 31 July 2016 in order to study efficiency in the Bitcoin market. Furthermore, they divide the sample into two subperiods, the first one spanning from 1 August 2010 to 31 July 2013, and the second one covering 1 August 2013 to 31 July 2016. They augment the research of Urquhart (2016) by adopting eight tests to investigate the EMH. More specifically, the Ljung-Box test (Ljung and Box 1978), the runs test (Wald and Wolfowitz 1940), the Bartels's test (Bartels 1982) and the wild-bootstrapped automatic variance ratio test (Kim 2009) are adopted. Moreover, the spectral shape tests (Durlauf 1991), the BDS test (Brock et al. 1996), the portmanteau test by Escanciano and Lobato (2009) and the generalized spectral test (Escanciano and Velasco 2006) are performed. The majority of them provide evidence about independence of returns. Thereby, no abnormal profits could be made in the Bitcoin market.

Bariviera (2017) uses daily data that cover the period from 18 August 2011, until 15 February 2017, in order to study long-range dependence of Bitcoin returns and volatility. The methodology employed is the Hurst exponent by using Detrended Fluctuation Analysis (DFA) and overlapping sliding windows. Results provided evidence that during the 2011-2014 period, Bitcoin's returns exhibited persistence but after 2014 there is a tendency towards efficiency. On the contrary, outcomes about Bitcoin's volatility advocate that this has been persistent during the whole period under scrutiny. Moreover, Bariviera et al. (2017) used daily data from 2011 until 2017 and intraday data from 2013 to 2016 concerning prices of Bitcoin and currency values of EUR and GBP, expressed in USD. The Hurst exponent by Detrended Fluctuation Analysis (DFA) in a sliding window is adopted to estimate long-range dependence. Results indicate that values of Hurst exponent alter by significant levels during the early life of Bitcoin, that is until 2014, but takes steps towards stabilization as time passes, as its value moves around 0.5 . It was found that alternative time scales do not significantly affect long-range memory. Moreover, there is evidence that market liquidity does not influence long-term dependence. Furthermore, Kurihara and Fukushima (2017) investigate whether weekly price anomalies exist or not by looking into the market efficiency of Bitcoin. They extract data that cover the period from 17 July 2010 to 29 December 2016 and employ standard ordinary least squares (OLS) and robust least squares (RLS) methodologies. Findings indicate that the Bitcoin market is not characterized by weak-form efficiency. Nevertheless, higher levels of efficiency in the Bitcoin market are revealed as time passes.

The intensely bullish market had taken place in 2017 brought about an increasing volume of academic work investigating the Bitcoin markets. This reflects the increasing interest of academics, investors, speculators and portfolio managers concerning the dominant coin in the cryptocurrency market. As cryptocurrency markets in general are believed to be strongly directed by investor sentiment about Bitcoin, such bibliography casts light on the reasons of investors' decision making.

Alvarez-Ramirez et al. (2018) examine the period June 2013 to June 2017 by applying detrended fluctuation analysis (DFA) over rolling windows to identify long-range correlations for Bitcoin returns. Findings indicate that the Hurst component exhibits cycles and Bitcoin has periods of efficiency but also periods of inefficiency. Asymmetric correlations are found that depend on whether price trends are upwards or downwards, thereby leading to inefficiency due to anti-persistence. By another perspective, Jiang et al. (2018) investigate the existence of long-term dependence in the Bitcoin market in order to provide a clearer picture about the existence or not of efficiency concerning Bitcoin. The data adopted are in a daily frequency and span the period 1 December 2010, to 30 November 2017. The Hurst exponent and a rolling-window approach with a 14-day shift are employed. Furthermore, 
the Ljung-Box test and AVR test are adopted to measure efficiency in the Bitcoin market. Empirical outcomes indicate that this market is not efficient as long-memory is detected and a high value in the inefficiency ratio. Nevertheless, a tendency towards efficiency has been found as time passes. Moreover, Tiwari et al. (2018) adopt daily data from 18 July 2010 to 16 June 2017, in order to employ a battery of tests and examine long-range dependence and informational efficiency of Bitcoin. More specifically, they employ the Detrended Fluctuation Analysis (DFA), the Centered Moving Average- squared absolute fluctuation (CMA-1) and Centered Moving Average-mean absolute fluctuation (CMA-2). Furthermore, they use the Periodogram-Least Squares (Periodogram-LS) and the Periodogram Least Absolute Deviation (Periodogram-LAD). Moreover, the maximum-likelihood estimator (MLE) and the Geweke-Porter-Hudak (GPH) methodologies are employed. Overall, findings reveal that the Bitcoin market is efficient. Nevertheless, outcomes in favor of inefficiency are found regarding the subperiods of April to August 2013 and from August to November 2016. In their paper, Cheah et al. (2018) employ daily closing Bitcoin prices concerning the period 27 November 2011, to 17 March 2017, about the markets in Europe, USA, Australia, Canada and the United Kingdom, in order to study interdependence in a cross-country level. Treatment of cross-market Bitcoin quotes as long-memory procedures by employing a fractionally cointegrated VAR (FCVAR) specification brings about evidence of informational inefficiency across markets. Thereby, long-memory is detected in separate Bitcoin markets as well as in the five-market system. Apart from findings of medium to high inefficiency across Bitcoin markets and long-memory characteristics that permit trading profits, it was found that uncertainty exerts a negative impact on Bitcoin markets. Disequilibrium errors adjust slowly, thereby stochastic shocks could prove really influential for independent Bitcoin markets.

Köchling et al. (2018) used data covering a period before the launch of Bitcoin futures (10 August 2017-10 December 2017) and just after the launch (10 December 2017-10 April 2018) and conducted a number of efficiency tests to investigate the impacts of Bitcoin futures introduction on Bitcoin's efficiency. Seven out of the nine tests employed provide evidence of inefficiency before these futures were initiated. Nevertheless, since the Bitcoin futures started trading, no inefficiency has been detected, so weak-form efficiency has been present. Moreover, no appearance of inefficiency is revealed concerning BitcoinCash, which is a hard fork of Bitcoin. When it comes to Sensoy (2018), he adopted data from 1 January 2013 to 5 March 2015 about tick-by-tick trades in 15, 20, 30, 40 and 45-min frequencies concerning trading volumes and prices of Bitcoin in relation to USD and EUR. Permutation entropy based on Shannon's entropy, a time-varying approach with rolling samples, is employed in order to estimate efficiency. Results indicated that the exchange rates of BTC to USD and to EUR enjoy higher levels of informational efficiency since the beginning of 2016. It should be noted that this amelioration in efficiency exhibits a cyclical pattern as regards the cryptocurrency's value in relation to USD whereas a gradual increase is detected in relation to EUR. Moreover, the former exchange rate is found to be more efficient than the latter. Evidence indicates that higher frequencies lead to lower pricing efficiency. Furthermore, higher liquidity has a positive nexus with informational efficiency while higher volatility presents a negative impact on efficiency in Bitcoin markets.

Among relevant studies is Kristoufek (2018), that investigates the existence of efficiency in two Bitcoin markets regarding the US dollar and the Chinese yuan. He uses data ending July 2017 and starting on 18 July 2010, and 1 February 2014, respectively. The Efficiency Index (EI) developed by Kristoufek and Vosvrda (2013) is employed to measure efficiency. Moreover, the Hurst exponent, the fractal dimension and entropy measures are adopted. Results provide evidence that the USD market is efficient from the middle of 2011 to the middle of 2012. The same is found regarding the period between March and November 2014. Nevertheless, empirical outcomes abide by the conclusion that both the USD and the CNY Bitcoin markets are mostly inefficient during the seven-year period examined. Efficiency is only apparent when Bitcoin quotes render too high and contractionary action in the form of stability is necessary. Moreover, Phillip et al. (2018a) adopted daily data about Bitcoin, Ethereum, Ripple, NEM and Dash from alternative trading platforms until the date of 31 July 2017. They measure generalized long memory (GLM), stochastic volatility (SV), leverage (LVG) and heavy 
tails (HT) by the GLM-SV-LGV-HT model. It is revealed that these highest-capitalized currencies tend to behave similarly regarding their long-memory characteristics as their markets mature. Evidence is found that digital currency markets are not efficient. It should be underlined that long memory, leverage and stochastic volatility characteristics as well as heavy tailedness are detected in all cryptocurrencies under scrutiny. Almudhaf (2018) in his study, looks into the pricing efficiency of Bitcoin Investment Trust (BIT) by employing daily data concerning the closing price and the net asset value (NAV) from 4 May 2015 to 18 November 2016. Ordinary least squares (OLS) methodology with Newey West's (HAC) estimators are utilized. Evidence indicates the existence of a strong and positive nexus between prices and NAV. A powerful and positive linkage between returns of Bitcoin Investment Trust and premiums -in the form of contemporaneous percentage deviations- is detected. The premium is found to be approximately equal to $44 \%$ of the NAV. Outcomes reveal the existence of inefficiency. Therefore, profitable trading strategies could be implemented.

Khuntia and Pattanayak (2018) employ daily Bitcoin data from 18 July 2010 to 21 December 2017 in order to investigate the adaptive market hypothesis $(\mathrm{AMH})$ and the alterations in return predictability in the Bitcoin market. The Dominguez-Lobato (DL) consistent test and generalized spectral (GS) test in a rolling window framework are adopted to test the Martingale Difference Hypothesis (MDH) and detect linear and nonlinear dependence in quotes. Findings reveal the existence of high levels of efficiency from the middle of 2012 until November 2013 as well as since 2015. Nevertheless, inefficiency is found to exist during the subperiods of August 2011-August 2012 and December 2013-December 2014. Thereby, evolving efficiency is verified as periods of efficiency are followed by times of inefficiency and the $\mathrm{AMH}$ is valid.

An alternative perspective in examination of efficiency in Bitcoin markets is adopted by Ji et al. (2018). To be more precise, they employ the directed acyclic graph (DAG) methodology along with vector autoregressive (VAR) and error correction model (ECM) schemes as well as the forecast error variance decomposition (FEVD) methodology. They aim to reveal the present and past nexus between Bitcoin and other financial assets, such as equities, bonds, currencies and commodities. The degree of centrality is found to be the lowest concerning the Bitcoin market so its prices cannot be predicted by being based on quotes of other assets. A very small level of inefficiency is detected. Moreover, El Alaoui et al. (2018) investigate the non-linear linkage between alterations in prices and alterations in the trading volume of Bitcoin. They adopt daily data covering the period from 17 July 2010 to 2 May 2018. The methodology they use is the multifractal detrended cross-correlation analysis (MF-DCCA). Empirical findings indicate that non-linear dependency as well as multifractality appear in Bitcoin prices and volume. Anti-persistence is traced in volumes for positive but also for negative values of moments " $\mathrm{q}$ ". Thereby, inefficiency is revealed in the Bitcoin market and there are significant opportunities for profitability by traders.

In their work, Vidal-Tomás and Ibañez (2018) employed daily data from 13 September 2011 to 17 December 2017, and from 13 September 2011 to 25 February 2014, concerning the Bitstamp and Mt.Gox markets, respectively. They focused on investigating the existence of semi-strong efficiency in Bitcoin markets, and on how Bitcoin returns were affected by news about this currency and monetary policy events. By adopting Autoregressive Copula Generalized Autoregressive Conditional Heteroskedasticity (AR-CGARCH) and Autoregressive Copula Generalized Autoregressive Conditional Heteroskedasticity in Mean (AR-CGARCH-M) specifications, they provided evidence that while negative events are important for both models, positive news meaningfully affects only Bitstamp and the Bitstamp market is more efficient than Mt.Gox. Furthermore, the Bitcoin market has rendered more efficient as time passes. It should be noted that this digital currency is influenced by its own events, but takes much influence from news about central bank policymaking in an international level. Thereby, higher levels of inefficiency are apparent in response to monetary policy events. Additionally, Al-Yahyaee et al. (2018) conduct a comparison of Bitcoin market's efficiency to markets of alternative assets of primary importance, that is gold, equity and foreign exchange markets. The period under consideration spans 18 July 2010 to 31 October 2017 and daily data are extracted. The methodology they adopt 
in order to estimate efficiency is the multifractal detracted fluctuation analysis (MF-DFA) method that was developed by Kantelhardt et al. (2002) as it is considered to be more flexible than the MF and DFA methodologies. Slopes of Generalized Hurst exponents are employed to represent long-memory characteristics. Empirical outcomes indicate that Bitcoin is the least efficient and with the most time-varying efficiency asset among the markets investigated whereas the equity market is the most efficient one. Notably, Bitcoin has been found to exhibit the largest long-range persistence. Multifractality and long-memory are better detected in small fluctuations and such outcomes could be attributable to lack of confidence by Bitcoin investors. In connection with the study of Urquhart (2017), the academic paper of Mbanga (2018) uses daily volume and closing prices of Bitstamp covering the period from 20 February 2011 to 15 May 2018 to investigate the day-of-week pattern of price clustering in Bitcoin. Findings provide evidence that Bitcoin prices cluster around whole numbers. Additionally, it is found that price clustering does not constitute a phenomenon of Mondays or Fridays, even though evidence shows that it is stronger on Fridays in relation to other days of the week. The most frequent ending decimals of values in Fridays are 0.00, 0.99 and 0.50. Overall, no evidence is revealing a weekend effect in Bitcoin price clustering.

An econophysics perspective into cryptocurrencies is provided by Lahmiri and Bekiros (2018). They employed daily data of Bitcoin covering the period from 18 July 2010 to 23 October 2017 so as to study the chaos, randomness and multi-scale correlation structure of prices and returns in a low- and a high-regime period. The largest Lyapunov exponent, Shannon entropy, the multi-fractal detrended fluctuation analysis (MF-DFA) and the generalized Hurst exponent are employed for estimations. Evidence advocates the existence of higher uncertainty in returns during the high-price regime period. Multifractality is detected in prices and returns during both periods and this is due to fat-tailed distributions. Furthermore, short alterations in returns dominate in the low regime, whereas long ones during the high regime period. All in all, nonlinear patterns in the Bitcoin market are traced in the high-price level regime. In a somewhat similar vein, Lahmiri et al. (2018) used data in a daily frequency of seven Bitcoin markets so as to study long-range memory of Bitcoin volatility. The methodology employed is the fractionally integrated GARCH (FIGARCH) and the Shannon entropy measure. The analysis takes place under four alternative distributions, that is the Normal, Student-t, generalized error (GED) and the t-skewed distributions. Empirical outcomes provide evidence of long-range memory existing no matter which distribution assumption is made. It is found that predictions about volatility can take place based on past information about volatility. BITX presents the lowest level of inefficiency, whereas COINBASE the highest. Overall, there is powerful evidence against the Efficient Market Hypothesis and Bitcoin markets are found to be too risky to serve for hedging.

A number of Japanese authors have also investigated digital currencies. Takaishi (2018) examines the statistical properties of Bitcoin by employing one-minute data from January 2014 to December 2016 and by adopting the multifractal Detrended Fluctuation Analysis (MF-DFA) and Generalized Autoregressive Conditional Heteroskedasticity (GARCH), Glosten-Jagannathan-Runkle Generalized Autoregressive Conditional Heteroskedasticity (GJR-GARCH) and Rational Generalized Autoregressive Conditional Heteroskedasticity (RGARCH) models. Results indicated that Bitcoin prices exhibit multifractality, which comes from temporal correlation as well as the fat-tailed distribution so inefficiency in the Bitcoin market is detected. Moreover, the Brexit decision is found not to have influenced Bitcoin. Takaishi and Adachi (2018) extract data from a one-minute Bitcoin price index (BPI) concerning the period 1 January 2014 to 31 December 2017 as well as one-minute data on EUR-GBP, USD-CHF and USD-JPY exchange rates. Investigation about Taylor effects in Bitcoin time series takes place. Empirical outcomes provide evidence in favor of existence of a Taylor effect. Moreover, it is found that the value of power that renders maximum the autocorrelation of the power of absolute returns is influenced by a time lag in the autocorrelation function. Furthermore, no daily seasonality was detected in the Taylor effect of Bitcoin. This is in contrast to the Taylor impact about currency values in relation to foreign currencies, as they present daily seasonality. Hattori and Ishida (2019) look into how investors conduct arbitrage between Bitcoin spot and futures markets by adopting intraday 
data of CBOE futures price on active contracts and Gemini price from Bloomberg. The data employed cover the period December 2017 to December 2018. They find that arbitrage is sufficient in normal times, whereas market crashed provide opportunities to conduct arbitrage.

There is also a number of recent academic papers concerning efficiency in cryptocurrencies, such as Aggarwal (2019), Bouri et al. (2019), and Zargar and Kumar (2019b). Aggarwal (2019) examines efficiency in Bitcoin markets by employing daily Bitcoin prices about the period from 19 July 2010 until 20 March 2018. In order to do so, he employs serial correlation coefficient tests, unit root tests and the $\mathrm{ARCH}$ test. According to estimation results, Bitcoin returns do not follow a random walk. Thereby, evidence is provided in favor of strong inefficiency in the Bitcoin market. Moreover, tests for non-linear dependence lend support to the claim that high volatility persistence in returns is responsible for such inefficiencies. Furthermore, Bouri et al. (2019) investigated the persistence in the level and volatility of Bitcoin price by also looking for structural break effects. Data was extracted by Bitstamp and covered the period from 19 August 2011 to 29 April 2016. Moreover, data from the Coindesk price index were extracted from the period of 18 July 2010 to 15 December 2015. Parametric and semi-parametric techniques were employed and evidence is in favor of a permanent character of shocks and that there is no mean reversion in levels. Structural alterations are detected in Bitcoin dynamics and at least four structural breaks in each period are traced. Long memory is found both in absolute and squared returns measures of volatility and some occasions of short memory are revealed in the latter case. Overall, evidence towards inefficiency leaves room for trading benefits.

Zargar and Kumar (2019a) adopted data referring to Bitstamp exchange from 21 January 2013 to 8 January 2018. More specifically, 15-, 30-, 60-, 120-min and daily data were employed. They adopted the multiple variance ratio (MVR) test, the automatic variance ratio (AVR) test and the joint variance ratio (JVR) test as well as the Kuan and Lee (KL) test in order to examine whether the martingale hypothesis is valid in the Bitcoin market. Findings provide evidence in favor of informational inefficiency in the Bitcoin market when higher frequencies are employed. This is confirmed by full sample, non-overlapping window and overlapping moving window estimations. Zargar and Kumar (2019b) employ data of the same time period and frequency as Zargar and Kumar (2019a) to investigate the existence of long memory in the Bitcoin market. The Local Whittle estimator (LW), the exact Local Whittle estimator (ELW) and the Autoregressive Moving Average- Fractionally Integrated Asymmetric Power Autoregressive Conditional Heteroskedasticity (ARMA-FIAPARCH) model are employed. Findings indicate statistically significant long-memory parameters that do not fluctuate either for unconditional nor for conditional volatility measures in alternative time scales. Inefficiency is also presented by the examination of "realized" volatilities estimated by LW, ELW and ARFIMA methodologies. Quarterly non-overlapping rolling window estimations also reveal high persistence. Thereby, inefficiency is found to be evident in the Bitcoin market.

\section{Studies about Efficiency in Cryptocurrency Markets in General}

Despite the first-appearing academic papers investigating exclusively Bitcoin, the skyrocketing bullish market of 2017 has led to a number of significant studies concerning alternative digital currencies of high-capitalization. This is because Bitcoin had lost a significant portion of its market share during this boom period owing to investment in alternative digital coins providing a solution to also to lower-budget investors.

Zhang et al. (2018) adopt daily data about Bitcoin, Ethereum, Ripple, Litecoin, Stellar, Dash, Monero and Nem covering the period from 28 April 2013 to 30 April 2018. They employ skewness, kurtosis and Jarque-Bera tests, autocorrelations, GARCH and GJR specifications as well as Detrended Moving Average cross-correlation analysis to discover stylized facts about digital currencies. These methodologies are employed in order to analyze heavy tails, autocorrelations, volatility clustering, leverage impacts, long-range dependence and power-law correlation for these cryptocurrencies. The Hurst exponent combined with rolling windows reveal that the Bitcoin market is moving towards efficiency, as the exponent's value is around 0.5. When it comes to long-range 
dependence of volatility, Bitcoin, Ethereum and Nem present long-range dependence in every period under scrutiny. Moreover, Phillip et al. (2018b) used data of 149 digital currencies with different starting dates but include up to 31 December 2017. They looked into whether long-run autocorrelation exists in the daily-based volatility measures as the very volatile nature of cryptocurrencies can allow. They investigated for jump behavior in volatility. To be more precise, the focus was made on Bitcoin, Ethereum, Ripple, Litecoin, Dash and Monero and they adopt the Jump BAR SV Gegenbauer Log Range (JBAR-SV-GLR) model. Volatility oscillation memory ratios (VOMRs) are employed in order to make out whether currencies have oscillatory features. Results reveal that cryptocurrencies which need more time for transactions such as Bitcoin, exhibit less oscillatory characteristics in comparison with coins like Ripple that are very fast to transact (VOMR $>1)$. It is found that long-run autocorrelations in digital coins should be studied through their volatility dynamics and not by focusing on returns.

Brauneis and Mestel (2018) used daily data covering quotes, dollar volume and market capitalization of 73 digital currencies covering the period of 31 August 2015 to 30 November 2017, in order to look into their efficiency. They employed the Ljung and Box (1978) test for autocorrelation, the runs test (Wald and Wolfowitz 1940), the variance ratio test (Lo and MacKinlay 1988) and the Kim wild-bootstrapped VR test (Chow and Denning 1993). Moreover, the Kim (2009) automatic version of the latter (Choi 1999), the Bartels (1982), the Brock et al. (1996) non-parametric BDS tests as well as the Hurst exponent are employed. Additionally, the non-parametric measure for market efficiency (Godfrey 2017) is adopted. Liquidity is measured by the Amihud (2002) ratio. Results indicated that Bitcoin is the most efficient across cryptocurrencies. It should be noted that the higher is the level of liquidity of a digital currency, the more inefficient this digital coin renders. Thereby, higher liquidity leads to higher capacity of achieving abnormal profits. In their study, Charfeddine and Maouchi (2018) employed daily closing prices of Bitcoin, Ethereum, Ripple and Litecoin covering periods from their launch until February 2018. They investigated long-range dependence (LRD) in returns and volatility of these cryptocurrencies. Empirical outcomes indicate that the LRD behavior (if it exists) in the Bitcoin, Litecoin and Ripple returns series and in the volatility series of Ethereum, is a true behavior, not a statistical artifact. Thereby, evidence indicates that inefficiency exists in the markets of there out of the four digital coins investigated, as Ethereum is the only efficient market.

Wei (2018) collected price and aggregate volume data about 458 cryptocurrencies during the year of 2017. The Amihud (2002) illiquidity ratio was employed in order to measure liquidity and also a series of efficiency tests take place in order to detect signs of autocorrelation and non-independence. Based on the Hurst exponent, evidence revealed anti-persistence in illiquid markets, as the test used values lower than 0.5. Furthermore, smaller currencies were found to go through small boom-bust cycles that depend on the sentiment of speculators. As the digital currencies investigated are separated into five categories depending on their level of liquidity, it can be seen that in more liquid cryptocurrencies, the Hurst exponent takes values close to 0.5 . Thereby, in levels of higher liquidity, prices follow a random walk and markets are more efficient so no abnormal returns by speculation can be achieved. Furthermore, Caporale et al. (2018) employ daily data concerning the four cryptocurrencies with the highest market capitalization (Bitcoin, Litecoin, Ripple, Dash) for the biggest time length possible up to 2017. The methodologies they adopt are the R/S Hurst analysis and fractional integration. Results indicate that the level of persistence is not stable overtime, thereby a large number of fluctuations take place. This is more evident in the case of Litecoin. Findings provide evidence in favor of the Adaptive Market Hypothesis as expressed by Lo (1991) and that higher level of efficiency emerges as time goes by. Litecoin was initially much more inefficient. According to values of the Hurst exponent, it is revealed that Bitcoin, Litecoin and Dash are more efficient, whereas Ripple is not. Overall, the cryptocurrency market is found to be still inefficient, but steps towards efficiency have been realized as the Hurst exponent is decreasing. All in all, opportunities for profitable trading in cryptocurrencies still exist. Bouri et al. (2018) looked into the causality nexus between returns and trading volume of seven major cryptocurrencies (Bitcoin, Ripple, Ethereum, Litecoin, NEM, Dash and Stellar). Daily data was used and the Copula-quantile causality methodology is adopted. Econometric estimations provide 
evidence that trade volume Granger causes extreme negative as well as positive returns on all the seven currencies examined. Nevertheless, findings about impacts on return volatility are weaker. This happens because only the Litecoin, NEM and Dash are found to be recipients of effects and only in low volatility levels. Therefore, no efficiency is detected in cryptocurrency markets in an overall view.

Chaim and Laurini (2018) used a sample of Bitcoin and gold returns as well as USD to EUR exchange rate and the SP500 index concerning the April 2013-May 2018 period. They employ a standard log-normal volatility model and then incorporate the existence of discontinuous jumps to volatility and returns. Markov Chain Monte Carlo (MCMC) procedures are employed for estimations. It was argued that jumps to volatility exhibit a permanent character whereas only contemporaneous impacts exist due to jumps to mean returns. It can be seen that the first volatility period covers from late 2013 to early 2014 and is linked to the Mt.Gox incident. The second period covers 2017 with highest volatility shown in December due to increased public interest. Jumps to mean returns are found to be connected with large and negative price movements due to hacks and forks failed attempts. In a somewhat similar vein, Chaim and Laurini (2019) used data about nine major cryptocurrencies (Bitcoin, Ethereum, Ripple, Litecoin, Stellar, Dash, Monero, Nem, Verge) covering from 16 August 2015 to 31 October 2018. They employed the multivariate non-linear stochastic volatility model proposed by Laurini et al. (2016) for considering common jumps to the mean and volatility of returns. This is based on a Bayesian mechanism that adopts a mixed MCMC procedure. Findings indicate that transitory mean jumps render larger and exhibit higher frequency since early 2017. Simulations revealed that long-memory dependence characteristics are well described by stationary models having jump components.

Kaiser (2018) employed daily data for Bitcoin, BitcoinCash, Cardano, Dash, Ethereum, IOTA, Litecoin, NEO, Ripple and Monero in order to examine seasonality patterns in their returns, volatility, trading volume and a spread estimator. To be more precise, he tested for (i) the Monday effect, (ii) the weekend effect, (iii) the January effect, (iv) the turn-of-the month effect and (v) the Halloween effect. Overall, the EMH in its weak form cannot be rejected. No calendar effect in a consistent and robust level was detected. Nevertheless, Monday and reverse January effects are presented in the Bitcoin market. Moreover, partial significance is found concerning the trading volume, volatility and spreads. In a recent study, Köchling et al. (2019) use data from about 75 cryptocurrencies covering the period from 31 August 2015 until 31 August 2018. Only currencies with capitalization of at least 1 million USD were taken into consideration. They adopt the three delay measures as proposed by Hou and Moskowitz (2005) in order to study time delay of digital currency markets to price information. Outcomes indicated that price delays get significantly lower during the investigated period. It can be seen that cryptocurrency markets render more efficient as time passes. Furthermore, results strongly advocate that there is a powerful nexus of price delay with liquidity and market capitalization.

It should be noted that the majority of studies provide evidence towards the existence of inefficiency in cryptocurrency markets. This lends support to the attractive character of the digital currency markets for investors and particularly for speculators. Market participants can gain insight into future quotes of cryptocurrencies and gain large amounts of profits by studying the determinants of returns and return volatility of Bitcoin and other similar currencies.

\section{Conclusions}

The body of evidence that intends to measure the economic and financial repercussions of the Efficient Market Hypothesis (EMH) on cryptocurrencies has accumulated in an increasing pace. There is already a significant bulk of academic work that provides evidence in favor of inefficiency in digital currency markets and primarily in the Bitcoin market.

Weak-form efficiency that shows whether prices reflect the information contained in the past series of prices has been tested in the great majority of the thirty-eight studies under scrutiny. The largest number of academic papers examined advocate that the EMH does not hold. Long memory in cryptocurrency time series is detected as dependence from past returns is revealed. A battery of tests 
from a wide spectrum are employed such as the Hurst exponent, the Bartels test, the variance ratio test and its specifications among others. Thereby, investors can use past information to predict future returns. This enables speculators to exercise profitable trading strategies suffering only very low risk.

It should be noted that long-range dependence that leads to inefficiency is found to fade out as time passes in the Bitcoin markets as well as in the cryptocurrencies market in general. This provides useful feedback and generates an even more vivid debate about the future of digital currencies. These coins constitute extremely sophisticated investment assets that have attracted an overwhelmingly upcoming number of investors and are expected to become a cornerstone in finance.

The present study fills a gap in relevant literature by providing an overall perspective of the efficiency characteristics and profit opportunities in digital currency markets. Therefore, this systematic survey enlightens policymakers, academics, investors and the economic press about the profitability dynamics inhibited in the markets of these innovative liquidity forms. Avenues for future research include the mapping of the efficiency-measuring dynamics of every methodology adopted in the relevant literature. Moreover, the connection of investor sentiment with the speed of adjustment of cryptocurrency markets towards validity of the Efficient Market Hypothesis should pave the way for new empirical examinations and systematic surveys.

Funding: This research received no external funding.

Conflicts of Interest: The author declares no conflict of interest.

\section{References}

Abdi, Farshid, and Angelo Ranaldo. 2017. A simple estimation of bid-ask spreads from daily close, high, and low prices. The Review of Financial Studies 30: 4437-80. [CrossRef]

Aggarwal, M. Divya. 2019. Do bitcoins follow a random walk model? Research in Economics 73: 15-22. [CrossRef]

Almudhaf, Fahad. 2018. Pricing efficiency of Bitcoin Trusts. Applied Economics Letters 25: 504-8. [CrossRef]

Alvarez-Ramirez, Jose, Eduardo Rodriguez, and Carlos Ibarra-Valdez. 2018. Long-range correlations and asymmetry in the Bitcoin market. Physica A: Statistical Mechanics and Its Applications 492: 948-55. [CrossRef]

Al-Yahyaee, Khamis Hamed, Walid Mensi, and Seong-Min Yoon. 2018. Efficiency, multifractality, and the long-memory property of the Bitcoin market: A comparative analysis with stock, currency, and gold markets. Finance Research Letters 27: 228-34. [CrossRef]

Amihud, Yakov. 2002. Illiquidity and stock returns: cross-section and time-series effects. Journal of Financial Markets 5: 31-56. [CrossRef]

Ammous, Saifedain. 2018. Can cryptocurrencies fulfil the functions of money? The Quarterly Review of Economics and Finance 70: 38-51. [CrossRef]

Bai, Jushan, and Pierre Perron. 2003. Computation and analysis of multiple structural change models. Journal of Applied Econometrics 18: 1-22. [CrossRef]

Baillie, Richard T., Tim Bollerslev, and Hans Ole Mikkelsen. 1996. Fractionally integrated generalized autoregressive conditional heteroskedasticity. Journal of Econometrics 74: 3-30. [CrossRef]

Bariviera, Aurelio F. 2017. The inefficiency of Bitcoin revisited: A dynamic approach. Economics Letters 161: 1-4. [CrossRef]

Bariviera, Aurelio F., María José Basgall, Waldo Hasperué, and Marcelo Naiouf. 2017. Some stylized facts of the Bitcoin market. Physica A: Statistical Mechanics and Its Applications 484: 82-90. [CrossRef]

Bartels, Robert. 1982. The rank version of von Neumann's ratio test for randomness. Journal of the American Statistical Association 77: 40-46. [CrossRef]

Bashan, Amir, Ronny Bartsch, Jan W. Kantelhardt, and Shlomo Havlin. 2008. Comparison of detrending methods for fluctuation analysis. Physica A: Statistical Mechanics and Its Applications 387: 5080-90. [CrossRef]

Baur, Dirk G., Thomas Dimpfl, and Konstantin Kuck. 2018a. Bitcoin, gold and the US dollar-A replication and extension. Finance Research Letters 25: 103-10. [CrossRef]

Baur, Dirk G., Ki Hoon Hong, and Adrian D. Lee. 2018b. Bitcoin: Medium of exchange or speculative assets? Journal of International Financial Markets, Institutions and Money 54: 177-89. [CrossRef] 
Beneki, Christina, Alexandros Koulis, Nikolaos A. Kyriazis, and Stephanos Papadamou. 2019. Investigating volatility transmission and hedging properties between Bitcoin and Ethereum. Research in International Business and Finance 48: 219-27. [CrossRef]

Bollerslev, Tim. 1986. Generalized autoregressive conditional heteroskedasticity. Journal of Econometrics 31: 307-27. [CrossRef]

Bouri, Elie, Naji Jalkh, Peter Molnár, and David Roubaud. 2017a. Bitcoin for energy commodities before and after the December 2013 crash: diversifier, hedge or safe haven? Applied Economics 49: 5063-73. [CrossRef]

Bouri, Elie, Peter Molnár, Georges Azzi, David Roubaud, and Lars Ivar Hagfors. 2017b. On the hedge and safe haven properties of Bitcoin: Is it really more than a diversifier? Finance Research Letters 20: 192-98. [CrossRef]

Bouri, Elie, Chi Keung Marco Lau, Brian Lucey, and David Roubaud. 2018. Trading volume and the predictability of return and volatility in the cryptocurrency market. Finance Research Letters. [CrossRef]

Bouri, Elie, Luis A. Gil-Alana, Rangan Gupta, and David Roubaud. 2019. Modelling long memory volatility in the Bitcoin market: Evidence of persistence and structural breaks. International Journal of Finance E Economics 24: 412-26. [CrossRef]

Brauneis, Alexander, and Roland Mestel. 2018. Price discovery of cryptocurrencies: Bitcoin and beyond. Economics Letters 165: 58-61. [CrossRef]

Brock, W. A., J. A. Scheinkman, W. D. Dechert, and B. LeBaron. 1996. A test for independence based on the correlation dimension. Econometric Reviews 15: 197-235. [CrossRef]

Caporale, Guglielmo Maria, Luis Gil-Alana, and Alex Plastun. 2018. Persistence in the cryptocurrency market. Research in International Business and Finance 46: 141-48. [CrossRef]

Chaim, Pedro, and Márcio P. Laurini. 2018. Volatility and return jumps in bitcoin. Economics Letters 173: 158-63. [CrossRef]

Chaim, Pedro, and Márcio P. Laurini. 2019. Nonlinear dependence in cryptocurrency markets. The North American Journal of Economics and Finance 48: 32-47. [CrossRef]

Charfeddine, Lanouar, and Youcef Maouchi. 2018. Are shocks on the returns and volatility of cryptocurrencies really persistent? Finance Research Letters. [CrossRef]

Cheah, Eng-Tuck, Tapas Mishra, Mamata Parhi, and Zhuang Zhang. 2018. Long memory interdependency and inefficiency in Bitcoin markets. Economics Letters 167: 18-25. [CrossRef]

Chen, Willa W., and Rohit S. Deo. 2006. The variance ratio statistic at large horizons. Econometric Theory 22: 206-34. [CrossRef]

Choi, In. 1999. Testing the random walk hypothesis for real exchange rates. Journal of Applied Econometrics 14: 293-308. [CrossRef]

Chow, K. Victor, and Karen C. Denning. 1993. A simple multiple variance ratio test. Journal of Econometrics 58: 385-401. [CrossRef]

Corbet, Shaen, Andrew Meegan, Charles Larkin, Brian Lucey, and Larisa Yarovaya. 2018. Exploring the dynamic relationships between cryptocurrencies and other financial assets. Economics Letters 165: 28-34. [CrossRef]

Corbet, Shaen, Brian Lucey, Andrew Urquhart, and Larisa Yarovaya. 2019. Cryptocurrencies as a financial asset: A systematic analysis. International Review of Financial Analysis 62: 182-99. [CrossRef]

Dickey, David A., and Wayne A. Fuller. 1979. Distribution of the estimators for autoregressive time series with a unit root. Journal of the American Statistical Association 74: 427-31.

Durlauf, Steven N. 1991. Spectral based testing of the martingale hypothesis. Journal of Econometrics 50: 355-76. [CrossRef]

Dyhrberg, Anne Haubo. 2016a. Bitcoin, gold and the dollar-A GARCH volatility analysis. Finance Research Letters 16: 85-92. [CrossRef]

Dyhrberg, Anne Haubo. 2016b. Hedging capabilities of bitcoin. Is it the virtual gold? Finance Research Letters 16: 139-44. [CrossRef]

El Alaoui, Marwane, Elie Bouri, and David Roubaud. 2018. Bitcoin price-volume: A multifractal cross-correlation approach. Finance Research Letters. [CrossRef]

Engle, R. Fobert. 1982. Autoregressive conditional heteroscedasticity with estimates of the variance of United Kingdom inflation. Econometrica: Journal of the Econometric Society 50: 987-1007. [CrossRef]

Escanciano, J. Carlos, and Carlos Velasco. 2006. Generalized spectral tests for the martingale difference hypothesis. Journal of Econometrics 134: 151-85. [CrossRef] 
Escanciano, J. Carlos, and Ignacio N. Lobato. 2009. An automatic portmanteau test for serial correlation. Journal of Econometrics 151: 140-49. [CrossRef]

Fama, Eugene. F. 1970. Efficient Capital Markets: A Review of Theory and Empirical Work. Journal of Finance 25: 383-417. [CrossRef]

Fry, John, and Eng-Tuck Cheah. 2016. Negative bubbles and shocks in cryptocurrency markets. International Review of Financial Analysis 47: 343-52. [CrossRef]

Geweke, John, and Susan Porter-Hudak. 1983. The estimation and application of long memory time series models. Journal of Time Series Analysis 4: 221-38. [CrossRef]

Giraitis, Liudas, Piotr Kokoszka, Remigijus Leipus, and Gilles Teyssière. 2003. Rescaled variance and related tests for long memory in volatility and levels. Journal of Econometrics 112: 265-94. [CrossRef]

Glosten, Lawrence R., Ravi Jagannathan, and David E. Runkle. 1993. On the relation between the expected value and the volatility of the nominal excess return on stocks. The Journal of Finance 48: 1779-801. [CrossRef]

Godfrey, Keith R. 2017. Toward a model-free measure of market efficiency. Pacific-Basin Finance Journal 44: 97-112. [CrossRef]

Gray, Henry L., Nien-Fan Zhang, and Wayne A. Woodward. 1989. On generalized fractional processes. Journal of Time Series Analysis 10: 233-57. [CrossRef]

Harris, Lawrence. 1991. Stock price clustering and discreteness. The Review of Financial Studies 4: $389-415$. [CrossRef]

Haslett, John, and Adrian E. Raftery. 1989. Space-time modelling with long-memory dependence: Assessing Ireland's wind power resource. Journal of the Royal Statistical Society: Series C (Applied Statistics) 38: 1-21. [CrossRef]

Hattori, Takahiro, and Ryo Ishida. 2019. Do Investors Arbitrage in the Cryptocurrency Market? Evidence from the Bitcoin Futures Market. February 8. Available online: https://ssrn.com/abstract=3209625 (accessed on 30 March 2019). [CrossRef]

He, Ling-Yun, and Shu-Peng Chen. 2011. A new approach to quantify power-law cross-correlation and its application to commodity markets. Physica A: Statistical Mechanics and Its Applications 390: 3806-14. [CrossRef]

Hou, Kewei, and Tobias J. Moskowitz. 2005. Market frictions, price delay, and the cross-section of expected returns. The Review of Financial Studies 18: 981-1020. [CrossRef]

Huber, Peter J. 1964. Robust Estimation of a Location Parameter. The Annals of Mathematical Statistics 35: 73-101. [CrossRef]

Hurst, Harold Ervin. 1951. Long-term storage capacity of reservoirs. Transactions of the American Society of Civil Engineers 116: 770-99.

Ji, Qiang, Elie Bouri, Rangan Gupta, and David Roubaud. 2018. Network causality structures among Bitcoin and other financial assets: A directed acyclic graph approach. The Quarterly Review of Economics and Finance 70: 203-13. [CrossRef]

Jiang, Yonghong, He Nie, and Weihua Ruan. 2018. Time-varying long-term memory in Bitcoin market. Finance Research Letters 25: 280-84. [CrossRef]

Johansen, Søren, and Morten Ørregaard Nielsen. 2012. Likelihood inference for a fractionally cointegrated vector autoregressive model. Econometrica 80: 2667-732. [CrossRef]

Kaiser, Lars. 2018. Seasonality in cryptocurrencies. Finance Research Letters. [CrossRef]

Kantelhardt, Jan W., S. A. Zschiegner, Eva Koscielny-Bunde, Shlomo Havlin, Armin Bunde, and H. Eugene Stanley. 2002. Multifractal detrended fluctuation analysis of nonstationary time series. Physica A: Statistical Mechanics and its Applications 316: 87-114. [CrossRef]

Katsiampa, Paraskevi. 2017. Volatility estimation for Bitcoin: A comparison of GARCH models. Economics Letters 158: 3-6. [CrossRef]

Khuntia, Sashikanta, and J. K. Pattanayak. 2018. Adaptive market hypothesis and evolving predictability of bitcoin. Economics Letters 167: 26-28. [CrossRef]

Kim, Jae H. 2009. Automatic variance ratio test under conditional heteroskedasticity. Finance Research Letters 6 : 179-85. [CrossRef]

Köchling, Gerrit, Janis Müller, and Peter N. Posch. 2018. Does the introduction of futures improve the efficiency of Bitcoin? Finance Research Letters. [CrossRef]

Köchling, Gerrit, Janis Müller, and Peter N. Posch. 2019. Price delay and market frictions in cryptocurrency markets. Economics Letters 174: 39-41. [CrossRef] 
Kristoufek, Ladislav. 2018. On Bitcoin markets (in) efficiency and its evolution. Physica A: Statistical Mechanics and its Applications 503: 257-62. [CrossRef]

Kristoufek, Ladislav, and Miloslav Vosvrda. 2013. Measuring capital market efficiency: Global and local correlations structure. Physica A: Statistical Mechanics and its Applications 392: 184-93. [CrossRef]

Kuan, Chung-Ming, and Wei-Ming Lee. 2004. A new test of the martingale difference hypothesis. Studies in Nonlinear Dynamics E Econometrics 8: 1-26.

Kurihara, Yutaka, and Akio Fukushima. 2017. The market efficiency of Bitcoin: A weekly anomaly perspective. Journal of Applied Finance and Banking 7: 57-64.

Kwiatkowski, Denis, Peter C. Phillips, Peter Schmidt, and Yongcheol Shin. 1992. Testing the null hypothesis of stationarity against the alternative of a unit root: How sure are we that economic time series have a unit root? Journal of econometrics 54: 159-78. [CrossRef]

Lahmiri, Selim, and Stelios Bekiros. 2018. Chaos, randomness and multi-fractality in Bitcoin market. Chaos, Solitons $\mathcal{E}$ Fractals 106: 28-34.

Lahmiri, Salim, Stelios Bekiros, and Antonio Salvi. 2018. Long-range memory, distributional variation and randomness of bitcoin volatility. Chaos, Solitons \& Fractals 107: 43-48.

Laurini, Márcio Poletti, Mauad, Roberto Baltieri, and Fernando Antonio Aiube. 2016. Multivariate Stochastic Volatility-Double Jump Model: An application for oil assets. Banco Central do Brasil, Working Papers, 415. Brasília, Brazil: Central Bank of Brazil.

Lee, Tae-Hwy, and Weiping Yang. 2014. Granger-causality in quantiles between financial markets: Using copula approach. International Review of Financial Analysis 33: 70-78. [CrossRef]

Ljung, Greta M., and George E. Box. 1978. On a measure of lack of fit in time series models. Biometrika 65: 297-303. [CrossRef]

Lo, Andrew W. 1991. Long-Term Memory in Stock Market Prices. Econometrica 59: 1279-313. [CrossRef]

Lo, Andrew W., and A. Craig MacKinlay. 1988. Stock market prices do not follow random walks: Evidence from a simple specification test. The Review of Financial Studies 1: 41-66. [CrossRef]

López, Fernando, Mariano Matilla-García, Jesús Mur, and Manuel Ruiz Marín. 2010. A non-parametric spatial independence test using symbolic entropy. Regional Science and Urban Economics 40: 106-15. [CrossRef]

Massey, Frank J., Jr. 1951. The Kolmogorov-Smirnov test for goodness of fit. Journal of the American Statistical Association 46: 68-78. [CrossRef]

Matilla-García, Mariano, and Manuel Ruiz Marín. 2008. A non-parametric independence test using permutation entropy. Journal of Econometrics 144: 139-55. [CrossRef]

Mbanga, Cedric L. 2018. The day-of-the-week pattern of price clustering in bitcoin. Applied Economics Letters 1-5. [CrossRef]

Nadarajah, Saralees, and Jeffrey Chu. 2017. On the inefficiency of Bitcoin. Economics Letters 150: 6-9. [CrossRef]

Nakamoto, Satoshi. 2008. Bitcoin: A Peer-to-Peer Electronic Cash System. Cambridge: MIT Press.

Nelson, Daniel B. 1991. Conditional heteroskedasticity in asset returns: A new approach. Econometrica: Journal of the Econometric Society 59: 347-70. [CrossRef]

Peng, C. K., Shlomo Havlin, H. Eugene Stanley, and Ary L. Goldberger. 1995. Quantification of scaling exponents and crossover phenomena in nonstationary heartbeat time series. Chaos: An Interdisciplinary Journal of Nonlinear Science 5: 82-87. [CrossRef] [PubMed]

Phillip, Andrew, Jennifer S. Chan, and Shelton Peiris. 2018a. A new look at Cryptocurrencies. Economics Letters 163: 6-9. [CrossRef]

Phillip, Andrew, Jennifer S. Chan, and Shelton Peiris. 2018b. On long memory effects in the volatility measure of Cryptocurrencies. Finance Research Letters 28. [CrossRef]

Phillips, Peter C. 1987. Time series regression with a unit root. Econometrica: Journal of the Econometric Society 55: 277-301. [CrossRef]

Robinson, Peter M. 1995a. Gaussian semiparametric estimation of long range dependence. The Annals of Statistics 23: 1630-61. [CrossRef]

Robinson, Peter M. 1995b. Log-periodogram regression of time series with long range dependence. The Annals of Statstics 23: 1048-72. [CrossRef]

Rogers, L. Chris G., and Steven E. Satchell. 1991. Estimating variance from high, low and closing prices. The Annals of Applied Probability 1: 504-12. [CrossRef]

Selgin, George. 2015. Synthetic commodity money. Journal of Financial Stability 17: 92-99. [CrossRef] 
Sensoy, Ahmet. 2018. The inefficiency of Bitcoin revisited: A high-frequency analysis with alternative currencies. Finance Research Letters. [CrossRef]

Shannon, Claude E. 1948. A note on the concept of entropy. Bell System Technical Journal 27: 379-423. [CrossRef]

Shimotsu, Katsumi, and Peter C. Phillips. 2005. Exact local Whittle estimation of fractional integration. The Annals of Statistics 33: 1890-933. [CrossRef]

Spirtes, Peter, Clark N. Glymour, Richard Scheines, David Heckerman, Christopher Meek, Gregory Cooper, and Thomas Richardson. 2000. Causation, Prediction, and Search. Cambridge: MIT Press.

Takaishi, T. 2018. Statistical properties and multifractality of Bitcoin. Physica A: Statistical Mechanics and Its Applications 506: 507-19. [CrossRef]

Takaishi, Tetsuya, and Takanori Adachi. 2018. Taylor effect in Bitcoin time series. Economics Letters 172: 5-7. [CrossRef]

Taqqu, Murad S., Vadim Teverovsky, and Walter Willinger. 1995. Estimators for long-range dependence: An empirical study. Fractals 3: 785-98. [CrossRef]

Taylor, Stephen J. 2007. Modelling Financial Time Series. Hackensack: World Scientific Publishing Co. Pte. Ltd.

Tiwari, Aviral Kumar, R. K. Jana, Debojyoti Das, and David Roubaud. 2018. Informational efficiency of Bitcoin-An extension. Economics Letters 163: 106-9. [CrossRef]

Urquhart, Andrew. 2016. The inefficiency of Bitcoin. Economics Letters 148: 80-82. [CrossRef]

Urquhart, Andrew. 2017. Price clustering in Bitcoin. Economics letters 159: 145-48. [CrossRef]

Vidal-Tomás, David, and Ana Ibañez. 2018. Semi-strong efficiency of Bitcoin. Finance Research Letters 27: 259-65. [CrossRef]

Wald, Abraham, and Jacob Wolfowitz. 1940. On a test whether two samples are from the same population. The Annals of Mathematical Statistics 11: 147-62. [CrossRef]

Wei, Wang Chun. 2018. Liquidity and market efficiency in cryptocurrencies. Economics Letters 168: 21-24. [CrossRef]

Zakoian, Jean-Michel. 1994. Threshold heteroskedastic models. Journal of Economic Dynamics and control 18: 931-55. [CrossRef]

Zargar, Faisal Nazir, and Dilip Kumar. 2019a. Informational inefficiency of Bitcoin: A study based on high-frequency data. Research in International Business and Finance 47: 344-53. [CrossRef]

Zargar, Faisal Nazir, and Dilip Kumar. 2019b. Long range dependence in the Bitcoin market: A study based on high-frequency data. Physica A: Statistical Mechanics and Its Applications 515: 625-40. [CrossRef]

Zhang, Wei, Pengfei Wang, Xiao Li, and Dehua Shen. 2018. The inefficiency of cryptocurrency and its cross-correlation with Dow Jones Industrial Average. Physica A: Statistical Mechanics and Its Applications 510: 658-70. [CrossRef]

Zhou, Wei-Xing. 2008. Multifractal detrended cross-correlation analysis for two nonstationary signals. Physical Review E 77: 066211. [CrossRef] [PubMed]

Zhu, Ke, Philip L. Yu, and Wai Keung Li. 2014. Testing for the buffered autoregressive processes. Statistica Sinica 24: 971-84. [CrossRef]

Zivot, Eric, and Donald W. K. Andrews. 2002. Further evidence on the great crash, the oil-price shock, and the unit-root hypothesis. Journal of Business \& Economic Statistics 20: 25-44.

(C) 2019 by the author. Licensee MDPI, Basel, Switzerland. This article is an open access article distributed under the terms and conditions of the Creative Commons Attribution (CC BY) license (http://creativecommons.org/licenses/by/4.0/). 



\title{
Article
}

\section{Next-Day Bitcoin Price Forecast}

\author{
Ziaul Haque Munim ${ }^{1,2, *}$, Mohammad Hassan Shakil ${ }^{3}$ and Ilan Alon ${ }^{1}$ \\ 1 School of Business and Law, University of Agder, 4630 Kristiansand, Norway; ilan.alon@uia.no \\ 2 Department of Maritime Operations, University of South-Eastern Norway, 3184 Borre, Norway \\ 3 Taylor's Business School, Taylor's University, 47500 Subang Jaya, Malaysia; \\ mohammadhassanshakil@sd.taylors.edu.my \\ * Correspondence: ziaul.h.munim@uia.no
}

Received: 30 April 2019; Accepted: 14 June 2019; Published: 20 June 2019

\begin{abstract}
This study analyzes forecasts of Bitcoin price using the autoregressive integrated moving average (ARIMA) and neural network autoregression (NNAR) models. Employing the static forecast approach, we forecast next-day Bitcoin price both with and without re-estimation of the forecast model for each step. For cross-validation of forecast results, we consider two different training and test samples. In the first training-sample, NNAR performs better than ARIMA, while ARIMA outperforms NNAR in the second training-sample. Additionally, ARIMA with model re-estimation at each step outperforms NNAR in the two test-sample forecast periods. The Diebold Mariano test confirms the superiority of forecast results of ARIMA model over NNAR in the test-sample periods. Forecast performance of ARIMA models with and without re-estimation are identical for the estimated test-sample periods. Despite the sophistication of NNAR, this paper demonstrates ARIMA enduring power of volatile Bitcoin price prediction.
\end{abstract}

Keywords: ARIMA; artificial neural network; Bitcoin; cryptocurrency; static forecast

\section{Introduction}

Bitcoin, the world's first decentralised and currently biggest digital currency, is similar to synthetic commodity money, which shares the attributes of both commodity (e.g., gold) and fiat money (e.g., US dollar) (Selgin 2015). Bitcoin was introduced in 2008 by a group of programmers using the pseudonym 'Satoshi Nakamoto' (Cheah and Fry 2015). Some argue that it has the same finite economic attributes of gold and labelled as digital gold (Popper 2015). Meanwhile, the acceptance of the Bitcoin is still debatable due to its frictionless nature, lack of intrinsic value, and unclear issuing authority (Ciaian et al. 2016). The price volatility of Bitcoin makes it one of the most speculative digital currency, and a poor form of "holder of value". Investors can lose their capital due to high volatility and uncertainty of Bitcoin price.

Media coverage about Bitcoin drew in amateur investors leading to a gambling mentality (Roberts 2017). However, Bitcoin is coming into the mainstream with large institutional investors eyeing its potential. Despite its limitations, Bitcoin is the most valuable and popular cryptocurrency to date (Corbet et al. 2019).

Bitcoin price has been extremely volatile since the inception of the cryptocurrency (Dwyer 2015). Due to concerns with speculative trading, in January 2018, Facebook banned all ads for Bitcoin and other cryptocurrencies (Robertson 2018). Additionally, experts foresee another financial crisis in the near future caused by the cryptocurrency boom (Lam et al. 2018). A major crash of the Bitcoin price can be triggered by a cyber hack and a government crackdown, and can take weeks or months to bounce back (Roberts 2017). Typically, investors predict future Bitcoin price based on past trends. But it is not easy to predict future Bitcoin price with a high level of accuracy. The price of Bitcoin follows a 
boom-bust pattern due to its speculative nature (Cheah and Fry 2015). Additionally, Bitcoin investors are speculative and short term oriented (Salisu et al. 2019).

Due to the progressive price change and increase in the market cap, the popularity of investment in Bitcoin has been increasing dramatically. Meanwhile, Urquhart (2016) found that Bitcoin is an inefficient market. Caporale et al. (2018) also observe inefficiency in the cryptocurrency market. In the same vein, due to high price volatility, speculators have a generic question of whether the price of Bitcoin can be forecasted in advance.

Thus far, there have been limited attempts in the literature to forecast the price of Bitcoin. Katsiampa (2017) scrutinised the in-sample goodness-of-fit of GARCH models for Bitcoin price but did not perform out-sample forecast. Kristjanpoller and Minutolo (2018) proposed a hybrid-forecasting model to predict Bitcoin price volatility, integrating artificial neural network (ANN), generalised autoregressive conditional heteroscedasticity $(\mathrm{GARCH})$ and principal components analysis (PCA). They found that the accuracy of the hybrid model increases after incorporation of PCA pre-processing. Similar to Katsiampa (2017), Kristjanpoller and Minutolo (2018) also only examined in-sample forecast performance. Meanwhile, Aalborg et al. (2018) found that Bitcoin returns cannot be predicted $\left(R^{2} \leq 0.01\right)$ using explanatory variables (i.e., google trend, trading volume, transaction volume, VIX index, and unique user addresses).

Given that Bitcoin is becoming more popular, yet still volatile and not well explained, a need exists to study methods to better understand its price fluctuations. Accurately forecasting the daily movements can increase the returns of day traders and consequently make the market more efficient. The choice of forecasting models can have a significant effect on performance (Chen et al. 2019). We contribute to the Bitcoin forecasting literature by testing autoregressive integrated moving average (ARIMA) and neural network autoregression (NNAR). ARIMA is one of the traditional forecasting methods, and NNAR is a rather sophisticated and more modern approach to forecasting (Hyndman and Athanasopoulos 2018). To ensure validation and implementation, as suggested by Adya and Collopy (1998), we use ex-ante Bitcoin forecast performance using a relatively large sample, and multiple training and testing samples to demonstrate the stability of the forecast results. By following this procedure, we differentiate the results of this study with the ones mentioned earlier.

In the next section, we discuss existing literature on Bitcoin price modelling. Section 3 presents daily Bitcoin price data used in this study. Section 4 presents the adopted forecast methodologies and performance measures. The analysis and findings are presented in Section 5, and final remarks are made in Section 6.

\section{Literature Review}

Bitcoin is the most popular among the cryptocurrencies (Kyriazis 2019). Recent fluctuations in Bitcoin price has captured the attention of academic researchers (Beneki et al. 2019). Given the nescancy of this research stream, previous studies on Bitcoin and other digital currencies (for instance, Ethereum, Litecoin, Ripple) mainly explain the concepts, principles and economics of cryptocurrencies (Segendorf 2014; Dwyer 2015; Becker et al. 2011). Among the authors, Dwyer (2015) addressed the principles of Bitcoin and other relevant digital currencies. The author explains the supply and demand of digital currencies, equilibria of Bitcoin, uses of Bitcoin in exchange for goods and services with a rivalry to other currencies (Dwyer 2015). Likewise, Brière et al. (2015) investigated the connection of Bitcoin with other cryptocurrencies.

The total market cap of Bitcoin is approximately USD237 billion (as of 30 March 2018), which is nearly $42.69 \%$ of the entire cryptocurrency market capitalizations (coinmarketcap.com). As such, some studies consider the price dynamics of Bitcoin (Brandvold et al. 2015; Ciaian et al. 2016). Brandvold et al. (2015) investigated the price discovery of Bitcoin exchanges and find that two exchanges-Mt.Gox and BTC-e, are leading the market with the maximum information share. Besides, Ciaian et al. (2016) studied the underlying economics of Bitcoin price by taking into account the traditional determinants of the currency price. Moreover, Shubik (2014) and Rogojanu and Badea (2014) 
studied Bitcoin in the setting of alternative monetary systems by considering the challenges of the economic environment. Meanwhile, Bouoiyour and Selmi (2014); Bouoiyour et al. (2014) and Yermack (2013) described Bitcoin as a speculative investment or speculative bubble. Similarly, according to Yermack (2013), Bitcoin behaves more like a speculative investment rather than currency. It fails to satisfy the features of currency as a medium of exchange, a store of value, and a unit of account. In the same vein, Molnár et al. (2015) studied the exchange rate risk of Bitcoin by comparing with other variables, for instance, gold and Euro and find that Bitcoin is more volatile and riskier than gold and Euro, which restrict the applicability of Bitcoin as a medium of transaction. Furthermore, Bouri et al. (2017) investigated the Bitcoin price and its volatility and found persistence in the Bitcoin price and volatility.

As Bitcoin price volatility is exceptionally high, speculators have a general quest whether future Bitcoin price can be forecasted. Bitcoin price or return forecasting is getting more attention due to its boom-bust nature. Speculators are looking for tools and techniques that can forecast Bitcoin price with higher accuracy, at least better than the naïve forecast to set their investment portfolios in a profit margin. The majority of the studies on Bitcoin either focus on price returns and volatility or consider Bitcoin as a speculative investment or bubble (Bouoiyour and Selmi 2014; Bouoiyour et al. 2014; Yermack 2013). Some studies consider risk, hedge and safe haven attributes of Bitcoin and Ethereum (Beneki et al. 2019, Bouri et al. 2017). However, to the best of the authors' knowledge, there are no studies on the forecasting of test-sample (out-sample) Bitcoin price (Corbet et al. 2019). Thus, this study presents a novel approach to forecasting daily Bitcoin price using both with and without model re-estimation at each step while comparing ARIMA and NNAR models.

\section{Data}

Daily Bitcoin exchange rate data (USD per Bitcoin) is collected from the Quandl ${ }^{1}$ database. Data from the same source has been used by others, too (Chu et al. 2015). We use daily Bitcoin price data from 1 January 2012 to 4 October $2018^{2}$, daily Bitcoin price of 2466 days. Figure 1 presents the (a) original time series along with (b) log-transformed and (c) first differenced log operator series. For the effectiveness of forecast validation (Adya and Collopy 1998), we divide the dataset into a training-sample (in-sample) and test-sample (out-sample). We consider two training-samples and subsequently two-test samples for cross-validation purposes. The first training sample is from 1 January 2012 until 14 May 2013 (500 days), and the second from 1 January 2012 until 25 June 2017 (2000 days). As a consequence, the first test-sample is from 15 May 2013 to 4 October 2018 (1966 days), and the second from 16 June 2017 to 4 October 2018 (466 days).

At the end of 2014, the price of Bitcoin dropped significantly to USD 302 (www.coindesk.com). The cause of the price decline was the suspension of trading of Bitcoin by Mt. Gox, one of the leading Bitcoin exchanges, which handled $70 \%$ of the Bitcoin exchange worldwide at that time. They reported that around 850,000 Bitcoins were hacked, which belongs to customers and are worth around USD 3.5 billion (Roberts 2017). The incident resulted in a lack of confidence in the security system of Bitcoin; thus, the price decline continued until 2016. At the beginning of 2017, the Bitcoin price increased dramatically, and at the end of 2017 the price of Bitcoin surged at USD 19,661.63, but again after five days from 17 December 2017 it dropped to USD 12,616.64 (www.coindesk.com).

1 www.quandl.com/data/BCHARTS/BITSTAMPUSD-Bitcoin-Markets-bitstampUSD.
2 Bitcoin price data for three days, that is, 6-8 January 2015 was not available. 


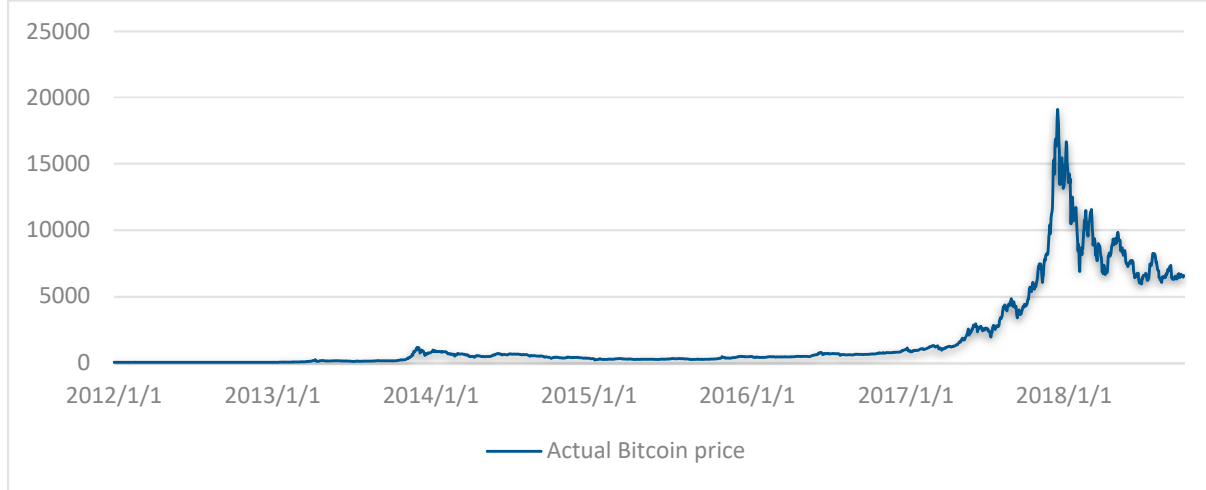

(a) Original daily time series of Bitcoin price in USD

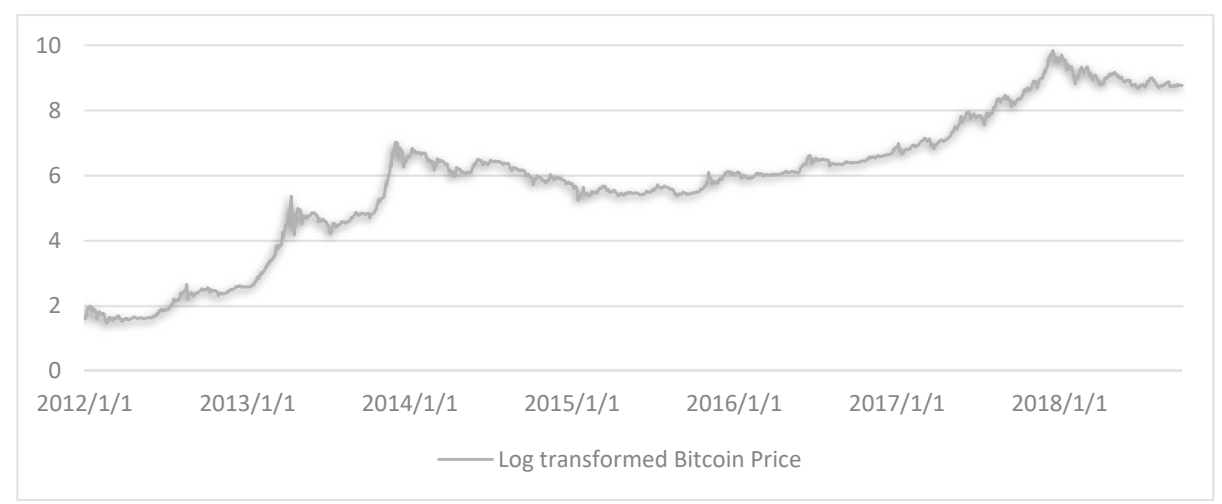

(b) Log transformed daily Bitcoin price in USD

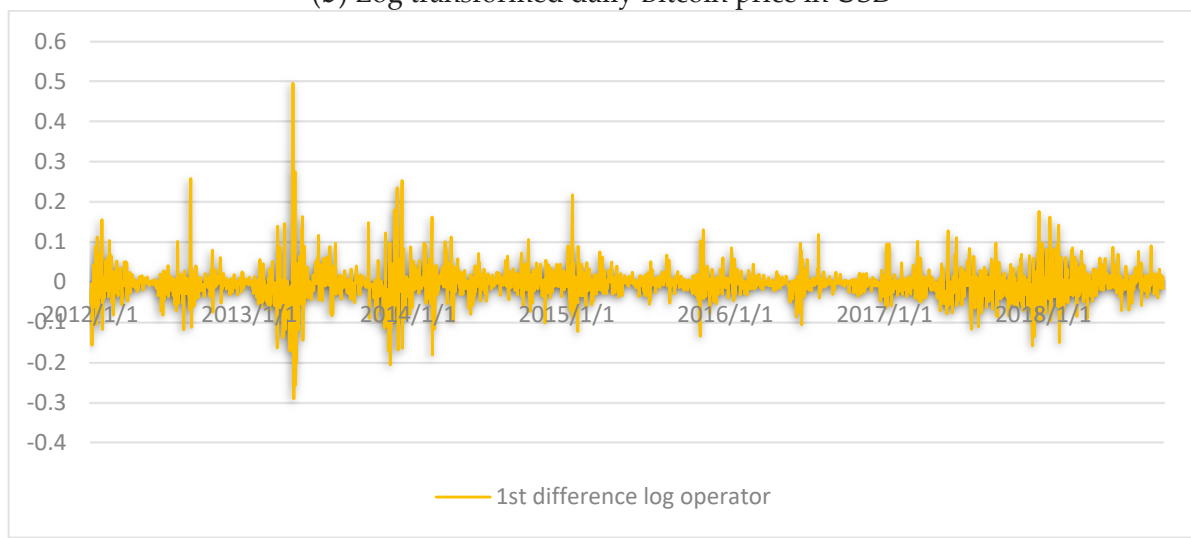

(c) First difference log operator of daily Bitcoin price in USD

Figure 1. (a) Original, (b) log-transformed and (c) first difference log operator bitcoin price in USD.

Stationarity of data is a prerequisite for predictive modelling, particularly when using autoregressive time series models such as ARIMA. Table 1 shows results of the stationary test of the training-data samples using the Augmented Dicky-Fuller test (ADF) (Dickey and Fuller 1979) and Phillips-Perron test (PP) (Phillips and Perron 1988). Data, both in levels and log-transformed series, are not stationary but become stationary at first difference log operator; thus, the ARIMA modelling 
approach is feasible. It might be noted that the stationarity of data is not essential for neural network models (Hyndman and Athanasopoulos 2018).

Table 1. Stationary test of data.

\begin{tabular}{lccc}
\hline \multicolumn{1}{c}{ Data } & Training Sample & ADF Test & PP Test \\
\hline First in-sample window (500 days) & $01 / 01 / 2012 ~ 14 / 05 / 2013$ & $-1.725(0.695)$ & $-10.597(0.519)$ \\
Original data & $01 / 01 / 2012 ~ 14 / 05 / 2013$ & $-1.478(0.800)$ & $-3.333(0.919)$ \\
Log transformed data & $01 / 01 / 2012 ~ 14 / 05 / 2013$ & $-9.593(0.01)$ & $-338.72(0.01)$ \\
1st difference log operator & $01 / 01 / 2012 ~ 25 / 06 / 2017$ & $1.021(0.99)$ & $6.109(0.99)$ \\
\hline Second in-sample window (2000 days) & $01 / 01 / 2012 \sim 25 / 06 / 2017$ & $-1.327(0.86)$ & $-3.321(0.92)$ \\
Original data & $01 / 01 / 2012 ~ 25 / 06 / 2017$ & $-11.19(0.01)$ & $-1513.50(0.01)$ \\
Log transformed data & 1st difference log operator &
\end{tabular}

ADF. Augmented Dicky-Fuller test; PP. Phillips-Perron test. $p$-values in parenthesis, $p$-value less than 0.05 confirms stationarity.

\section{Methodology}

\subsection{Forecast Methods}

Association of Bitcoin prices with other micro and macro-economic indicators, such as oil price and gold price, are still not clear (Aalborg et al. 2018). Thus, the univariate modelling approach, where data speaks for itself (Gujarati and Porter 2003), becomes an appropriate forecasting tool. Additionally, a positive association between past and future values of Bitcoin price is evident in the literature (Caporale et al. 2018). However, the degree of association varies over time (Caporale et al. 2018); thus, re-estimating the forecast model every time for the one-step forecast with each additional daily Bitcoin price becomes relevant. Additionally, this signifies the essence for investigating non-linear approach. Thus, we employ two univariate time series models-ARIMA and NNAR. Application of ARIMA can be found in many fields of studies such as in finance (Ariyo et al. 2014), shipping (Munim and Schramm 2017), logistics (Miller 2018), and electric power (Contreras et al. 2003). Meanwhile, NNAR models are also used to forecast global solar radiation (Benmouiza and Cheknane 2013), river flow (Abrahart and See 2000), tourism demand (Álvarez-Díaz et al. 2018). For both ARIMA and NNAR models, we scrutinize forecasting next-day Bitcoin price with and without re-estimating the forecast model for each step. For the computational purpose, we used the Forecast package (Hyndman and Khandakar 2007) in the R software.

\subsubsection{ARIMA}

ARIMA is probably the most popular method when it comes to time series forecasting, initially developed by Box and Jenkins (1976). Typically, an ARIMA model has two components: an autoregressive (AR) component and a moving average (MA) component. The AR component models association between the value of a variable at a specified time with its value in previous time(s), and the MA component models association between values of error term of a variable at a specified time with its error term value in previous time(s). The integrated (I) component comes into consideration when the time series becomes stationary after the first (or second) difference. An ARIMA $(p, d, q)$ model can be represented by Equation (1).

$$
\Delta z_{t}=\sum_{i=1}^{p} \varnothing_{i} \Delta z_{t-i}+\sum_{i=1}^{q} \theta_{i} \varepsilon_{t-i}+\varepsilon_{t}
$$

Here, $\Delta z_{t}=z_{t}-z_{t-1} ; z_{t}$ is the Bitcoin price in USD at time $t, z_{t-i}$ is the Bitcoin price in USD of all previous periods until lag $p, \varnothing_{i}$ is the parameter for $z_{t-i}, \varepsilon_{t}$ is the error term in time $t, \varepsilon_{t-i}$ is the error term of all previous periods until lag $q$ and $\theta_{i}$ is the parameter for $\varepsilon_{t-i}$. 


\subsubsection{Neural Network Autoregression (NNAR)}

Artificial neural network (ANN) methods rely on mathematical models in a similar pattern as 'neurons' in the brain. ANN models help design complex non-linear associations between the dependent variable and its predictors (Adya and Collopy 1998; Hyndman and Athanasopoulos 2018). The simplest ANN models would only have predictors (independent variables or inputs) in the bottom layer and the dependent variable (output) in the top layer, which would be equivalent to a linear regression model. After adding the hidden layer(s) in-between bottom and top layers, the ANN structure becomes non-linear. A sample ANN model is depicted in Figure 2. This type of ANN is called multi-layered feed-forward network, where each layer of neurons (nodes) receive inputs from the previous layer. The inputs to each node are estimated using a weighted linear combination, as in Equation (2):

$$
z_{j}=\beta_{j}+\sum_{i=1}^{n} W_{i, j} X_{i}
$$

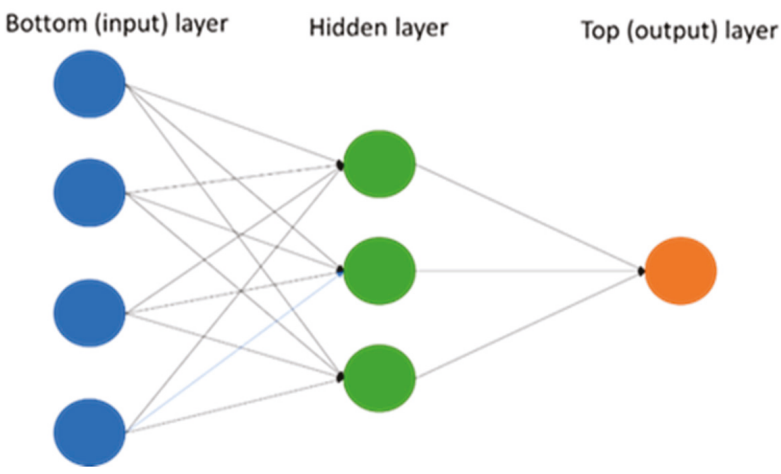

Figure 2. An ANN model with four inputs and one hidden layer with three neurons.

Here, $z_{j}$ is the value of output node $j, \beta_{j}$ is the constant for node $j, W_{i, j}$ is the weight from the input node $i$ to output node $j, X_{i}$ represents the inputs, and $n$ is number of input variables. In the hidden layer, Equation (2) is transformed into non-linear function using sigmoid, as shown in Equation (3).

$$
s(z)=\frac{1}{1+e^{-z}}
$$

The parameters $\beta_{1}, \beta_{2}, \beta_{3}, \ldots, \beta_{n}$ and $W_{1,1}, \ldots, W_{4,3}$ are "learned" from the training data. To prevent the weights from becoming too large, usually, the values of the weights are restricted. Decay parameter-the parameter that restricts the weights is typically set to be equal to 0.1 (Hyndman and Athanasopoulos 2018). With time series data such as daily Bitcoin price, lagged values of the time series can be used as inputs in an ANN structure, which is known as neural network autoregression (NNAR). A non-seasonal feed-forward network model with one hidden layer is usually denoted as NNAR $(p, k)$, where $\mathrm{p}$ represents the number of lags and $k$ represents the number of nodes in the hidden layer.

\subsection{Forecast Accuracy Measures}

Forecasting models are evaluated based on their accuracy of the forecast. Typical forecast accuracy measures such as RMSE (root mean square error) and MAPE (mean absolute percent error) are criticised for their instability with varying number of test-sample forecast periods. Thus, we adopt three indices to measure the accuracy of forecast results: RMSE, MAPE, and MASE (mean absolute scaled error). MASE was proposed by Hyndman and Koehler (2006) as a remedy to overcome the drawbacks of 
RMSE and MAPE when dealing with a varying number of test-sample periods. The three adopted accuracy measures can be expressed as follows:

$$
\begin{gathered}
\text { RMSE }=\sqrt{\frac{1}{n} \sum_{t=1}^{n}\left(d_{t}-z_{t}\right)^{2}} \\
M A P E=\frac{100}{n} \sum_{t=1}^{n}\left|\frac{\left(d_{t}-z_{t}\right)}{d_{t}}\right| \\
M A S E=\operatorname{mean}\left|\frac{e_{t}}{\frac{1}{n-1} \sum_{t=2}^{n}\left|z_{t}-z_{t-1}\right|}\right|
\end{gathered}
$$

Here, $e_{t}$ is the forecast error calculated as $\left(d_{t}-z_{t}\right), d_{t}$ is the actual Bitcoin price at time $t, z_{t}$ is the forecasted price at time $t, n$ is the total number of observations and $z_{t}-z_{t-1}$ is the forecast error of the naïve forecast.

\section{Empirical Results}

First, the appropriate ARIMA and NNAR models are to be selected to forecast next-day Bitcoin price for the test-sample. ARIMA models are chosen based on the lowest AIC, while considering the PP test for stationarity using the auto.arima function provided by the Forecast package in R. However, it is challenging to select the appropriate NNAR model. For the first training-sample period (500 days), 14 different NNAR(p,k) specifications are estimated and evaluated for the forecast (without re-estimation) performance of the first test-sample period (1966 days). The results are presented in Figure A1 in Appendix A. Interestingly, training-sample forecast performance gets better with increasing the numbers of lags and hidden layers (see Figure A1a) but NNAR $(2,1)$ performs best for test-sample forecast (see Figure A1b). Therefore, NNAR $(2,1)$ is selected for the estimation of the first training and test samples. The same 14 models are estimated and compared for the second training and test samples (see Figure A2), and NNAR $(1,2)$ is selected based on test-sample forecast performance. In the employed NNAR framework, it is noteworthy that test-sample forecast performance is always better with a lower number of lags and nodes in contrast to the training-sample forecast performance.

For next-day Bitcoin price forecast without re-estimation of the model for next step, the two selected models for first training and test samples are ARIMA $(4,1,0)$ and NNAR $(2,1)$, and for the second training and test samples are ARIMA $(4,1,1)$ and NNAR $(1,2)$. We adopt the static forecast approach, as depicted in Figure 3. When using an autoregressive model in the static forecast approach, the actual value of the dependent variable in previous periods is used to estimate each step forecast for the training sample. On the contrary, when forecasting multiple periods, dynamic forecast approach uses the previously forecasted value (out-sample period) of the dependent variable to compute a forecast. In Table 2, first, we present the training-sample forecast performance of ARIMA and NNAR models by means of RMSE, MAPE and MASE. Then, in Table 3, we present the test-sample forecast performance of the employed models. According to Table 2, NNAR models perform better than ARIMA in the first training-sample period, but ARIMA is better in the second training-sample. According to Table 3, for both cases, without and with re-estimation of forecast models for next-day Bitcoin price forecasting, ARIMA models outperform NNAR in the test-sample forecast. Log-transformed Bitcoin price series and its forecasted values using ARIMA and NNAR under different estimation approaches are presented in Figure 4. 


\begin{tabular}{|c|c|c|c|c|c|c|c|c|c|}
\hline$\bullet$ & $\bullet$ & $\bullet$ & $\bullet$ & $\bullet$ & $\bullet$ & $\bullet$ & $\bullet$ & $\bullet$ & $\bullet$ \\
\hline$\bullet$ & $\bullet$ & $\bullet$ & $\bullet$ & $\bullet$ & $\bullet$ & $\bullet$ & $\bullet$ & $\bullet$ & $\bullet$ \\
\hline$\bullet$ & $\bullet$ & $\bullet$ & $\bullet$ & $\bullet$ & $\bullet$ & $\bullet$ & $\bullet$ & $\bullet$ & $\bullet$ \\
\hline$\bullet$ & $\bullet$ & $\bullet$ & $\bullet$ & $\bullet$ & $\bullet$ & $\bullet$ & $\bullet$ & $\bullet$ & $\bullet$ \\
\hline$\bullet$ & $\bullet$ & $\bullet$ & $\bullet$ & $\bullet$ & $\bullet$ & $\bullet$ & $\bullet$ & $\bullet$ & $\bullet$ \\
\hline
\end{tabular}

Training data point

Forecast data point

Excluded data point

Figure 3. Illustration of static forecast approach.

Table 2. Training-sample forecast performance.

\begin{tabular}{cclcc}
\hline Forecast Model & Training Sample & RMSE & MAPE & MASE \\
\hline First training-sample window (500 days) & & & \\
ARIMA $(4,1,0)$ & $01 / 01 / 2012 ~ 14 / 05 / 2013$ & $\mathbf{0 . 0 5 3}$ & 1.225 & 0.987 \\
NNAR $(2,1)$ & $01 / 01 / 2012 ~ 14 / 05 / 2013$ & 0.055 & $\mathbf{1 . 1 7 2}$ & $\mathbf{0 . 9 6 3}$ \\
\hline Second training-sample window (2000 days) & & & \\
ARIMA $(4,1,1)$ & $01 / 01 / 2012 ~ 25 / 06 / 2017$ & $\mathbf{0 . 0 4 0}$ & $\mathbf{0 . 5 6 5}$ & $\mathbf{0 . 9 7 0}$ \\
NNAR $(1,2)$ & $01 / 01 / 2012 ~ 25 / 06 / 2017$ & 0.042 & 0.567 & 0.983 \\
\hline \multicolumn{7}{c}{ Bold numbers indicate best performance. }
\end{tabular}

Table 3. Test-sample static forecast performance.

\begin{tabular}{|c|c|c|c|c|}
\hline Forecast Model & Test Sample & RMSE & MAPE & MASE \\
\hline \multicolumn{5}{|c|}{ First test-sample window (1966 days) } \\
\hline \multicolumn{5}{|c|}{ Forecast without re-estimation at each step } \\
\hline ARIMA $(4,1,0)$ & 15/05/2013 04/10/2018 & 0.038 & 0.379 & 0.969 \\
\hline NNAR $(2,1)$ & $15 / 05 / 2013 \sim 04 / 10 / 2018$ & 0.924 & 8.289 & 24.990 \\
\hline \multicolumn{5}{|c|}{ Forecast with re-estimation at each step } \\
\hline ARIMA & $15 / 05 / 2013 \sim 04 / 10 / 2018$ & 0.037 & 0.365 & 0.935 \\
\hline NNAR & $15 / 05 / 2013 \sim 04 / 10 / 2018$ & 0.048 & 0.453 & 1.186 \\
\hline \multicolumn{5}{|c|}{ Second test-sample window (466 days) } \\
\hline \multicolumn{5}{|c|}{ Forecast without re-estimation at each step } \\
\hline ARIMA $(4,1,1)$ & 26/06/2017 04/10/2018 & 0.042 & 0.354 & 1.207 \\
\hline NNAR $(1,2)$ & 26/06/2017 04/10/2018 & 0.093 & 0.837 & 2.911 \\
\hline \multicolumn{5}{|c|}{ Forecast with re-estimation at each step } \\
\hline ARIMA & 26/06/2017 04/10/2018 & 0.042 & 0.354 & 1.209 \\
\hline NNAR & 26/06/2017 04/10/2018 & 0.069 & 0.537 & 1.828 \\
\hline
\end{tabular}

To confirm the validity of forecast models, diagnostic checks are conducted. $p$-values of the Box-Ljung (BL) test (Ljung and Box 1978) suggest that residuals of all employed models are free from autocorrelation ( $p$-values $>0.05$ considering eight lags). The BL test result of squared residuals of ARIMA models indicates the presence of conditional heteroscedasticity ( $p$-values $<0.05$ ); thus, future research on Bitcoin price forecast should consider nested ARIMA models combining ARCH and GARCH. The Jarque-Bera test (Jarque and Bera 1980) results suggest that residuals are not normally distributed ( $p$-values $<0.05$ ). Normality of residuals should not be an issue for the NNAR model as the error series in such models are assumed to be homoscedastic (and normally distributed) when training the model based on the training-sample (Hyndman and Athanasopoulos 2018). 


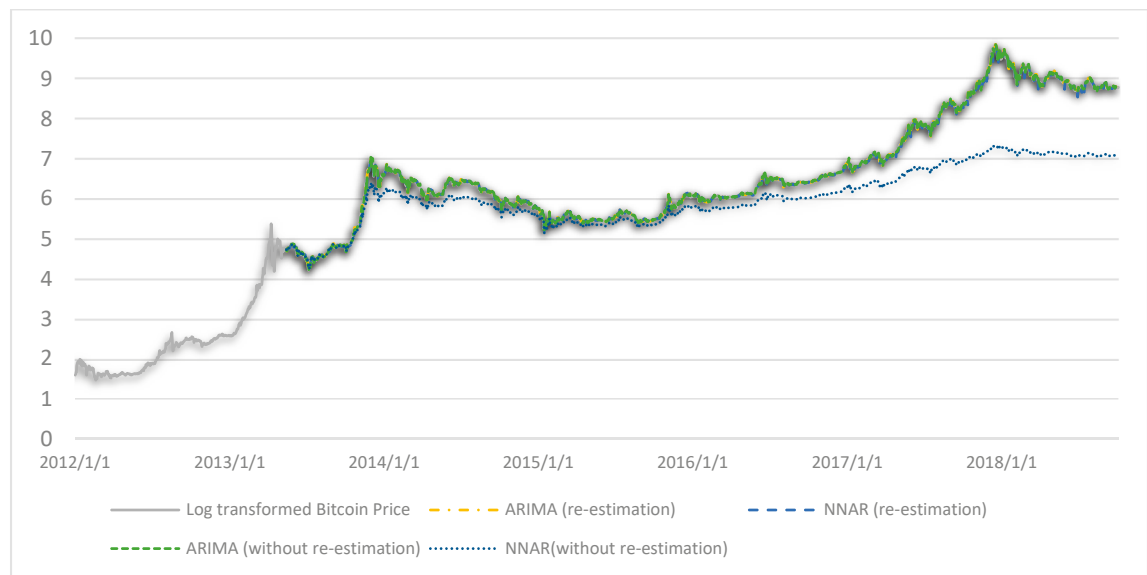

(a) Actual and forecasted Bitcoin price (training sample:500 days, test-sample:1966 days)

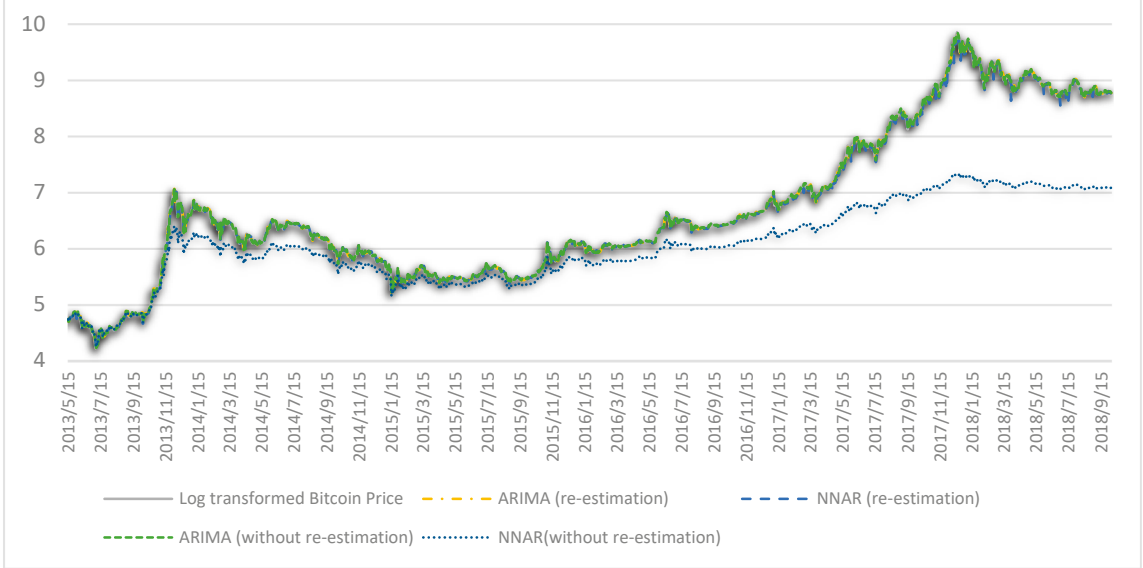

(b) Concentrated view on the forecast period (test-sample:1966 days)

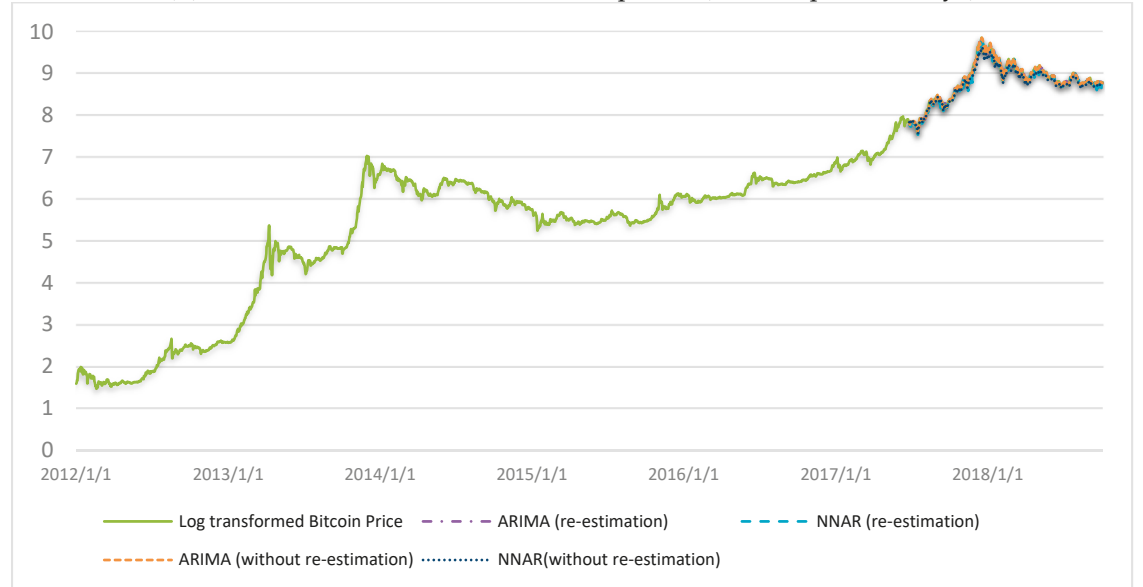

(c) Actual and forecasted Bitcoin price (training sample:2000 days, test-sample:466 days)

Figure 4. Cont. 


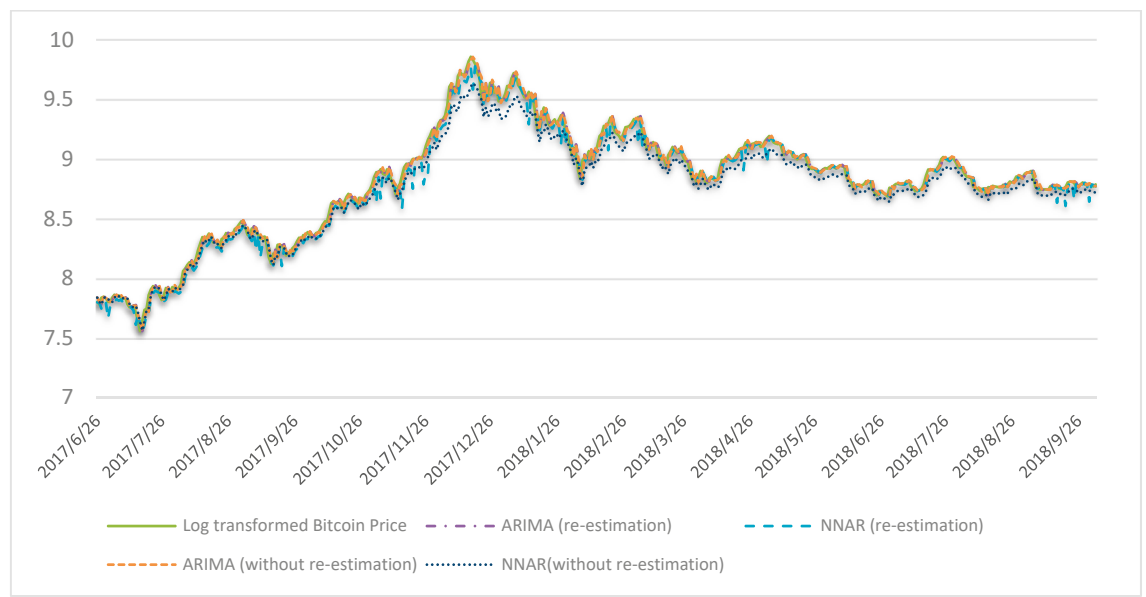

(d) Concentrated view on the forecast period (test-sample:466 days)

Figure 4. Bitcoin price forecast. $(\mathbf{a}, \mathbf{b})$ refer to the first training and test samples forecast in comprehensive and concentrated view, respectively, and (c,d) refer to the second training and test samples forecast in comprehensive and concentrated view, respectively.

Further, we perform the Diebold Mariano (DM) test (Diebold and Mariano 1995) to compare test-sample forecast results obtained from the two models used, ARIMA and NNAR. DM test results are presented in Table 4. In this case, the alternative hypothesis is that the forecast results of the second method are less accurate than the first method. Thus, a $p$-value of less than 0.05 indicates better accuracy of the first method. Result of the DM test is similar to as revealed in Table 3-the ARIMA model is more accurate than NNAR in forecasting the test-sample Bitcoin price. It is noteworthy that, forecast of ARIMA models, with or without model re-estimation in each step, are identical. Meanwhile, the NNAR model with re-estimation in each step performs considerably better than the without re-estimation approach.

Table 4. DM test of forecast results.

\begin{tabular}{lcc}
\hline Models Compared & DM Statistics & $p$-Value \\
\hline First test-sample window (1966 days) & -7.054 & $1.20 \times 10^{-12}$ \\
ARIMA vs. NNAR (re-estimation) & -27.061 & $2.20 \times 10^{-16}$ \\
ARIMA vs. NNAR (without re-estimation) & -4.502 & $3.56 \times 10^{-6}$ \\
ARIMA (re-estimation) vs. ARIMA (without re-estimation) & -27.052 & $2.20 \times 10^{-16}$ \\
NNAR (re-estimation) vs. NNAR (without re-estimation) & & \\
\hline Second test-sample window (466 days) & -6.006 & $1.92 \times 10^{-9}$ \\
ARIMA vs. NNAR (re-estimation) & -12.348 & $2.20 \times 10^{-16}$ \\
ARIMA vs. NNAR (without re-estimation) & -0.785 & 0.217 \\
ARIMA (re-estimation) vs. ARIMA (without re-estimation) & -6.172 & $7.34 \times 10^{-10}$ \\
NNAR (re-estimation) vs. NNAR (without re-estimation) &
\end{tabular}

$p<0.05$ indicates that forecast results of the first method is better than the second method. 


\section{Discussion and Conclusions}

This study forecasts the next-day Bitcoin price using two univariate models-ARIMA and NNAR. Based on the employed forecast accuracy measures (RMSE, MAPE and MASE), while NNAR models perform better than ARIMA in the first training-sample (500 days) Bitcoin price forecasts, ARIMA models outperform NNAR models in both the test-samples. In line with this, from Figure 4, one could argue than NNAR models perform better than ARIMA (see Table 2) in times of less volatility, but not during extremely volatile test-sample periods of Bitcoin price, particularly in the year 2018. Furthermore, the DM test suggests the same, that is, ARIMA forecast results are more accurate than the NNAR forecasts in the test-sample forecasts.

Meanwhile, existing studies offer interesting insights. In a review of neural network models in forecasting, Adya and Collopy (1998) find that neural networks are not necessarily the best modelling approach for all types of data. Abrahart and See (2000) and Álvarez-Díaz et al. (2018) find that ARIMA and NNAR perform similarly. On the other hand, similar to this study, Alon et al. (2001) and Munim and Schramm (2018) also find that neural networks outperform ARIMA in some training-sample, but the opposite holds for test-sample. The reason for better accuracy of ARIMA models could be that we employ the feed-forward NNAR model, which is found to be inferior by Ho et al. (2002) as well when comparing with ARIMA and recurrent neural network (RNN) models. Thus, future study should attempt the RNN approach to Bitcoin price forecast. Furthermore, according to the DM test results, the forecast of ARIMA models are similar for with or without model re-estimation in each step. However, the NNAR model with re-estimation in each step performs better than without re-estimation. Thus, this unique approach of model re-estimation at each step can be adopted in inter-day forecasts, such as in next-hour and next-minute Bitcoin price (also stock price) forecasts. However, the model re-estimation approach to forecast next-day price increases computational duration slightly. To this end, with the growing market-cap of cryptocurrencies and extreme volatility of cryptocurrency prices, further attention should be paid to modelling their returns.

Author Contributions: Conceptualization Z.H.M. and I.A., Data curation Z.H.M., Methodology Z.H.M., Visualization Z.H.M., Introduction M.H.S., Literature review M.H.S. and I.A., Writing-review \& editing Z.H.M., M.H.S. and I.A.

Funding: The APC was funded by the University of Agder.

Acknowledgments: The authors would like to thank the two anonymous reviewers and Qazi Haque for useful suggestions on an earlier draft of the manuscript.

Conflicts of Interest: The authors declare no conflict of interest. 


\section{Appendix A. The 14 Estimated NNAR(p,k) Models}

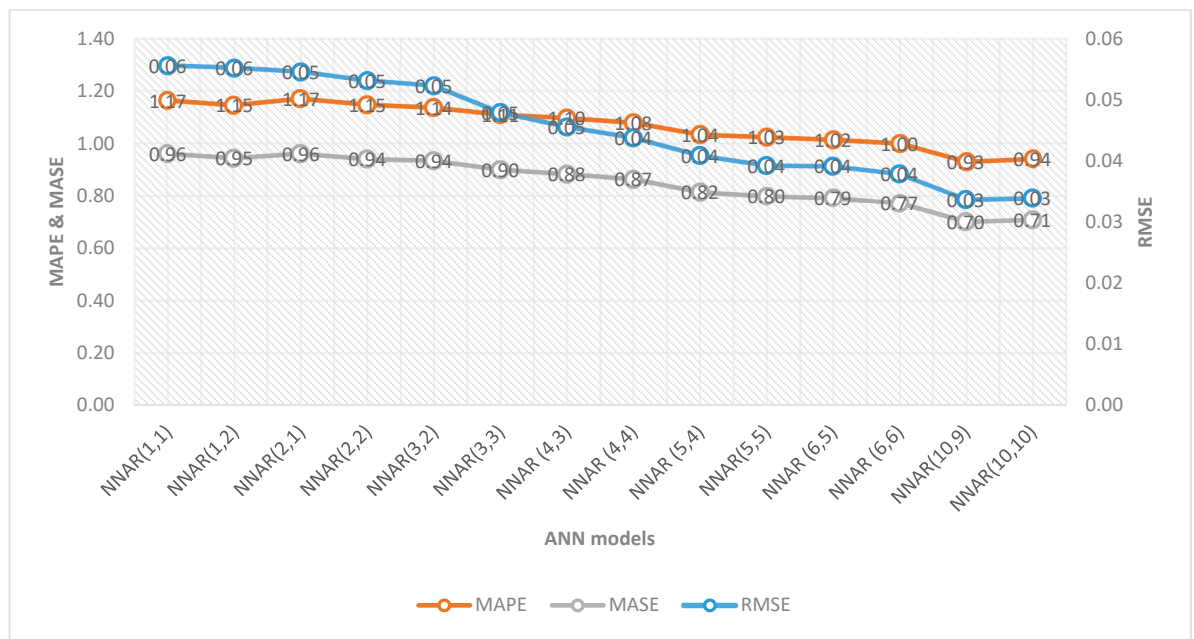

(a) Training-sample (500 days) forecast performance

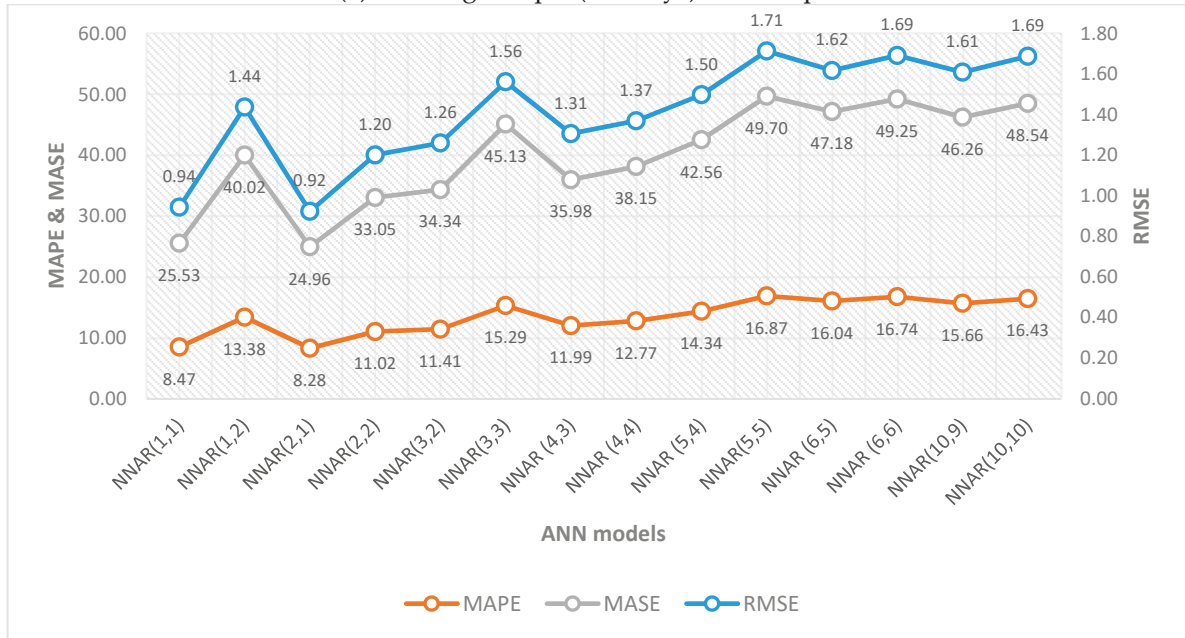

(b) Test-sample (1966 days) forecast performance

Figure A1. Examined NNAR model performance. $(\mathbf{a}, \mathbf{b})$ The first training and test-sample forecast performance, respectively. 


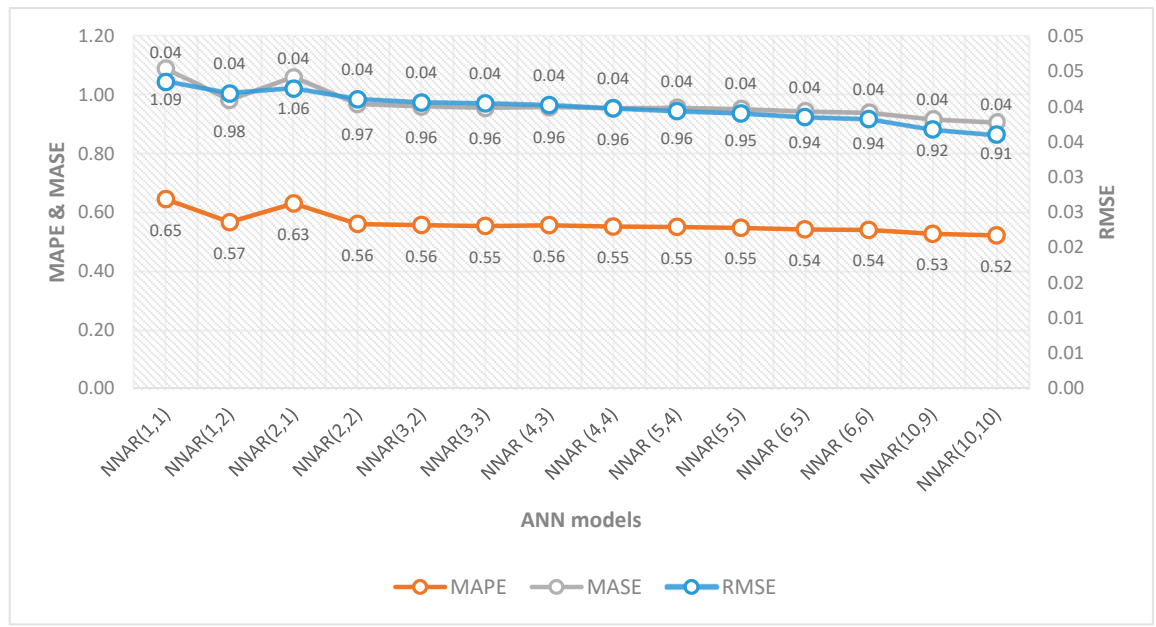

(a) Training-sample (2000 days) forecast performance

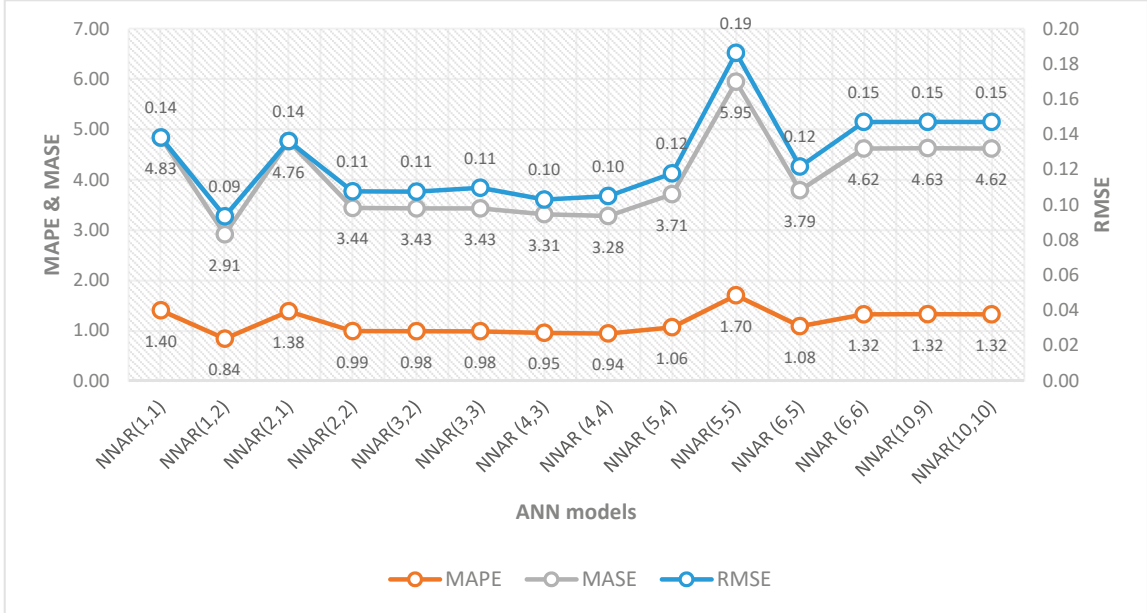

(b) Test-sample (466 days) forecast performance

Figure A2. Examined NNAR model performance. $(\mathbf{a}, \mathbf{b})$ The second training and test-sample forecast performance, respectively.

\section{References}

Aalborg, Halvor Aarhus, Peter Molnár, and Jon Erik de Vries. 2018. What can explain the price, volatility and trading volume of Bitcoin? Finance Research Letters. [CrossRef]

Abrahart, Robert J., and Linda See. 2000. Comparing neural network and autoregressive moving average techniques for the provision of continuous river flow forecasts in two contrasting catchments. Hydrological Processes 14: 2157-72. [CrossRef]

Adya, Monica, and Fred Collopy. 1998. How effective are neural networks at forecasting and prediction? A review and evaluation. Journal of Forecasting 17: 481-95. [CrossRef]

Alon, Ilan, Min Qi, and Robert J. Sadowski. 2001. Forecasting aggregate retail sales: A comparison of artificial neural networks and traditional methods. Journal of Retailing and Consumer Services 8: 147-56. [CrossRef]

Álvarez-Díaz, Marcos, Manuel González-Gómez, and María Otero-Giráldez. 2018. Forecasting international tourism demand using a non-linear autoregressive neural network and genetic programming. Forecasting 1 : 90-106. [CrossRef] 
Ariyo, Adebiyi Ayodele Adewumi, Ayo Oluyinka Adewumi, and Korede Charles. 2014. Stock price prediction using the ARIMA model. Paper presented at the 2014 UKSim-AMSS 16th International Conference on Computer Modelling and Simulation, Cambridge, UK, March 26-28.

Becker, Jörg, Dominic Breuker, Tobias Heide, Justus Holler, Hans Rauer, and Rainer Böhme. 2011. The Bitcoin System. Münster. Available online: https://papers.ssrn.com/sol3/papers.cfm?abstract_id=2041492 (accessed on 5 June 2019).

Beneki, Christina, Alexandros Koulis, Nikolaos A Kyriazis, and Stephanos Papadamou. 2019. Investigating volatility transmission and hedging properties between Bitcoin and Ethereum. Research in International Business and Finance 48: 219-27. [CrossRef]

Benmouiza, Khalil, and Ali Cheknane. 2013. Forecasting hourly global solar radiation using hybrid k-means and nonlinear autoregressive neural network models. Energy Conversion and Management 75: 561-69. [CrossRef]

Bouoiyour, Jamal, and Refk Selmi. 2014. What Bitcoin Looks Like? Technical Report. Munich: University Library of Munich.

Bouoiyour, Jamal, Refk Selmi, and Aviral Tiwari. 2014. Is Bitcoin Business Income or Speculative Bubble? Unconditional vs. Conditional Frequency Domain Analysis. Munich: University Library of Munich.

Bouri, Elie, Peter Molnár, Georges Azzi, David Roubaud, and Lars Ivar Hagfors. 2017. On the hedge and safe haven properties of Bitcoin: Is it really more than a diversifier? Finance Research Letters 20: 192-98. [CrossRef]

Box, George Edward Pelham, and Gwilym Meirion Jenkins. 1976. Time Series Analysis: Forecasting and Control. revised ed. San Francisco: Holden-Day.

Brandvold, Morten, Peter Molnár, Kristian Vagstad, and Ole Christian Andreas Valstad. 2015. Price discovery on Bitcoin exchanges. Journal of International Financial Markets, Institutions and Money 36: 18-35. [CrossRef]

Brière, Marie, Kim Oosterlinck, and Ariane Szafarz. 2015. Virtual currency, tangible return: Portfolio diversification with bitcoin. Journal of Asset Management 16: 365-73. [CrossRef]

Caporale, Guglielmo Maria, Luis Gil-Alana, and Alex Plastun. 2018. Persistence in the Cryptocurrency Market. Research in International Business and Finance 46: 141-48. [CrossRef]

Cheah, Eng-Tuck, and John Fry. 2015. Speculative bubbles in Bitcoin markets? An empirical investigation into the fundamental value of Bitcoin. Economics Letters 130: 32-36. [CrossRef]

Chen, An-Sing, Hung-Chou Chang, and Lee-Young Cheng. 2019. Time-varying Variance Scaling: Application of the Fractionally Integrated ARMA Model. The North American Journal of Economics and Finance 47: 1-12. [CrossRef]

Chu, Jeffrey, Saralees Nadarajah, and Stephen Chan. 2015. Statistical analysis of the exchange rate of bitcoin. PLoS ONE 10: e0133678. [CrossRef] [PubMed]

Ciaian, Pavel, Miroslava Rajcaniova, and d'Artis Kancs. 2016. The economics of BitCoin price formation. Applied Economics 48: 1799-815. [CrossRef]

Contreras, Javier, Rosario Espinola, Francisco J. Nogales, and Antonio J. Conejo. 2003. ARIMA models to predict next-day electricity prices. IEEE Transactions on Power Systems 18: 1014-20. [CrossRef]

Corbet, Shaen, Brian Lucey, Andrew Urquhart, and Larisa Yarovaya. 2019. Cryptocurrencies as a financial asset: A systematic analysis. International Review of Financial Analysis 62: 182-99. [CrossRef]

Dickey, David A., and Wayne A. Fuller. 1979. Distribution of the estimators for autoregressive time series with a unit root. Journal of the American Statistical Association 74: 427-31.

Diebold, Francis X., and Robert S Mariano. 1995. Comparing predictive accuracy. Journal of Business E Economic Statistics 13: 253-63.

Dwyer, Gerald P. 2015. The economics of Bitcoin and similar private digital currencies. Journal of Financial Stability 17: 81-91. [CrossRef]

Gujarati, Damodar N., and Dawn C. Porter. 2003. Basic Econometrics, 4th ed.New York: McGraw-Hill.

Ho, Sui-Lau, Min Xie, and Thong Ngee Goh. 2002. A comparative study of neural network and Box-Jenkins ARIMA modeling in time series prediction. Computers $\mathcal{E}$ Industrial Engineering 42: 371-75.

Hyndman, Rob J., and George Athanasopoulos. 2018. Forecasting: Principles and Practice. Melbourne: OTexts, Available online: https://otexts.com/fpp2/ (accessed on 10 March 2019).

Hyndman, Rob John, and Yeasmin Khandakar. 2007. Automatic Time Series for Forecasting: The Forecast Package for R. Melbourne: Department of Econometrics and Business Statistics, Monash University.

Hyndman, Rob John, and Anne B. Koehler. 2006. Another look at measures of forecast accuracy. International Journal of Forecasting 22: 679-88. [CrossRef] 
Jarque, Carlos Manuel, and Anil Kumar Bera. 1980. Efficient tests for normality, homoscedasticity and serial independence of regression residuals. Economics Letters 6: 255-59. [CrossRef]

Katsiampa, Paraskevi. 2017. Volatility estimation for Bitcoin: A comparison of GARCH models. Economics Letters 158: 3-6. [CrossRef]

Kristjanpoller, Werner, and Marcel C. Minutolo. 2018. A hybrid volatility forecasting framework integrating GARCH, artificial neural network, technical analysis and principal components analysis. Expert Systems with Applications 109: 1-11. [CrossRef]

Kyriazis, Nikolaos A. 2019. A Survey on Efficiency and Profitable Trading Opportunities in Cryptocurrency Markets. Journal of Risk and Financial Management 12: 67. [CrossRef]

Lam, Eric, Mathieu Benhamou, and Adrian Leung. 2018. Did Bitcoin Just Burst? How It Compares to History's Big Bubbles. Available online: https://www.bloomberg.com/news/articles/2018-01-17/did-bitcoin-just-bursthow-it-compares-to-history-s-big-bubbles (accessed on 17 January 2018).

Ljung, Greta Marianne, and George George Edward Pelham Box. 1978. On a measure of lack of fit in time series models. Biometrika 65: 297-303. [CrossRef]

Miller, Jason. 2018. ARIMA Time Series Models for Full Truckload Transportation Prices. Forecasting 1: 121-34. [CrossRef]

Molnár, Peter, Kristian Vagstad, and Ole Christian Andreas Valstad. 2015. A Bit Risky? A Comparison between Bitcoin and Other Assets using an Intraday Value at Risk Approach Working Paper. Available online: http://www.diva-portal.org/smash/get/diva2:742882/fulltext01.pdf (accessed on 5 June 2019).

Munim, Ziaul Haque, and Hans-Joachim Schramm. 2017. Forecasting container shipping freight rates for the Far East-Northern Europe trade lane. Maritime Economics \& Logistics 19: 106-25.

Munim, Ziaul Haque, and Hans-Joachim Schramm. 2018. Forecasting container freight rates: A comparison of artificial neural network and conventional methods. Paper presented at the Annual conference of the International Association of Maritime Economists (IAME), Mombasa, Kenya, September 11-14.

Phillips, Peter Charles Bonest, and Pierre Perron. 1988. Testing for a unit root in time series regression. Biometrika 75: 335-46. [CrossRef]

Popper, Nathaniel. 2015. Digital Gold: Bitcoin and the Inside Story of the Misfits and Millionaires Trying to Reinvent Money. New York: Harper.

Roberts, Jeff John. 2017. 5 Big Bitcoin Crashes: What We Learned. Fortune. Available online: https://finance.yahoo. com/news/5-big-bitcoin-crashes-learned-174604444.html (accessed on 5 June 2019).

Robertson, Adi. 2018. Facebook Bans All Ads for Bitcoin, ICOs, and Other Cryptocurrency. Available online: https://www.theverge.com/2018/1/30/16951670/facebook-cryptocurrency-bitcoin-ico-deceptivemarketing-ban (accessed on 31 January 2018).

Rogojanu, Angela, and Liana Badea. 2014. The issue of competing currencies: Case study-Bitcoin. Theoretical and Applied Economics 11: 103-14.

Salisu, Afees A., Kazeem Isah, and Lateef O. Akanni. 2019. Improving the predictability of stock returns with Bitcoin prices. The North American Journal of Economics and Finance 48: 857-67. [CrossRef]

Segendorf, Björn. 2014. What is Bitcoin? Sveriges Riksbank Economic Review 7: 71-87. Available online: http://www. riksbank.se/Documents/Rapporter/POV/2014/2014_2/rap_pov_artikel_4_1400918_eng.pdf (accessed on 5 June 2019).

Selgin, George. 2015. Synthetic commodity money. Journal of Financial Stability 17: 92-99. [CrossRef]

Shubik, Martin. 2014. Simecs, Ithaca Hours, Berkshares, Bitcoins and Walmarts. Cowles Foundation Discussion Paper No. 1947. Available online: https://papers.ssrn.com/sol3/papers.cfm?abstract_id=2435902 (accessed on 5 June 2019).

Urquhart, Andrew. 2016. The inefficiency of Bitcoin. Economics Letters 148: 80-82. [CrossRef]

Yermack, David. 2013. Is Bitcoin a Real Currency? An Economic Appraisal. Technical Report. National Bureau of Economic Research Working Paper No. 19747. Cambridge: National Bureau of Economic Research. Available online: https://www.nber.org/papers/w19747 (accessed on 5 June 2019).

(C) 2019 by the authors. Licensee MDPI, Basel, Switzerland. This article is an open access article distributed under the terms and conditions of the Creative Commons Attribution (CC BY) license (http://creativecommons.org/licenses/by/4.0/). 



\title{
Communication
}

\section{Contagion Effect in Cryptocurrency Market}

\author{
Paulo Ferreira ${ }^{1,2,3, *}$ and Éder Pereira ${ }^{4,5}$ \\ 1 VALORIZA—-Research Center for Endogenous Resource Valorization, 7300 Portalegre, Portugal \\ Instituto Politécnico de Portalegre, 7300 Portalegre, Portugal \\ 3 CEFAGE-UE, IIFA, Universidade de Évora, Largo dos Colegiais 2, 7000 Évora, Portugal \\ 4 Programa de Modelagem Computacional, SENAI Cimatec, Av. Orlando Gomes 1845, 41650-010 Salvador, \\ BA, Brazil \\ 5 Instituto Federal do Maranhão, 65075-441 São Luís-MA, Brazil \\ * Correspondence: pferreira@ipportalegre.pt; Tel.: +351-268-628-528
}

Received: 11 June 2019; Accepted: 8 July 2019; Published: 10 July 2019

\begin{abstract}
The rapid development of cryptocurrencies has drawn attention to this particular market, with investors trying to understand its behaviour and researchers trying to explain it. The evolution of cryptocurrencies' prices showed a kind of bubble and a crash at the end of 2017. Based on this event, and on the fact that Bitcoin is the most recognized cryptocurrency, we propose to evaluate the contagion effect between Bitcoin and other major cryptocurrencies. Using the Detrended Cross-Correlation Analysis correlation coefficient $(\triangle \rho \mathrm{DCCA})$ and comparing the period after and before the crash, we found evidence of a contagion effect, with this particular market being more integrated now than in the past-something that should be taken into account by current and potential investors.
\end{abstract}

Keywords: cryptocurrency; contagion effect; detrended cross-correlation analysis; Bitcoin

\section{Introduction}

Cryptocurrencies are digital currencies which can be used for direct retail purchases but also as financial assets in general. They are characterized by some features that make them different from other assets, namely the facts that they are not subject to any centralized institutional authority and that they do not have physical representation. Another important feature, which makes this kind of currency somewhat controversial, is the fact that they are not associated with any tangible assets (Corbet et al. 2019).

Since the creation of Bitcoin in 2009, which was the first cryptocurrency, this particular market has increased its value exponentially, reaching about 260 billion USD of capitalization in May 2019. Bitcoin itself was responsible for about $55 \%$ of that capitalization, being by far the most important cryptocurrency. This evolution makes cryptocurrencies very interesting for investors, as well as for researchers, with a growing body of literature on several issues (Urquhart 2018; Corbet et al. 2019). These studies include topics more linked with financial issues like efficiency or the relationship with other assets (which is addressed in the next section), in addition to analysis issues like regulation or even linkages with possibly illicit activities (see, respectively, the works of Chaffee (2018) and Campbell-Verduyn (2018) as examples on each of those topics).

Despite the evolution of cryptocurrencies' prices, during 2017 this market experienced a kind of bubble, with prices reaching maximum levels on 15 December 2017, followed by a sharp decrease. With such an episode, and considering Bitcoin as the most relevant cryptocurrency, we can evaluate the possibility of a contagion effect in this market. According to Forbes and Rigobon (2002), there is a certain pre-existing integration between assets and, after a given episode of instability, this relationship is intensified, i.e., correlations between those assets increase. 
Based on the Detrended Cross-Correlation Analysis correlation coefficient $(\rho \mathrm{DCCA})$, we calculated this correlation both before and after that episode. Furthermore, we estimated the $\triangle \rho$ DCCA, which could be considered a measure of contagion. Although the literature on cryptocurrencies is growing rapidly, our paper extends the existing literature by focusing on a specific event, showing the importance of not only that event but also the role of Bitcoin in this particular market. Moreover, the employed methodology allowed us to conduct an analysis of contagion considering different time scales, which could be interesting because short-run impacts (lower time scales) could be different from long-run ones (higher time scales).

Our main results show the existence of a contagion effect between Bitcoin and the other cryptocurrencies studied, excepting Tether, which indicates a more interconnected market now than in the past. The remainder of the work is organized as follows: Section 2 presents a literature review on work involving cryptocurrencies; Section 3 describes the methodology and data; Section 4 presents the results; Section 5 concludes the paper.

\section{Literature Review}

As previously identified, there is a clear interest in the cryptocurrency market, not only among the general public and investors but also among researchers in several different areas. Corbet et al. (2019) made a very interesting survey of work involving cryptocurrencies, dividing research in non-quantitative and quantitative and dividing papers in five different areas: bubble dynamics, regulation, cybercrime, diversification and efficiency.

Regarding quantitative research, which is our focus, this kind of work seems to originate in 2013. For example, Kristoufek (2013) related the increased valuation of Bitcoin to the increased interest in that currency. Gronwald (2014) used a GARCH (Generalized Autoregressive Conditional Heteroskedasticity) approach and concluded that Bitcoin was marked by extreme price movements, probably because it was still an immature market. Bornholdt and Sneppen (2014) compared Bitcoin with other cryptocurrencies in terms of their importance, and concluded at that time that Bitcoin did not show special advantages over other cryptocurrencies. Using complex networks, Kondor et al. (2014) identified that cryptocurrencies in general were evolving and accumulating value owing to their increasing acceptance. Kristoufek (2015) studied the potential drivers of Bitcoin prices, identifying that it has properties of a standard financial asset as well as properties of a speculative asset.

These are some prior papers devoted to analyzing the quantitative aspects of cryptocurrencies. However, as mentioned, the literature on cryptocurrencies is constantly growing, and recently many studies have been found to analyze cryptocurrencies. One of the most researched issues concerns the efficiency of the cryptocurrency market (Urquhart 2016; Bariviera 2017; Nadarajah and Chu 2017; Tiwari et al. 2018, among others), with most studies concluding on the inefficiency of these assets (although with some evidence that the market is becoming more efficient-see, for example, Khuntia and Pattanayak (2018)). A comprehensive recent survey about the efficiency of cryptocurrencies is found in Kyriazis (2019).

Some studies analyzed bubbles in the cryptocurrency market. For example, Cheah and Fry (2015), Corbet et al. (2018a) and Chaim and Laurini (2019) all found evidence of the possible existence of bubbles in cryptocurrencies.

We also found studies on the similarities of cryptocurrencies and other assets. For example, Baumöhl (2018) analyzed the connection between forex and cryptocurrencies and found evidence of a low connection between those markets. Corbet et al. (2018b) analyzed three different cryptocurrencies and other financial assets, and found some segmentation between them, concluding that investment in cryptocurrencies could offer diversification opportunities to investors, mainly in short time horizons. Symitsi and Chalvatzis (2018) analyzed the linkages between Bitcoin and energy and technology companies and also found some relationship between those markets. Kristjanpoller and Bouri (2019) also analyzed the cross-correlations between cryptocurrencies and conventional currencies, pointing out significant asymmetric characteristics in the cross-correlations. Ji et al. (2019a) applied network 
methodologies to analyze linkages between cryptocurrencies and other commodities, finding connections with some of those commodities. Bouri et al. (2019a) analyzed linkages between cryptocurrencies, focusing on the relationship between volatility measures and discriminating between transitory and permanent causalities. The authors concluded that permanent shocks are more important. Ji et al. (2019b) also analyzed the information interdependence between cryptocurrencies and commodities, with a time-varying approach, and concluded that cryptocurrencies are integrated within broadly defined commodity markets.

Previous work analyzed comovements between cryptocurrencies and other assets, while several studies analyzed comovements among different cryptocurrencies. For example, Beneki et al. (2019) centered their analysis on the relationship between Bitcoin and Ethereum, and determined that correlations exist, with each cryptocurrency influencing the other with a time-varying kind of influence. Mensi et al. (2019) used wavelet methodologies to study the comovements among major cryptocurrencies. Despite the existence of comovements, the authors concluded that mixed portfolios with different cryptocurrencies could be interesting for diversification purposes. Besides analyzing the linkages with commodities, Ji et al. (2019a) studied the connectedness of return and volatility in major cryptocurrencies, finding that Litecoin and Bitcoin are in the center of the connectedness in terms of returns, and that negative returns have larger effects than positive returns. In the case of volatility, Bitcoin is the cryptocurrency with greatest influence.

Bouri et al. (2019b) analyzed the possibility of herding behavior in the cryptocurrency market. While with a static approach, the evidence does not confirm that effect, with a dynamic analysis, due to the existence of breaks and non-linearities in data, that effect seems to be found. In another study, Bouri et al. (2019c) analyzed whether explosivity in one cryptocurrency can lead to explosivity in other cryptocurrencies, finding evidence of connections between those assets.

These two studies could be considered as a starting point for our analysis, because they draw attention to the need to study contagion in the cryptocurrency market. Analyzing the existence of a contagion effect in the cryptocurrency market is also present in other studies. For example, Antonakakis et al. (2019) investigated the transmission mechanism among the top nine cryptocurrencies between 15 August 2015 and 31 May 2018, finding that periods of high (low) uncertainty were characterized by strong (low) connectivity, with Bitcoin affecting the market's connectivity the most. In another analysis, Silva et al. (2019) analyzed 50 cryptocurrencies with greater liquidity, identifying the contagion effect of Bitcoin in almost all cases.

In this study, to analyze the possibility of a contagion effect, we used the $\Delta \rho D C C A$ proposed by Da Silva et al. (2016), based on Zebende (2011) cross-correlation coefficient. The main contribution of this work lies in the analysis of multiscale contagion applied to the cryptocurrency market. Moreover, and as mentioned by Bouri et al. (2019b), this market seems to suffer from non-linearities, so the use of the proposed methodology was appropriate. We employed the methodology proposed by Guedes et al. (2018a, 2018b) to test the statistical significance of the contagion effect.

\section{Data and Methodology}

Based on https://coinmarketcap.com/, we retrieved data for the cryptocurrencies with greatest capitalization and with information from at least as far back as July 2016 to 23 May 2019. As we wanted to compare the $\rho$ DCCA before and after the crash of December 2017, and as the post-crash period comprised a total of 523 observations, we looked for cryptocurrencies that had the same number of observations in the pre-crash period. Besides Bitcoin, the 10 cryptocurrencies with greatest capitalization and with information for the time period under analysis were Ethereum, Ripple (XRP), Litecoin, Tether, Stellar, Monero, Dash, NEM, Dogecoin and Waves.

According to Forbes and Rigobon (2002), the contagion effect implies an increase in the correlation between financial assets after the occurrence of a given event. We followed the intuition of those authors, analyzing the correlation between Bitcoin and 10 other major cryptocurrencies, splitting the sample before and after the price decrease at the end of 2017 and using the coefficient of 
Zebende (2011) based on the DCCA proposed by Podobnik and Stanley (2008). Considering two different datasets, $x_{t}$ and $y_{t}$, with $k=1, \ldots, t$ equidistant observations, the first step of DCCA consists of integrating both series and calculating $x(t)=\sum_{\mathrm{k}=1}^{\mathrm{t}} \mathrm{x}_{\mathrm{k}}$ and $\mathrm{y}(\mathrm{t})=\sum_{\mathrm{k}=1}^{\mathrm{t}} \mathrm{y}_{\mathrm{k}}$. After this, the whole samples are divided into boxes of equal length, with dimension $n$, and are divided into $N-n$ overlapping boxes. With ordinary least squares, local trends are calculated $\left(\widetilde{x}_{k}\right.$ and $\left.\widetilde{y}_{k}\right)$ and used to detrend the original time series, calculating the difference between the original values and the trend. The expression $\mathrm{f}_{\mathrm{DCCA}}^{2}=\frac{1}{\mathrm{n}-1} \sum_{\mathrm{k}=\mathrm{i}}^{\mathrm{i}+\mathrm{n}}\left(\mathrm{x}_{\mathrm{k}}-\widetilde{\mathrm{x}}_{\mathrm{k}}\right)\left(\mathrm{y}_{\mathrm{k}}-\widetilde{\mathrm{y}}_{\mathrm{k}}\right)$ identifies the covariance of the residuals of each box. Then, summing those values for all boxes of size $n$, we obtain the detrended covariance given by $\mathrm{F}_{\mathrm{DCCA}}^{2}(\mathrm{n})=\frac{1}{\mathrm{~N}-\mathrm{n}} \sum_{\mathrm{i}=1}^{\mathrm{N}-\mathrm{n}} \mathrm{f}_{\mathrm{DCCA}}^{2}$. Repeating the process for all possible length boxes leads to obtaining the DCCA exponent from the relationship between the DCCA fluctuation function and $n$. This results in the power law $\mathrm{F}_{\mathrm{DCCA}}(\mathrm{n}) \sim \mathrm{n}^{\lambda}$, with $\lambda$ being the parameter of interest of the DCCA, which quantifies the long-range power-law cross-correlations.

The DCCA identifies the type of cross-correlation (positive or negative) but does not quantify the level of cross-correlation. This quantification is made by the correlation coefficient proposed by Zebende (2011), which combines DCCA with DFA (Detrended Fluctuation Analysis), a methodology used to identify the level of dependence of each individual time series. That correlation coefficient is given by $\rho \operatorname{DCCA}(n)=\frac{\mathrm{F}^{2} \mathrm{DCCA}(\mathrm{n})}{\mathrm{F}_{\mathrm{DFA}\{\mathrm{xi}\}}(\mathrm{n}) \mathrm{F}_{\mathrm{DFA}\{\mathrm{yi}\}}(\mathrm{n})}$.

This is a scale-dependent coefficient, and it is possible to analyze different behaviors considering different time scales. Moreover, it has desirable properties, as described by Kristoufek (2014) and Zhao et al. (2017), namely its efficiency and the fact that it ranges from -1 to 1 . We used the procedure reported by Podobnik et al. (2011) to identify the critical values in order to test the significance of the correlation levels.

As previously mentioned, we intended to calculate contagion, so we obtained a correlation coefficient for the periods before and after the bubble episode at the end of 2017. Following the idea proposed by Da Silva et al. (2016), we calculated the $\Delta \rho_{\text {DCCA }}(n)$ given by the difference between the correlation level after the bubble episode and that before the episode. If the value of $\Delta \rho$ is positive, the correlation coefficients increase and, according to Forbes and Rigobon (2002), contagion exists. We used the critical values of Guedes et al. (2018a, 2018b) to evaluate the statistical significance of the effect.

\section{Results}

Figure 1 shows the evolution of prices in the cryptocurrencies and sample analyzed. Prices were transformed in an index for better comparison. The figure shows the constant increase in prices until December 2017. Except for Tether, whose price was relatively stable throughout the sample, the other cryptocurrencies seemed to have some similarities in their fluctuations.

The prices were then transformed in return rates, using the traditional difference of price logarithms between two consecutive moments, to calculate the correlations. Figure 2 shows the correlation coefficient in both sub-periods. It is clear that the correlation pattern was generally higher in the post-crash than in the pre-crash period. Tether did not show a significant correlation with Bitcoin in either the pre or post-crash period, which is not surprising from analysis of Figure 1 (which reinforces the robustness of the method). Besides this particular cryptocurrency, Dash (from 30 days), XRP (from 50 days) and Litecoin and Monero (for higher time scales) showed some evidence of a non-significant correlation with Bitcoin in the first period under analysis. In the second period, and once again except for Tether, all the cryptocurrencies showed significant correlations with Bitcoin, in some cases with a very high level of correlation. 


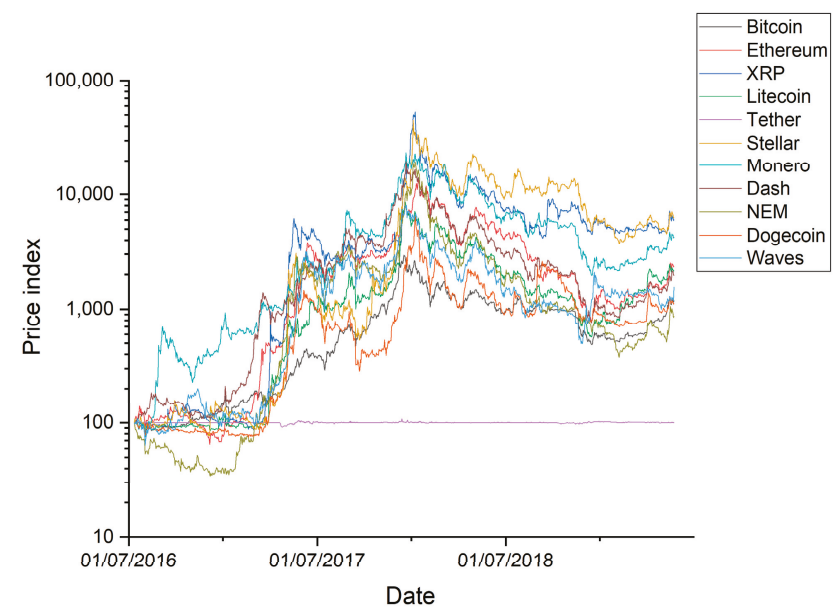

Figure 1. Evolution of cryptocurrency prices in the sample under analysis.
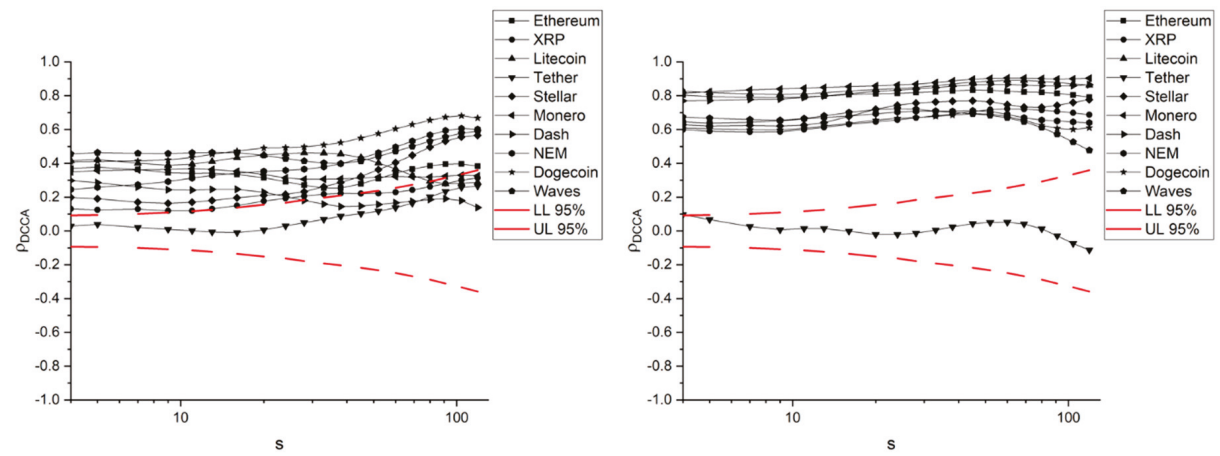

Figure 2. Detrended Cross-Correlation Analysis (DCCA) correlation coefficient between Bitcoin and the other cryptocurrencies in both periods (pre-crash in the left panel and post-crash in the right panel), depending on the time scale ( $\mathrm{s}$-in days). Dashed lines represent lower and upper critical values, which were used to test the hypotheses $\mathrm{H} 0: \rho \mathrm{DCCA}=0$ and $\mathrm{H} 1: \rho \mathrm{DCCA} \neq 0$.

Figure 3 represents the difference in the correlation coefficients before and after the crash. If positive, this could be understood as a contagion effect, as described by Forbes and Rigobon (2002). Except for Tether, Dogecoin and Waves (the latter two just for higher time scales and relatively low absolute values), all the other cryptocurrencies exhibited an increased correlation with Bitcoin, with Dash, Litecoin and Monero having the highest increases. This contagion effect means that the cryptocurrency market as a whole is now more integrated than in the past, implying that cryptocurrencies are now more exposed to possible price shocks in the main cryptocurrency (Bitcoin).

The increased integration of this particular market ultimately means that most of the cryptocurrencies being studied are now more sensitive to changes in the price of Bitcoin, with all the risks that arise from this increased exposure. So, any shock in Bitcoin's price could pass along to other cryptocurrencies, which could cause some degree of instability in the market. Moreover, due to the increase of the cryptocurrency market as a whole, those changes could also impact other financial markets, depending on their relationship with Bitcoin and other assets. 


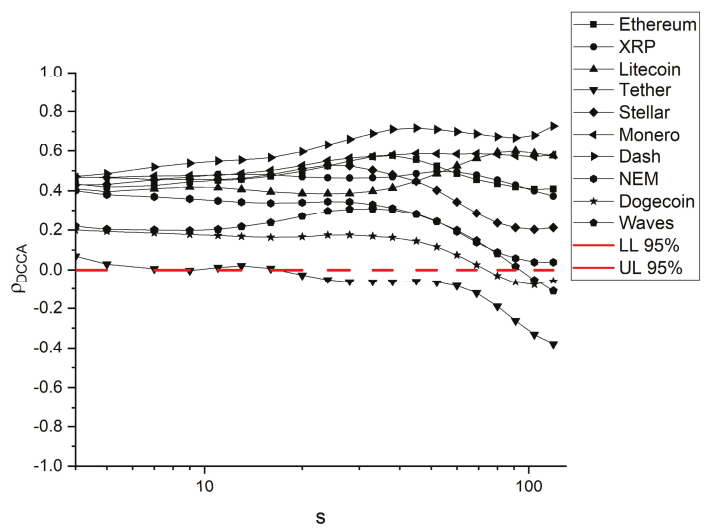

Figure 3. $\triangle \rho D C C A$ regarding Bitcoin. UL and LL represent upper and lower critical values (Guedes et al. 2018a, 2018b).

\section{Concluding Remarks}

Analysis of the contagion effect is an important instrument to observe how certain financial assets are related after extreme events such as crises or bubbles. Since the study of Forbes and Rigobon (2002), contagion effects have been identified in several markets, causing a wide and interesting debate in the world's financial community. In the present analysis, we adapted this contagion concept to analyze the cryptocurrency market, since this is an important market due to both its financial volume and the growing interest shown in it.

This research identified a contagion effect between Bitcoin returns and the returns of most of the other cryptocurrencies analyzed. The exception is Tether, with no evidence of a significant contagion effect for any time scale. This analysis reveals that this market experienced increasing integration between the main cryptocurrencies after the bubble that occurred in December 2017.

Our results provide important information for current and potential investors when analyzing financial risk in the cryptocurrency market. In fact, in constructing portfolios, it could be risky to consider investing in several cryptocurrencies, since they seem to be more highly integrated now than in the past (although Mensi et al. (2019) identified the possibility of diversification using cryptocurrencies). Moreover, and considering that other recent studies identified linkages between this particular market and other assets, this may also affect the possibility of diversification. In fact, the possibility of increased integration between markets, in addition to the cryptocurrency market, is an important issue for future research so as to continuously monitor the possibility of using several markets and assets for diversification purposes. Moreover, the possibility of conducting this analysis with time-varying approaches is also a challenge for future research, which could provide historical information about the evolution of these relationships.

Author Contributions: Conceptualization, P.F. and É.P.; methodology, P.F. and É.P.; software, P.F. and É.P.; formal analysis, P.F. and É.P.; investigation, P.F. and É.P.; data curation, P.F. and É.P.; writing一original draft preparation, P.F. and É.P.; writing—review and editing, P.F. and É.P.

Funding: Paulo Ferreira is pleased to acknowledge financial support from Fundação para a Ciência e a Tecnologia (grant number UID/ECO/04007/2019). Éder Pereira is pleased to acknowledge financial support from Fundação de Amparo e Pesquisa do Estado da Bahia-FAPESB (grant number BOL 0261/2017).

Conflicts of Interest: The authors declare no conflict of interest. 


\section{References}

Antonakakis, Nikolaos, Ioannis Chatziantoniou, and David Gabauer. 2019. Cryptocurrency market contagion: Market uncertainty, market complexity, and dynamic portfolios. Journal of International Financial Markets Institutions and Money 61: 37-51. [CrossRef]

Bariviera, Aurelio. 2017. The inefficiency of Bitcoin revisited: A dynamic approach. Economics Letters 161: 1-4. [CrossRef]

Baumöhl, Eduard. 2018. Are cryptocurrencies connected to forex? A quantile cross-spectral approach. Finance Research Letters 29: 363-72. [CrossRef]

Beneki, Christina, Alexandros Koulis, Nikolaos Kyriazis, and Stephanos Papadamou. 2019. Investigating Volatility Transmission and Hedging Properties between Bitcoin and Ethereum. Research in International Business and Finance 48: 219-27. [CrossRef]

Bornholdt, Stefan, and Kim Sneppen. 2014. Do Bitcoins make the world go around? on the dynamics of competing crypto-currencies. arXiv.

Bouri, Elie, Bryan Lucey, and David Roubaud. 2019a. The volatility surprise of leading cryptocurrencies: Transitory and permanent linkages. Finance Research Letters. [CrossRef]

Bouri, Elie, Rangan Gupta, and David Roubaud. 2019b. Herding behaviour in cryptocurrencies. Finance Research Letters 29: 216-21. [CrossRef]

Bouri, Elie, Syed Shahzad, and David Roubaud. 2019c. Co-explosivity in the cryptocurrency market. Finance Research Letters 29: 178-83. [CrossRef]

Campbell-Verduyn, Malcolm. 2018. Bitcoin, crypto-coins, and global anti-money laundering governance. Crime, Law and Social Change 69: 283-305. [CrossRef]

Chaffee, Eric. 2018. The Heavy Burden of Thin Regulation: Lessons Learned from the SEC's Regulation of Cryptocurrencies. Mercer Law Review 70: 615.

Chaim, Pedro, and Márcio Laurini. 2019. Is Bitcoin a bubble? Physica A 517: 222-32. [CrossRef]

Cheah, Eng-Tuck, and John Fry. 2015. Speculative bubbles in Bitcoin markets? An empirical investigation into the fundamental value of Bitcoin. Economics Letters 130: 32-36. [CrossRef]

Corbet, Shaen, Brian Lucey, and Larisa Yarovaya. 2018a. Datestamping the Bitcoin and Ethereum bubbles. Finance Research Letters 26: 81-88. [CrossRef]

Corbet, Shaen, Andrew Meegan, Charles Larkin, Brian Lucey, and Larisa Yarovaya. 2018b. Exploring the dynamic relationships between cryptocurrencies and other financial assets. Economics Letters 165: 28-34. [CrossRef]

Corbet, Shaen, Brian Lucey, Andrew Urquhart, and Larisa Yarovaya. 2019. Cryptocurrencies as a financial asset: A systematic analysis. International Review of Financial Analysis 62: 182-99. [CrossRef]

Da Silva, Marcus Fernandes, Éder Johnson de Area Leão Pereira, Aloisio Machado da Silva Filho, Arleys Pereira Nunes de Castro, José Garcia Vivas Miranda, and Gilney Figueira Zebende. 2016. Quantifying the contagion effect of the 2008 financial crisis between the G7 countries (by GDP nominal). Physica A: Statistical Mechanics and Its Applications 453: 1-8. [CrossRef]

Forbes, Kristin, and Roberto Rigobon. 2002. No contagion, only interdependence: Measuring stock market comovements. The Journal of Finance 57: 2223-61. [CrossRef]

Gronwald, Marc. 2014. The Economics of Bitcoins-Market Characteristics and Price Jumps. CESifo Working Paper Series No. 5121. Munich: CESifo Group.

Guedes, Everaldo, Andréa Brito, Florêncio Filho, B. Fernandez, Arleys Castro, Aloísio Filho, and Gilney Zebende. 2018a. Statistical test for DCCA cross-correlation coefficient. Physica A 501: 134-40. [CrossRef]

Guedes, Everaldo, Andreá Brito, Florêncio Filho, B. Fernandez, Arleys Castro, Aloísio Filho, and Gilney Zebende. 2018b. Statistical test for DCCA: Methods and data. Data Brief 18: 795-98. [CrossRef]

Ji, Qiang, Elie Bouri, Chi Keung Marco Lau, and David Roubaud. 2019a. Dynamic connectedness and integration in cryptocurrency markets. International Review of Financial Analysis 63: 257-72. [CrossRef]

Ji, Qiang, Elie Bouri, David Roubaud, and Ladislav Kristoufek. 2019b. Information interdependence among energy, cryptocurrency and major commodity markets. Energy Economics 81: 1042-55. [CrossRef]

Khuntia, Sashikanta, and Jamini Pattanayak. 2018. Adaptive market hypothesis and evolving predictability of bitcoin. Economics Letters 167: 26-28. [CrossRef]

Kondor, Dániel, Márton Posfai, István Csabai, and Gábor Vattay. 2014. Do the rich get richer? an empirical analysis of the Bitcoin transaction network. PLoS ONE 9: e86197. [CrossRef] [PubMed] 
Kristjanpoller, Werner, and Elie Bouri. 2019. Asymmetric multifractal cross-correlations between the main world currencies and the main cryptocurrencies. Physica A 523: 1057-71. [CrossRef]

Kristoufek, Ladislav. 2013. BitCoin meets Google Trends and Wikipedia: Quantifying the relationship between phenomena of the Internet era. Scientific Reports 3: 3415. [CrossRef] [PubMed]

Kristoufek, Ladislav. 2014. Measuring correlations between non-stationary series with DCCA coefficient. Physica A 402: 291-98. [CrossRef]

Kristoufek, Ladislav. 2015. What Are the Main Drivers of the Bitcoin Price? Evidence from Wavelet Coherence Analysis. PLoS ONE 10: e0123923. [CrossRef] [PubMed]

Kyriazis, Nikolaos. 2019. A Survey on Efficiency and Profitable Trading Opportunities in Cryptocurrency Markets. Journal of Risk and Financial Management 12: 67. [CrossRef]

Mensi, Walid, Mobeen Rehman, Khamis Al-Yahyaee, Idries Al-Jarrah, and Sang Kang. 2019. Time frequency analysis of the commonalities between Bitcoin and major Cryptocurrencies: Portfolio risk management implications. The North American Journal of Economics and Finance 48: 283-94. [CrossRef]

Nadarajah, Saralees, and Jeffrey Chu. 2017. On the inefficiency of Bitcoin. Economics Letters 150: 6-9. [CrossRef]

Podobnik, Boris, and Harry Eugene Stanley. 2008. Detrended Cross-Correlation Analysis: A new method for analyzing two nonstationary time series. Physical Review Letters 100: 084102. [CrossRef] [PubMed]

Podobnik, Boris, Zhi-Qiang Jiang, Wei-Xing Zhou, and Harry Eugene Stanley. 2011. Statistical tests for power-law cross-correlated processes. Physical Review E 84: 066118. [CrossRef] [PubMed]

Silva, Paulo, Marcelo Klotzle, Antonio Pinto, and Leonardo Gomes. 2019. Herding behavior and contagion in the cryptocurrency market. Journal of Behavioral and Experimental Finance 22: 41-45. [CrossRef]

Symitsi, Efthymia, and Konstantinos Chalvatzis. 2018. Return, volatility and shock spillovers of Bitcoin with energy and technology companies. Economics Letters 170: 127-30. [CrossRef]

Tiwari, Aviral, Rabin Jana, Debojyoti Das, and David Roubaud. 2018. Informational efficiency of Bitcoin-An extension. Economics Letters 163: 106-9. [CrossRef]

Urquhart, Andrew. 2016. The inefficiency of Bitcoin. Economics Letters 148: 80-82. [CrossRef]

Urquhart, Andrew. 2018. What causes the attention of Bitcoin? Economics Letters 166: 40-44. [CrossRef]

Zebende, Gilney. 2011. DCCA cross-correlation coefficient: Quantifying level of cross-correlation. Physica A 390: 614-18. [CrossRef]

Zhao, Xiaojun, Pengjian Shang, and Jingjing Huang. 2017. Several fundamental properties of DCCA cross-correlation coefficient. Fractals 25: 1750017. [CrossRef]

(C) 2019 by the authors. Licensee MDPI, Basel, Switzerland. This article is an open access article distributed under the terms and conditions of the Creative Commons Attribution (CC BY) license (http://creativecommons.org/licenses/by/4.0/). 


\title{
Which Cryptocurrencies Are Mostly Traded in Distressed Times?
}

\author{
Nikolaos A. Kyriazis * and Paraskevi Prassa \\ Department of Economics, University of Thessaly, 28th October 78 Street, 38333 Volos, Greece \\ * Correspondence: knikolaos@uth.gr
}

Received: 10 July 2019; Accepted: 14 August 2019; Published: 20 August 2019

\begin{abstract}
This paper investigates the level of liquidity of digital currencies during the very intense bearish phase in their markets. The data employed span the period from April 2018 until January 2019, which is the second phase of bearish times with almost constant decreases. The Amihud's illiquidity ratio is employed in order to measure the liquidity of these digital assets. Findings indicate that the most popular cryptocurrencies exhibit higher levels of liquidity during stressed periods. Thereby, it is revealed that investors' preferences for trading during highly risky times are favorable for well-known virtual currencies in the detriment of less-known ones. This enhances findings of relevant literature about strong and persistent positive or negative herding behavior of investors based on Bitcoin, Ethereum and highly-capitalized cryptocurrencies in general. Notably though, a tendency towards investing in the TrueUSD stablecoin has also emerged.
\end{abstract}

Keywords: Bitcoin; cryptocurrency; liquidity

JEL Classification: E44; G11; G12; G15

\section{Introduction}

Bitcoin and other digital currencies have spurred interest for research since late 2016 due to their increasing attractiveness as an investment tool. This has brought about a proliferating bulk of high-quality relevant academic papers (inter alia: Dyhrberg 2016a, 2016b; Katsiampa 2017; Corbet et al. 2018, 2019; Beneki et al. 2019; Kyriazis 2019). Cryptocurrencies are highly innovative means of transactions that have gained increasing popularity among investors and especially speculators seeking high profits, despite risk. Nevertheless, the functions of digital currencies as means for store of value and a unit of account are far from being established in the perceptions of economic agents. Nevertheless, the innovative character, the non-complexity and the lack of opacity in such currencies has led to the flourishing of issuance of new cryptocurrencies.

Decentralized transaction systems with blockchain technology have proven very promising for economic units of various risk appetites. Investments in digital currencies are considered to be extremely volatile although amazingly profitable in bullish periods. Investment and profit-making opportunities have also been apparent during bearish markets due to the high volatility of digital currencies. Emphasis should be paid to the fact that a small number of virtual coins that are most popular for investors make up a very large portion of market capitalization in the cryptocurrency markets.

This study builds on Wei (2018) which was the first academic paper investigating the liquidity levels of a very wide range of digital currencies. There are two main research hypotheses tested in this paper. Firstly, it is examined whether popular cryptocurrencies such as Bitcoin, Ethereum, Monero, Dash, Cardano and Steem are preferable by investors in bearish conditions in the cryptocurrency markets. Thereby, we investigate how the popularity and the incumbent character of specific coins in the virtual currency markets affect decision-making about active trading. 
The remainder of this study is organized as follows: Section 2 provides the main literature concerning digital currencies up to the present. Section 3 presents the data and methodology employed in order to conduct estimations about liquidity levels. Section 4 lays out and discusses the results as well as analyzes the economic implications. Finally, Section 5 concludes.

\section{Literature Review}

There has been a proliferating bulk of high-quality academic studies that investigate the factors determining performance of digital currencies. Ammous (2018) looks into whether Bitcoin, Ethereum, Litecoin, Ripple or Steem can fulfil the functions of money. He argues that only Bitcoin can be used as a store of value because of its commitment to increase its supply only by predetermined amounts. All cryptocurrencies are found to be inappropriate as units of account due to their large fluctuations. Moreover, theoretically, they can serve as a medium of exchange, but it is unlikely that they will become popular for this function. Bitcoin is found to be the most promising to function as money.

Brandvold et al. (2015) investigate how Bitcoin exchanges contribute to price discovery from April 2013 to February 2014. The unobserved components discovery model they employ leads to results supporting that MtGox was the main determinant of the price discovery process until its end. Furthermore, the Bitcoin's information share was found to be high, reflecting the increasing Chinese interest in Bitcoin. Overall, the information share is found to have been dynamic and evolve over time. Baur et al. (2018) investigate whether Bitcoin should be best considered as a medium of exchange or an asset for speculation by adopting data from July 2010 to June 2015. They argue that it is not a safe haven due to its weak correlation with conventional assets, such as stocks, bonds and commodities in normal times but also during crises. Findings indicate that Bitcoin is mostly used for speculative trading rather than as a medium of exchange and a new form of currency. By another perspective, Hayes (2017) investigates the determinants for value formation of cryptocurrencies by employing cross-sectional analysis for sixty-six of the most used digital currencies. He reveals that the level of competition in the network of producers, the rate of unit production as well as how difficult is the algorithm for mining are determinants of cryptocurrency value.

Bouri et al. (2017) examine how Bitcoin has affected global uncertainty during the period from March 2011 to October 2016, by employing the World VIX as a measure of uncertainty. The wavelet-based quantile-in-quantile methodology employed provides evidence that Bitcoin acts as a hedger against global uncertainty. This is valid especially in short investment horizons for both lower and upper quantiles of Bitcoin returns and uncertainty. Balcilar et al. (2017) utilize a Generalized Autoregressive Conditional Heteroskedasticity $(\mathrm{GARCH})$ methodology and a non-parametric causality-in-quantiles test for examining the causal nexus between trading volume and Bitcoin returns and volatility. Volume is found to be able to predict returns but not volatility at any point of the conditional distribution. However, the former is not true in Bitcoin bear and bull markets. It is also found that non-linearities are important for explaining behavior in tails regarding the causal nexus of Bitcoin returns with trading volume. Bitcoin trading based on the volume-return linkage can prove profitable. Furthermore, Pieters and Vivanco (2017) investigate whether Bitcoin prices follow the Rule of One Price across markets by evaluating eleven Bitcoin exchanges from June 2014 to July 2015. Findings indicate that failure of this rule is connected with markets where no ID is needed to fund an account, as they exhibit larger price deviations. Thereby, know-your-customer regulations can lead to a sizable effect on Bitcoin market. Further exploration of determinants of digital currency prices includes Gandal et al. (2018). They investigate the effect of suspicious trading activity on the Mt. Bitcoin currency exchange, in which almost 600,000 BTC were fraudulently acquired. They argue that this activity led to the spike of BTC price in late 2013, as trading volume increased significantly on those trading days. They support that a lack of regulations in markets lead to vulnerability regarding manipulation by speculators today.

Feng et al. (2018) propose a novel indicator for estimating the informed trades ahead of events related to cryptocurrencies and provide evidence that informed trading takes place in the Bitcoin 
market before such events. The preference of such traders is revealed for taking their positions two days before large positive events and one day before large negative events. This triggers large profits from trading. Corbet et al. (2018) employ a generalized variance decomposition methodology to measure the direction and intensity of spillovers across Bitcoin, Ripple, Litecoin and other selected markets. There is evidence that cryptocurrency markets are interconnected with each other and present similar patterns of connectedness with other important asset categories. Furthermore, Panagiotidis et al. (2018) examine the determinants of Bitcoin returns from June 2010 to June 2017 by adopting a Least Absolute Shrinkage and Selection Operator (LASSO) approach. Evidence uncovers that uncertainty negatively influences returns whereas currency exchange rates as well as interest rates, gold and oil have positive effects. The predicted signs are found for information demand and mixed impacts are traced from stock markets. Empirical outcomes reveal that search intensity and gold returns are the most influential. Amid literature on price determinants is Kim (2017) who examines the transaction cost of Bitcoin from April 2014 to April 2015. He argues that the bid-ask spreads of Bitcoin exchanges are lower than those of the retail foreign exchange market. This cost advantage equals $5 \%$ and is due to the simpler infrastructure and the efficiency that characterizes the Bitcoin market.

In another vein, Adhami et al. (2018) analyze 253 Initial Coin Offerings (ICOs) of cryptocurrencies from August 2014 to August 2017 in order to reveal the determinants of their success. They document that when the code source is available, a token presale is organized and tokens allow contributors to access a specific service or to share profits, then success is higher. Bouri et al. (2018) employ the Generalized Supremum Augmented Dickey Fuller (GSADF) test in order to study co-explosivity in cryptocurrency markets. They detect multiple periods of explosivity, especially during the 2017 bullish market and this is more intense concerning Bitcoin. Explosivity in a digital currency market is found to affect explosivity in markets of other virtual coins. Moreover, Bouri et al. (2019b) reveal that the market of cryptocurrencies presents time-varying herding behavior. High comovement is detected in the cross-sectional returns' dispersion across digital currency markets. This implies that mimicking of others' decisions takes place by investors in digital currency markets.

Schilling and Uhlig (2019) present a model of an endowment economy with the US dollar and Bitcoin constituting two competing but intrinsically worthless currencies. They support that fluctuations in prices are not harmful for the medium-of-exchange function of Bitcoin. Moreover, they support that if all economic units were impatient, no speculation opportunities would occur in the Bitcoin market. Giudici and Abu-Hashish (2019) adopt a correlation network Vector Autoregressive (VAR) process and provide evidence that Bitcoin prices from different exchanges are highly interrelated and that prices from larger exchanges drive prices in smaller ones. Furthermore, they support that the inclusion of Bitcoin in portfolios results in diversification benefits. Ji et al. (2019) investigate the spillovers among six major virtual currencies by building positive and negative returns-connectedness and volatility-connectedness networks. They argue that leading digital currencies are interconnected and that Litecoin exerts a significant impact on Bitcoin and other digital coins of primary importance. Asymmetries in spillovers are also detected and are larger in negative-return spillovers than in positive-returns impacts. Kyriazis et al. (2019) examine whether high-capitalization cryptocurrencies are affected by Bitcoin, Ethereum and Ripple during bearish times by employing a number of Generalized Autoregressive Conditional Heteroskedasticty (GARCH) specifications. Evidence reveals that the majority of digital coins investigated are complementary with the three drivers of the market and that no hedging abilities exist.

Bouri et al. (2019a) examine the persistence in the level and volatility of Bitcoin prices by taking into consideration the impact of structural breaks. They argue for the existence of long-memory in volatility of Bitcoin and identify structural changes in the dynamics of this leading digital currency. Moreover, Bouri et al. (2019c) investigate the ability of trading volume of seven major digital currencies on predicting their returns and volatility. They provide evidence that trading volume triggers extreme negative and positive effects of all currencies under scrutiny whereas only influences the volatility of Litecoin, Nem and Dash. Ferreira and Pereira (2019) examine the contagion effects in markets 
of virtual currencies by employing detrended cross-correlation analysis coefficients. They provide evidence that the contagion effect between Bitcoin and other digital coins has been more intense and that the digital currency market has been more integrated during bearish times. Hyun et al. (2019) examine dependency among Bitcoin, Ethereum, Litecoin, Ripple and Stellar using a copula directional dependence (CDD) approach. They provide evidence that dependency from Bitcoin to Litecoin is the highest one and that dependency from Ethereum to the other four currencies is higher than the other way around. By their own perspective, Dastgir et al. (2019) investigate the causality between the Google Trends search queries and returns of Bitcoin from January 2013 to December 2017, by applying a Copula-based Granger causality in Distribution (GCCD) test. They document that a bi-directional causal nexus between Bitcoin attention and Bitcoin returns exists mainly in the left tail (bad performance) and the right tail (superior performance) of the distribution, but not in the central distributions. In a somewhat similar vein, Shen et al. (2019) use the number of tweets from Twitter as a measure of attention and examine their influence on Bitcoin. They argue that tweets constitute a significant determinant of the next day's trading volume and realized volatility of Bitcoin.

\section{Data and Methodology}

This study has undertaken the strenuous task of investigating the level of liquidity of cryptocurrencies during the second phase of bearish behavior in the digital coins market. In order to provide the most representative view of liquidity in virtual currencies, we have downloaded, from the reliable source of coinmarketcap.com, the full spectrum of such currencies that existed on 12 February 2019. This has led to a total number of over 1900 coins from which we have short-listed only those that did not have gaps in the time series of their quotes. Thereby, the final sample consists of 846 digital currencies that cover the extra-bearish period of 1 April 2018 to 31 January 2019. All quotes about prices and trading volume are in daily frequencies.

The methodology employed for our estimations is based on the well-known Amihud's illiquidity ratio based on Amihud (2002), which takes the following form:

$$
\text { Illiquidity }_{T}^{i}=\frac{1}{D_{T}} \sum_{t=1}^{D_{T}} \frac{\left|R_{t}^{i}\right|}{P_{t}^{i} V_{t}^{i}}
$$

where $D_{T}$ represents the number of traded days during the period examined, $R_{t, T}^{i}$ stands for the daily return of digital currency $i$ on day $t, V_{t}^{i}$ is the volume traded of asset $i$ in day $t$ and $P_{t}^{i}$ represents the daily price of cryptocurrency $i$ on day $t$. All market prices of digital coins are expressed in relation to US dollars. It should be noted that the currencies that exhibit low values of the Amihud's illiquidity ratio are considered to the most liquid.

\section{Empirical Results}

In Tables 1 and 2, we categorize cryptocurrencies into eight groups based on the Amihud's illiquidity ratio in order to detect investors' trading preferences during the distressed bearish period investigated. The first group represents the most liquid digital currencies whereas the eighth group is comprised by the least liquid ones. 
Table 1. Groups of most liquid cryptocurrencies.

\begin{tabular}{|c|c|c|c|c|c|c|c|}
\hline \multicolumn{2}{|c|}{ Group 1 (Most Liquid) } & \multicolumn{2}{|c|}{ Group 2} & \multicolumn{2}{|c|}{ Group 3} & \multicolumn{2}{|c|}{ Group 4} \\
\hline Names & $\begin{array}{c}\text { Amihud } \\
\text { Illiquidity } \\
\text { Ratio }\end{array}$ & Names & $\begin{array}{l}\text { Amihud } \\
\text { Illiquidity } \\
\text { Ratio }\end{array}$ & Names & $\begin{array}{c}\text { Amihud } \\
\text { Illiquidity } \\
\text { Ratio }\end{array}$ & Names & $\begin{array}{l}\text { Amihud } \\
\text { Illiquidity } \\
\text { Ratio }\end{array}$ \\
\hline Tether & $9.09 \times 10^{-28}$ & Storj & $5.72 \times 10^{-12}$ & Ignis & $6.62 \times 10^{-11}$ & SIBCoin & $3.39 \times 10^{-10}$ \\
\hline Bitcoin & $2.3 \times 10^{-19}$ & Tezos & $5.73 \times 10^{-12}$ & FirstBlood & $6.74 \times 10^{-11}$ & Syndicate & $3.41 \times 10^{-10}$ \\
\hline Ethereum & $2 \times 10^{-17}$ & United Bitcoin & $5.76 \times 10^{-12}$ & ZrCoin & $7 \times 10^{-11}$ & Bezop & $3.43 \times 10^{-10}$ \\
\hline Stellar & $3.47 \times 10^{-17}$ & Loom Network & $5.78 \times 10^{-12}$ & TaaS & $7.05 \times 10^{-11}$ & IXT & $3.45 \times 10^{-10}$ \\
\hline Bitcoin Cash & $4.73 \times 10^{-17}$ & Loopring & $5.84 \times 10^{-12}$ & MinexCoin & $7.11 \times 10^{-11}$ & PayPie & $3.46 \times 10^{-10}$ \\
\hline IOTA & $5.14 \times 10^{-16}$ & Power Ledger & $5.88 \times 10^{-12}$ & GameCredits & $7.29 \times 10^{-11}$ & DecentBet & $3.48 \times 10^{-10}$ \\
\hline Tether & $5.14 \times 10^{-16}$ & BitShares & $6.1 \times 10^{-12}$ & $\begin{array}{l}\text { Molecular } \\
\text { Future }\end{array}$ & $7.47 \times 10^{-11}$ & BlackCoin & $3.49 \times 10^{-10}$ \\
\hline Zcash & $9.34 \times 10^{-16}$ & iExec RLC & $6.13 \times 10^{-12}$ & Siacoin & $7.48 \times 10^{-11}$ & Acute Angle C & $3.51 \times 10^{-10}$ \\
\hline EOS & $1.21 \times 10^{-15}$ & bitUSD & $6.27 \times 10^{-12}$ & Dynamic & $7.61 \times 10^{-11}$ & KickCoin & $3.55 \times 10^{-10}$ \\
\hline $\begin{array}{c}\text { Ethereum } \\
\text { Classic }\end{array}$ & $5.28 \times 10^{-15}$ & Ark & $6.34 \times 10^{-12}$ & Bottos & $7.86 \times 10^{-11}$ & BridgeCoin & $3.63 \times 10^{-10}$ \\
\hline NEO & $5.73 \times 10^{-15}$ & Emercoin & $6.54 \times 10^{-12}$ & $\begin{array}{c}\text { Genaro } \\
\text { Network }\end{array}$ & $7.91 \times 10^{-11}$ & Playkey & $3.8 \times 10^{-10}$ \\
\hline Dai & $6.28 \times 10^{-15}$ & IoT Chain & $6.77 \times 10^{-12}$ & NAGA & $8.19 \times 10^{-11}$ & ReddCoin & $3.84 \times 10^{-10}$ \\
\hline Maker & $6.58 \times 10^{-15}$ & Polymath & $6.96 \times 10^{-12}$ & Quantstamp & $8.31 \times 10^{-11}$ & ETHLend & $3.87 \times 10^{-10}$ \\
\hline Binance Coin & $1.04 \times 10^{-14}$ & Exchange Union & $7 \times 10^{-12}$ & SONM & $8.32 \times 10^{-11}$ & Aeon & $3.89 \times 10^{-10}$ \\
\hline Qtum & $1.76 \times 10^{-14}$ & Numeraire & $7.11 \times 10^{-12}$ & Stox & $8.43 \times 10^{-11}$ & RevolutionVR & $3.92 \times 10^{-10}$ \\
\hline Bitcoin Gold & $2.91 \times 10^{-14}$ & Chronobank & $7.19 \times 10^{-12}$ & Qbao & $8.43 \times 10^{-11}$ & $\begin{array}{l}\text { DeepBrain } \\
\text { Chain }\end{array}$ & $3.94 \times 10^{-10}$ \\
\hline Augur & $3.35 \times 10^{-14}$ & Viacoin & $7.57 \times 10^{-12}$ & DADI & $8.47 \times 10^{-11}$ & Paragon & $3.95 \times 10^{-10}$ \\
\hline Waves & $3.44 \times 10^{-14}$ & Blocknet & $8.66 \times 10^{-12}$ & Phore & $8.84 \times 10^{-11}$ & HollyWoodCoin & $4.03 \times 10^{-10}$ \\
\hline Decred & $3.67 \times 10^{-14}$ & Nexus & $8.68 \times 10^{-12}$ & Rcoin & $8.93 \times 10^{-11}$ & DeepOnion & $4.1 \times 10^{-10}$ \\
\hline Huobi Token & $4.74 \times 10^{-14}$ & $\begin{array}{c}\text { Raiden } \\
\text { Networ... }\end{array}$ & $8.76 \times 10^{-12}$ & SingularityNET & $9.07 \times 10^{-11}$ & LatiumX & $4.11 \times 10^{-10}$ \\
\hline WETH & $4.8 \times 10^{-14}$ & Vertcoin & $9.29 \times 10^{-12}$ & Ink & $9.66 \times 10^{-11}$ & DEW & $4.3 \times 10^{-10}$ \\
\hline 42-coin & $5.62 \times 10^{-14}$ & Santiment Net & $9.78 \times 10^{-12}$ & Bitcoin Green & $9.79 \times 10^{-11}$ & Crown & $4.42 \times 10^{-10}$ \\
\hline DigixDAO & $5.82 \times 10^{-14}$ & $\begin{array}{c}\text { SIRIN LABS } \\
\text { Token }\end{array}$ & $9.79 \times 10^{-12}$ & Expanse & $9.81 \times 10^{-11}$ & Profile Utili & $4.53 \times 10^{-10}$ \\
\hline OmiseGO & $6.33 \times 10^{-14}$ & Status & $1.01 \times 10^{-11}$ & Espers & $9.81 \times 10^{-11}$ & Blox & $4.59 \times 10^{-10}$ \\
\hline Moeda Loyalty & $6.93 \times 10^{-14}$ & Decentraland & $1.01 \times 10^{-11}$ & LEOcoin & $9.86 \times 10^{-11}$ & FLO & $4.6 \times 10^{-10}$ \\
\hline Project-X & $9.21 \times 10^{-14}$ & Smartlands & $1.02 \times 10^{-11}$ & OST & $9.88 \times 10^{-11}$ & Gambit & $4.66 \times 10^{-10}$ \\
\hline TrueChain & $1.02 \times 10^{-13}$ & AdEx & $1.04 \times 10^{-11}$ & VIBE & $1.02 \times 10^{-10}$ & WhiteCoin & $4.87 \times 10^{-10}$ \\
\hline MobileGo & $1.48 \times 10^{-13}$ & Verge & $1.09 \times 10^{-11}$ & Republic Prot & $1.05 \times 10^{-10}$ & TopChain & $4.9 \times 10^{-10}$ \\
\hline TRON & $2.28 \times 10^{-13}$ & Blocktix & $1.2 \times 10^{-11}$ & CPChain & $1.06 \times 10^{-10}$ & DATA & $4.97 \times 10^{-10}$ \\
\hline Lisk & $2.69 \times 10^{-13}$ & Bodhi & $1.22 \times 10^{-11}$ & Pundi $X$ & $1.07 \times 10^{-10}$ & Anoncoin & $5.05 \times 10^{-10}$ \\
\hline Genesis Vision & $3.16 \times 10^{-13}$ & $\begin{array}{l}\text { Global Tour } \\
\text { Coin }\end{array}$ & $1.25 \times 10^{-11}$ & adToken & $1.08 \times 10^{-10}$ & REBL & $5.09 \times 10^{-10}$ \\
\hline bitCNY & $3.27 \times 10^{-13}$ & Everex & $1.28 \times 10^{-11}$ & Kcash & $1.09 \times 10^{-10}$ & SmartCash & $5.27 \times 10^{-10}$ \\
\hline Groestlcoin & $3.35 \times 10^{-13}$ & Delphy & $1.29 \times 10^{-11}$ & $\begin{array}{c}\text { Streamr } \\
\text { DATAcoin }\end{array}$ & $1.09 \times 10^{-10}$ & Swarm & $5.29 \times 10^{-10}$ \\
\hline Metaverse ETP & $3.38 \times 10^{-13}$ & KuCoin Shares & $1.31 \times 10^{-11}$ & RChain & $1.11 \times 10^{-10}$ & Patientory & $5.57 \times 10^{-10}$ \\
\hline Ontology & $3.43 \times 10^{-13}$ & Matrix AI Net & $1.34 \times 10^{-11}$ & $\begin{array}{c}\text { Request } \\
\text { Network }\end{array}$ & $1.12 \times 10^{-10}$ & BOScoin & $5.67 \times 10^{-10}$ \\
\hline Lunyr & $3.89 \times 10^{-13}$ & Civic & $1.34 \times 10^{-11}$ & DubaiCoin & $1.12 \times 10^{-10}$ & Bulwark & $5.75 \times 10^{-10}$ \\
\hline ICON & $4.15 \times 10^{-13}$ & Factom & $1.39 \times 10^{-11}$ & Quantum Resis & $1.17 \times 10^{-10}$ & GET Protocol & $5.79 \times 10^{-10}$ \\
\hline HorizenHorizen & $4.2 \times 10^{-13}$ & IOST & $1.47 \times 10^{-11}$ & SunContract & $1.18 \times 10^{-10}$ & YEE & $6.19 \times 10^{-10}$ \\
\hline Populous & $4.34 \times 10^{-13}$ & Bread & $1.49 \times 10^{-11}$ & TokenCard & $1.18 \times 10^{-10}$ & Hi Mutual Soc & $6.36 \times 10^{-10}$ \\
\hline $0 \mathrm{x}$ & $4.61 \times 10^{-13}$ & NavCoin & $1.58 \times 10^{-11}$ & Jibrel Network & $1.2 \times 10^{-10}$ & Everus & $6.41 \times 10^{-10}$ \\
\hline Nano & $4.71 \times 10^{-13}$ & Counterparty & $1.61 \times 10^{-11}$ & TransferCoin & $1.23 \times 10^{-10}$ & Upfiring & $6.47 \times 10^{-10}$ \\
\hline Gas & $4.85 \times 10^{-13}$ & ProChain & $1.62 \times 10^{-11}$ & district0x & $1.24 \times 10^{-10}$ & Elastic & $6.5 \times 10^{-10}$ \\
\hline Gnosis & $4.86 \times 10^{-13}$ & Monero & $1.68 \times 10^{-11}$ & NeosCoin & $1.28 \times 10^{-10}$ & LBRY Credits & $6.52 \times 10^{-10}$ \\
\hline Bibox Token & $4.96 \times 10^{-13}$ & Achain & $1.7 \times 10^{-11}$ & WePower & $1.28 \times 10^{-10}$ & Cofound.it & $6.55 \times 10^{-10}$ \\
\hline Aeternity & $5.2 \times 10^{-13}$ & Revain & $1.7 \times 10^{-11}$ & Scry.info & $1.3 \times 10^{-10}$ & ATN & $6.65 \times 10^{-10}$ \\
\hline SaluS & $5.22 \times 10^{-13}$ & Peercoin & $1.77 \times 10^{-11}$ & Suretly & $1.31 \times 10^{-10}$ & $\begin{array}{c}\text { Insights } \\
\text { Network }\end{array}$ & $7.6 \times 10^{-10}$ \\
\hline Stellar & $5.72 \times 10^{-13}$ & Substratum & $1.8 \times 10^{-11}$ & YOYOW & $1.31 \times 10^{-10}$ & Electroneum & $7.67 \times 10^{-10}$ \\
\hline Veritaseum & $5.76 \times 10^{-13}$ & Syscoin & $1.8 \times 10^{-11}$ & Global Curren & $1.33 \times 10^{-10}$ & Decision Token & $7.85 \times 10^{-10}$ \\
\hline $\mathrm{MCO}$ & $5.87 \times 10^{-13}$ & IPChain & $1.89 \times 10^{-11}$ & Polis & $1.35 \times 10^{-10}$ & HalalChain & $8.01 \times 10^{-10}$ \\
\hline
\end{tabular}


Table 1. Cont.

\begin{tabular}{|c|c|c|c|c|c|c|c|}
\hline \multicolumn{2}{|c|}{ Group 1 (Most Liquid) } & \multicolumn{2}{|c|}{ Group 2} & \multicolumn{2}{|c|}{ Group 3} & \multicolumn{2}{|c|}{ Group 4} \\
\hline Names & $\begin{array}{c}\text { Amihud } \\
\text { Illiquidity } \\
\text { Ratio }\end{array}$ & Names & $\begin{array}{c}\text { Amihud } \\
\text { Illiquidity } \\
\text { Ratio }\end{array}$ & Names & $\begin{array}{l}\text { Amihud } \\
\text { Illiquidity } \\
\text { Ratio }\end{array}$ & Names & $\begin{array}{c}\text { Amihud } \\
\text { Illiquidity } \\
\text { Ratio }\end{array}$ \\
\hline Waltonchain & $6.01 \times 10^{-13}$ & LockTrip & $1.93 \times 10^{-11}$ & Matryx & $1.36 \times 10^{-10}$ & Flixxo & $8.07 \times 10^{-10}$ \\
\hline ZClassic & $6.51 \times 10^{-13}$ & CRYPTO20 & $1.93 \times 10^{-11}$ & UpToken & $1.38 \times 10^{-10}$ & TerraNova & $8.08 \times 10^{-10}$ \\
\hline ZCoin & $6.85 \times 10^{-13}$ & MaidSafeCoin & $1.98 \times 10^{-11}$ & Bytecoin & $1.43 \times 10^{-10}$ & $\begin{array}{c}\mathrm{ACE} \\
\text { (TokenStars) }\end{array}$ & $8.09 \times 10^{-10}$ \\
\hline Neblio & $7.22 \times 10^{-13}$ & Aragon & $1.98 \times 10^{-11}$ & CPChain & $1.46 \times 10^{-10}$ & RealChain & $8.18 \times 10^{-10}$ \\
\hline $\begin{array}{c}\text { Bitcoin } \\
\text { Diamond }\end{array}$ & $7.3 \times 10^{-13}$ & $\mathrm{~B} 2 \mathrm{BX}$ & $2.06 \times 10^{-11}$ & Bankex & $1.47 \times 10^{-10}$ & Zeepin & $8.22 \times 10^{-10}$ \\
\hline $\begin{array}{c}\text { IDEX } \\
\text { Membership }\end{array}$ & $7.42 \times 10^{-13}$ & POA Network & $2.15 \times 10^{-11}$ & Hacken & $1.51 \times 10^{-10}$ & CryptoPing & $8.29 \times 10^{-10}$ \\
\hline GXChain & $7.68 \times 10^{-13}$ & All Sports & $2.24 \times 10^{-11}$ & Solaris & $1.51 \times 10^{-10}$ & QunQun & $8.32 \times 10^{-10}$ \\
\hline Stratis & $7.94 \times 10^{-13}$ & Fargocoin & $2.35 \times 10^{-11}$ & Unikoin Gold & $1.58 \times 10^{-10}$ & Fortuna & $8.33 \times 10^{-10}$ \\
\hline Mithril & $7.95 \times 10^{-13}$ & Bitcoin God & $2.42 \times 10^{-11}$ & Tierion & $1.62 \times 10^{-10}$ & Memetic/Pep & $8.34 \times 10^{-10}$ \\
\hline aelf & $7.96 \times 10^{-13}$ & Ardor & $2.55 \times 10^{-11}$ & SmartMesh & $1.66 \times 10^{-10}$ & EZToken & $8.69 \times 10^{-10}$ \\
\hline SPINDLE & $8.04 \times 10^{-13}$ & Ormeus Coin & $2.84 \times 10^{-11}$ & Agrello & $1.73 \times 10^{-10}$ & ClubCoin & $8.73 \times 10^{-10}$ \\
\hline Wanchain & $8.23 \times 10^{-13}$ & Crypterium & $2.96 \times 10^{-11}$ & Red Pulse Pho... & $1.73 \times 10^{-10}$ & SportyCo & $8.86 \times 10^{-10}$ \\
\hline Bitmark & $8.26 \times 10^{-13}$ & TransferCoin & $2.97 \times 10^{-11}$ & Time New Bank & $1.76 \times 10^{-10}$ & $\begin{array}{c}\text { Banyan } \\
\text { Network }\end{array}$ & $9.14 \times 10^{-10}$ \\
\hline Skycoin & $8.57 \times 10^{-13}$ & Wings & $3.03 \times 10^{-11}$ & Nucleus Vision & $1.79 \times 10^{-10}$ & Mobius & $9.16 \times 10^{-10}$ \\
\hline Dash & $9.13 \times 10^{-13}$ & Dragonchain & $3.06 \times 10^{-11}$ & GoByte & $1.81 \times 10^{-10}$ & BitBay & $9.35 \times 10^{-10}$ \\
\hline Cardano & $9.13 \times 10^{-13}$ & iCoin & $3.15 \times 10^{-11}$ & Swarm City & $1.82 \times 10^{-10}$ & United Trader... & $9.58 \times 10^{-10}$ \\
\hline Bancor & $9.62 \times 10^{-13}$ & Iconomi & $3.15 \times 10^{-11}$ & Bloom & $1.82 \times 10^{-10}$ & Lamden & $9.62 \times 10^{-10}$ \\
\hline Steem & $9.91 \times 10^{-13}$ & Einsteinium & $3.16 \times 10^{-11}$ & Etheroll & $1.84 \times 10^{-10}$ & I/O Coin & $9.91 \times 10^{-10}$ \\
\hline CloakCoin & $1.29 \times 10^{-12}$ & Uquid Coin & $3.21 \times 10^{-11}$ & TrueFlip & $1.86 \times 10^{-10}$ & Radium & $9.91 \times 10^{-10}$ \\
\hline LiteBitcoin & $1.36 \times 10^{-12}$ & Internet Node & $3.26 \times 10^{-11}$ & MediShares & $1.87 \times 10^{-10}$ & Change & $1.01 \times 10^{-9}$ \\
\hline Nuls & $1.39 \times 10^{-12}$ & BnkToTheFuture & $3.27 \times 10^{-11}$ & Polybius & $1.89 \times 10^{-10}$ & EchoLink & $1.03 \times 10^{-9}$ \\
\hline Super Bitcoin & $1.55 \times 10^{-12}$ & QASH & $3.5 \times 10^{-11}$ & Po.et & $1.98 \times 10^{-10}$ & Stipend & $1.04 \times 10^{-9}$ \\
\hline AurumCoin & $1.6 \times 10^{-12}$ & Storm & $3.5 \times 10^{-11}$ & Pascal Coin & $2 \times 10^{-10}$ & VeriumReserve & $1.04 \times 10^{-9}$ \\
\hline Fusion & $1.64 \times 10^{-12}$ & WAX & $3.59 \times 10^{-11}$ & Privatix & $2.01 \times 10^{-10}$ & Open Trading & $1.04 \times 10^{-9}$ \\
\hline WaykiChain & $1.71 \times 10^{-12}$ & OAX & $3.71 \times 10^{-11}$ & Neumark & $2.06 \times 10^{-10}$ & Sumokoin & $1.13 \times 10^{-9}$ \\
\hline KingN Coin & $1.84 \times 10^{-12}$ & Ambrosus & $3.79 \times 10^{-11}$ & Coss & $2.11 \times 10^{-10}$ & MyBit & $1.16 \times 10^{-9}$ \\
\hline Cryptonex & $1.87 \times 10^{-12}$ & Enjin Coin & $3.81 \times 10^{-11}$ & SingularDTV & $2.12 \times 10^{-10}$ & Hydro Protocol & $1.16 \times 10^{-9}$ \\
\hline Golem & $1.9 \times 10^{-12}$ & Credits & $3.94 \times 10^{-11}$ & SureRemit & $2.15 \times 10^{-10}$ & Humaniq & $1.18 \times 10^{-9}$ \\
\hline Particl & $1.9 \times 10^{-12}$ & Ubiq & $4.06 \times 10^{-11}$ & NetKoin & $2.17 \times 10^{-10}$ & Measurable Da & $1.19 \times 10^{-9}$ \\
\hline Metal & $1.97 \times 10^{-12}$ & Tokenomy & $4.12 \times 10^{-11}$ & CVCoin & $2.2 \times 10^{-10}$ & LGO Exchange & $1.21 \times 10^{-9}$ \\
\hline Filecoin [Fut] & $2.01 \times 10^{-12}$ & Namecoin & $4.17 \times 10^{-11}$ & Olympus Labs & $2.22 \times 10^{-10}$ & Dent & $1.22 \times 10^{-9}$ \\
\hline Eidoo & $2.12 \times 10^{-12}$ & LUXCoin & $4.21 \times 10^{-11}$ & Miners' Rewar & $2.25 \times 10^{-10}$ & Galactrum & $1.22 \times 10^{-9}$ \\
\hline Aeron & $2.19 \times 10^{-12}$ & LATOKEN & $4.21 \times 10^{-11}$ & BitSend & $2.3 \times 10^{-10}$ & ClearPoll & $1.27 \times 10^{-9}$ \\
\hline Chainlink & $2.38 \times 10^{-12}$ & Mercury & $4.25 \times 10^{-11}$ & RefToken & $2.32 \times 10^{-10}$ & $\begin{array}{c}\text { Ethereum } \\
\text { Classic }\end{array}$ & $1.31 \times 10^{-9}$ \\
\hline Arcblock & $2.4 \times 10^{-12}$ & NuBits & $4.28 \times 10^{-11}$ & Speed Mining & $2.34 \times 10^{-10}$ & 1World & $1.31 \times 10^{-9}$ \\
\hline High Performa & $2.52 \times 10^{-12}$ & Dragon Coins & $4.39 \times 10^{-11}$ & Novacoin & $2.36 \times 10^{-10}$ & Cube & $1.33 \times 10^{-9}$ \\
\hline Basic Attenti & $2.68 \times 10^{-12}$ & EDUCare & $4.44 \times 10^{-11}$ & SophiaTX & $2.42 \times 10^{-10}$ & Happycoin & $1.34 \times 10^{-9}$ \\
\hline $\begin{array}{c}\text { Waves } \\
\text { Communi }\end{array}$ & $2.84 \times 10^{-12}$ & BlockMason Cr & $4.46 \times 10^{-11}$ & Covesting & $2.48 \times 10^{-10}$ & SelfSell & $1.36 \times 10^{-9}$ \\
\hline Comet & $2.86 \times 10^{-12}$ & ION & $4.76 \times 10^{-11}$ & ExclusiveCoin & $2.52 \times 10^{-10}$ & DigitalNote & $1.37 \times 10^{-9}$ \\
\hline TenX & $3.03 \times 10^{-12}$ & AppCoins & $4.79 \times 10^{-11}$ & eBoost & $2.56 \times 10^{-10}$ & Bitmark & $1.43 \times 10^{-9}$ \\
\hline PIVX & $3.06 \times 10^{-12}$ & IHT Real Esta & $4.8 \times 10^{-11}$ & Aventus & $2.62 \times 10^{-10}$ & Tokes & $1.44 \times 10^{-9}$ \\
\hline TomoChain & $3.08 \times 10^{-12}$ & Kore & $4.86 \times 10^{-11}$ & CoinMeet & $2.7 \times 10^{-10}$ & BitcoinX & $1.47 \times 10^{-9}$ \\
\hline Melon & $3.15 \times 10^{-12}$ & Matchpool & $4.93 \times 10^{-11}$ & GoldCoin & $2.72 \times 10^{-10}$ & Datawallet & $1.48 \times 10^{-9}$ \\
\hline Zilliqa & $3.42 \times 10^{-12}$ & Nxt & $5.24 \times 10^{-11}$ & Spectre.ai Ut & $2.72 \times 10^{-10}$ & Experty & $1.53 \times 10^{-9}$ \\
\hline Enigma & $3.5 \times 10^{-12}$ & Sphere & $5.35 \times 10^{-11}$ & VeriCoin & $2.72 \times 10^{-10}$ & Indorse Token & $1.54 \times 10^{-9}$ \\
\hline Komodo & $3.7 \times 10^{-12}$ & AirSwap & $5.38 \times 10^{-11}$ & Boolberry & $2.82 \times 10^{-10}$ & More Coin & $1.55 \times 10^{-9}$ \\
\hline SALT & $3.82 \times 10^{-12}$ & Dogecoin & $5.49 \times 10^{-11}$ & Monetha & $2.83 \times 10^{-10}$ & EncrypGen & $1.56 \times 10^{-9}$ \\
\hline Unobtanium & $4.06 \times 10^{-12}$ & Octoin Coin & $5.6 \times 10^{-11}$ & Peerplays & $2.86 \times 10^{-10}$ & EvenCoin & $1.59 \times 10^{-9}$ \\
\hline Aion & $4.5 \times 10^{-12}$ & OctoCoin & $5.6 \times 10^{-11}$ & Pura & $2.96 \times 10^{-10}$ & Wagerr & $1.62 \times 10^{-9}$ \\
\hline Omni & $4.79 \times 10^{-12}$ & Blackmoon & $5.67 \times 10^{-11}$ & Internxt & $3.06 \times 10^{-10}$ & Bitcoin Atom & $1.65 \times 10^{-9}$ \\
\hline Bitcoin Private & $4.89 \times 10^{-12}$ & QLC Chain & $5.94 \times 10^{-11}$ & AidCoin & $3.07 \times 10^{-10}$ & MonetaryUnit & $1.75 \times 10^{-9}$ \\
\hline Primas & $4.95 \times 10^{-12}$ & DECENT & $6.27 \times 10^{-11}$ & TokenClub & $3.08 \times 10^{-10}$ & AMLT & $1.79 \times 10^{-9}$ \\
\hline Gifto & $5.07 \times 10^{-12}$ & Clams & $6.28 \times 10^{-11}$ & LinkEye & $3.15 \times 10^{-10}$ & Diamond & $1.86 \times 10^{-9}$ \\
\hline
\end{tabular}


Table 1. Cont.

\begin{tabular}{cccccccc}
\hline \multicolumn{2}{c}{ Group 1 (Most Liquid) } & \multicolumn{2}{c}{ Group 2 } & \multicolumn{2}{c}{ Group 3 } & \multicolumn{2}{c}{ Group 4 } \\
\hline \multirow{2}{*}{ Names } & $\begin{array}{c}\text { Amihud } \\
\text { Illiquidity } \\
\text { Ratio }\end{array}$ & Names & $\begin{array}{c}\text { Amihud } \\
\text { Illiquidity } \\
\text { Ratio }\end{array}$ & Names & $\begin{array}{c}\text { Amihud } \\
\text { Illiquidity } \\
\text { Ratio }\end{array}$ & $\begin{array}{c}\text { Amihud } \\
\text { Names }\end{array}$ & $\begin{array}{c}\text { Illiquidity } \\
\text { Ratio }\end{array}$ \\
\hline NEM & $5.17 \times 10^{-12}$ & GridCoin & $6.28 \times 10^{-11}$ & Infinity Econ & $3.15 \times 10^{-10}$ & Kolion & $1.88 \times 10^{-9}$ \\
\hline Aidos Kuneen & $5.2 \times 10^{-12}$ & Edgeless & $6.38 \times 10^{-11}$ & ATBCoin & $3.2 \times 10^{-10}$ & HelloGold & $1.9 \times 10^{-9}$ \\
\hline MonaCoin & $5.25 \times 10^{-12}$ & Viberate & $6.43 \times 10^{-11}$ & UTRUST & $3.22 \times 10^{-10}$ & Sether & $1.95 \times 10^{-9}$ \\
\hline Bitcoin Plus & $5.66 \times 10^{-12}$ & Internet of P & $6.45 \times 10^{-11}$ & Cindicator & $3.34 \times 10^{-10}$ & Spectrecoin & $1.96 \times 10^{-9}$ \\
\hline
\end{tabular}

Table 2. Groups of less liquid cryptocurrencies.

\begin{tabular}{|c|c|c|c|c|c|c|c|}
\hline \multicolumn{2}{|c|}{ Group 5} & \multicolumn{2}{|c|}{ Group 6} & \multicolumn{2}{|c|}{ Group 7} & \multicolumn{2}{|c|}{ Group 8 (Least Liquid) } \\
\hline Names & $\begin{array}{c}\text { Amihud } \\
\text { Illiquidity } \\
\text { Ratio }\end{array}$ & Names & $\begin{array}{c}\text { Amihud } \\
\text { Illiquidity } \\
\text { Ratio }\end{array}$ & Names & $\begin{array}{c}\text { Amihud } \\
\text { Illiquidity } \\
\text { Ratio }\end{array}$ & Names & $\begin{array}{c}\text { Amihud } \\
\text { Illiquidity } \\
\text { Ratio }\end{array}$ \\
\hline MicroMoney & $1.96 \times 10^{-9}$ & VIVO & $1.46 \times 10^{-8}$ & Neutron & $8.14 \times 10^{-8}$ & Cryptonite & $1.95 \times 10^{-6}$ \\
\hline PRIZM & $1.98 \times 10^{-9}$ & CryptoCarbon & $1.5 \times 10^{-8}$ & HEAT & $8.41 \times 10^{-8}$ & Renos & $2.05 \times 10^{-6}$ \\
\hline Starta & $2 \times 10^{-9}$ & SpaceChain & $1.52 \times 10^{-8}$ & Credo & $8.58 \times 10^{-8}$ & InsaneCoin & $2.05 \times 10^{-6}$ \\
\hline Devery & $2 \times 10^{-9}$ & SwissBorg & $1.53 \times 10^{-8}$ & Tigereum & $9.03 \times 10^{-8}$ & MojoCoin & $2.06 \times 10^{-6}$ \\
\hline Monoeci & $2.01 \times 10^{-9}$ & XTRABYTES & $1.58 \times 10^{-8}$ & AdCoin & $9.15 \times 10^{-8}$ & BlockCDN & $2.16 \times 10^{-6}$ \\
\hline LALA World & $2.09 \times 10^{-9}$ & Sequence & $1.61 \times 10^{-8}$ & Crave & $9.17 \times 10^{-8}$ & TOKYO & $2.21 \times 10^{-6}$ \\
\hline Chronologic & $2.1 \times 10^{-9}$ & BitClave & $1.62 \times 10^{-8}$ & MarteXcoin & $9.35 \times 10^{-8}$ & GoldBlocks & $2.34 \times 10^{-6}$ \\
\hline WeTrust & $2.1 \times 10^{-9}$ & Nexium & $1.64 \times 10^{-8}$ & PeepCoin & $9.67 \times 10^{-8}$ & Bitcoin Red & $2.46 \times 10^{-6}$ \\
\hline $\mathrm{XPA}$ & $2.16 \times 10^{-9}$ & Bela & $1.65 \times 10^{-8}$ & BlitzPredict & $9.9 \times 10^{-8}$ & Universe & $2.51 \times 10^{-6}$ \\
\hline Endor Protocol & $2.21 \times 10^{-9}$ & OFCOIN & $1.74 \times 10^{-8}$ & SoMee.Social & $1.01 \times 10^{-7}$ & ELTCOIN & $2.55 \times 10^{-6}$ \\
\hline OracleChain & $2.22 \times 10^{-9}$ & DomRaider & $1.75 \times 10^{-8}$ & Orbitcoin & $1.05 \times 10^{-7}$ & LiteCoin Ultra & $2.83 \times 10^{-6}$ \\
\hline PotCoin & $2.25 \times 10^{-9}$ & CannaCoin & $1.82 \times 10^{-8}$ & Authorship & $1.05 \times 10^{-7}$ & LIFE & $2.87 \times 10^{-6}$ \\
\hline SpankChain & $2.29 \times 10^{-9}$ & SHIELD & $1.84 \times 10^{-8}$ & BitDegree & $1.08 \times 10^{-7}$ & Ratecoin & $2.98 \times 10^{-6}$ \\
\hline Maverick Chain & $2.33 \times 10^{-9}$ & BitStation & $1.85 \times 10^{-8}$ & MktCoin & $1.12 \times 10^{-7}$ & Version & $3.17 \times 10^{-6}$ \\
\hline BitBar & $2.35 \times 10^{-9}$ & OBITS & $1.89 \times 10^{-8}$ & Dentacoin & $1.17 \times 10^{-7}$ & BitCoal & $3.69 \times 10^{-6}$ \\
\hline Auroracoin & $2.46 \times 10^{-9}$ & Debitum & $1.91 \times 10^{-8}$ & Deutsche eMark & $1.18 \times 10^{-7}$ & PostCoin & $3.7 \times 10^{-6}$ \\
\hline Pillar & $2.47 \times 10^{-9}$ & Cryptopay & $1.93 \times 10^{-8}$ & DigitalPrice & $1.19 \times 10^{-7}$ & BiblePay & $3.76 \times 10^{-6}$ \\
\hline Ignition & $2.48 \times 10^{-9}$ & Graft & $1.99 \times 10^{-8}$ & Storjcoin $X$ & $1.21 \times 10^{-7}$ & AudioCoin & $3.92 \times 10^{-6}$ \\
\hline Cashaa & $2.49 \times 10^{-9}$ & Payfair & $2.01 \times 10^{-8}$ & PetroDollar & $1.23 \times 10^{-7}$ & Joulecoin & $4.13 \times 10^{-6}$ \\
\hline HOQU & $2.56 \times 10^{-9}$ & EDRCoin & $2.02 \times 10^{-8}$ & Pesetacoin & $1.24 \times 10^{-7}$ & Fujinto & $4.37 \times 10^{-6}$ \\
\hline Universal Cur... & $2.57 \times 10^{-9}$ & Sociall & $2.07 \times 10^{-8}$ & Vezt & $1.24 \times 10^{-7}$ & BlueCoin & $4.58 \times 10^{-6}$ \\
\hline Veros & $2.67 \times 10^{-9}$ & Qube & $2.08 \times 10^{-8}$ & Circuits of V... & $1.28 \times 10^{-7}$ & Blue Protocol & $4.58 \times 10^{-6}$ \\
\hline Datum & $2.67 \times 10^{-9}$ & WhaleCoin & $2.13 \times 10^{-8}$ & Bata & $1.37 \times 10^{-7}$ & XRP & $4.78 \times 10^{-6}$ \\
\hline Energo & $2.67 \times 10^{-9}$ & EverGreenCoin & $2.14 \times 10^{-8}$ & carVertical & $1.48 \times 10^{-7}$ & Atomic Coin & $5.06 \times 10^{-6}$ \\
\hline Hush & $2.7 \times 10^{-9}$ & Engine & $2.14 \times 10^{-8}$ & InvestFeed & $1.54 \times 10^{-7}$ & Swisscoin & $5.25 \times 10^{-6}$ \\
\hline PIECoin & $2.72 \times 10^{-9}$ & Zap & $2.14 \times 10^{-8}$ & Flash & $1.57 \times 10^{-7}$ & HiCoin & $5.53 \times 10^{-6}$ \\
\hline $\begin{array}{l}\text { MediBloc } \\
\text { [QRC20] }\end{array}$ & $2.75 \times 10^{-9}$ & Innova & $2.19 \times 10^{-8}$ & Rise & $1.57 \times 10^{-7}$ & Digital Money & $5.84 \times 10^{-6}$ \\
\hline Litecoin Cash & $2.81 \times 10^{-9}$ & Dovu & $2.34 \times 10^{-8}$ & ATMChain & $1.6 \times 10^{-7}$ & HyperStake & $5.91 \times 10^{-6}$ \\
\hline Databits & $2.86 \times 10^{-9}$ & Gold Bits Coin & $2.37 \times 10^{-8}$ & iEthereum & $1.68 \times 10^{-7}$ & HyperStake & $5.91 \times 10^{-6}$ \\
\hline Gulden & $3.01 \times 10^{-9}$ & LOCIcoin & $2.38 \times 10^{-8}$ & Opus & $1.71 \times 10^{-7}$ & SecureCoin & $5.97 \times 10^{-6}$ \\
\hline AICHAIN & $3.03 \times 10^{-9}$ & Dynamic Tradi... & $2.39 \times 10^{-8}$ & 2GIVE & $1.81 \times 10^{-7}$ & Superior Coin & $6.45 \times 10^{-6}$ \\
\hline HempCoin & $3.06 \times 10^{-9}$ & bitJob & $2.42 \times 10^{-8}$ & ArtByte & $1.93 \times 10^{-7}$ & TajCoin & $6.56 \times 10^{-6}$ \\
\hline Gladius Token & $3.15 \times 10^{-9}$ & CFun & $2.43 \times 10^{-8}$ & Kin & $1.93 \times 10^{-7}$ & XGOX & $7.04 \times 10^{-6}$ \\
\hline Content and A... & $3.17 \times 10^{-9}$ & Minereum & $2.43 \times 10^{-8}$ & Bitcloud & $1.99 \times 10^{-7}$ & Rimbit & $7.4 \times 10^{-6}$ \\
\hline SpreadCoin & $3.17 \times 10^{-9}$ & Safe Exchange & $2.46 \times 10^{-8}$ & Sparks & $2.06 \times 10^{-7}$ & Eternity & $7.41 \times 10^{-6}$ \\
\hline Rubycoin & $3.25 \times 10^{-9}$ & DraftCoin & $2.48 \times 10^{-8}$ & Intelligent $\mathrm{T}$ & $2.07 \times 10^{-7}$ & FujiCoin & $8.01 \times 10^{-6}$ \\
\hline OceanChain & $3.45 \times 10^{-9}$ & Pepe Cash & $2.62 \times 10^{-8}$ & $\mathrm{Cl}$ & $2.08 \times 10^{-7}$ & Xenon & $8.04 \times 10^{-6}$ \\
\hline VouchForMe & $3.69 \times 10^{-9}$ & COPYTRACK & $2.63 \times 10^{-8}$ & Zetacoin & $2.13 \times 10^{-7}$ & Pakcoin & $8.24 \times 10^{-6}$ \\
\hline PiplCoin & $3.8 \times 10^{-9}$ & MaxCoin & $2.67 \times 10^{-8}$ & ZetaMicron & $2.13 \times 10^{-7}$ & Eryllium & $8.54 \times 10^{-6}$ \\
\hline CoinPoker & $3.84 \times 10^{-9}$ & Snovian.Space & $2.7 \times 10^{-8}$ & Advanced Tech & $2.14 \times 10^{-7}$ & MintCoin & $9.36 \times 10^{-6}$ \\
\hline
\end{tabular}


Table 2. Cont.

\begin{tabular}{|c|c|c|c|c|c|c|c|}
\hline \multicolumn{2}{|c|}{ Group 5} & \multicolumn{2}{|c|}{ Group 6} & \multicolumn{2}{|c|}{ Group 7} & \multicolumn{2}{|c|}{ Group 8 (Least Liquid) } \\
\hline Names & $\begin{array}{c}\text { Amihud } \\
\text { Illiquidity } \\
\text { Ratio }\end{array}$ & Names & $\begin{array}{c}\text { Amihud } \\
\text { Illiquidity } \\
\text { Ratio }\end{array}$ & Names & $\begin{array}{c}\text { Amihud } \\
\text { Illiquidity } \\
\text { Ratio }\end{array}$ & Names & $\begin{array}{c}\text { Amihud } \\
\text { Illiquidity } \\
\text { Ratio }\end{array}$ \\
\hline Universa & $3.95 \times 10^{-9}$ & Golos & $2.75 \times 10^{-8}$ & Unify & $2.15 \times 10^{-7}$ & Profile Utili... & $9.58 \times 10^{-6}$ \\
\hline Bonpay & $3.96 \times 10^{-9}$ & Social Send & $2.92 \times 10^{-8}$ & The ChampCoin & $2.2 \times 10^{-7}$ & Helleniccoin & $9.93 \times 10^{-6}$ \\
\hline Gems & $4.06 \times 10^{-9}$ & LoMoCoin & $2.93 \times 10^{-8}$ & Ixcoin & $2.26 \times 10^{-7}$ & $\mathrm{Z}$ & $1 \times 10^{-5}$ \\
\hline Incent & $4.16 \times 10^{-9}$ & GeyserCoin & $2.93 \times 10^{-8}$ & Ixcoin & $2.26 \times 10^{-7}$ & Nekonium & $1.03 \times 10^{-5}$ \\
\hline Bitcrystals & $4.21 \times 10^{-9}$ & Yocoin & $3 \times 10^{-8}$ & Mao Zedong & $2.49 \times 10^{-7}$ & First Bitcoin & $1.04 \times 10^{-5}$ \\
\hline BitRent & $4.42 \times 10^{-9}$ & Crystal Clear & $3.06 \times 10^{-8}$ & OP Coin & $2.63 \times 10^{-7}$ & First Bitcoin & $1.04 \times 10^{-5}$ \\
\hline Verify & $4.42 \times 10^{-9}$ & SounDAC & $3.07 \times 10^{-8}$ & $\begin{array}{c}\text { UNIVERSAL } \\
\text { CASH }\end{array}$ & $2.64 \times 10^{-7}$ & BumbaCoin & $1.05 \times 10^{-5}$ \\
\hline Zero & $4.49 \times 10^{-9}$ & Viuly & $3.1 \times 10^{-8}$ & BitcoinZ & $2.67 \times 10^{-7}$ & LiteBitcoin & $1.08 \times 10^{-5}$ \\
\hline Stealth & $4.51 \times 10^{-9}$ & Terracoin & $3.14 \times 10^{-8}$ & TeslaCoin & $2.85 \times 10^{-7}$ & BigUp & $1.12 \times 10^{-5}$ \\
\hline Peculium & $4.96 \times 10^{-9}$ & Sugar Exchange & $3.16 \times 10^{-8}$ & TeslaCoin & $2.85 \times 10^{-7}$ & FedoraCoin & $1.16 \times 10^{-5}$ \\
\hline ShipChain & $4.96 \times 10^{-9}$ & FirstCoin & $3.18 \times 10^{-8}$ & NEVERDIE & $2.91 \times 10^{-7}$ & Bitcoin Planet & $1.2 \times 10^{-5}$ \\
\hline Breakout Stake & $5.03 \times 10^{-9}$ & Dropil & $3.2 \times 10^{-8}$ & Ccore & $2.91 \times 10^{-7}$ & Titcoin & $1.25 \times 10^{-5}$ \\
\hline Karbo & $5.1 \times 10^{-9}$ & FlypMe & $3.21 \times 10^{-8}$ & ToaCoin & $2.98 \times 10^{-7}$ & CoinonatX & $1.44 \times 10^{-5}$ \\
\hline Soma & $5.33 \times 10^{-9}$ & PlatinumBAR & $3.27 \times 10^{-8}$ & EA Coin & $3.29 \times 10^{-7}$ & Phantomx & $1.67 \times 10^{-5}$ \\
\hline TE-FOOD & $5.42 \times 10^{-9}$ & HunterCoin & $3.4 \times 10^{-8}$ & Mincoin & $3.32 \times 10^{-7}$ & PopularCoin & $1.67 \times 10^{-5}$ \\
\hline Education Eco & $5.45 \times 10^{-9}$ & HunterCoin & $3.4 \times 10^{-8}$ & Linker Coin & $3.49 \times 10^{-7}$ & Luna Coin & $1.75 \times 10^{-5}$ \\
\hline Block Array & $5.53 \times 10^{-9}$ & Litecoin Plus & $3.43 \times 10^{-8}$ & Blocklancer & $3.49 \times 10^{-7}$ & bitqy & $1.94 \times 10^{-5}$ \\
\hline Curecoin & $5.6 \times 10^{-9}$ & Bee Token & $3.45 \times 10^{-8}$ & Safecoin & $3.49 \times 10^{-7}$ & Coinonat & $2 \times 10^{-5}$ \\
\hline aXpire & $5.77 \times 10^{-9}$ & indaHash & $3.47 \times 10^{-8}$ & Dalecoin & $3.92 \times 10^{-7}$ & Goodomy & $2.05 \times 10^{-5}$ \\
\hline REAL & $5.82 \times 10^{-9}$ & DopeCoin & $3.6 \times 10^{-8}$ & Moin & $4 \times 10^{-7}$ & Pandacoin & $2.11 \times 10^{-5}$ \\
\hline CoinFi & $5.84 \times 10^{-9}$ & Voise & $3.71 \times 10^{-8}$ & Honey & $4.19 \times 10^{-7}$ & BuzzCoin & $2.13 \times 10^{-5}$ \\
\hline Banca & $5.91 \times 10^{-9}$ & Cobinhood & $3.77 \times 10^{-8}$ & Motocoin & $4.7 \times 10^{-7}$ & SmartCoin & $2.41 \times 10^{-5}$ \\
\hline HEROcoin & $5.91 \times 10^{-9}$ & PinkCoin & $3.79 \times 10^{-8}$ & Elcoin & $4.74 \times 10^{-7}$ & Bitbase & $2.49 \times 10^{-5}$ \\
\hline Sovereign Hero & $5.91 \times 10^{-9}$ & Rupee & $3.84 \times 10^{-8}$ & Equal & $4.82 \times 10^{-7}$ & Argus & $2.64 \times 10^{-5}$ \\
\hline Show & $5.97 \times 10^{-9}$ & BitDice & $3.93 \times 10^{-8}$ & Garlicoin & $4.89 \times 10^{-7}$ & Dinastycoin & $2.66 \times 10^{-5}$ \\
\hline SolarCoin & $6.04 \times 10^{-9}$ & MaxCoin & $4.09 \times 10^{-8}$ & BTCMoon & $4.95 \times 10^{-7}$ & AnarchistsPrime & $3.21 \times 10^{-5}$ \\
\hline Rivetz & $6.05 \times 10^{-9}$ & SkinCoin & $4.2 \times 10^{-8}$ & BioCoin & $5.15 \times 10^{-7}$ & Cryptojacks & $3.29 \times 10^{-5}$ \\
\hline AdShares & $6.12 \times 10^{-9}$ & GridCoin & $4.29 \times 10^{-8}$ & Bitradio & $5.61 \times 10^{-7}$ & NewYorkCoin & $3.33 \times 10^{-5}$ \\
\hline BitClave & $6.2 \times 10^{-9}$ & Tracto & $4.38 \times 10^{-8}$ & GlobalBoost-Y & $5.72 \times 10^{-7}$ & YENTEN & $3.51 \times 10^{-5}$ \\
\hline Zeusshield & $6.24 \times 10^{-9}$ & DAO.Casino & $4.41 \times 10^{-8}$ & High Voltage & $5.72 \times 10^{-7}$ & AmsterdamCoin & $3.96 \times 10^{-5}$ \\
\hline SegWit $2 x$ & $6.32 \times 10^{-9}$ & Animation Vis & $4.72 \times 10^{-8}$ & ZenGold & $5.78 \times 10^{-7}$ & LiteDoge & $4.06 \times 10^{-5}$ \\
\hline Cappasity & $6.5 \times 10^{-9}$ & MedicCoin & $4.76 \times 10^{-8}$ & HTMLCOIN & $6.07 \times 10^{-7}$ & Uniform Fisca & $4.15 \times 10^{-5}$ \\
\hline MCAP & $6.65 \times 10^{-9}$ & Eroscoin & $5.18 \times 10^{-8}$ & Skeincoin & $6.22 \times 10^{-7}$ & Trollcoin & $4.42 \times 10^{-5}$ \\
\hline Global Crypto & $6.81 \times 10^{-9}$ & EventChain & $5.32 \times 10^{-8}$ & Comet & $6.31 \times 10^{-7}$ & Dimecoin & $4.97 \times 10^{-5}$ \\
\hline SpeedCash & $6.91 \times 10^{-9}$ & TrumpCoin & $5.39 \times 10^{-8}$ & TrezarCoin & $6.33 \times 10^{-7}$ & BERNcash & $5.04 \times 10^{-5}$ \\
\hline Elixir & $6.93 \times 10^{-9}$ & Telcoin & $5.46 \times 10^{-8}$ & Oceanlab & $6.52 \times 10^{-7}$ & Coupecoin & $5.1 \times 10^{-5}$ \\
\hline Maecenas & $7.27 \times 10^{-9}$ & Spectiv & $5.47 \times 10^{-8}$ & Regalcoin & $6.75 \times 10^{-7}$ & Grimcoin & $5.1 \times 10^{-5}$ \\
\hline Ink Protocol & $7.82 \times 10^{-9}$ & ALQO & $5.51 \times 10^{-8}$ & $\begin{array}{l}\text { President } \\
\text { Trump }\end{array}$ & $7.14 \times 10^{-7}$ & $\begin{array}{c}\text { Theresa May } \\
\text { Coin }\end{array}$ & $5.75 \times 10^{-5}$ \\
\hline Blue Protocol & $8.11 \times 10^{-9}$ & ColossusXT & $5.51 \times 10^{-8}$ & Quark & $7.27 \times 10^{-7}$ & Nyancoin & $5.92 \times 10^{-5}$ \\
\hline Alphacat & $8.18 \times 10^{-9}$ & PACcoin & $5.57 \times 10^{-8}$ & Onix & $7.56 \times 10^{-7}$ & Blakecoin & $5.92 \times 10^{-5}$ \\
\hline Xaurum & $8.39 \times 10^{-9}$ & Argentum & $5.63 \times 10^{-8}$ & Digitalcoin & $7.58 \times 10^{-7}$ & Megacoin & $5.92 \times 10^{-5}$ \\
\hline Bean Cash & $8.6 \times 10^{-9}$ & Desire & $5.65 \times 10^{-8}$ & Ethereum Cash & $7.6 \times 10^{-7}$ & Elite & $5.93 \times 10^{-5}$ \\
\hline Pareto Network & $8.77 \times 10^{-9}$ & Obsidian & $5.72 \times 10^{-8}$ & FORCE & $7.62 \times 10^{-7}$ & C-Bit & $6.1 \times 10^{-5}$ \\
\hline Bounty0x & $9.02 \times 10^{-9}$ & Soarcoin & $5.72 \times 10^{-8}$ & Adzcoin & $8.24 \times 10^{-7}$ & TEKcoin & $8.39 \times 10^{-5}$ \\
\hline IP Exchange & $9.85 \times 10^{-9}$ & Billionaire $\mathrm{T} . .$. & $5.86 \times 10^{-8}$ & Francs & $9.05 \times 10^{-7}$ & Zeitcoin & $9.66 \times 10^{-5}$ \\
\hline Dether & $9.91 \times 10^{-9}$ & X-Coin & $5.89 \times 10^{-8}$ & WavesGo & $9.24 \times 10^{-7}$ & ZEIT & $9.66 \times 10^{-5}$ \\
\hline Sharpe Platfo.. & $9.94 \times 10^{-9}$ & Musicoin & $5.91 \times 10^{-8}$ & Lendroid Supp & $9.26 \times 10^{-7}$ & HOdlcoin & $9.81 \times 10^{-5}$ \\
\hline SiaCashCoin & $1.01 \times 10^{-8}$ & EquiTrader & $5.95 \times 10^{-8}$ & VoteCoin & $1.01 \times 10^{-6}$ & Piggycoin & $1.03 \times 10^{-4}$ \\
\hline MyWish & $1.06 \times 10^{-8}$ & $\begin{array}{l}\text { Dinnerful } \\
\text { Network }\end{array}$ & $6.05 \times 10^{-8}$ & ArbitrageCT & $1.01 \times 10^{-6}$ & SongCoin & $1.07 \times 10^{-4}$ \\
\hline ATLANT & $1.11 \times 10^{-8}$ & FoldingCoin & $6.1 \times 10^{-8}$ & ERA & $1.01 \times 10^{-6}$ & Golfcoin & $1.18 \times 10^{-4}$ \\
\hline BlockCDN & $1.12 \times 10^{-8}$ & ParallelCoin & $6.1 \times 10^{-8}$ & Sharechain & $1.04 \times 10^{-6}$ & Jesus Coin & $1.44 \times 10^{-4}$ \\
\hline Autonio & $1.14 \times 10^{-8}$ & Ellaism & $6.14 \times 10^{-8}$ & Swing & $1.08 \times 10^{-6}$ & DynamicCoin & $1.48 \times 10^{-4}$ \\
\hline Read & $1.15 \times 10^{-8}$ & StarterCoin & $6.18 \times 10^{-8}$ & Cream & $1.16 \times 10^{-6}$ & POLY AI & $1.62 \times 10^{-4}$ \\
\hline FairCoin & $1.15 \times 10^{-8}$ & Fluz Fluz & $6.53 \times 10^{-8}$ & Bitdeal & $1.16 \times 10^{-6}$ & CrevaCoin & $2.49 \times 10^{-4}$ \\
\hline
\end{tabular}


Table 2. Cont.

\begin{tabular}{cccccccc}
\hline \multicolumn{2}{c}{ Group 5 } & \multicolumn{2}{c}{ Group 6 } & \multicolumn{2}{c}{ Group 7 } & \multicolumn{2}{c}{ Group 8 (Least Liquid) } \\
\hline Names & $\begin{array}{c}\text { Amihud } \\
\text { Illiquidity } \\
\text { Ratio }\end{array}$ & Names & $\begin{array}{c}\text { Amihud } \\
\text { Illiquidity } \\
\text { Ratio }\end{array}$ & Names & $\begin{array}{c}\text { Amihud } \\
\text { Illiquidity } \\
\text { Ratio }\end{array}$ & $\begin{array}{c}\text { Amihud } \\
\text { Names }\end{array}$ & $\begin{array}{c}\text { Illiquidity } \\
\text { Ratio }\end{array}$ \\
\hline Tidex Token & $1.16 \times 10^{-8}$ & Tokenbox & $6.62 \times 10^{-8}$ & Centurion & $1.31 \times 10^{-6}$ & BunnyCoin & $5.01 \times 10^{-4}$ \\
\hline STRAKS & $1.18 \times 10^{-8}$ & AquariusCoin & $6.63 \times 10^{-8}$ & Startcoin & $1.35 \times 10^{-6}$ & Tellurion & $6.64 \times 10^{-4}$ \\
\hline Breakout & $1.21 \times 10^{-8}$ & DIMCOIN & $6.7 \times 10^{-8}$ & Master Swiscoin & $1.44 \times 10^{-6}$ & Carboncoin & $8.57 \times 10^{-4}$ \\
\hline eBitcoin & $1.27 \times 10^{-8}$ & Qbic & $6.73 \times 10^{-8}$ & Bolivarcoin & $1.58 \times 10^{-6}$ & InflationCoin & $8.89 \times 10^{-4}$ \\
\hline Travelflex & $1.29 \times 10^{-8}$ & Myriad & $7.08 \times 10^{-8}$ & Ethereum Gold & $1.59 \times 10^{-6}$ & FunFair & $1.06 \times 10^{-3}$ \\
\hline ALIS & $1.33 \times 10^{-8}$ & Pure & $7.09 \times 10^{-8}$ & WorldCoin & $1.61 \times 10^{-6}$ & StrongHands & $1.27 \times 10^{-3}$ \\
\hline e-Gulden & $1.33 \times 10^{-8}$ & PlanetPay & $7.1 \times 10^{-8}$ & ECC & $1.61 \times 10^{-6}$ & 808 Coin & $1.61 \times 10^{-3}$ \\
\hline DCORP Utility & $1.37 \times 10^{-8}$ & JET8 & $7.55 \times 10^{-8}$ & Condensate & $1.64 \times 10^{-6}$ & Dix Asset & $3.58 \times 10^{-3}$ \\
\hline FidentiaX & $1.37 \times 10^{-8}$ & HomeBlockCoin & $7.73 \times 10^{-8}$ & Shekel & $1.65 \times 10^{-6}$ & Sprouts & $7.08 \times 10^{-3}$ \\
\hline Jetcoin & $1.39 \times 10^{-8}$ & Elementrem & $7.9 \times 10^{-8}$ & HarmonyCoin & $1.78 \times 10^{-6}$ & WeAreSatoshi & $1.73 \times 10^{-2}$ \\
\hline NoLimitCoin & $1.43 \times 10^{-8}$ & Lampix & $7.98 \times 10^{-8}$ & Experience Po... & $1.85 \times 10^{-6}$ & \\
\hline Magi & $1.44 \times 10^{-8}$ & adbank & $8.14 \times 10^{-8}$ & NevaCoin & $1.87 \times 10^{-6}$ & \\
\hline
\end{tabular}

It can be observed that the most important coins in the cryptocurrency markets, such as Bitcoin, Ethereum, Monero, BitcoinCash, IOTA, Tether, EOS, Ethereum Classic, Stellar, Stratis, Dash and Cardano remain the most popular across investor trading preferences even in bearish periods, despite their large price decreases. In this highest liquidity group, the Amihud's illiquidity ratio takes values from $9.09 \times 10^{-28}$ (most liquid) to $5.66 \times 10^{-12}$ (least liquid in this group). The number of active traders of these currencies remains high as it costs less for investors and speculators to trade with these coins due to lower spreads as well as lower transaction costs. Investors believe that if the liquidity of a cryptocurrency is low, it is more difficult to make profit from it as it would be more time-consuming to find a preference matching with other traders willing to make the opposite move. This is why more liquid assets are found to be more preferable during distressed times and not only during flourishing periods that previous academic work has shown (Wei 2018).

On the other hand, less known virtual currencies such as the 808, Dix Asset, Sprouts and WeAreSatoshi appear to exhibit much lower levels of liquidity. More specifically, the Amihud's illiquidity ratio takes values from $1.95 \times 10^{-6}$ to 0.017296 in this eighth group of currencies that stands for the least liquid digital coins. This provides evidence that investors do not prefer during bearish periods currencies that traditionally exhibit low market capitalization, as they are considered more costly to invest in.

Overall, our findings are partly in line with conventional methods for measuring liquidity, based on, such as, the market capitalization or the trading volume of digital currencies. As one can easily observe, the great majority of high-capitalization cryptocurrencies are found to be the most liquid ones according to the Amihud's illiquidity ratio. Moreover, lower-capitalization currencies are part of the lower-liquidity groups based on the categorization performed by Amihud's method. Liquidity examination based on trading volume brings about similar outcomes.

The results of our study are informative about the potential that investors have on substituting investments in high-capitalization cryptocurrencies with lower-capitalization ones during turbulent times when market values of Bitcoin are decreasing. Evidence reveals that there is little tendency of economic agents to invest in alternative digital currencies, but only in the best-known ones. It is remarkable that the most liquid currency during this bearish period, which leaves Bitcoin at the second place, has been the TrueUSD stablecoin that is tied to the US dollar. This is very informative about investors' preferences during distressed times. Notably, they do not abandon investments in the already unstable cryptocurrencies in order to invest in less known and probably more volatile ones, but they rather invest in a coin tied to the most prestigious international currency that carries a global legal tender. These findings reveal that economic units tend to diversify their portfolios and hold a mildly more risk-averse investment profile during crises rather than a more risky attitude. 


\section{Conclusions}

Liquidity has been one of the principal interests of investors and speculators when they decide how to conduct active trading on a particular asset. Cryptocurrencies constitute innovative forms of investment assets where markets are characterized by high levels of herding behavior and a very large portion of market capitalization is concentrated in a small number of important currencies.

This study undertakes the task of estimating the level of liquidity during bearish times in cryptocurrency markets for every digital currency on about which full data are provided in a daily frequency. Thereby, the extra-bearish second phase of downwards movements in digital currency markets is under scrutiny, spanning from 1 April 2018-when the second very sudden drop in digital coin prices took place- until 31 January 2019 when the market started recovering. This paper casts light on whether the active trading preferences of investors are more favorable for well-established cryptocurrencies such as Bitcoin, Ethereum, Ripple, Litecoin, BitcoinCash, Cardano, Stellar and Nem. Previous academic work (Bouri et al. 2019a) has identified these currencies as the primary determinants of herding behavior.

The Amihud's illiquidity ratio by Amihud (2002) enables us to categorize the finally short-listed digital currencies into eight groups, where the first group stands for lower values of the ratio, that is the most liquid cryptocurrencies. Results reveal that the leading virtual currencies that also exhibit the highest market capitalization in normal times, remain the most actively traded digital assets also during bearish periods. The Amihud's illiquidity ratio takes values from $9.09 \times 10^{-28}$ (most liquid) to $5.66 \times 10^{-12}$ (least liquid) in this first group that presents the highest levels of liquidity. On the other hand, the eighth (least liquid) group comprises of significantly less known virtual coins that are much more costly and time-consuming to invest in. This group of least liquid currencies present values for Amihud's illiquidity ratio that are significantly lower than those of previous groups. Lower spreads and lower transaction costs remain the basic determinants of popularity that most liquid cryptocurrencies enjoy, even in distressed times. It is worth noting that the highest-capitalization digital currencies remain the most liquid during distressed periods. Intriguingly, the most liquid currency is found to be the TrueUSD stablecoin which is tied to the US dollar. This reveals that during bearish trends in the cryptocurrency market, investors are slightly more adverse to risk. This is the reason why they diversify their portfolios through the inclusion of less volatile currencies tied to legal and widely-approved forms of money.

This paper is the first one to provide an overall view of the liquidity levels concerning a very wide range of digital currencies during the intensely bearish period in digital currency investments. The main research axis of this study lies on investigating how the popularity and the incumbent character of specific coins in the virtual currency markets affect decision-making about active trading. Our results reinforce previous findings that support the existence of a leading group of high-capitalization currencies being the determinants of herding behavior and the vivid investor sentiment in cryptocurrency markets.

Author Contributions: Conceptualisation and methodology, N.A.K.; software and validation, P.P.; investigation, N.A.K. and P.P.; writing — original draft preparation, N.A.K. and P.P.; writing—review and editing, N.A.K. and P.P.; and supervision, N.A.K.

Funding: This research received no external funding.

Conflicts of Interest: The authors declare no conflict of interest.

\section{References}

Adhami, Saman, Giancarlo Giudici, and Stefano Martinazzi. 2018. Why do businesses go crypto? An empirical analysis of initial coin offerings. Journal of Economics and Business 100: 64-75. [CrossRef]

Amihud, Yakov. 2002. Illiquidity and stock returns: cross-section and time-series effects. Journal of Financial Markets 5: 31-56. [CrossRef]

Ammous, Saifedean. 2018. Can cryptocurrencies fulfil the functions of money? The Quarterly Review of Economics and Finance 70: 38-51. [CrossRef] 
Balcilar, Mehmet, Elie Bouri, Rangan Gupta, and David Roubaud. 2017. Can volume predict Bitcoin returns and volatility? A quantiles-based approach. Economic Modelling 64: 74-81. [CrossRef]

Baur, Dirk G., KiHoon Hong, and Adrian D. Lee. 2018. Bitcoin: Medium of exchange or speculative assets? Journal of International Financial Markets, Institutions and Money 54: 177-89. [CrossRef]

Beneki, Christina, Alexandros Koulis, Nikolaos A. Kyriazis, and Stephanos Papadamou. 2019. Investigating Volatility Transmission and Hedging Properties between Bitcoin and Ethereum. Research in International Business and Finance 48: 219-27. [CrossRef]

Bouri, Elie, Rangan Gupta, Aviral Kumar Tiwari, and David Roubaud. 2017. Does Bitcoin hedge global uncertainty? Evidence from wavelet-based quantile-in-quantile regressions. Finance Research Letters 23: 87-95. [CrossRef]

Bouri, Elie, Syed Jawad Hussain Shahzad, and David Roubaud. 2018. Co-explosivity in the cryptocurrency market. Finance Research Letters 29: 178-83. [CrossRef]

Bouri, Elie, Luis A. Gil-Alana, Rangan Gupta, and David Roubaud. 2019a. Modelling long memory volatility in the Bitcoin market: Evidence of persistence and structural breaks. International Journal of Finance E Economics 24: 412-26.

Bouri, Elie, Rangan Gupta, and David Roubaud. 2019b. Herding behaviour in cryptocurrencies. Finance Research Letters 29: 216-21. [CrossRef]

Bouri, Elie, Chi Keung Marco Lau, Brian Lucey, and David Roubaud. 2019c. Trading volume and the predictability of return and volatility in the cryptocurrency market. Finance Research Letters 29: 340-46. [CrossRef]

Brandvold, Morten, Peter Molnár, Kristian Vagstad, and Ole Christian Andreas Valstad. 2015. Price discovery on Bitcoin exchanges. Journal of International Financial Markets, Institutions and Money 36: 18-35. [CrossRef]

Corbet, Shaen, Andrew Meegan, Charles Larkin, Brian Lucey, and Larisa Yarovaya. 2018. Exploring the dynamic relationships between cryptocurrencies and other financial assets. Economics Letters 165: 28-34. [CrossRef]

Corbet, Shaen, Brian Lucey, Andrew Urquhart, and Larisa Yarovaya. 2019. Cryptocurrencies as a financial asset: A systematic analysis. International Review of Financial Analysis 62: 182-99. [CrossRef]

Dastgir, Shabbir, Ender Demir, Gareth Downing, Giray Gozgor, and Chi Keung Marco Lau. 2019. The causal relationship between Bitcoin attention and Bitcoin returns: Evidence from the Copula-based Granger causality test. Finance Research Letters 28: 160-64. [CrossRef]

Dyhrberg, Anne Haubo. 2016a. Bitcoin, gold and the dollar-A GARCH volatility analysis. Finance Research Letters 16: 85-92. [CrossRef]

Dyhrberg, Anne Haubo. 2016b. Hedging capabilities of bitcoin. Is it the virtual gold? Finance Research Letters 16: 139-44. [CrossRef]

Feng, Wenjun, Yiming Wang, and Zhengjun Zhang. 2018. Informed trading in the Bitcoin market. Finance Research Letters 26: 63-70. [CrossRef]

Ferreira, Paulo, and Éder Pereira. 2019. Contagion Effect in Cryptocurrency Market. Journal of Risk and Financial Management 12: 115. [CrossRef]

Gandal, Neil, J. T. Hamrick, Tyler Moore, and Tali Oberman. 2018. Price manipulation in the Bitcoin ecosystem. Journal of Monetary Economics 95: 86-96. [CrossRef]

Giudici, Paolo, and Iman Abu-Hashish. 2019. What determines bitcoin exchange prices? A network VAR approach. Finance Research Letters 28: 309-18. [CrossRef]

Hayes, Adam S. 2017. Cryptocurrency value formation: An empirical study leading to a cost of production model for valuing bitcoin. Telematics and Informatics 34: 1308-21. [CrossRef]

Hyun, Steve, Jimin Lee, Jong-Min Kim, and Chulhee Jun. 2019. What Coins Lead in the Cryptocurrency Market: Using Copula and Neural Networks Models. Journal of Risk and Financial Management 12: 132. [CrossRef]

Ji, Qiang, Elie Bouri, Chi Keung Marco Lau, and David Roubaud. 2019. Dynamic connectedness and integration in cryptocurrency markets. International Review of Financial Analysis 63: 257-72. [CrossRef]

Katsiampa, Paraskevi. 2017. Volatility estimation for Bitcoin: A comparison of GARCH models. Economics Letters 158: 3-6. [CrossRef]

Kim, Thomas. 2017. On the transaction cost of Bitcoin. Finance Research Letters 23: 300-5. [CrossRef]

Kyriazis, Nikolaos A. 2019. A Survey on Efficiency and Profitable Trading Opportunities in Cryptocurrency Markets. Journal of Risk and Financial Management 12: 67. [CrossRef]

Kyriazis, Nikolaos A., Kalliopi Daskalou, Marios Arampatzis, Paraskevi Prassa, and Evangelia Papaioannou. 2019. Estimating the volatility of cryptocurrencies during bearish markets by employing GARCH models. Heliyon 5: e02239. [CrossRef] 
Panagiotidis, Theodore, Thanasis Stengos, and Orestis Vravosinos. 2018. On the determinants of bitcoin returns: A LASSO approach. Finance Research Letters 27: 235-40. [CrossRef]

Pieters, Gina, and Sofia Vivanco. 2017. Financial regulations and price inconsistencies across Bitcoin markets. Information Economics and Policy 39: 1-14. [CrossRef]

Schilling, Linda, and Harald Uhlig. 2019. Some simple bitcoin economics. Journal of Monetary Economics. [CrossRef] Shen, Dehua, Andrew Urquhart, and Pengfei Wang. 2019. Does twitter predict Bitcoin? Economics Letters 174: 118-22. [CrossRef]

Wei, Wang Chun. 2018. Liquidity and market efficiency in cryptocurrencies. Economics Letters 168: 21-24. [CrossRef]

(C) 2019 by the authors. Licensee MDPI, Basel, Switzerland. This article is an open access article distributed under the terms and conditions of the Creative Commons Attribution (CC BY) license (http://creativecommons.org/licenses/by/4.0/). 


\title{
On the Market Efficiency and Liquidity of High-Frequency Cryptocurrencies in a Bull and Bear Market
}

\author{
Yuanyuan Zhang ${ }^{1}$, Stephen Chan ${ }^{2, *}$, Jeffrey $\mathrm{Chu}^{3}$ and Hana Sulieman ${ }^{2}$ \\ 1 School of Mathematics, University of Manchester, Manchester M13 9PL, UK; \\ yuanyuan.zhang@manchester.ac.uk \\ 2 Department of Mathematics and Statistics, American University of Sharjah, Sharjah, P.O. Box 26666, UAE; \\ hsulieman@aus.edu \\ 3 Department of Statistics, Universidad Carlos III de Madrid, 28903 Getafe, Spain; jchu@est-econ.uc3m.es \\ * Correspondence: schan@aus.edu
}

Received: 2 December 2019; Accepted: 28 December 2019; Published: 3 January 2020

\begin{abstract}
The market for cryptocurrencies has experienced extremely turbulent conditions in recent times, and we can clearly identify strong bull and bear market phenomena over the past year. In this paper, we utilise algorithms for detecting turnings points to identify both bull and bear phases in high-frequency markets for the three largest cryptocurrencies of Bitcoin, Ethereum, and Litecoin. We also examine the market efficiency and liquidity of the selected cryptocurrencies during these periods using high-frequency data. Our findings show that the hourly returns of the three cryptocurrencies during a bull market indicate market efficiency when using the detrended-fluctuation-analysis (DFA) method to analyse the Hurst exponent with a rolling window. However, when conditions turn and there is a bear-market period, we see signs of a more inefficient market. Furthermore, our results indicated differences between the cryptocurrencies in terms of their liquidity during the two market states. Moving from a bull to a bear market, Ethereum and Litecoin appear to become more illiquid, as opposed to Bitcoin, which appears to become more liquid. The motivation to study the high-frequency cryptocurrency market came from the increasing availability of higher-frequency cryptocurrency-pricing data. However, it also comes from a movement towards higher-frequency trading of cryptocurrency. In addition, the efficiency of cryptocurrency markets relates not only to whether prices are predictable and arbitrage opportunities exist, but, more widely, to topics such as testing the profitability of trading strategies and determining the maturity of cryptocurrency markets.
\end{abstract}

Keywords: Bitcoin; Ethereum; market liquidity; Hurst exponent; cryptocurrency; high frequency

\section{Introduction}

Recently, the market for cryptocurrencies has exhibited one of the most volatile periods in its history. While the total market capitalisation for cryptocurrencies reached a record high of over USD 800 billion in the last quarter of 2017, it was followed by a massive correction in the market leading to significantly reduced market capitalisation, which now stands at under USD 100 billion. This clearly suggests that the market has experienced a bull (cryptocurrency-price rising, precrisis) and bear (cryptocurrency-price falling, crisis) market throughout this period. Overspeculation, and interest from academics and those in the industry in this new financial technology are a few reasons behind this recent market phenomenon.

Over the past few years, the cryptocurrency literature has been rapidly expanding. The general literature on cryptocurrencies covers topics including (but not limited to) statistical analysis, modelling, 
and predicting the Bitcoin/USD exchange rate, measuring the volatility of the Bitcoin exchange rate against different financial assets and commodities, stylised facts of cryptocurrencies, and the market efficiency of cryptocurrencies. Chu et al. (2015) provided the first statistical and risk modelling analysis on Bitcoin returns. The generalized hyperbolic distribution provided the best fit; Glaser et al. (2014) investigated whether Bitcoin users see it as a currency or asset, and found that most uninformed users were not interested in Bitcoin as a transaction system but instead saw it as an alternative investment method. Kristoufek (2013) investigated the relationship between Bitcoin prices and search queries from Google and Wikipedia. They found that there was a significant positive correlation between prices and search queries, and that search queries had asymmetric effects on Bitcoin prices depending on whether prices were above or below the short-term trend. The significant volatility in Bitcoin prices and returns cannot simply be explained by economic or financial theory. Sapuric and Kokkinaki (2014) analysed the volatility of the exchange rate of Bitcoin during its early years and found that it was significantly greater than that of major exchange rates. However, when they accounted for transaction volume, volatility appeared to be more stable. Baur et al. (2018) analysed the statistical properties of Bitcoin and found that they were "uncorrelated with traditional asset classes such as stocks, bonds, and commodities, both in normal times and in periods of financial turmoil". In addition, the authors found that Bitcoin is primarily used as an investment asset and not as a currency. Briere et al. (2015) investigated Bitcoin from an investment perspective and found that it had significantly high average return and volatility, and little correlation with traditional financial assets. Results showed that, by including Bitcoin in well-diversified portfolios, the risk-return trade-off could be significantly improved.

The efficient market hypothesis (EMH) is a core and fundamental concept used in finance that was introduced by Malkiel and Fama (1970) through modelling financial data. There are three main forms of efficiency, with the most common being the weak form. The weak form states that investors cannot use historical-price information to make future-price predictions. The importance of understanding market efficiency can be beneficial to investors, academics, and financial practitioners, as historical-price pattern information can assist in the greater understanding or discovery of arbitrage returns. On the other hand, liquidity is a concept of how easily capital and assets can be traded without causing a dramatic change in an asset's price. In general, an illiquid asset would procure a higher bid ask spread and transaction cost, increasing the cost for speculators and investors to trade. Hence, if cryptocurrency markets are very illiquid, this results in market inefficiency, as the lack of market makers and traders causes a delay in market participants acting on new information.

Many attempts were made so far to study the market efficiency of various cryptocurrency markets, but the vast majority of the known work has been exclusively directed towards the Bitcoin market. For example, Bariviera (2017) studied the long-range memory of the Bitcoin market by analysing the Hurst exponent via the R/S and detrended-fluctuation-analysis (DFA) methods, and confirmed that daily volatility exhibits long-range memory; Alvarez-Ramirez et al. (2018) implemented the DFA method to estimate the long-range dependence of Bitcoin and found that the Bitcoin market exhibited periods of efficiency, alternating in different periods; Tiwari et al. (2018) reported that the Bitcoin market is informationally efficient, by using a battery of robust long-range dependence estimators; Khuntia and Pattanayak (2018) examined the efficiency of the Bitcoin market by using the Dominguez-Lobato consistent test and generalized spectral test, and concluded that dynamic efficiency in the Bitcoin market actually follows the proposition of adaptive market hypothesis (AMH); Jiang et al. (2018) employed the generalised Hurst exponent to investigate long-term memory in the Bitcoin market, and results suggested that the Bitcoin market was inefficient over the whole sample period; Zhang et al. (2018a) illustrated that the nine most popular cryptocurrency markets were inefficient by employing a battery of efficiency tests, and the MF-DFA and MF-DCCA approaches; Zhang et al. (2018b) analysed the stylised facts of cryptocurrencies in terms of long-range dependence by using the Hurst exponent with both the R/S and DFA methods for high-frequency-return data of the four most popular cryptocurrencies, while features of dependence between the different cryptocurrencies were also provided; Chu et al. (2019) analysed the efficiency of the high-frequency 
markets of the two largest cryptocurrencies, Bitcoin and Ethereum, versus the euro and US dollar, by investigating the existence of the AMH.

Our main motivation was to analyse and understand market-efficiency patterns and liquidity behaviour during a bull (precrisis) and bear (crisis) market for cryptocurrencies. These periods are very intriguing as they represent different market conditions. The main contributions of this paper are: (i) utilising algorithms for detecting turning points to identify bull and bear phases for the three largest cryptocurrencies of Bitcoin, Ethereum and Litecoin in high-frequency (hourly) markets; and (ii) analysing and understanding the characteristics of market efficiency and liquidity in high-frequency cryptocurrency returns during a bull or bear market. This is the first study of detecting bull and bear periods in high-frequency cryptocurrency markets, and analysing their market efficiency and liquidity during such periods.

For each cryptocurrency, we analysed data from 1 July 2017 to 19 September 2018. This time period was divided into two subperiods, corresponding to a bull market (precrisis period) from 1 July 2017 to 16 January 2018 (4789 observations), and a bear market (crisis period) from 17 January 2018 to 19 September 2018 (5888 observations). Sections 2 and 3 provide a detailed justification of how the bull and bear markets were identified.

For each cryptocurrency, we performed analysis by using two different methods. The first was to apply the DFA method to compute the Hurst exponent over a rolling window during a bull and bear market to analyse the behaviour of the high-frequency (hourly) returns of Ethereum, Bitcoin and Litecoin. The DFA method is most commonly implemented by using a rolling-window approach for analysing the Hurst exponent in financial time series (see, for example, Matos et al. 2008, Grech and Mazur 2004, and Carbone et al. 2004). The second was to use a series of tests, presented in Section 2, which examined the efficient market hypothesis within fixed periods (bull and bear markets). A rolling-window approach splits a dataset into subsamples of a specific size rather than analysing the whole data sample in one process. The initial subsample is analysed before the next most recent data are added to the subsample, and the earliest data in the subsample are removed. This process is then repeated until the subsample reaches the most recent data in the whole sample. A conventional fixed-period method analyses the whole data sample in one go.

The contents of the paper are organised as follows. The algorithms used in detecting bull and bear markets in cryptocurrencies and the methods used to measure the long-range memory, liquidity, and market efficiency of cryptocurrencies in a bull and bear market are discussed in Section 2. The three cryptocurrency datasets and their summary statistics are described in Section 3. Data analysis using a range of different methods, including analysis of the Hurst exponent, is presented in Section 4. Finally, conclusions are drawn in Section 5.

\section{Method}

\subsection{Detecting Bull and Bear Markets}

In the finance literature, there is no generally accepted formal definition of a bull or bear market. Therefore, in this paper, the considered time period was split into bull and bear phases in the cryptocurrency markets on the basis of two well-known algorithms: the algorithm of Lunde and Timmermann (2004) (filtering method) and the algorithm of Bry and Boschan (1971) (dating method). Both of these methods were designed to capture financial and business cycles. Here, we give a brief explanation of these two methods.

The Lunde and Timmermann (2004) algorithm is based on imposing a minimum on the price change since the last peak or trough. Let $\lambda_{1}$ be a scalar defining the threshold for a transition from a bear to bull market, and $\lambda_{2}$ be a threshold for a transition from a bull to bear market. Suppose $X_{t}$ denotes the hourly price of a cryptocurrency at time $t$, and a trough in $X$ has been detected at time 
$t_{0} \leq t$. A bull phase begins in the algorithm at time $t_{0}+1$. The algorithm first detects the maximum value in $X$ at time $\left[t_{0}, t\right]$ :

$$
X_{t_{0}, t}^{\max }=\max \left\{X_{t_{0}}, X_{t_{0}+1}, \ldots, X_{t}\right\}
$$

Then, the relative change in $X$ is computed as

$$
\delta_{t}=\frac{X_{t_{0}, t}^{\max }-X_{t}}{X_{t_{0}, t}^{\max }} .
$$

If $\delta_{t}>\lambda_{2}$, this point is denoted as a new peak (maximum) occurring at $t_{\text {peak }}$ in interval $\left[t_{0}, t\right]$. Then, $\left[t_{0}+1, t_{\text {peak }}\right]$ is labelled as a bull state period. By contrast, a Bear state period begins from $t_{\text {peak }}+1$ and if a peak has been identified in $X$ at time $t_{0} \leq t$, then the algorithm finds the minimum value of $X$ on the time interval $\left[t_{0}, t\right]$,

$$
X_{t_{0}, t}^{\min }=\min \left\{X_{t_{0}}, X_{t_{0}+1}, \ldots, X_{t}\right\}
$$

and then the relative change in $X$ is computed as

$$
\delta_{t}=\frac{X_{t_{0}, t}^{\min }-X_{t}}{X_{t_{0}, t}^{\min }} .
$$

If $\delta_{t}>\lambda_{1}$, this point is denoted as a new trough (minimum) occurring at $t_{\text {trough }}$ in the interval $\left[t_{0}, t\right]$. Then, $\left[t_{0}+1, t_{\text {trough }}\right]$ is labelled as a bear period. A bull period begins from $t_{\text {trough }}+1$. For more details on this method, see Lunde and Timmermann (2004).

The main objective of the Bry and Boschan (1971) algorithm is to detect turning points in a financial cycle. This method consists of two main steps: identifying the initial turning points in $X$, followed by guided censoring operations. First, one identifies a window of length $\tau_{\text {window }}$ months on either side of the date and defines a peak (trough) in $X$ as a point higher (lower) than other points within the window. Next, censoring requires eliminating peaks and troughs in the first and last $\tau_{\text {censor }}$ months; eliminating phases that last less than $\tau_{\text {phase }}$ months; and eliminating cycles that last less than $\tau_{\text {cycles }}$ months. We repeated the procedure of the censoring operation many times, until the sequence of turning points satisfied all constraints. For more details on this method, see Bry and Boschan (1971).

A major drawback of the Bry and Boschan (1971) method is that it is mostly applied to monthly frequency data, and it is very sensitive to data frequency. On the other hand, one can just edit the parameters to account for the data frequency. Compared with the Bry and Boschan (1971) method, the Lunde and Timmermann (2004) method is not that sensitive when applied to either daily or hourly frequency data because parameters in the algorithm are computed as two relative changes in the cryptocurrency prices in the algorithm. Implementation of the two algorithms to our selected data is described in Section 3.

One may question if the use of these methods is adequate for analysing cryptocurrency markets or whether it can only be applied to traditional business cycles. To answer this question, it is best not to look specifically at the duration of business cycles and say whether cryptocurrency cycles are similar or not, but rather to look back at the algorithm itself (see Section 3). The algorithm determines bull and bear markets in any financial markets through the setting of a threshold relating to a level of price change that, if exceeded, represents a change in the market state. Hence, these methods are robust to application in any financial market, as discussed by Bry and Boschan (1971) and Lunde and Timmermann (2004). 


\subsection{Detrended Fluctuation Analysis (DFA) Method}

We tested for long-range memory in the bull and bear markets of Ethereum, Bitcoin, and Litecoin by computing the Hurst exponent via the DFA method. The DFA method examines dependence in these markets, and was an indicator of random and nonrandom behaviour in our time series. Other methods for detecting long-range memory include R/S analysis, which is one of the most popular extended methods that can be used to estimate long-term memory in time-series data; however, it is not that stable. For instance, when a process under investigation has short memory, the R/S statistic may wrongly indicate the presence of long-term memory. The DFA method has been shown to be more suitable in dealing with nonstationary time-series data. In addition, as highlighted by Grau-Carles (2000), the DFA method avoids the spurious detection of long-range dependence. Hence, this is the main reason why chose to use the method. The computation of the Hurst exponent was conducted using the R statistical software package (R Development Core Team 2019). We followed the method presented in Section 2.1 of Zhang et al. (2018b), to compute Hurst exponent values, using the default parameters given in the procedure, and a rolling window of 720 (approximately one month) lagged data points. Further details on these methods applied to cryptocurrency data can be found in Zhang et al. (2018b).

The values that the Hurst exponent $(\alpha)$ could take range from 0 to 1 . A value of $\alpha=0.5$ indicates that the time series follows a random walk and does not exhibit a long memory. However, if $\alpha \neq 0.5$, this indicates that the considered time series exhibits evidence of long-term correlations. If $0.5<\alpha<1$, the series indicates trend-reinforcing behaviour; if $0<\alpha<0.5$, the series exhibits antipersistence behaviour. The stochastic behaviour of the Hurst exponent computed using the DFA method for hourly returns of Ethereum, Bitcoin, and Litecoin in bull and bear markets is illustrated in Section 4.

\subsection{Efficiency Market Hypothesis Tests}

Other methods used to test the efficiency market hypothesis include the Ljung-Box test (Ljung and Box 1978) that examines the null hypothesis of no autocorrelation; and the Wald-Wolfowitz Runs Test (Wald and Wolfowitz 1940) and the Bartels Rank Test (Bartels, 1982), both testing the null hypothesis of independence of the returns; the Wild Bootstrapping of Automatic Variance Ratio Test (Kim 2009) and the Spectral shape tests (Durlauf 1991), testing the null hypothesis that returns follow a random walk; and the Automatic Portmanteau Test (Escanciano and Lobato 2009), testing a null hypothesis of serial correlation.

\subsection{Illiquidity Measure}

The Amihud illiquidity (ILLIQ) ratio (Amihud 2002) is a common measure used to calculate the degree of stock liquidity. Here, we applied this measure to compute and compare the liquidity of cryptocurrencies during bull and bear markets. We could also interpret this ratio as a measure of price impact because it represents an hourly price response associated with one dollar of trading volume. This illiquidity measure was chosen for its simplicity and robustness as it requires only high-frequency trade data. More importantly, other liquidity measures require microstructure data on cryptocurrencies, and these data are not freely available, as the market is still in its infancy. The Amihud illiquidity ratio is defined as

$$
I L L I Q_{i T}=1 / D_{i T} \sum_{t=1}^{D_{i T}} \frac{\left|R_{i t}\right|}{V O L D_{i t}},
$$

where $D_{i T}$ denotes the number of traded hours in cryptocurrency $i$ in year $T, R_{i t}$ is the hourly return on cryptocurrency $i$ in hour $t$ in USD, and $V O L D_{i t}$ is the hourly volume in dollars (price at time $t \times$ volume at time $t$ ) on cryptocurrency $i$ in hour $t$. 


\section{Data}

In this paper, the datasets that we used consisted of historical high-frequency (hourly) prices of cryptocurrencies versus the US Dollar (USD) from 11:00 on 11 July 2017 to 00:00 on 19 September 2018 inclusive. The data were obtained from CryptoCompare (2018), and our analysis was limited to data that were available for download at the time. We chose cryptocurrencies for our analysis on the basis of the most popular cryptocurrencies traded on the GDAX exchange during that time, namely, Bitcoin, Ethereum, and Litecoin. These three cryptocurrencies accounted for around $80 \%$ of total market capitalisation for cryptocurrencies during that period, and we could therefore assume that the used datasets provide an adequate representation of the market. Chan et al. (2017) provides more details on the individual cryptocurrencies.

Before analysis, our preliminary approach in determining the bull and bear run period was to first identify the highest point (peak) in the dataset, which occurred on 16 January 2018. We then classified all data points prior to the peak (from 1 July 2017 to 16 January 2018) as being part of a general bull run in the market, and all points after the peak (17 January 2018 to 19 September 2018) as part of a general bear market run. However, to theoretically justify our selected periods, we implemented the Bry and Boschan (1971) and Lunde and Timmermann (2004) algorithms using the parameter values mentioned in Section 2 for detecting bull and bear periods.

There are numerous software packages that could be implemented to detect bull and bear markets in financial data, and in this analysis we use the R statistical software package (2019). To implement the 'dating' and 'filtering' algorithm methods introduced by Bry and Boschan (1971), and Lunde and Timmermann (2004), respectively, in R, we used R package bbdetection. The parameter values for the two methods were set using the two commands setpar_dating_alg and setpar_filtering_alg, respectively. For the dating algorithm, we selected parameter values of

$$
\tau_{\text {window }}=168, \tau_{\text {censor }}=24, \tau_{\text {phase }}=12, \tau_{\text {cycle }}=12, \theta=20 \text {. }
$$

For the filtering algorithm, we selected parameters of

$$
\lambda_{1}=20, \lambda_{2}=20
$$

Our reasoning for the values of $\lambda_{1}, \lambda_{2}$, and $\theta$ was to have a consistent threshold relating to price changes in both methods to detect peaks and troughs to determine the start and end of bull- and bear-market states. In the dating algorithm, $\tau_{\text {window }}$ was selected so that, at each time point, only turning points in the one week before and after were considered. The remainder of the parameter values were chosen to remove bull- and bear-market states that were only short-lived and insignificant.

Figure 1 plots the results of these algorithms in detecting bull and bear periods in cryptocurrency data. The shaded-white (grey) areas identify periods of a bull (bear) market run in the cryptocurrency data. The top-left (-right) diagram in Figure 1 shows the result through implementing the dating (filtering) algorithm, respectively, for Ethereum. The majority of the area before the peak for both approaches has a greater proportion of shaded-white areas than grey, which indicates that, in general, the market was a bull market. In contrast, the period after the peak sees a greater proportion of shaded-grey areas, which suggests that the market was more of a bear market in that period. Similar results were also seen for Bitcoin and Litecoin using the dating and filtering algorithms. Hence, the results used in this analysis support our preliminary results. This provides us with a reasonable case for selecting our chosen time periods for the bull and bear periods in our main analysis. 

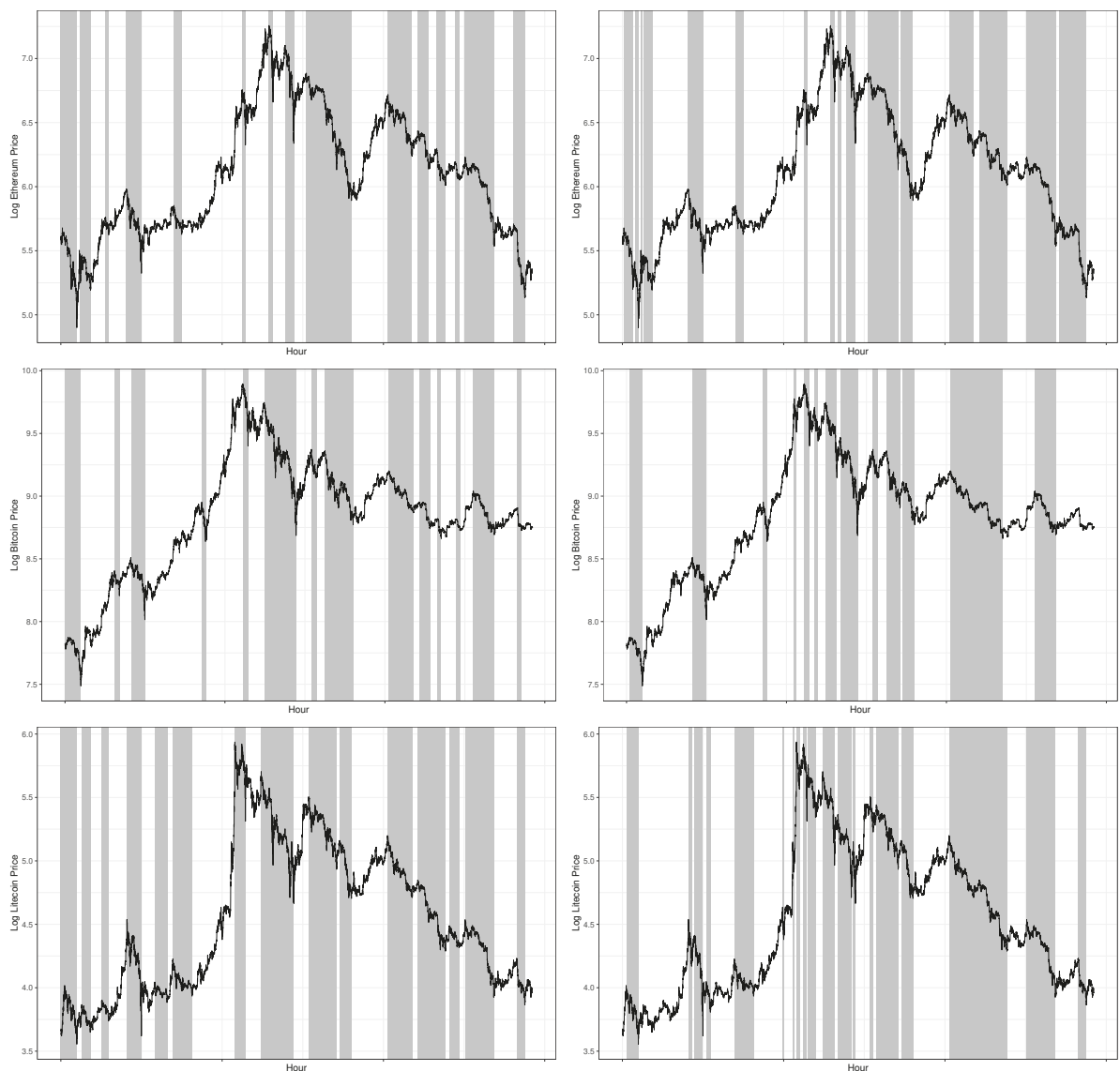

Figure 1. Plots indicating bull-bear periods using Ethereum (top left) dating and (top right) filtering algorithm, Bitcoin (middle left) dating and (middle right) filtering algorithm, and Litecoin (bottom left) dating and (bottom right) filtering algorithm. Bull and bear periods indicated by white and grey shaded areas, respectively.

Tables 1 and 2 provide summary statistics of log returns of high-frequency (hourly) market prices during a bull and bear market. In Table 1, the summary statistics of the log returns of the market-price index for Ethereum, Bitcoin, and Litecoin versus USD in a bull market are given. The BTC/USD index had the highest minimum, first quartile, median, and mean, while it had the lowest third quartile, maximum, and range. In contrast, the LTC/USD index had the lowest minimum, first quartile, and median, while it had the highest mean, third quartile, maximum, and range. Bitcoin was the only negatively skewed cryptocurrency. All cryptocurrencies showed significantly greater peakedness than normal distribution, and the LTC/USD index gave the highest kurtosis value. In terms of index spread, the values of standard deviation and variance for all cryptocurrencies were fairly similar (almost 0 ). 
Table 1. Summary statistics of log returns of hourly market price index during a bull market in $\mathrm{ETH} / \mathrm{USD}, \mathrm{BTC} / \mathrm{USD}$ and LTC/USD.

\begin{tabular}{cccc}
\hline Statistics & ETH/USD & BTC/USD & LIT/USD \\
\hline Observation size & 4789 & 4789 & 4789 \\
Minimum & -0.1596 & -0.1316 & -0.1951 \\
Q1 & -0.0053 & -0.0048 & -0.0063 \\
Median & 0.0002 & 0.0005 & 0.0000 \\
Mean & 0.0002 & 0.0003 & 0.0003 \\
Q3 & 0.0058 & 0.0058 & 0.0060 \\
Maximum & 0.1398 & 0.1088 & 0.1825 \\
Skewness & 0.0628 & -0.0964 & 0.8616 \\
Kurtosis & 12.1973 & 9.8589 & 18.7298 \\
SD & 0.0148 & 0.0126 & 0.0173 \\
Variance & 0.0002 & 0.0002 & 0.0003 \\
CV & 51.7825 & 39.4293 & 52.3381 \\
Range & 0.2994 & 0.2405 & 0.3776 \\
IQR & 0.0111 & 0.0105 & 0.0123 \\
\hline
\end{tabular}

Table 2. Summary statistics of log returns of hourly market price index during bear market in ETH/USD, BTC/USD and LTC/USD.

\begin{tabular}{cccc}
\hline Statistics & ETH/USD & BTC/USD & LIT/USD \\
\hline Observation size & 5888 & 5888 & 5888 \\
Minimum & -0.0900 & -0.0730 & -0.1037 \\
Q1 & -0.0051 & -0.0032 & -0.0053 \\
Median & 0.0000 & 0.0000 & -0.0003 \\
Mean & -0.0003 & -0.0001 & -0.0002 \\
Q3 & 0.0050 & 0.0031 & 0.0047 \\
Maximum & 0.1593 & 0.1086 & 0.1874 \\
Skewness & 0.6534 & 0.6156 & 1.0088 \\
Kurtosis & 15.1537 & 13.6283 & 16.4544 \\
SD & 0.0125 & 0.0100 & 0.0131 \\
Variance & 0.0002 & 0.0001 & 0.0002 \\
CV & -46.3241 & -101.9201 & -60.7999 \\
Range & 0.2493 & 0.1816 & 0.2911 \\
IQR & 0.0101 & 0.0064 & 0.0100 \\
\hline
\end{tabular}

Table 2 presents summary statistics of log returns of market price index for Ethereum, Bitcoin, and Litecoin versus USD during a bear market. Similar to Table 1, the BTC/USD index had the highest minimum, first quartile, median, and mean, while it had the lowest third quartile, maximum, and range. Litecoin had the lowest minimum, first quartile, and median, and the highest maximum and range. Once again, all cryptocurrencies showed significantly greater peakedness than normal distribution, and the LTC/USD index gave the highest kurtosis value. Compared with bull-market summary statistics, all cryptocurrencies were positively skewed, and Litecoin had the largest skewness value. With regard to variation, ETH/USD gave the greatest standard deviation and variance. Standard deviation and variance values of log returns for all cryptocurrencies were very small and close to 0 .

By comparing Tables 1 and 2, there was significant difference in some statistical properties between bull and bear markets. Compared with the bull market, the values of the minimum, skewness, and kurtosis for all cryptocurrencies increased during the bear market. However, the coefficient of variation for all cryptocurrencies significantly decreased, changing from positive to negative values. The interquartile range (IQR) for all cryptocurrencies also decreased in the bear market, implying that the middle $50 \%$ of data during the bear market were less spread out. 


\section{Results and Discussion}

Tables 3-5 show the results of the various test for the efficient market hypothesis on Ethereum, Bitcoin, and Litecoin, respectively. These tests were conducted over two fixed subperiods, during the bull market and during the bear market. In each case, corresponding $p$-values are shown. For the bull-market period, the majority of the $p$-values (with the exception of the Runs test for Ethereum and the AVR test for Litecoin) for all cryptocurrencies rejected the null hypotheses of no autocorrelation, independence, and random walk. Similarly, during the bear-market period, the majority of the $p$-values (with the exception of the Ljung-Box test and AVR test for Ethereum) for all cryptocurrencies rejected the null hypotheses of no autocorrelation, independence, and random walk. Overall, these tests indicated that high-frequency (hourly) cryptocurrency returns exhibited behaviour consistent with an inefficient market during both a bull and bear market. When compared to other financial markets, similar results can be seen, for example, Gil-Alana et al. (2018) noted that the Baltic stock market rejected the theory of market efficiency during the bull and bear markets; Jiang and Li (2019) investigated market efficiency for the Chinese, Japanese, and U.S. stock markets, and found market inefficiency in both the bull- and bear-market states, which could be explained by behavioural finance theory.

Table 3. Market-efficiency test for hourly returns of Ethereum during bull and bear market.

\begin{tabular}{ccccccc}
\hline Test & Ljung-Box Test & Runs Test & Bartels Test & AVR Tests & SST & SST \\
\hline Ethereum (Bull) & 0.00591 & 0.174 & 0.000615 & 0.022 & $4.47 \times 10^{-5}$ & $3.38 \times 10^{-4}$ \\
Ethereum (Bear) & 0.297 & $1.41 \times 10^{-6}$ & $9.27 \times 10^{-6}$ & 0.566 & 0.00167 & 0.00366 \\
\hline
\end{tabular}

Table 4. Market-efficiency test for hourly returns of Bitcoin during bull and bear market.

\begin{tabular}{ccccccc}
\hline Test & Ljung-Box Test & Runs Test & Bartels Test & AVR Tests & SST & SST \\
\hline Bitcoin (Bull) & 0.0003 & $3.26 \times 10^{-6}$ & $6.01 \times 10^{-4}$ & 0.018 & $1.04 \times 10^{-5}$ & $6.65 \times 10^{-5}$ \\
Bitcoin (Bear) & 0.04676 & $4.44 \times 10^{-16}$ & $2.60 \times 10^{-14}$ & 0.062 & $7.63 \times 10^{-4}$ & 0.00131 \\
\hline
\end{tabular}

Table 5. Market-efficiency test for hourly returns of Litecoin during bull and bear market.

\begin{tabular}{ccccccc}
\hline Test & Ljung-Box Test & Runs Test & Bartels Test & AVR Tests & SST & SST \\
\hline Litecoin (Bull) & 0.0777 & 0.0128 & 0.0188 & 0.7 & $7.16 \times 10^{-4}$ & 0.00194 \\
Litecoin (Bear) & $9.33 \times 10^{-4}$ & $2.37 \times 10^{-10}$ & $2.08 \times 10^{-9}$ & 0.02 & $6.02 \times 10^{-6}$ & $2.08 \times 10^{-5}$ \\
\hline
\end{tabular}

The results of Amihud's illiquidity ratio are shown in Table 6. Results were multiplied by $10^{8}$ for a simpler comparison, and this did not lead to loss of information. When comparing the three cryptocurrencies on the basis of the Amihud ratio, Bitcoin had the smallest value, followed by Ethereum and Litecoin. This illustrates that Bitcoin is the most liquid cryptocurrency. This result is consistent with our expectations, as Bitcoin holds the largest share of the cryptocurrency-market capitalisation, making it the most actively traded cryptocurrency. Other factors that led to Bitcoin being the most actively traded cryptocurrency include numerous trading platforms requiring users to hold Bitcoin before being able to trade other cryptocurrencies; the launch of Bitcoin futures, which allowed speculators to long and short Bitcoin and increased Bitcoin volatility; and the majority of exchanges providing other products, such as the trading of cryptocurrency pairs (e.g., BTC/ETH, BTC/LTC, $\mathrm{BTC} / \mathrm{XRP}$ ), with the majority of pairs involving Bitcoin. 
Table 6. Amihud illiquidity ratio on hourly returns for Ethereum, Bitcoin, and Litecoin during bull and bear market.

\begin{tabular}{cc}
\hline Test & Amihud \\
\hline Ethereum (Bull) & 0.415756 \\
Ethereum (Bear) & 0.438561 \\
Bitcoin (Bull) & 0.275500 \\
Bitcoin (Bear) & 0.162648 \\
Litecoin (Bull) & 0.943289 \\
Litecoin (Bear) & 0.949993 \\
\hline
\end{tabular}

When comparing bull- and bear-market liquidity and volatility, there was a strong relationship between liquidity and volatility for Ethereum and Litecoin. For Ethereum and Litecoin, market volatility decreases during a bear market, and the market becomes less liquid. However, results were different for Bitcoin, as market volatility decreases during a bear market, and Bitcoin becomes more liquid than in the bull market. This phenomenon could be explained by investors becoming irrational and worrying about the whole cryptocurrency market collapsing, leading to a majority of investors cashing out their cryptocurrency holdings. Most trading exchanges only allow cashing out cryptocurrencies through Bitcoin; therefore, this also causes Bitcoin to be traded by more active traders, which makes the market more liquid.

The long-range memory for all three cryptocurrencies during a bull and bear market was computed using the DFA method. The difference between this and previous methods is that this technique uses a rolling-window approach, as discussed in Section 2. A dotted black line in each plot was included to enable easier comparison between plots. Figure 2, illustrates the fluctuating behaviour of the Hurst exponent for the hourly returns of Ethereum, Bitcoin, and Litecoin during the different market periods. Ethereum and Bitcoin Hurst exponent values follow a similar pattern during the bull and bear market. In contrast, Litecoin results look slightly different. Throughout the bull period, Ethereum and Bitcoin generated a Hurst exponent of around 0.5, with Ethereum being slightly higher than Bitcoin. However, at around 2700 lags (bull period), the value significantly drops to below 0.4 before correcting and fluctuating back to around 0.5. In general, a Hurst exponent close to 0.5 indicates that the series is more random and resembles a random walk. This suggests that hourly Ethereum and Bitcoin returns are relatively efficient during a bull market. During the bear market, Ethereum and Bitcoin exhibit an increasing trend in the Hurst exponent as lag times increase. This indicates that the returns of both cryptocurrencies experience long-term positive autocorrelation. For Litecoin, the pattern of the Hurst exponent during a bull market is very close to 0.5 for the first 3000 lags, which illustrates that returns follow a random walk. However, after 3000 lags, the Hurst exponent suddenly increases to a value over 0.6, suggesting persistent behaviour. During a bear market, Litecoin exhibits a similar pattern to Bitcoin and Ethereum, suggesting that the market experiences long-term positive autocorrelation. Overall, we can conclude that, during a bull market, cryptocurrencies exhibit random-walk behaviour. However, when a bear market occurs, returns start to show persistent positive autocorrelation behaviour (market inefficiency). These results are also in line with those of Wang and Yang (2010), who identified intraday market inefficiency in heating-oil and natural-gas energy future markets during bull-market states, but not during bear markets. 

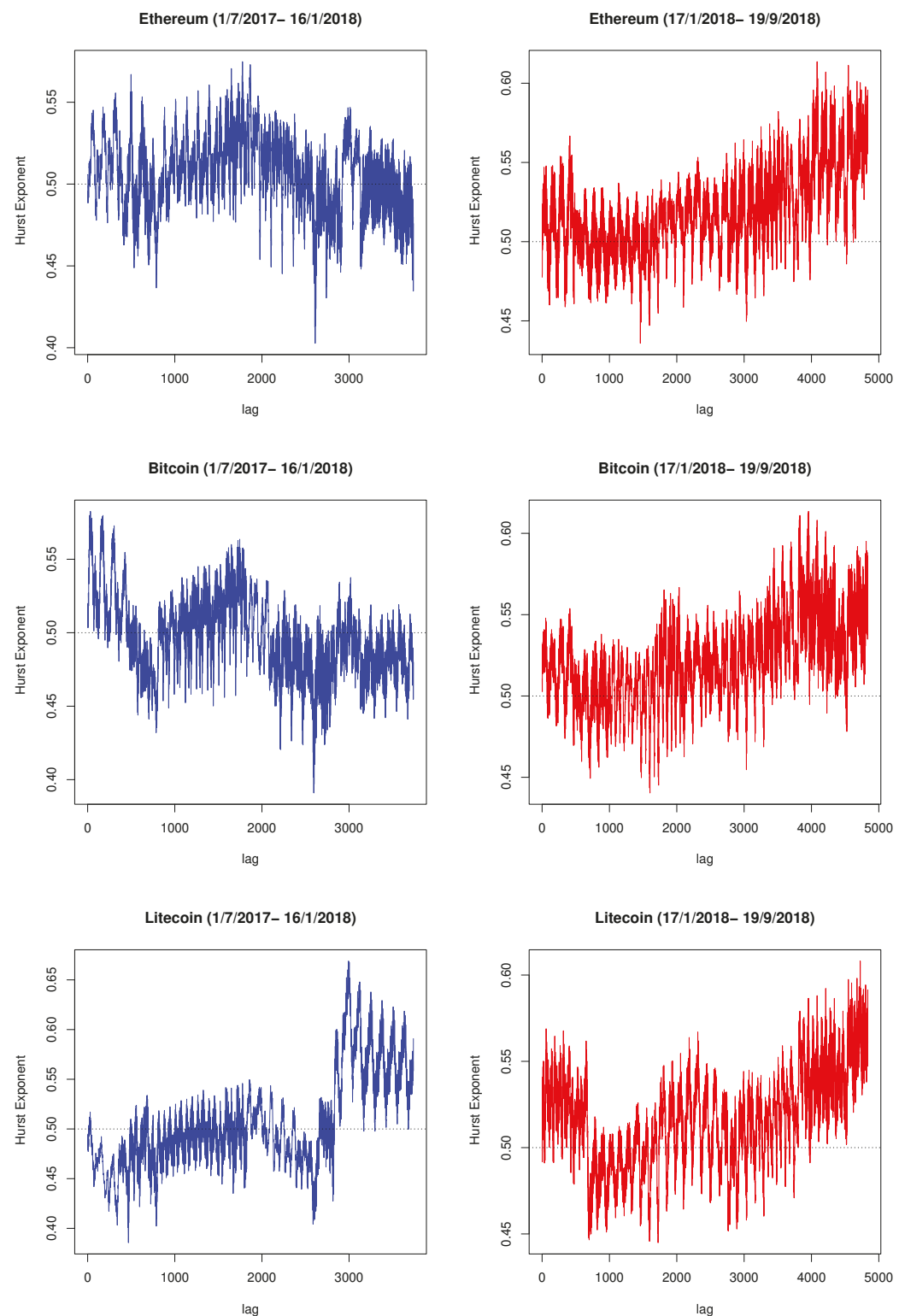

Figure 2. Plots of Hurst exponent of high-frequency $1 \mathrm{~h}$ log returns of (top left, top right) Ethereum, (middle left, middle right) Bitcoin, and (bottom left, bottom right) Litecoin using a sliding window of 720 lagged data points. Bull and bear markets indicated by blue and red lines, respectively.

A contrast in results from both methods during the bull-market phase could be interpreted in the following way. Analysis involving the Hurst exponent utilises a rolling-window approach; during these individual rolling windows (subsamples of a specific size) within the bull market, the cryptocurrency market had actually steadily grown with investors gradually entering the market, thus leading to an efficient-market phenomenon. However, if we look at the overall picture of the bull-market phase, 
we see the market significantly rises; when considering the method that uses a fixed sample period, this appears to create an inefficient market. On the contrary, during the bear-market phase, the price consistently decreased throughout the whole period, which may have caused panic and irrational trading by investors, leading to a downward spiral in market prices, resulting in market inefficiency.

The actual methods and tests used here could also lead to result divergence due to the difference in tested samples in each case. For example, methods such as the Ljung-Box, Runs, and Bartels tests analyse all bull-/bear-market phase data as one, as opposed to the DFA method that analyses dynamic rolling data windows from the bull-/bear-market periods. In other words, the size of the samples analysed by the DFA method is smaller, but data points vary, while samples used in general tests are larger and data are fixed. Therefore, it is possible that the DFA method picks up variations within particular subsamples of return data (thus affecting results relating to market efficiency), which may be masked when considering bull-/bear-market samples as a whole. Furthermore, our results illustrate that, in a bear market, hourly Bitcoin returns become more liquid during this period of market inefficiency. In contrast, hourly Ethereum and Litecoin returns exhibit less liquidity in this period.

Here, we only tested the hypothesis of market efficiency through a range of different tests (including classical tests and the DFA method). We cannot claim that the DFA is better or more trustworthy, but results of DFA analysis suggest that the level of market efficiency is different in bull and bear markets. Although the Hurst exponent (as a proxy for market efficiency) shows general trends in bull and bear markets, there are shorter-term changes that are also captured, likely due to the rolling-window approach. One could run the classical tests over different sample periods, but a problem that remains is that classical tests only generate a $p$-value. This $p$-value only gives us an indication of whether we can reject or fail to reject the null hypothesis of tests for properties such as independence, autocorrelation, and random walk. This is in contrast to DFA analysis, which not only gives us a numerical value indicating deviations from market inefficiency, but could provide further information, such as trend-reinforcing or antipersistence behaviour.

\section{Conclusions}

We provided the first analysis for detecting bull and bear markets for the three largest cryptocurrencies of Bitcoin, Ethereum, and Litecoin in high-frequency (hourly) markets using algorithms on the basis of Lunde and Timmermann (2004) and Bry and Boschan (1971). Results from Section 4 showed that hourly returns of Ethereum, Bitcoin, and Litecoin during a bull market exhibited a random walk (market efficiency) when using a rolling DFA Hurst exponent test. However, when conditions changed and the market entered a bear-market period, we saw signs that the market started to show persistence positive autocorrelation behaviour (market inefficiency).

In addition, we utilised six different tests to investigate market efficiency using a nonrolling fixed period. During the bull- and bear-market periods, the hourly returns of the three cryptocurrencies exhibited market inefficiency.

Similar results could be seen for other financial markets, for example, Gil-Alana et al. (2018) noted that the Baltic stock market rejected the theory of market efficiency during bull- and bear-market states; Jiang and Li (2019) investigated market efficiency for the Chinese, Japanese, and U.S. stock markets, and found market inefficiency in bull- and bear-market states. Furthermore, the Amihud illiquidity ratio illustrated that, in a bear market, hourly Bitcoin returns become more liquid. In contrast, hourly Ethereum and Litecoin returns exhibit less liquidity in this period compared to during a bull-market period.

In addition, we saw that volatility of hourly returns of all three cryptocurrencies decreased during a bear market. There is much scope for future work, and possible extensions could include: (i) focusing not only on hourly, but also higher-frequency data (minutes) due to movement towards higher-frequency cryptocurrency trading; (ii) further investigations into how these results for bull and bear markets could be used for arbitrage or trading strategies, for example, if there is inefficiency in the market during particular periods, if we could use market properties to monitor and predict 
when it would be the best time to buy or sell; (iii) investigate how to define bull and bear periods in a high-frequency market. Theoretically, there are many short bull- and bear-market periods within our two subsamples, so this may be more useful if we are considering trading at a higher-frequency level.

Author Contributions: Conceptualization, Y.Z.; Methodology, H.S., S.C., J.C. and Y.Z.; Software, Y.Z., and J.C,.; Validation Y.Z.; Formal Analysis, H.S., S.C., J.C. and Y.Z.; Investigation, H.S., S.C., J.C. and Y.Z.; Resources, H.S., S.C., J.C. and Y.Z.; Data Curation, H.S., and Y.Z.; Writing-Original Draft Preparation, H.S., S.C., J.C. and Y.Z.; Writing-Review \& Editing, H.S., S.C., J.C. and Y.Z.; Visualization, H.S., S.C., J.C. and Y.Z.; Supervision, S.C., and J.C.; Project Administration, Y.Z. All authors have read and agreed to the published version of the manuscript.

Funding: This research received no external funding.

Conflicts of Interest: The authors declare no conflict of interest.

\section{References}

Amihud, Yakov. 2002. Illiquidity and stock returns: Cross-section and time-series effects. Journal of Financial Markets 5: 31-56. [CrossRef]

Alvarez-Ramirez, Eduardo Rodriguez, and Carlos Ibarra-Valdez. 2018. Long-range correlations and asymmetry in the Bitcoin market. Physica A: Statistical Mechanics and its Applications 492: 948-55. [CrossRef]

Bariviera, Aurelio F. 2017. The inefficiency of Bitcoin revisited: A dynamic approach. Economics Letters 161: 1-4. [CrossRef]

Bartels, Robert. 1982. The rank version of von Neumann's ratio test for randomness. Journal of the American Statistical Association 77: 40-46. [CrossRef]

Baur, Dirk G., Kihoon Hong, and Adrian D. Lee. 2018. Bitcoin: Medium of exchange or speculative assets? Journal of International Financial Markets, Institutions and Money 54: 177-89. [CrossRef]

Briere, Marie, Kim Oosterlinck, and Ariane Szafarz. 2015. Virtual Currency, Tangible Return: Portfolio Diversification with Bitcoin. Journal of Asset Management 16: 365-73. [CrossRef]

Bry, Gerhard, and Charlotte Boschan. 1971. Front matter to "Cyclical Analysis of Time Series: Selected Procedures and Computer Programs". In Cyclical Analysis of Time Series: Selected Procedures and Computer Programs. Cambridge: NBER. p. 13-2. [CrossRef]

Carbone, Anna, Giuliano Castelli, and H. Eugene Stanley. 2004. Time-dependent Hurst exponent in financial time series. Physica A 344: 267-71. [CrossRef]

Chan, Stephen, Jeffrey Chu, Saralees Nadarajah, and Joerg Osterrieder. 2017. A statistical analysis of cryptocurrencies. Journal of Risk and Financial Management 10: 12.

Chu, Jeffrey, Saralees Nadarajah, and Stephen Chan. 2015. Statistical analysis of the exchange rate of Bitcoin. PLOS ONE 10: e0133678.

Chu, Jeffrey, Yuanyuan Zhang, and Stephen Chan. 2019. The adaptive market hypothesis in the high frequency cryptocurrency market. International Review of Financial Analysis 64: 221-31. [CrossRef]

CryptoCompare. 2018. CryptoCompare API. Available online: https://www.cryptocompare.com/api/ (accessed on 5 January 2019).

Durlauf, Steven N. 1991. Spectral based testing of the martingale hypothesis. Journal of Econometrics 50: 355-76. [CrossRef]

Escanciano, J. Carlos, and Ignacio N. Lobato. 2009. An automatic portmanteau test for serial correlation. Journal of Econometrics 151: 140-49. [CrossRef]

Malkiel, Burton G., and Eugene F. Fama. 1970. Efficient capital markets: A review of theory and empirical work. The Journal of Finance 25: 383-417.

Grau-Carles, Pilar. 2000. Empirical evidence of long-range correlations in stock returns. Physica A: Statistical Mechanics and Its Applications 287: 396-404. [CrossRef]

Gil-Alana, Luis A., Rangan Gupta, Olanrewaju I. Shittu, and OlaOluwa S. Yaya. 2018. Market efficiency of Baltic stock markets: A fractional integration approach. Physica A: Statistical Mechanics and Its Applications 511: 251-62. [CrossRef]

Glaser, Florian, Kai Zimmermann, Martin Haferkorn, Moritz Christian Weber, and Michael Siering. 2014. Bitcoin-Asset or Currency? Revealing Users' Hidden Intentions. Revealing Users' Hidden Intentions (April 15, 2014). London: ECIS. [CrossRef] 
Grech, Dariusz, and Zygmunt Mazur. 2004. Can one make any crash prediction in finance using the local Hurst exponent idea? Physica A 336: 133-45. [CrossRef]

Jiang, Jinjin, and Haiqi Li. 2019. A new measure for market efficiency and its application. Finance Research Letters. [CrossRef]

Jiang, Yonghong, He Nie, and Weihua Ruan. 2018. Time-varying long-term memory in Bitcoin market. Finance Research Letters 25: 280-84.

Kim, Jae H. 2009. Automatic variance ratio test under conditional heteroskedasticity. Finance Research Letters 6: 179-85. [CrossRef]

Khuntia, Sashikanta, and J. K. Pattanayak. 2018. Adaptive market hypothesis and evolving predictability of bitcoin. Economics Letters 167: 26-28. [CrossRef]

Kristoufek, Ladislav. 2013. BitCoin meets Google Trends and Wikipedia: Quantifying the relationship between phenomena of the Internet era. Scientific Reports 3: 3415. [CrossRef]

Ljung, Greta M., and George E. P. Box. 1978. On a measure of lack of fit in time series models. Biometrika 65: 297-303. [CrossRef]

Lunde, Asger, and Allan Timmermann. 2004. Duration dependence in stock prices: An analysis of bull and bear markets. Journal of Business \& Economic Statistics 22: 253-73. [CrossRef]

Matos, José A. O., Sílvio M. A. Gama, Heather J. Ruskin, Adel Al Sharkasi, and Martin Crane. 2008. Time and scale Hurst exponent analysis for financial markets. Physica A 387: 3910-15. [CrossRef]

R Development Core Team. 2019. A Language and Environment for Statistical Computing: R Foundation for Statistical Computing. Vienna: R Development Core Team. [CrossRef] [PubMed]

Sapuric, Svetlana, and Angelika Kokkinaki. 2014. Bitcoin is volatile! Isn't that right? Paper presented at Business Information Systems Workshops, Lecture Notes in Business Information Processing, Larnaca, May 22-23, pp. 255-65. [CrossRef]

Tiwari, Aviral Kumar, R. K. Jana, Debojyoti Das, and David Roubaud. 2018. Informational efficiency of Bitcoin-An extension. Economics Letters 163: 106-9.

Wald, Abraham, and Jacob Wolfowitz. 1940. On a test whether two samples are from the same population. The Annals of Mathematical Statistics 11: 147-62. [CrossRef]

Wang, Tao, and Jian Yang. 2010. Nonlinearity and intraday efficiency tests on energy futures markets. Energy Economics 32: 496-503.

Zhang, Wei, Pengfei Wang, Xiao Li, and Dehua Shen. 2018a. Some stylized facts of the cryptocurrency market. Applied Economics 50: 5950-65.

Zhang, Yuanyuan, Stephen Chan, Jeffrey Chu, and Saralees Nadarajah. 2018b. Stylised facts for high frequency cryptocurrency data. Physica A: Statistical Mechanics and Its Applications 513: 598-612. [CrossRef]

(C) 2020 by the authors. Licensee MDPI, Basel, Switzerland. This article is an open access article distributed under the terms and conditions of the Creative Commons Attribution (CC BY) license (http:/ / creativecommons.org/licenses/by/4.0/). 


\title{
Review
}

\section{A Cryptocurrency Spectrum Short Analysis}

\author{
Mircea Constantin Șcheau ${ }^{1}$, Simona Liliana Crăciunescu ${ }^{2}$, Iulia Brici ${ }^{3}$ and \\ Monica Violeta Achim ${ }^{3, *}$ \\ 1 Faculty of Automation, Computers and Electronics, University of Craiova, 200585 Craiova, Romania; \\ mircea.scheau@edu.ucv.ro \\ 2 Simona Liliana Crăciunescu, The Bucharest University of Economic Studies, 010374 Bucharest, Romania; \\ liliana.craciunescu@gmail.com \\ 3 Faculty of Economics and Business Administration, Babeș-Bolyai University, 400591 Cluj-Napoca, Romania; \\ iulia.brici@econ.ubbcluj.ro \\ * Correspondence: monica.achim@econ.ubbcluj.ro
}

Received: 30 June 2020; Accepted: 11 August 2020; Published: 17 August 2020

\begin{abstract}
Technological development brings about economic changes that affect most citizens, both in developed and undeveloped countries. The implementation of blockchain technologies that bring cryptocurrencies into the economy and everyday life also induce risks. Authorities are continuously concerned about ensuring balance, which is, among other things, a prudent attitude. Achieving this goal sometimes requires the development of standards and regulations applicable at the national or global level. This paper attempts to dive deeper into the worldwide operations, related to cryptocurrencies, as part of a general phenomenon, and also expose some of the intersections with cybercrime. Without impeding creativity, implementing suggested proposals must comply with the rules in effect and provide sufficient flexibility for adapting and integrating them. Different segments need to align or reposition, as alteration is only allowed in a positive way. Adopting cryptocurrency decisions should be unitary, based on standard policies.
\end{abstract}

Keywords: cryptocurrencies; fraud; algorithms; correlations; impact; risks; regulation; blockchain

\section{Introduction}

In the area of influence of computer science, the terms undergo rapid mutations, both in sense and interpretability. Even if some have ephemeral appearances, those supported by well-defined reasons are assimilated and reclassified or regrouped, their similarities widening the spectrum of understanding the phenomenon.

According to a study by Data Bridge Market Research based on data from 2015 to date, without considering an a priori order, the top 10 cloud technologies that dynamically divide most of their market shares refer to Hybrid Cloud, Cloud Storage, Cloud Migration Services, Cloud Orchestration, Platform-As-A-Service, Disaster Recovery-As-A-Service, Multi-Cloud Management, Video-As-A-Service, Cloud Analytics, and Wi-Fi-As-A-Service. We do not estimate that the debate regarding the benefits and vulnerabilities introduced by modern storage and processing facilities, compared to traditional structures, will stop at any time soon. Perhaps a mixed architecture is a valid compromise until a new viable alternative emerges. Until then, we can only monitor adoption and note that financial organizations are more focused on saving and processing information in the cloud $(96 \%)$, according to cybersecurity expert Ryan Brooks. In some instances (34\%), there was a declarative improvement in the IT infrastructure security, while for others it worsened $(22 \%)$ or reported no change (31\%). Overall, $88 \%$ agreed to transfer sensitive data to the cloud, while $47 \%$ advocated a cloud-first approach.

These references can be correlated with those reported by Dan Williams, senior cybersecurity systems engineer, regarding ransomware. His 2017 statistics indicated a total of 9.2 billion global 
attacks, a $101 \%$ increase in the number of developed variants; only $42 \%$ of companies managed to restore their databases using backups, and Petya was the most common malicious product during an email campaign.

We estimate that the connection between cloud, cyber-crime, and cryptocurrency is getting stronger, and the distributed consequences are directly proportional to the evolution graph of each one. Analog and inductive research methods are very well suited to the subject, and we believe that the reason-effect ratio and adjustable inflection points can be expressed with sufficient clarity by changing the parameters.

Cryptocurrencies feature both benefits and disadvantages. The subtle way in which they appear is the main reason why they have made changes in the financial market. This is where the most significant threats come from, specifically cybercriminal activities that are becoming easier to carry out. Additionally, blockchain technology can produce changes in various fields of activity, as long as there is no superior technology to challenge it. For this reason, careful study of cryptocurrency issues is an essential step in both economics and research.

The purpose of this research is to explain what cryptocurrency is, how important it is, how it has evolved, what its use brings to the economy, and what influence cryptocurrency has on cybercrime. This paper focuses more on the arguments, connections, implications, risks, algorithms, regulation, and standardization, and less on the technical aspects of blockchain, block of blocks, or multichain.

Deliberations on the advantages and disadvantages in this direction have been made and will probably continue to be the subject of other specialized studies for a long time. We can say that an optimum is identified if it responds positively to the evaluation criteria.

\section{Literature Review}

To define cryptocurrency and its role, conceptual aspects related to virtual currencies are available in the literature review section.

Cryptocurrency emerged around 2014 along with the FinTech concept, and it is now a part of the larger digitalization process. Up to 2018, the literature has revolved around the concept of cyptocurrency and diversified classification. However, post-2018, authors have chosen fascinating niches of the literature.

In 2019, Corbet et al. (2019) mentioned cryptocurrencies as a financial asset. The paper presented a review of the literature from an empirical point of view of the aspects associated with cryptocurrency as a financial asset, since its appearance. Based on previous papers, the author chose the topic of cryptocurrency because of existing questions about market efficiency, asset pricing bubbles, contagion, and decoupling hypotheses or volatility clustering. Situated at the intersection between regulatory oversight, the potential for illicit use through its anonymity within a young under-developed exchange system and infrastructural breaches influenced by the growth of cyber criminality, the role of cryptocurrency proves to be influenced by each of these. Furthermore, in 2019, Bouri et al. (2019) studied the similar movements of cryptocurrencies. They set Bitcoin as the reference currency and discovered the presence of concurrent movements, in the same direction, of 12 types of cryptocurrencies. As a basis for research, they used daily data on the price of cryptocurrencies. The study found that the movement of one cryptocurrency determines, in a large proportion, the movement of other cryptocurrencies in the same direction. The process is called co-jumping. The study concluded that their trading volume highlighted the volatility of cryptocurrencies.

In 2019, Chu et al. (2019) investigated the adaptive market hypothesis regarding the markets of two popular cryptocurrencies (Bitcoin and Ethereum) against the Euro and the U.S. dollar where the results were consistent with this theory. The authors also discussed that events could coincide with significant changes in market efficiency. The sentiment of these market efficiency factors was verified using a simple analysis of events to investigate whether these actions affected market efficiency/inefficiency. The bottom line is that sentiment and events cannot be a significant factor in determining the effectiveness of cryptocurrency markets. The collected data involved logged hours 
with high-frequency Bitcoin and Ethereum prices against the Euro (EUR) and the U.S. dollar (USD). It followed transactions listed on the Kraken cryptocurrency exchange starting 11:00 a.m. on 1 July 2017 until 12 a.m. on 1 September 2018. The particular timespan was selected so that we could analyze the intervals in which prices for the two cryptocurrencies faced huge spikes (before January 2018) and slumps (after January 2018). The results appeared to be consistent with the hypothesis, where the efficiency of the markets varied over time.

In 2018, Zhang et al. (2018) also wrote about the 'stylized facts.' Cryptocurrencies were investigated as a financial asset. They analyzed the stylized facts in terms of the Hurst exponent by using the Detrended Fluctuation Analysis (DFA) and R/S Analysis, of the four most popular cryptocurrencies ranked according to their market capitalization. The datasets contained historical high-frequency prices of those cryptocurrencies versus the U.S. dollar, from 25 February until 17 August 2017. The top four chosen cryptocurrencies for our analysis involved Bitcoin, Ethereum, Ripple, and Litecoin. The study was conducted on high-frequency returns data with varying lags. It also considered features of dependence between the different cryptocurrencies. These features provide academics and industrial practitioners with information about the structure and characteristics of these four popular cryptocurrencies and may also be useful in developing models of pricing cryptocurrencies.

Other authors such as $\mathrm{Xu}$ et al. (2019) have measured the tail-risk interdependence between 23 cryptocurrencies using previous methods. They estimated the value at risk (VaR) for each cryptocurrency by using quantile regression, also called the Tail-Event driven NETwork (TENET) framework. With the help of this study, it was identified that a significant risk spillover effect exists and that the degree of the total connectedness of all the sampled cryptocurrencies increased steadily over time. Bitcoin seems to be the most significant systemic risk receiver, and Ethereum the largest systemic risk emitter. Like Bouri did, Grobys also developed a study in (Grobys et al. 2019) based on the daily data of the price of cryptocurrencies. This time, their processing involved determining the moving average trading strategies employ. The 11 most traded currencies from 2016-2018 were used for this purpose. The result indicated that a variable moving average strategy is successful when using a 20-day moving average trading strategy. In addition, the results revealed that cryptocurrency markets were inefficient. Another study by Corbet et al. (2020) showed the destabilizing effects of cryptocurrency and cyber criminality. The purpose of the article was to discover what the financial market effects of recent cybercrime were in cryptocurrency markets. Corbet used data from the Bitfinex exchange at a 60-min frequency for the eight most liquid cryptocurrencies. The results led to the conclusion that hacking events also increased both the price volatility of the targeted cryptocurrency and cross-cryptocurrency correlations. Cybercrime events reduce the price discovery sourced within the hacked currency relative to other cryptocurrencies. In 2019, Koerhuis et al. (2019) conducted a forensic analysis of privacy-oriented cryptocurrencies and found that criminals used cryptocurrencies that had built-in anonymity and privacy features that made them nearly impossible to trace funds back to a particular user in different kinds of malware to launder money. The author investigated Monero and Verge and studied which valuable forensic artifacts the software of these cryptocurrencies left behind on a computer system. Different sources of potential evidence were also examined in this paper.

In another article, Caporale et al. (2019) wrote about non-linearities, cyber-attacks, and cryptocurrencies. For this purpose, he used a Markov-switching non-linear specification to analyze the effects of cyber-attacks on the returns of four cryptocurrencies from 2015 to 2019 . The analysis considered cyber-attacks and targeting cryptocurrencies. The results suggest the existence of the significant adverse effects of cyber-attacks on the probability of cryptocurrencies staying in the low volatility regime. This reveals the importance of knowing how to deal with cybercriminals to prevent the disruptions of the markets.

\section{Standardization and Regulations}

A report elaborated by The Law Library of Congress, Global Legal Research Center, Staff of Global Legal Research Directorate (2018) examines the legal, political, and fiscal landscape regarding the 
regulated status (or not) of cryptocurrencies in over 100 countries and notes that the terminology of addressing (and implicitly of perceiving cryptocurrencies) differs from one jurisdiction to another (Figure 1). In Taiwan, China, and Canada, cryptocurrencies are seen and described as a virtual commodity; in Mexico and Honduras as a virtual asset; in Thailand and Argentina as digital currency; in Lebanon and Colombia as electronic currency; in Italy as cyber currency; in Switzerland as token payment; in Germany as a crypto-token, etc. The approach is different and reflects the acceptance decisions (or not) as a means of payment or taxation method. For example, Switzerland taxes cryptocurrencies as foreign currency, while in Israel, they are assets. If some jurisdictions impose direct or indirect restrictions (e.g., by financial restriction) on investments in cryptocurrencies, others prohibit citizens from engaging in activities at the local level, but not abroad.

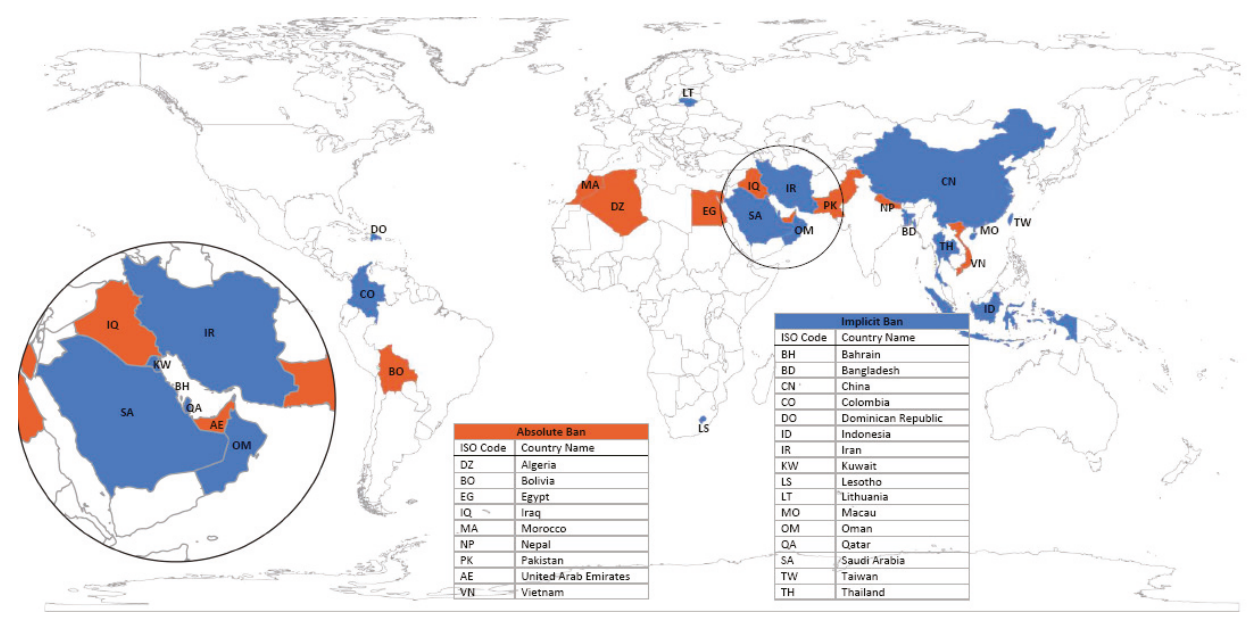

Figure 1. Legal status of cryptocurrencies. Source: Staff of Global Legal Research Directorate (2018).

The European Central Bank and the national central banks may also open accounts for participating credit institutions or public entities according to national regulations for insurance companies or other parties involved in the transaction or transfer process (Zellweger-Gutknecht 2018). One of the challenges generated by the desire to regulate cryptocurrencies brings to the forefront the need to combat money laundering, which is focused on combating terrorism financing while monitoring illegal markets (e.g., drug trafficking, trafficking in human beings, etc.). Another challenge refers to rules concerning securities and consumer and investor protection guidelines. Regulatory boundaries need to take into account concrete realities, in which the delimitation of responsibilities of various authorities from the jurisdiction point of view related to cryptocurrencies is rather unclear. Central banks adopt a prudential policy, capitalizing on digital technologies in the direction of saving resources. Distributed Ledger Technology components apply inter alia to the Central Bank Digital Currency (CBDC) and therefore must be modeled on authorized protocols. The design should include options for reserve convertibility to support day-to-day liquidity, minimizing settlement risks (Bank for International Settlements 2018). In addition, the introduction of the CBDC as a guarantee, deposit facilitation for commercial banks, or the interest payable for individuals' holdings emphasizes fixing margins that are difficult to control. Taxation of profits earned by individuals or intermediary companies implies the existence of "monetary" legislation, tax provisions, and clear enforcement rules. The likelihood of correlation is rather low in terms of end-user anonymity, and it is virtually impossible to comply with the minimum Know Your Customer/Client (KYC) provisions, which are also necessary for risk assessment. Nevertheless, we are witnessing bold moves regarding the assimilation of Financial Technology and FinTech-blockchain into platforms dedicated to banking operations. The open architecture is designed 
to be flexible and tailored to the needs of customers, with the digitized models in operation validating the avant-garde character (Erste Group 2018).

A new tendency, which was perhaps born out of the desire to eliminate one of the most disturbing factors, is to freeze values. It theoretically addresses players who do not have a high-risk appetite and who want to trade at default quotes. Anonymity is maintained, but parity is fixed in comparison with a widely-recognized financial standard. Specifically, the cryptocurrency is supported by an equivalent amount in one of the traditional currencies (e.g., dollar, euro, or Japanese yen) and may be deposited in an account. The native tokens trading under the USD symbol in 2014 were about twenty-five million units, with more than 2.5 billion units in circulation by the end of 2018. At the time of issue, a Tether was quoted at the value of one US dollar, and a Roncoin, built on the Ethereum blockchain platform, was rated at the cost of one Romanian RON. Tether allows for dollar-like operations without a bank connection and can be converted into another cryptocurrency, with leverage in manipulating quotes. 'Scheduled' Tether issuing and the acquisition of cryptocurrencies almost always have a strong effect on stabilizing or raising prices, with massive reconversion leading to a controlled decline. Symmetrical or asymmetric correlations were carefully investigated, and the results were delivered in graphical form and tables (Griffin and Shams 2018) as clearly as possible.

In the same context, the idea of creating a decentralized cryptocurrency using blockchain technology, whose parity is in line with the global gold quote, has begun to emerge. More precisely, through the token process, AurusGOLD (AWG) was born. Each currency represents the equivalent of one gram of $99.99 \%$ pure gold at the London Bullion Market Association's accepted quotation. The cryptocurrency is claimed by promoters, some of whom have gained experience in specialized software firms in a country located at the intersection of Central, Eastern, and Southeast Europe, that it is designed to support market pullout at any time, supported $100 \%$ by physical gold, and that the storage and securing of the precious metal is in line with the international regulations in force including those on the payment of taxes. The debate aims at the direct convertibility of gold-cryptocurrency, under the conditions of a regulatory vacuum in this area and predictability placed under the sign of doubt (BitScreener 2018). Regardless of the asset attempted for anchor, manipulation is present in several forms, with one or more powerful players having the ability to force the platforms. Making seemingly valid operations without real holdings through scheduled robots and exploiting hourly intervals has revealed new market vulnerabilities, which are responsive to false messages and fraudulent transactions. Even though the material treated rigorously, with extensive robustness checks, addresses the Bitcoin ecosystem, the evaluation can easily be extrapolated to the crypto phenomenon generally, or to any other cryptocurrency in particular (Gandal et al. 2018).

In the report submitted for analysis in July 2018 to the G20 (Group of Twenty, International Forum set up in 1999), it was noted that the Financial Stability Board (FSB) has developed, together with the Committee on Payments and Market Infrastructures (CPMI), an identifying metrics frame to monitor transmission channel implications, exposure, growth rate, convertibility, volatility, transparency, accessibility, jurisdiction, and other elements that can influence the financial stability of cryptographic markets. CPMI pays special attention to payment innovations and provides assistance and advice in studying topics related to decentralized assets or support assets. The International Organization of Securities Commissions has developed a support platform for enrolled members to look into possible cross-border issues, investor protection, regulatory matters, etc. The question is whether the line of conduct designed for secondary markets is also pursued in this case, especially if we take into account critical issues related to custody, settlement, cybersecurity, and system integrity. As we have already said, the legal status of cryptocurrencies is quite unclear, and the weather variations in the quotes lead to changing the calculation coefficients. The terminology is somewhat fluid and indicates a focus on property regulation, with crypto-tokens being often equated with securities, instruments used to raise funds by representing a security or tangible asset, tangible things that can be held, or controlled (e.g., buildings, commodities, patents, etc.). New indicators refer to capital: the minimum required balance of reserves, custody, pledges, receivables, accounting records, private or property rights, 
transfer rights, assignment, future contracts, solvency, bankruptcy, etc. Are we finally discussing the regulation of goods, money, assets, financial instruments (e.g., promissory notes, checks, securities, etc.) or the regulation of commercial services?

The convertibility on demand of a cryptocurrency as a legal means of payment, the admissibility of cryptocurrencies and related products such as derivatives traded on stock exchanges (Auer and Claessens 2018) is one of the reasons why the Basel Committee on Banking Supervision quantifies direct and indirect exposure, monitors the evolution of FinTech's crypto-assets, and seeks to clarify prudential procedures from banks and supervisors. Respecting all the compliance rules is one of the stated goals, and the implementation of RegTech (Regulatory Technology) solutions aims to increase transparency and consistency, with the correct interpretation of ambiguous regulations, to impose the right level of quality.

Similarly, the Euro Cyber Resilience Board was created, a forum for cooperation between central banks, supervision institutions, and critical financial infrastructure providers, responsible fiscal policies and economic reforms being under discussion. Governance studies occupy an important place in the list of relevant concerns and are added to those dedicated to improving the financial transaction mechanics. Due to their high volatility, the crypto-assets should have an assigned risk weight around the minimum $1000 \%$ threshold, the weighting coefficients varying according to the nature of the crypto-asset. The financial market supervisory authorities will express the consensus within the Basel Committee by developing an international standard.

One thing is clear: international collaboration is essential in the successful imposition and enforcement of rules for combating tax evasion, money laundering, and terrorist financing. An initiative on a unified global regulatory framework must be supported by all official organizations involved such as the G20, the Egmont Group, the FATF or the UN Office on Drugs and Crime (Robby and Snyers 2018).

\section{Primary Analysis of Cryptocurrencies}

This section includes a proper analysis of cryptocurrencies, focusing on the structure, evolution, and volumes of virtual currency transactions.

According to a study made by Jeff Desjardins (2017) for Visual Capitalist, at the starting point of the cryptocurrency era, the total amount of money in the world between 2014 and 2015 was $\$ 90.4$ trillion and only about $8 \%$ of the money was in physical form. Initial Coin Offering (ICO) is regarded as part of a critical topic, closely related to the theme of cryptocurrencies and the blockchain, representing the main fund-raising mechanism for new projects and unique ideas. As we have already said, some can be a real success, and others may prove to be scams. In 2017, these ICOs benefited, based on service offerings or product offerings, from funding over $\$ 6.5$ billion for about 450 proposals, and in 2018, getting seven billion for just over 1000 projects.

According to the latest information provided by coinhouse.com (8 April 2020), from over 2000 !existing types of cryptocurrency, Bitcoin holds the market majority, as can be seen in Figure 2, totaling $64.55 \%$.

In terms of $24 \mathrm{~h}$ purchase volume, on May 2020, the ranking was slightly different, with Bitcoin ranking second under Tether with 56.16 trillion U.S. dollars (Figure 3).

According to the data (Figure 4), the vast majority of currencies move in the same direction as Bitcoin, with small variations over the same time frame. We can conclude that the significant events that affect Bitcoin's price, change in value, profitability, or investments also affect the entire market proportionally. To reinforce and also prove what we have already said, we present Figure 4, compiled with Thomson Reuters data, who has kept a record since 2012, way before cryptocurrency was on the rise, up to now (Figure 4). The movements made in almost the same direction were evident by observing the last three years of analysis. 


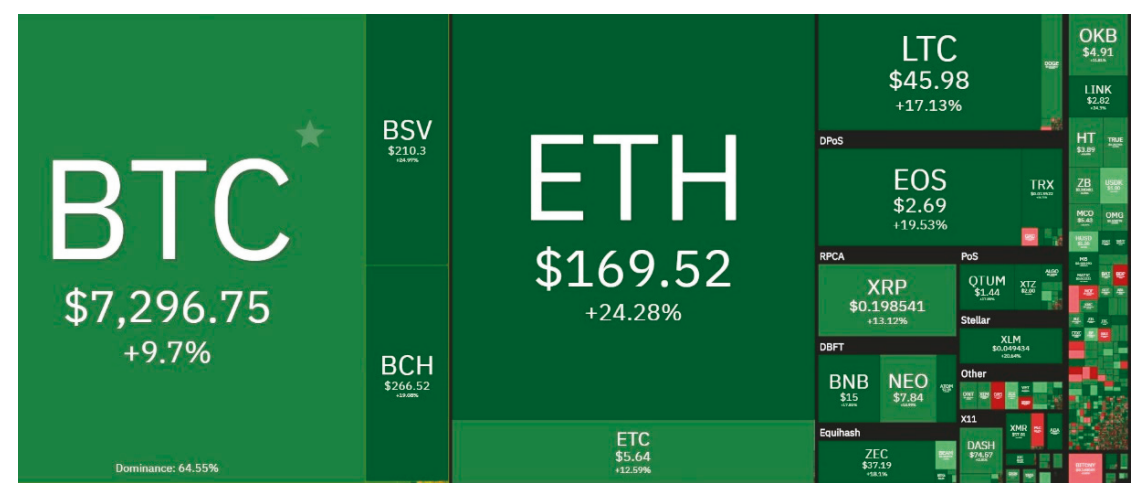

Figure 2. The share of cryptocurrencies in the world market in 2020. Source: coinhouse.com.

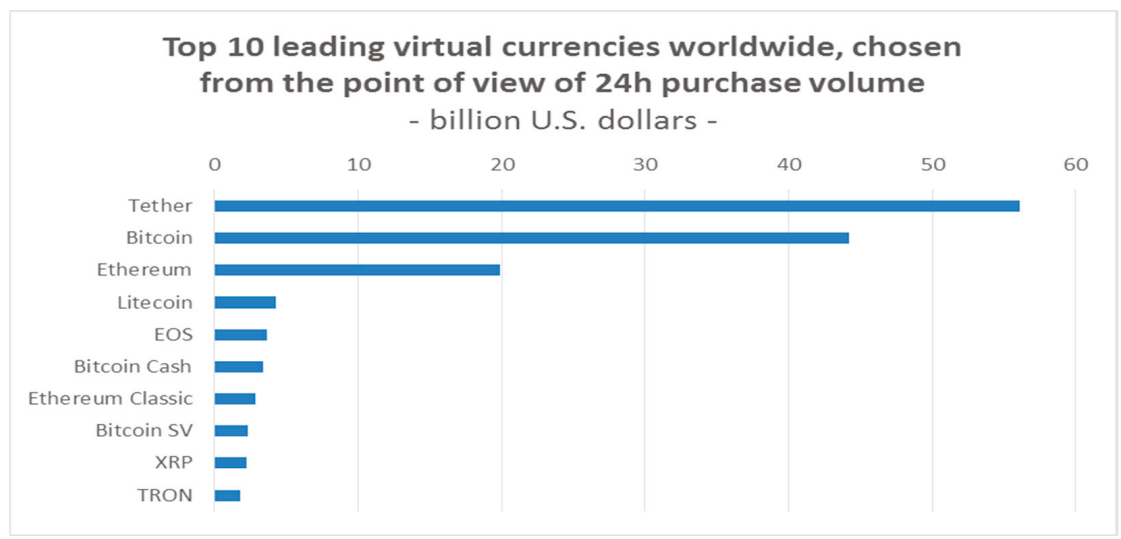

Figure 3. Top 10 leading virtual currencies worldwide. Source: Authors' own processing based on Statista data.

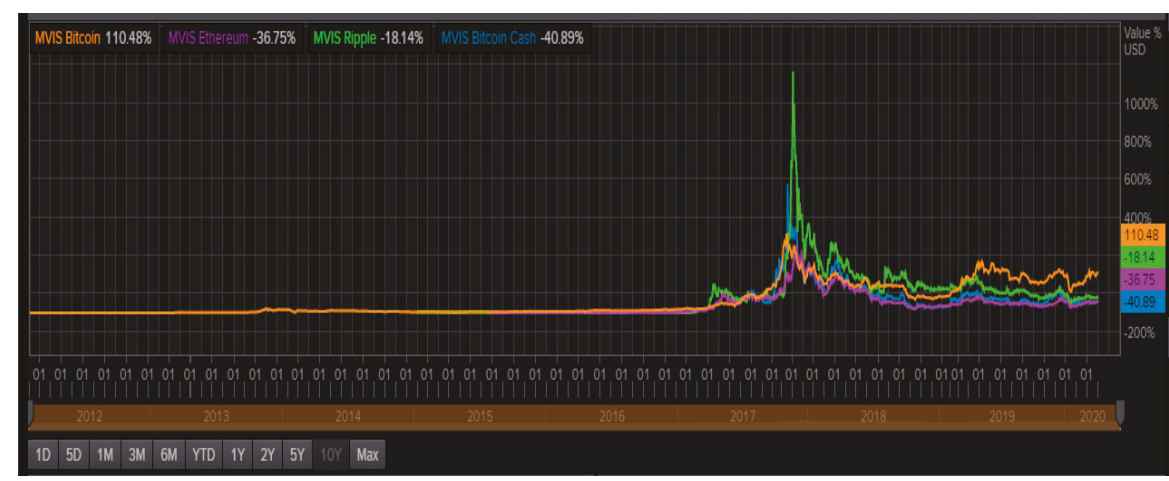

Figure 4. The evolution of worldwide cryptocurrencies, 2012-2020. Source: Authors' own processing based on Thomson Reuters data.

Continuously evolving since its appearance, the price of Bitcoin reached an unprecedented peak in 2017. Then, at the beginning of 2018, more precisely, on January 4, came the phenomenon known as the Great Crypto Crash (Figure 5). For about one month, as a consequence of this event, the price of 
Bitcoin fell sharply by about $65 \%$. That moment highlighted, more than ever, that the movements of Bitcoin are followed by the other cryptocurrencies, which reached declines of up to $80 \%$.

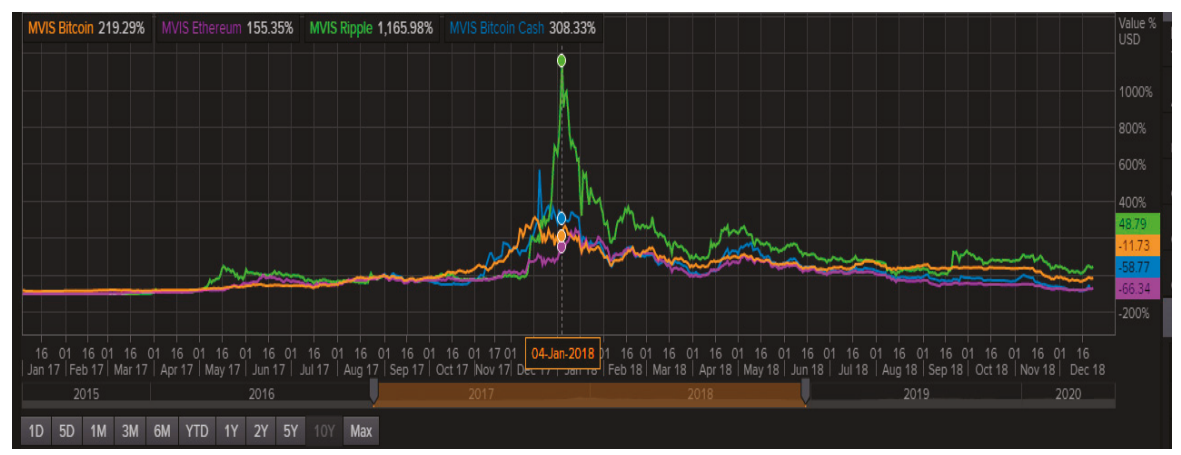

Figure 5. The Great Crypto Crash. Source: Authors' own processing based on Thomson Reuters data.

The correlation between the reference cryptocurrency, Bitcoin, and 12 other cryptocurrencies was described in Bouri's study (Bouri et al. 2019), which contained data recorded from 8 August 2015 to 28 February 2019. The highest positive correlation we could see was between the reference cryptocurrency and Litecoin (0.6178), and the weakest was between Bytecoin and Litecoin (0.0697).

\section{Influences of Cryptocurrencies on Cybercrime}

One of the main characteristics of cryptocurrencies-pseudo-anonymity or total anonymity-can be seen as a bridge to the criminal field, and cybercrime in particular. Haken is a consulting company that audits blockchain systems and more to discover vulnerabilities and fraud with service packages covering a large number of customer needs. Following analysis, a list of essential value frauds related to new or old ICOs is published on the blog, Monero being one of them because it trades in the dark web and uses a type of encryption that theoretically ensures $100 \%$ anonymity.

We can highlight Modern Tech, a Vietnamese company that developed an ICO and managed to raise funds for Pincoin of about $\$ 660$ million from over 32,000 people, and then disappeared from the market. Another example is Plexcoin, which capitalized $\$ 15$ million, and the administrators were fined by the Securities and Exchange Commission, arrested, and convicted. Building on a good marketing campaign, Benebit has attracted many investors and nearly \$3 million.

Established entities abuse the status of "online influencer", DJ Khaled, Floyd Mayweather, and Centratech, who accumulated more than \$32 million until discovered. Fifteen people have been arrested in Taiwan for an estimated $\$ 8.6$ million in fraud, promoting IBCoin, a currency that is strictly usable in adult industries.

Since the beginning of 2019, the legitimacy of two major ICOs-Neluns for $\$ 136$ million and Ruby-X for $\$ 1.2$ billion-has been investigated. The EOS project, which raised over $\$ 4$ billion, pushed the currency into the top 10 most important virtual currencies. EOS is a platform that supports decentralized applications, creating a more friendly environment for developers. CoinDesk statistics, the leading platform for the community of people interested in blockchain and cryptocurrencies) for 2018 indicated that an ICO could raise an average of $\$ 25$ million, with estimates that $11 \%$ of the total amount of money generated by ICOs each year would be scams, with losses amounting to about $\$ 250$ million in 2018 alone.

Another form of online scam related to cryptocurrencies is promoted in the Defense of the Ancients game (DOTA) players community, the Multiplayer Online Battle Arena video game developed and supported by Valve Corporation. Screensaver files for Windows sent through chats contained scripts that could modify the computer's configuration, record keyboard activities, and, implicitly, 
the credentials introduced. This method is also standard in other communities, so it is recommended that more attention is given, especially if the files have the SCR extension.

According to an article made by Kaspersky (2020), other common scams are imposter websites, which seem to look like the original ones. The 's' from 'https' in the link indicates the real website of a company. Another common way of cheating in this area is fake mobile applications. These are available in the App Store, and are difficult to detect. Many people have been victims of cryptocurrency transactions in such counterfeit applications. Usually, there is a misspelling in their name or the representative image of the brand is noticeably modified; very common are scams due to bad tweets or other social media updates. There are many impostors who claim to be well-known people and demand small amounts of money, but who never recover once you become trapped. Perhaps the most common scam are bad emails. We often receive emails from seemingly legitimate companies that want to invest in our digital currency. Through a simple search of the respective company, we can find out if the information is true or only someone trying to fool us, wanting to procure substantial funds from the movements that we allow them.

2019 was a year full of fraud and cybercrime where about $\$ 4.26$ trillion was stolen from cryptocurrency exchanges. The culprits go unpunished if they attack unsuspecting users. According to an article written in 2020 by Business Insider (2019), among the biggest scams was the exchange between BITPoint and the Japanese cryptocurrency with a resulting loss of 28 million dollars. Bitcoin, XRP, Ethereum, Litecoin, and Bitcoin Cash were stolen in this event.

Another event, which took place in May 2019, was the theft of 40 million dollars through an exchange with Binance. Even if no one expected such an event to take place, Binance could not stop the attack because the hackers who executed this scam were very well organized.

In June 2019, six people suspected of a \$27 million Bitcoin scam were arrested. The theft affected more than 4000 victims from 12 different countries. The method used was "typosquatting", which involves creating a fake online cryptocurrency to gain access to victims' Bitcoin wallets.

June also saw hackers obtaining XRP worth about $\$ 10$ million from GateHub users, and cybercriminals have compromised about 100 Ledger Led wallets.

Bitrue is a cryptocurrency exchange in Singapore that lost $\$ 4.2$ million in June 2019. Hackers bypassed the exchange's security system, thus exploiting a risk control issue.

Phishing is also present in the world of cryptocurrencies, with at least one clone for each ICO site. There is a need to set up official Internet traffic monitoring structures to remove fraudulent links in browser searches and social networking news as these methods are increasingly taking a toll by exploiting naivety, promising fabulous gains that are just a click away (Khatwani 2018 and PYMNTS 2018).

Two Israeli brothers were arrested after a three-year phishing scam. Meanwhile, the two stole $\$ 100$ million worth of cryptocurrency by attracting investors such as large companies, imitating cryptocurrency exchanges.

According to a study made by ZD Net (n.d.) in 2020, a total of 109 people involved in the PlusToken cryptocurrency fraud have been arrested in China. This cryptocurrency from South Korea was marketed as a high-yield investment opportunity for traders interested in cryptocurrencies. Investors have allocated funds in Bitcoin, Ethereum, and EOS. As a result of the scam, $\$ 3$ billion was taken from about four million users. The attack was also through phishing, but this time, chain phishing.

An article written in 2020 by AARP (2020) tells us that, in order not to be the victim of an unfortunate event like the ones above-mentioned, there are a few things to keep in mind. First, it is not appropriate to invest in virtual currencies whose functionality we do not understand. The purchase of virtual coins is not recommended following advice received from anonymous companies by email or advertising. It is also not recommended to invest money from a pension fund in cryptocurrencies. It is imperative to know not to share "private keys" that allow us to access the virtual currency, with anyone. 
According to an article written by CoinDesk (2020), a scam can be identified if we know a few tricks. If it is a website we have met before and promises instant returns for small crypto investments, it is definitely a scam.

The first step before using any cryptographic website is to contact a known third party. CoinDesk answers questions about cryptocurrencies and related scams.

Hackers use the image of celebrities to manipulate and fool people. On social networks, the original accounts have a blue check mark next to the name. Other accounts with the same name are held only by imposters.

If we have already sent money to a cryptocurrency wallet, it is probably gone. Scammers can easily withdraw funds by buying and selling cryptocurrency. If the wallet provider is notified, they can sometimes try to stop transfers, but this rarely works.

A very important thing is that anyone who says you can get rich quick only talks about themselves as such a thing cannot be generally true.

"The butterfly effect" leads to an artificial increase in demand, volumes, and premature maturation of the industry. As an example, according to speculation and analysis by market players and unconfirmed by the targeted managers, the financial platform for cryptocurrencies Bitforex became, within a few months of launching, one of the best rated virtual currency exchange platforms with a technique fraudulently known as "wash trading". To unmask the perturbators with uncertain intentions, they compared their online activity, the number of users, the number of unique visitors on the website, the number of social network subscribers combined with the volumes traded by them, reported at the same time in other top 10 markets. Concretely, if the volume traded by a user on the Bittrex trading platform in June 2018 was $\$ 280$, \$861 on the Binance exchange platform, and the BitForex volumes traded by a single user in a month were nearly $\$ 13,000$, the calculated figures have a source in https://coinmarketcap.com/, specifically the $24 \mathrm{~h}$ volume exchanges.

As a specific situation, in Romania, CoinFlux, one of the leaders in exchange services with volumes of over 185 million $€$, ceased to work as a result of an investigation into its actions carried out in 2018, with banks not allowing transfers to be carried out through bank accounts (e.g., Transilvania Bank, BRD-Groupe Société Générale, etc.). Still, applications such as Revolut or Mistertango can ensure debiting by way of bypassing the electronic wallet, converting the money into virtual currencies. Even if a contradiction with one of the main characteristics of the cryptocurrencies-anonymity-can arise, at the beginning of 2018, the National Agency for Fiscal Administration requested that the earnings from the trading of virtual coins be taxed, this being stipulated in Law no. 30/2019 of 10 January 2019 for the approval of Government Emergency Ordinance no. 25/2018 regarding the modification and completion of specific normative acts as well as for the approval of fiscal-budgetary measures, as published in Official Gazette no. 44 of 17 January 2019. One possible solution would be the source taxation of firms through which they are traded.

In this case, we cannot accurately determine how many Romanians have invested or invest in virtual currencies and in what amount. Referring to the approximate volume over the last six months of the RON transactions to the total volume of transactions in all other currencies over the past six months, we can see that 845.5 Bitcoins were purchased with RON on the LocalBitcoins market, with a daily average of 32.5 Bitcoins, out of a total of 18,070,900 Bitcoins traded, with a daily average of 72,280 Bitcoins recorded by platforms like Bitfinex, Coinbase, Kraken and so on. It follows that a percentage $\alpha=0.000468$ of the total volume of cryptocurrencies transactions is linked to the national currency. Of course, these estimates do not include the operations of the Romanians who chose to use euros, dollars, or other international exchange currencies, that is, the number of people who traded virtual currencies after calling for the exchange in another accepted currency as the reference currency and the double conversion rate applied to currency conversions. Figure 6 captures the interest in Bitcoin in Romania from the beginning of 2014 to the end of 2020. It can be noted that the evolution was similar to the worldwide one, the turning point of the Great Crash Crypto being felt at the same impact for Romania. 


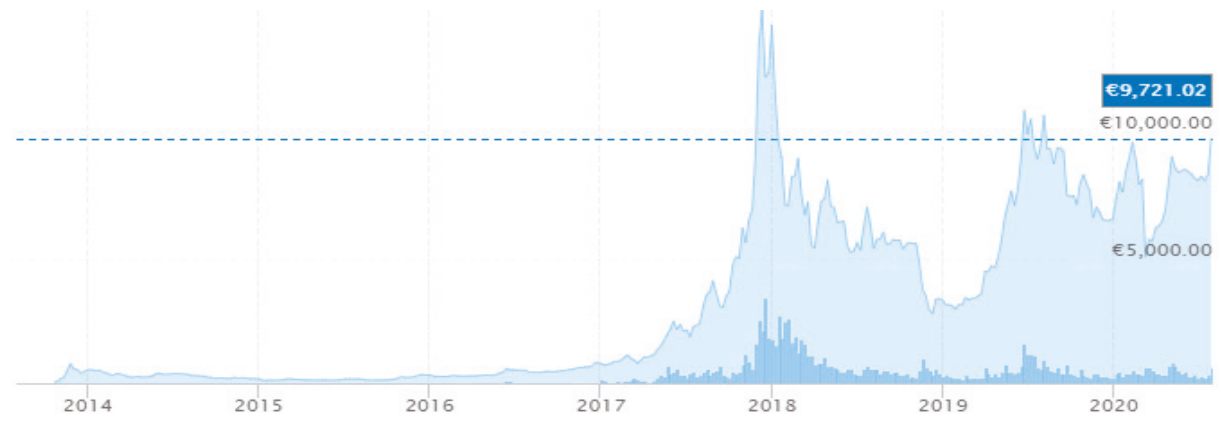

Figure 6. The evolution of Bitcoin in Romania, 2014-2020. Source: bitcoinromania.ro.

Metcalfe's law says that the value of a network is proportional to the square of the number of users connected to the system. Cryptocurrency networks can be compared to social networks, which means that the evolution value is directly proportional to engagement. More than $90 \%$ of Bitcoin movements can be explained by this law, using the square of the number of users and the average of transaction values performed. In the long run, this model may not be stable, since the number of users may vary considerably and the estimate for a large interval may not be in line with reality.

On the Coin Dance platform it is estimated that over $90 \%$ of the users are male, almost $50 \%$ aged between 25-34 years, confirming the wariness of older people against risk or innovation and the rapid assimilation of modern technologies by those younger, the phenomenon being considered an innovation trend of the Millennial generation, also known as Generation Y, which includes people born after 1980.

Positions regarding cryptocurrencies are different. Sweden and Denmark see a solution for storing values in the context of eliminating the physical currency. According to an article written in The Fintech Times (2018), Finland classified Bitcoin as a financial service and as a property in Australia.

A virtual currency regulated by a central bank is assumed to operate on the same principle as Bitcoin, with individuals or companies having a unique address for identification that is needed for transactions. The significant difference comes from banks and the other financial institutions agreeing that a central bank will hold the system (or the ledger), with the location where the transactions and the accounts are recorded. The currency distributed in this system may correspond to a traditional national currency (e.g., leu, euro, dollar) with the same status to maintain its value. Financial institutions would maintain their role in the economic system, through this method by replacing miners, known as people who keep the blockchain system up-to-date and investing computing power to solve cryptographic problems in exchange for new virtual currencies. Once transactions are confirmed, they become public, transparent, irreversible, and subject to audit.

The evolution of cryptocurrencies is generally dictated by quotes that reflect demand and offer for predefined periods. Of the more than 1000 virtual currencies that continually dispute their market shares, many disappear after launch. Others are supported by government bodies and are used declaratively as tools to regulate economic imbalances. Introducing and running them in financial circuits, like any other, facilitates routing to areas that are assimilated with cybercrime, money laundering, and financing terrorism, or to areas that make it possible to obtain undue profits. The connection between cryptocurrencies and ransom requests as a result of the ransomware attacks is no longer something unknown: only the methods change, but the goal remains the same.

This aspect is also highlighted by recent attack techniques, which consist of taking control by diverting or hijacking the mobile phone service and data transfer of one or more victims to devices managed by criminals without the knowledge or authorization of the account holder. Account synchronization gives almost total access to the fraudulent person to both mail, financial applications, and sensitive information that may affect privacy. Unique codes sent through SMS or delivered using 
automatic calls including authentication are available to persons other than those to whom they were legally intended. The monetization of information is generally subordinated to the anonymization principle and thus we cross into the cryptocurrencies assimilated as target elements or components of an exchange gear. On one of the online stores, several applications for cryptocurrency fake wallets, which mimic the original services pages, were loaded. Immediate removal measures were taken after referral, but the reasonably high availability of nearly twelve months facilitated more than five thousand installations.

This subject is approached from several perspectives, and manufacturers exploit its controversial side, software facilities, and filters made available by the latest devices covering a wide range of customer requests. The need for security is on the second level at the base of Maslow's pyramid and is strong at the time of an election. The security of the digital wallet or the desire not to be in any way involved in adjacent activities has made the segregation very clear, and the percentages appear in the marketing plans. With a smartphone, you can communicate, download apps, connect to various servers, and you can, of course, manage your "financial" resources. According to a study made by Gian Volpicelli for WIRED, a technology magazine from UK, in (Volpicelli 2018), the trend is toward a blockchain smartphone, but there are situations where the theft or destruction of the phone is equivalent to the loss of credentials and automatic loss of access to the virtual deposit. Rescue distributed on different physical or cloud compartments of different parts of encryption keys has become an alternative to maintaining on a chip in quarantine and promises to rebuild these in the event of an accident. The settings allow you to activate or block all of the operating functions.

Evolving to meet societal needs, money is associated with value. Otherwise, it would have just become a symbol represented by a piece of printed paper or a digital token. Economists identify money with a verifiable asset, one of the attributes being to act as an accounting unit without which buyers and sellers cannot measure the value of a good or service (Mersch 2018). Compared to the traditional system, cryptocurrencies have two significant limitations. One is the lack of scalability, and the other is the uncertainty about the end of the transaction, the fragmented or segmented nature of the markets introducing new complications. We face an apparent rigidity, a lack of flexibility of systems and of crypto-infrastructures as long as it is not guaranteed that payment is final and irrevocable. Officially, in the most permissive scenario, cryptocurrencies are perceived as transferable assets (Shin 2018), decentralized technology being a poor financial substitute, regarded indulgently as the golden nuggets obtained with much effort and very good luck in the middle of the nineteenth century and, in the case of more demanding approaches, they are categorized as a combination of a soap bubble, a Ponzi scheme, and an ecological disaster. A (speculative) bubble is interpreted as a deviation of the price of an asset from its fundamental value. The irrational investment snowball rolls at a rate high enough to send an alarm signal to intelligent investors and it can be said that addressing a regulation is "asymmetric paternalistic if it creates advantages for those committing errors, not imposing constraints on those who are fully rational" (Juurikkala 2012; Sherman 2018).

The Venn diagram (Bech and Garratt 2017) illustrates the four key-properties of money: the issuer (e.g., the central bank); the form (e.g., digital or physical); accessibility (e.g., broad or restricted); and technology (e.g., based on accounts or token).

To fulfill the mandate, which implies, among other things, the maintenance of financial stability, central banks have an active role in supervision and, in some cases, in the provision of the payment system infrastructure. Even though the "mass" of cryptocurrencies is rather low in weight and too small to be considered systemic, this can change, and public authorities are aware of the potential risks induced and the effect on resilience. The risk of manipulating and changing levels is quite high given that the presumed proportion of holdings is inversely proportional to the owners. The emergence of crypto-assets requires, among other things, political decisions. There are sensitive issues regarding the possible issuance of cryptocurrencies other than conventional digital currencies by central banks. It is implicitly necessary for a coordinated approach at the global level to prevent abuses and to limit interconnections with regulated financial institutions and the risk of contamination (e.g., immature 
technologies or superficial business models that can cause chain reactions) cannot be ignored. One of the members of the Executive Board of the European Central Bank noted the abundance of problems, and, in that context, it was pointed out that it is inappropriate to ignore the apparent coincidence of Bitcoin's launch period, a few months after the Lehman Brothers collapse in 2008.

Moreover, a particularly interesting study, already cited in the literature review (Corbet et al. 2019), draws attention to the increasing volatility of cryptocurrencies during periods of stress to the detriment of yield stability. The authors tried to highlight the destabilizing effects of cybercrime, the different ways in which quotations are affected, and the impact felt on prices. Some of the factors that influence the evolution of the market and the changes in the correlation between cryptocurrencies are dependent on informatic events (e.g., wallet hacking, computer frauds, etc.) and serious negative reputational events, which lead, among others, to a decrease in the level of investor confidence.

Views related to the term "money" may change, but we believe that one of the challenges will be in close connection to lending or guaranteeing, interest, and taxation services. In this research, Bascand presents his views related to this subject (Bascand 2018). Even though cash still occupies an essential share in the preference of the population and has proven its usefulness over several thousand years, it is not excluded to witness its reinvention in a digital form, but to impose itself, the functions fulfilled must bend over social constructions that call for the modification of technological frontiers. The time horizon is difficult to estimate. The form in which they will be incorporated into the banking system, if they are incorporated, will depend on the transformations dictated by the repositioning of financial bodies and the ability to synchronize. The dilemma is also strategic. There are few ways to recover your investment in the case of loss or destruction of credentials. Many packages remain locked and cannot be reintroduced into the circuit. They appear to be valid, but can no longer be traded, an inert mass whose percentage changes the indicators and graphs. The unstable degree of volatility over a day, and even more so for a longer period as well as a lack of correlation with the volume of officially unregistered holdings, influences any attempt of mathematical analysis. We believe that only one based on probability theory may approach the truth. However, one bold author has tried to formulate a fascinating model, but was limited by the terms taken into account and by the sources accessed (Kakushadze 2018). This is why we do not make any predictions in this study. However, we try to capture some essential arguments in motivating the steps meant to have the finality of transposing the proposals into standards and regulations.

\section{Conclusions}

To conclude our study, we highlight that the storage and processing of information spaces are at the forefront of the attackers' preferences, and there are gaps in regulations, similar to those in the cryptostream area. There are very few companies covering the risk of data corruption or compromising privacy, just as there are very few companies that provide the risk of volatility of cryptocurrencies. The fraudulent outflow of information packs, coupled with concerted intervention on quotations and counterfeiting of indicators, are possible attributes of manipulating a financial market. The term "financial market" may have different connotations, its influence being likely to manifest itself on one or more components of the set of values. Primary ingredients are to be dissolved to combat the complex, concentrated, or distributed effect. Therefore all evaluation steps should include an audit chapter, but it is impossible to foresee in the absence of precise, classifiable, input and output data.

Jurisdictional competencies or, more precisely, undefining them clearly, also induce constraints that should be eliminated. The link between cybercrime and cryptocurrencies is biunivocal, and therefore, the regulations in the field of cryptocurrencies must be harmonized with those in the field of cybercrime. The rights and responsibilities of international bodies need to be reviewed in the sense that they have the legal framework and the tools to allow them to intervene promptly to prevent, avoid, or counteract criminal slippage.

Distributed Ledger Technology has great potential to revolutionize the way activities can be coordinated and offers many benefits. However, the step from exploration to implementation must 
first be tested on the test environment and on models that allow for real-life simulation. All public or private entities should be interested in identifying the best forms of collaboration to ensure security and stability. The role of central banks in this context is decisive while encouraging competition and cooperation.

The contribution that we consider to bring to the literature of the studied field is the summary of what has been studied and a great opening of a new path to empirical studies related to the interferences between cryptocurrency and cybercrime. The approached topic lends itself to more detailed development, which is why it remains a topic of future research. Our study is limited by the lack of consolidated and verifiable data in the field of cryptocurrencies and especially in terms of the influence of cryptocurrencies in cybercrime. We intend to identify suitable methods in the future to substantiate our finding both in the study of the impact of cybercrime in the evolution of cryptocurrencies, and of the influence of cryptocurrencies in cybercrime.

Author Contributions: Conceptualization, M.C.S. and S.L.C.; Methodology, M.C.S. and S.L.C.; Formal analysis, I.B.; Investigation, M.C.S., I.B., and M.V.A.; Resources, I.B.; Data curation, M.C.S. and S.L.C. Writing-original draft preparation, M.C.S.; Writing—review and editing, M.C.S., I.B., and M.V.A.; Visualization, M.V.A.; Supervision, M.V.A.; Project administration, M.V.A.; Funding acquisition, M.C.S. All authors have read and agreed to the published version of the manuscript.

Funding: This work was supported by the grant POCU 380/6/13/123990, co-financed by the European Social Fund within the Sectorial Operational Program Human Capital 2014-2020.

Conflicts of Interest: The authors declare no conflict of interest.

\section{References}

AARP. 2020. Cryptocurrency Fraud. Available online: https://www.aarp.org/money/scams-fraud/info-2019/ cryptocurrency.html (accessed on 9 August 2020).

Auer, Raphael, and Stijn Claessens. 2018. Regulating Cryptocurrencies: Assessing Market Reactions. Basel: Bank for International Settlements Quarterly Review, September.

Bank for International Settlements. 2018. Promoting Global Monetary and Financial Stability. Annual Economic Report. Basel: Bank for International Settlements, June.

Bascand, Geoff. 2018. In Search of Gold: Exploring Central Bank Issued Digital Currency. Paper presented at The Point Conference, Auckland, New Zealand, June 26.

Bech, Morten, and Rodney Garratt. 2017. Central Bank Cryptocurrencies. Basel: Bank for International Settlements Quarterly Review, September, pp. 55-70.

BitScreener. 2018. Aurus.io, the Groundbreaking Startup Uses Blockchain to Create A Decentralized Global Standard Gold Currency. Press Release. February 15. Available online: https://bitscreener.com/news/aurus-io-thegroundbreaking-startup-uses-blockchain-to-create-a-decentralized-global-standard-gold-currency (accessed on 17 June 2020).

Bouri, Elie, Roubaud David, and Shahzad Syed Jawad Hussain. 2019. Do Bitcoin and Other Cryptocurrencies Jump Together? The Quarterly Review of Economics and Finance. [CrossRef]

Business Insider. 2019. Top Cryptocurrency Scams of 2019-And How Most Hackers Got Away with It. Available online: https://www.businessinsider.com/the-biggest-cryptocurrency-scams-and-arrests-of-2019-so-far2019-8 (accessed on 9 August 2020).

Caporale, Guglielmo Maria, Woo-young Kang, Spagnolo Fabio, and Spagnolo Nicola. 2019. Non-Linearities, Cyber Attacks and Cryptocurrencies. Finance Research Letters 32: 101297. [CrossRef]

Chu, Jeffrey, Yuanyuan Zhang, and Stephen Chan. 2019. The Adaptive Market Hypothesis in the High Frequency Cryptocurrency Market. International Review of Financial Analysis 64: 221-31. [CrossRef]

CoinDesk. 2020. How to Spot a Crypto Scam. Available online: https://www.coindesk.com/how-to-spot-a-cryptoscam (accessed on 9 August 2020).

Corbet, Shaen, Douglas J. Cumming, Brian M. Lucey, and Peat Maurice. 2019. The Destablishing Effects of Cryptocurrency Cybercriminality. Economics Letters 191: 108741. [CrossRef]

Corbet, Shaen, Larkin Charles, and Lucey Brian. 2020. The Contagion Effects of the COVID-19 Pandemic: Evidence from Gold and Cryptocurrencies. Finance Research Letters 35: 101554. [CrossRef] 
Desjardins, Jeff. 2017. All of the World's Money and Markets in One Visualization. The Money Project. October 26. Available online: http://money.visualcapitalist.com/worlds-money-markets-one-visualization-2017/ (accessed on 25 March 2020).

Erste Group. 2018. Erste Group and ASFINAG Successfully Launch Europe's First Entirely Blockchain-Based Capital Markets Issuance. Available online: https://www.erstegroup.com/en/news-media/press-releases/ 2018/10/23/paperless-ssd-blockchain-alias (accessed on 23 October 2018).

Gandal, Neil, James Hamrick, Moore Tyler, and Oberman Tali. 2018. Price Manipulation in the Bitcoin Ecosystem. Journal of Monetary Economics 95: 86-96, Online Supplementary Material 20 December. Available online: https://ars.els-cdn.com/content/image/1-s2.0-S0304393217301666-mmc1.pdf (accessed on 25 March 2020).

Griffin, John M., and Amin Shams. 2018. Is Bitcoin Really Un-Tethered? The Journal of Finance 75: 1913-64. [CrossRef]

Grobys, Klaus, Ahmed Shaker, and Sapkota Niranjan. 2019. Technical Trading Rules in the Cryptocurrency Market. Finance Research Letters 32: 101396. [CrossRef]

Juurikkala, Oskari. 2012. The Behavioral Paradox: Why Investor Irrationality Calls for Lighter and Simpler Financial Regulation. Fordham Journal of Corporate E Financial Law 33: 40-42.

Kakushadze, Zura. 2018. Cryptoasset Factor Models. Algorithmic Finance 7: 87-104. [CrossRef]

Kaspersky. 2020. 4 Common Cryptocurrency Scams and How to Avoid Them. Available online: https: //www.kaspersky.com/resource-center/definitions/cryptocurrency-scams (accessed on 9 August 2020).

Khatwani, Sudhir. 2018. 7 Most Common Types Of Cryptocurrency Scams \& Tips to Avoid Them. Consutra. October 15. Available online: https://coinsutra.com/cryptocurrency-scams/ (accessed on 9 August 2020).

Koerhuis, Wiebe, Kechadi Tahar, and Le-Khac Nhien-An. 2019. Forensic Analysis of Privacy-Oriented Cryptocurrencies. Forensic Science International: Digital Investigation 33: 200891. [CrossRef]

Mersch, Yves. 2018. Virtual Currencies Ante Portas. Paper presented at 39th Meeting of the Governor's Club of The Central Asia, Black Sea Region and Balkan Countries, Bodrum, Turkey, May 14.

PYMNTS. 2018. ICO Investors Fall For Exit Scams, Phishing. Cryptocurrency. August 15. Available online: https://www.pymnts.com/cryptocurrency/2018/ico-investors-exit-scams-phishing-attempts-bitcoinethereum/ (accessed on 17 June 2020).

Robby, Houben, and Alexander Snyers. 2018. Cryptocurrencies and Blockchain, Legal Context and Implications for Financial Crime, Money Laundering and Tax Evasion. PE 619.024. Brussels: European Parlament, Policy Department for Economic, Scientific and Quality of Life Policies, Directorate-General for Internal Policies, July.

Sherman, Nathan J. 2018. A Behavioral Economics Approach to Regulating Initial Coin Offerings. Georgetown University Law Center, J.D. expected May 2019; University of Richmond, B.S.B.A 2016. Available online: https: //georgetownlawjournal.org/articles/280/behavioral-economics-approach-to/pdf (accessed on 20 June 2020).

Shin, Hyun Song. 2018. Cryptocurrencies and the Economics of Money. Bank for International Settlements lecture on the occasion of the Bank's Annual General Meeting in Basel. Basel: Bank for International Settlements, June 24 .

Staff of Global Legal Research Directorate. 2018. Regulation of Cryptocurrency Around the World; Washington, DC: The Law Library of Congress, Global Legal Research Center, United States.

The Fintech Times. 2018. 7 Bitcoin-Friendly Countries That Welcome Cryptocurrency Investments. Newsletter. July 4. Available online: https://thefintechtimes.com/7-bitcoin-friendly-countries-that-welcomecryptocurrency-investments/ (accessed on 25 March 2020).

Volpicelli, Gian. 2018. HTC Has Made a Blockchain Phone that Cryptocurrency Fans Will Hate. WIRED. November 2. Available online: https://www.wired.co.uk/article/htc-exodus-crypto-phone (accessed on 25 March 2020).

Xu, Qiuhua, Yixuan Zhang, and Ziyang Zhang. 2019. Tail-Risk Spillovers in Cryptocurrency Markets. Finance Research Letters. in press. [CrossRef]

ZD Net. n.d. China Arrests over 100 People Suspected of Involvement in PlusToken Cryptocurrency Scam. Available online: https:/www.zdnet.com/article/china-arrests-over-100-people-suspected-of-involvementin-plustoken-cryptocurrency-scam/ (accessed on 9 August 2020). 
Zellweger-Gutknecht, Corinne. 2018. Developing the Right Regulatory Regime for Cryptocurrencies and Other Value Data. In Private and Public Law Implications of Cryptocurrencies. Edited by David Fox and Sarah Green. Oxford: Oxford University Press, August.

Zhang, Yuanyuan, Stephen Chan, and Jeffrey Chu. 2018. Nadarajah Saralees. Stylised Facts for High Frequency Cryptocurrency Data. Physica A 513: 598-612. [CrossRef]

(C) 2020 by the authors. Licensee MDPI, Basel, Switzerland. This article is an open access article distributed under the terms and conditions of the Creative Commons Attribution (CC BY) license (http://creativecommons.org/licenses/by/4.0/). 


\title{
Bitcoin Network Mechanics: Forecasting the BTC Closing Price Using Vector Auto-Regression Models Based on Endogenous and Exogenous Feature Variables
}

\author{
Ahmed Ibrahim ${ }^{1}$, Rasha Kashef ${ }^{2, *}$, Menglu Li ${ }^{2}$, Esteban Valencia ${ }^{3}$ and Eric Huang ${ }^{4}$ \\ 1 Computer Science Department, Wilfried Laurier University, Waterloo, ON N2L 3C5, Canada; \\ ahibrahim@wlu.ca \\ 2 Electrical, Computer, and Biomedical Engineering Department, Ryerson University, Toronto, \\ ON M5B 2K3, Canada; menglu.li@ryerson.ca \\ 3 IVEY Business School, Management Science Department, London, ON N6G 0N1, Canada; \\ evalencia.msc2017@ivey.ca \\ 4 Advanced Analytics and Research Lab, Toronto, ON M5J 2P1, Canada; ehuang.msc2017@ivey.ca \\ * Correspondence: rkashef@ryerson.ca
}

Received: 29 July 2020; Accepted: 17 August 2020; Published: 19 August 2020

\begin{abstract}
The Bitcoin (BTC) market presents itself as a new unique medium currency, and it is often hailed as the "currency of the future". Simulating the BTC market in the price discovery process presents a unique set of market mechanics. The supply of BTC is determined by the number of miners and available BTC and by scripting algorithms for blockchain hashing, while both speculators and investors determine demand. One major question then is to understand how BTC is valued and how different factors influence it. In this paper, the BTC market mechanics are broken down using vector autoregression (VAR) and Bayesian vector autoregression (BVAR) prediction models. The models proved to be very useful in simulating past BTC prices using a feature set of exogenous variables. The VAR model allows the analysis of individual factors of influence. This analysis contributes to an in-depth understanding of what drives BTC, and it can be useful to numerous stakeholders. This paper's primary motivation is to capitalize on market movement and identify the significant price drivers, including stakeholders impacted, effects of time, as well as supply, demand, and other characteristics. The two VAR and BVAR models are compared with some state-of-the-art forecasting models over two time periods. Experimental results show that the vector-autoregression-based models achieved better performance compared to the traditional autoregression models and the Bayesian regression models.
\end{abstract}

Keywords: Bitcoin; blockchain; autoregression; time-series analysis; simulation; predictive modes; endogenous; exogenous variables

\section{Introduction}

Bitcoin (BTC) is a digital currency alternative to real currency and is the most popular among the cryptocurrencies. The BTC was created by a cryptologist known as "Satoshi Nakamoto", whose real identity is still unknown (Nakamoto 2008). As blockchain currencies are not as liquid as other forms of currency, understanding the behavior of this market draws insights as to how one could capitalize on this asset over time. Especially as society becomes more digitally inclined, the viability of a blockchain currency such as BTC to become a common currency seems like a possible reality. There are both winners and losers in the context of each capital market transaction. There are several drivers impacting the Bitcoin market, such as the total number of Bitcoin available, the difficulty of Bitcoin mining, 
and average blockchain size. Therefore, determining the essential endogenous and exogenous drivers in BTC markets is a critical task. Each of these endogenous and exogenous variables can be treated as a time series, and therefore suitable multivariate time series forecasting models are needed.

Vector autoregression (VAR) is one of the most widely-used stochastic process models to analyze interdependencies of multivariate time series, and it has proven to be a useful model to describe the behavior of economic and financial time series, and to forecasting (Campbell et al. 1996). The VAR model is an extension of the univariate autoregression model to multivariate time series data. In the VAR structure, each variable is a linear function of past lags of itself and the past lags of the other variables. However, the limited length of standard economic datasets may produce over-parameterization problems (Koop and Korobilis 2009) thus, the Bayesian vector autoregression (BVAR) model was introduced in Litterman (1980) to solve this problem. The BVAR model uses Bayesian methods to estimate a vector autoregression. In comparison with the standard VAR models, the BVAR model treats input parameters as random variables, and prior probabilities are then assigned. A feature-selection of the cryptocurrency drivers is strongly needed to enhance the performance of a multivariate time-series (e.g., BTC) prediction model. In this paper, we applied direct forecasting using VAR and BVAR models to simulate the BTC market to understand the behavior of market participants as well as their most and least favorable market conditions according to the closing price of BTC based on an optimal set of exogenous variables. The simulated BTC market includes forecasting the endogenous variables, such as the equilibrium closing price of the market for BTC as denominated by the US dollar (MKPRU), the number of unique MyWallet users (MWNUS), and the total BTC available in the market to date (TOTBC). Experimental analysis over 7-year and 10-year timeframes shows the efficiency of the VAR and BVAR models in predicting the set of endogenous variables compared to traditional autoregression and Bayesian regression models using the optimal selected set of exogenous variables. The rest of this paper is organized as follows: Section 2 introduces the background of Bitcoin; Section 3 focuses on the related work; Section 4 describes the prediction models for Bitcoin closing price; Section 5 presents and discusses the results of the prediction models; and Section 6 outlines the conclusions and future works.

\section{Background on Bitcoin}

Bitcoin is a unique digital currency with the potential to change the nature of the transactions that people conduct in digital space. Bitcoin enables consumers for the first time to make electronic transactions from person to person without the need for an intermediary between them, like cash (Brito 2014). Transactions conducted in the digital space with BTC allow individuals to push payments directly to the merchants without having to share personally identifiable information, which could be intercepted by cybercriminals for fraud. One of the greatest concerns for BTC as a commonly accepted currency is the security, as there is no intermediary to ensure the coverage on stolen BTC, should theft occur (Brito 2014). As the value of the asset appreciated 63\% YTD in 2016, and 87\% YTD in 2020, identifying historical patterns of behavior could help in understanding how the BTC security (and the security of similar cryptocurrencies) is likely to behave from inception.

\subsection{Bitcoin Ledger}

Each block in the Bitcoin blockchain contains a summary of all transactions in the block using a Merkle tree (aka binary hash tree) such that each transaction is first put into a pool of pending transactions. Then, they are put into the transaction chain (blockchain) (Antonopoulos 2014). Each block is linked in a chain by a reference to a previous header hash in which the addition of a transaction into the chain is through a "mathematical lottery" (United States Securities and Exchange Commission 2017). The miner solves the math problem (cryptographic hashing) and puts the transaction into the chain. The math helps everyone with a wallet know the order of transactions as well as all past transactions. 


\subsection{Bitcoin Development Process}

As other cryptocurrencies aim to perform the same computer distributed task, there are risks that any new digital currency faces from inception until maturity. There are three primary characteristics that a digital currency must satisfy to be deemed a sound form of currency. The following are the key success factors (Barski and Wilmer 2015):

- The network effect;

- Cryptocurrency volatility;

- Cryptocurrency-pegging technology.

\subsubsection{The Network Effect}

The simple concept of money is that people will be willing to use the currency (medium of exchange) so long as someone else is willing to accept it as a form of payment. Without an appropriate network for the payment mechanism, it is unlikely that people would desire to use the specific cryptocurrency if it turns out to be illiquid.

\subsubsection{Cryptocurrency Volatility}

For any cryptocurrency that is getting newly established as a payment method, the "fair" established value must be stable for consumers to be comfortable purchasing with the digital currency. As BTC is a newly available asset, the price discovery mechanism requires that the group of buyers and sellers exchanging the currency come to an agreed-upon value for the underlying asset (Pagnottoni and Dimpfl 2019). As the value of a BTCUSD in November 2016 was roughly $\$ 740$, the currency was far from stable at the time. Seeing prices as high as \$1200 in 2013, \$15,000 in 2020, and as low as \$355 in 2016 for BTCUSD, a true concern for consumers is to make a purchase with an asset that has varied so much in value. However, there are many cases of money being just as volatile. One famous example being the Zimbabwe hyperinflation, where the currency experienced 80 billion percent inflation in a single month.

\subsubsection{Cryptocurrency-Pegging Technology}

As the supply for the total BTC is limited to 21,000,000, more users have begun to use the BTC, which has modestly reduced volatility. The advantage of BTC over other cryptocurrencies is that it has been established and generated credibility for a sufficient network of users to adopt the use of the coin. Primarily, this has helped BTC outpace other digital currencies to normalize volatility. For any potential new e-coin that could enter the cryptocurrency market, it would make sense that the coin merges its stability according to a more stable cryptocurrency such as BTC.

\subsection{Market Participants}

The following are the market participants worthy of further analysis accompanied by a brief description of their role in the market:

- Miners-The market participants who are proactively adding transaction records to Bitcoin's public ledger of past transactions or blockchain and fueling the supply of BTC.

- Individual investors-Investors for the digital assets to purchase goods or services with the digital currency.

- Payment mechanism-Conduct business internationally as international payments are now available via BTC.

- Retail investors-Funds that are likely to pick up the currency as a portion of their portfolio to hedge, like gaining exposure to traditional currency markets. 


\subsection{Stakeholders}

As digital currency changes the evaluated value of money and other financial assets, several stakeholder requirements and motives should be considered. The following are the stakeholders (formal and informal) affected by the adoption of cryptocurrencies: savers/bullish investors, government, other cryptographers, BTC exchanges/brokers, illegal black markets, BTC miners, and members of the public. As stakeholders desire stability and strength with any medium of transaction, some stakeholders are opposed to the widespread adoption of BTC. Specifically, the government and other cryptographers may have an issue with the widespread adoption of the BTC as decentralized digital money where no government or single entity can control the price or value.

\section{Related Work}

In modeling and simulation of the economics of mining in the Bitcoin market (Cocco and Marchesi 2016), authors have discussed how a miner is impacted by BTC prices (Cocco and Marchesi 2016). The goal of this artificial market model is to model the economy of the mining process from the inception of the Graphics Processing Units (GPU) generation. The important findings for this computational experiment encompass the ability to reproduce the unit root property, the fat tail phenomenon, and the volatility clustering of the BTC prices (Cocco and Marchesi 2016). Research on Bitcoin price forecasting are mainly based on two approaches: machine learning and time series methods.

\subsection{Machine Learning Prediction Methods}

Felizardo et al. (2019) presented a comparative study of price prediction performance among several machine learning models: long short-term memory (LSTM), WaveNet, support vector machine (SVM), and random forest (RF). The results indicated that for time-series data, the LSTM model tends to perform better than other machine learning models. The research of Tandon et al. (2019) gave a similar conclusion. They applied three different machine-learning methods to forecast the Bitcoin price, and compared their prediction ability. As a result, the RNN (recurrent neural network) with LSTM gave a lower mean absolute error than the random forest and linear regression models. Many research focuses on improving the LSTM model to increase forecasting accuracy. Wu et al. (2018) proposed an LSTM called LSTM with AR(2) model to forecast Bitcoin's daily price. The conventional LSTM model only considers the previous price of to predict the current price; instead, the LSTM with $\mathrm{AR}(2)$ takes the previous two days' prices into account. The experimental results demonstrated that the proposed model with $\mathrm{AR}(2)$ achieved a better forecasting accuracy with a lower mean squared error. Hashish et al. (2019) proposed the addition of hidden Markov models (HMMs) to the conventional LSTM. The HMM was used to describe the historical movements of Bitcoin. The proposed hybrid of HMM and LSTM outperformed the traditional forecasting of LSTM by decreasing the mean squared error from 49.089 to 33.888 . The main drawback of the machine-learning models is that these models need high computational capacity, and so the execution time of the forecasting process is very time consuming. Thus, in this paper we focus on time-series prediction models. Support vector machine, latent source, and multilayer perceptron models work better for classification problems. The LSTM model performs well in solving long-term dependency problems, which means it is suitable for price prediction. However, the LSTM model needs a long computation time and has a large memory requirement.

\subsection{Time-Series Prediction Methods}

Bakar and Rosbi (2017) proposed the autoregressive integrated moving average model (ARIMA) to forecast the exchange rate between Bitcoin and the US dollar. In this method, the upcoming price depends upon autoregression, integration, and moving average, respectively. They believed the ARIMA model could be a reliable model to forecast the volatile characteristic of Bitcoin. Both Roy et al. (2018) 
and Anupriya and Garg (2018) applied the ARIMA model to predict Bitcoin's price. The experimental result demonstrated the strong forecasting ability of the ARIMA. The mean error between the actual prices and the predicted prices was less than $6 \%$ for most values. Roy et al. (2018) also compared the performance of the ARIMA model with the autoregressive model (AR) and moving average model (MA), and the ARIMA model resulted in better accuracy than the other two models. However, the ARIMA model's shortcoming is that this it can give a more accurate prediction for short-term data, based on the research result of Ariyo et al. (2014). Rane and Dhage (2019) introduced nine approaches for Bitcoin price prediction and discussed each methodology in their research. The ARIMA model targets to forecast uncertainty time-series data within a short-term period, but class imbalance can bias it. Linear regression is unsuitable to predict Bitcoin price as the time series data.

The strength of the vector autoregression (VAR) model and the Bayesian vector autoregression (BVAR) model to estimate currency and exchange rate fluctuations have been demonstrated in recent research. VAR has been used widely by financial theorists and economists in predicting time series economic variables in systems that involve supply and demand (Ito and Sato 2006; Wang et al. 2017; Carriero et al. 2009; Alquist et al. 2013; Sims 1993). We found several papers that use VARs to estimate currency and exchange rate fluctuations, notably Koray and Lastrapes, who use a VAR model to estimate the exchange rate on a series of macroeconomic variables (Koray and Lastrapes 1989). Additionally, Ito and Sato performed VAR research on the exchange rate of post-crisis Asia (Ito and Sato 2006). Wang et al. (2017) established a VAR model to analyze the impact of exchange rate volatility on economic growth. Furthermore, there is some research on forecasting using the Bayesian vector autoregression (BVAR) method. For example, Carriero, Kapetanio, and Marcellino demonstrated that the BVAR model produced better forecasting for exchange rates (Wang et al. 2017). In the econometric/finance community, (Catania et al. 2019) and (Bohte and Rossini 2019) have studied the forecasting performance of cryptocurrencies by vector autoregression with and without time-varying volatility. (Bianchi) has investigated the possible relationship between returns on cryptocurrencies and traditional asset classes. Bianchi et al. (2020) discussed the relationship between the returns on stable-coins and major cryptocurrency pairs within the context of a large Bayesian vector autoregression model. The BVAR model extends the classical VAR model by using Bayesian methods to estimate a vector autoregression. The BVAR model treats input parameters as random variables, and prior probabilities are then assigned. Current related work to both VAR and BVAR models in forecasting BTC prices does not focus on selecting the set of endogenous and exogenous variables and drivers that control the BTC market, which is the primary focus of this paper.

\section{BTC Closing Price Prediction Models}

Both VAR and BVAR models are used in this paper to forecast the Bitcoin price and simulate the BTC market to understand market participants' behavior as well as the market conditions according to the closing price of BTC.

\subsection{Endogenous and Exogenous Variables}

An autoregressive model is typically used to develop predictions and understand the trend of a time series. However, in financial and economic data, several factors are affecting the time series, such as supply, demand, and regulation. The complex nature of any financial market warrants a more sophisticated model. The performance of the VAR and BVAR forecasting models depends on the optimal selection of the set of endogenous variables of interest. Several variables were tested as proxies to represent the price, demand, and supply of the BTC market, respectively, after trying out numerous iterations of VARs and BVARs and using sensitivity analysis with different variables, lags, and time frames. The final set of endogenous variables is defined in Equation (1). Let $Y_{t}$ be a vector of the endogenous variable of interest such that:

$$
Y_{t}=\{\mathrm{MKPRU}, \mathrm{MWNUS}, \mathrm{TOTBC}\}
$$




$$
\begin{aligned}
& t_{1}=[04-01-2009,22-11-2016] \\
& t_{2}=[01-01-2011,01-08-2020]
\end{aligned}
$$

where MKPRU represents the equilibrium closing price of the market for BTC as denominated by the US dollar (Figures 1 and 2). MWNUS is the number of unique MyWallet users, and TOTBC is the total BTC available in the market to date, as there is a limited amount of BTC available at 21,000,000. Our time frames are across two intervals, the first one is [04-01-2009, 22-11-2016] (Figure 1), and the second period is [01-01-2011, 01-08-2020] (Figure 2). The decision-making process uses reasonable metrics deemed viable drivers of the endogenous variables, where the following were selected as the exogenous variables: Average Block Size in, MB (AVBLS), Bitcoin Difficulty (DIFF), Number of Transactions per Block (NTRBL), Miner's Revenue (MIREV), Change in the Number of unique addresses (NADDU), Total Output Volume (TRVOU), and Hash Rate (HRATE). A majority of the factors selected were those that had been a result of the BTC network's transaction behavior and how the fundamental mechanics influenced the closing price. The variables AVBLS, DIFF, TRVOU, and HRATE were taken as the variables which dictated the difficulty of accessing and supplying BTC to the market. NTRBL considers the growing number of transactions occurring per block of BTC as a measure of transaction volume per available block of BTC. The NADDU variable considers the changing number of unique addresses performing BTC transactions to understand behavior trends over time. TRVOU measures the exchange trade volume of USD within the BTC market, which serves as a guideline as to how the market reacts to changes in value when buying or selling BTC. Finally, $X_{t}$, as the list of exogenous variables, is defined in Equation (4) as:

$$
X t=\{\text { MIREV }, \text { NTRBL, AVBLS, DIFF, NADDU, TRVOU, HRATE }\}
$$

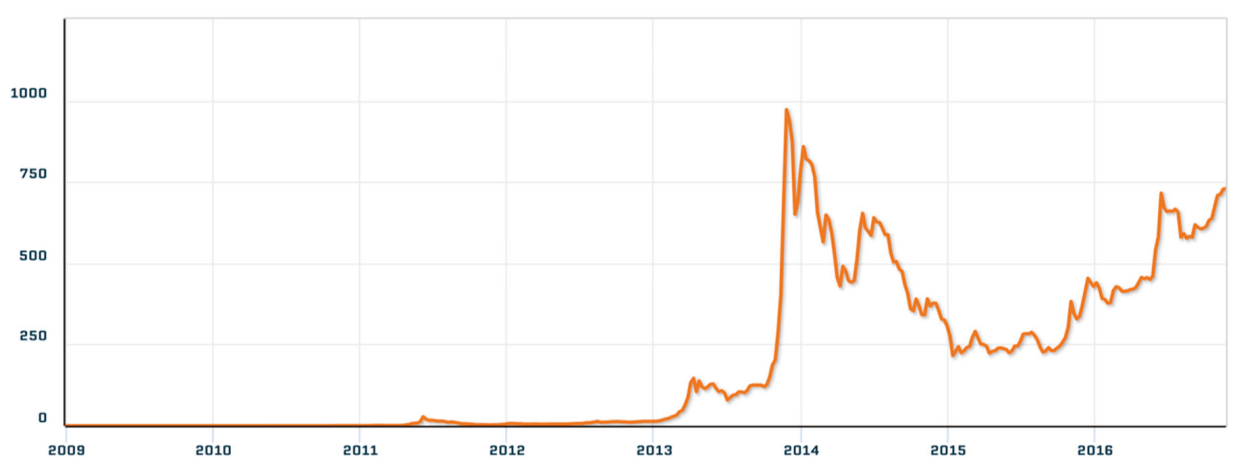

Figure 1. Bitcoin closing price in USD (MKPRU), [04-01-2009, 22-11-2016]. 


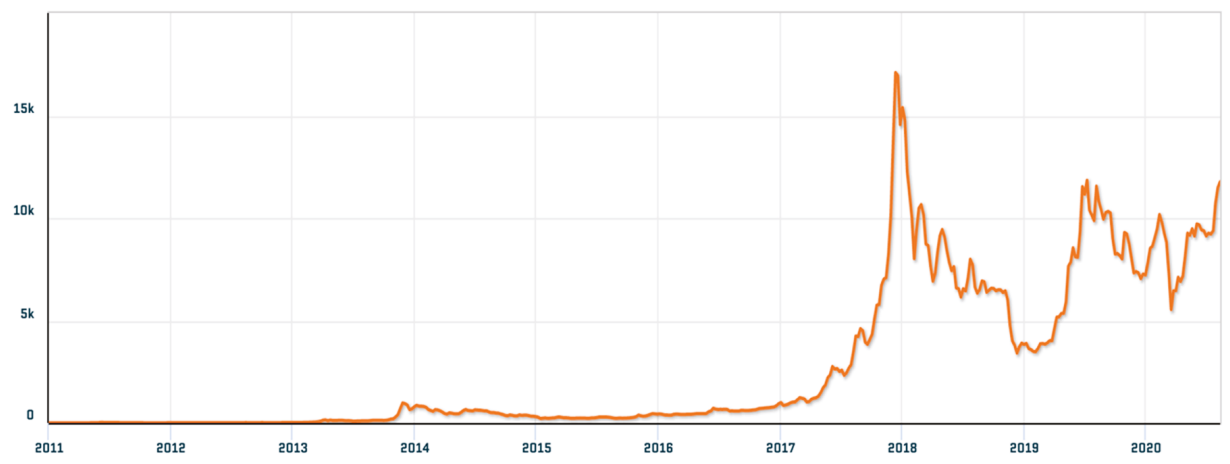

Figure 2. Bitcoin closing price in USD (MKPRU), [01-01-2011, 01-08-2020].

\subsection{Vector Autoregression (VAR) Model}

A Vector autoregression (VAR) (Sims 1993), (Kuschnig et al. 2020), and (Kuschnig and Vashold 2019) model was developed to understand the relationship between the system of variables that are of interest (Equations (1) and (4)). Thus, the VAR of interest is as follows:

$$
Y_{t}=\beta_{0}+\beta_{1} Y_{t-1}+\beta_{2} Y_{t-2}+\beta_{3} Y_{t-3}+\cdots \beta_{n} Y_{t-n}+\beta_{n+1} X_{t}+\epsilon_{t}
$$

where the betas $\left(\beta_{t}^{\prime} s\right)$ are vectors of constants and coefficients representative of the relationship between the variables, where $n$ is the number of lags used in the VAR model. The purpose of selecting this model is to use the model coefficients to simulate a certain period of BTC endogenous variable (Equation (1)) given the exogenous variables (Equation (4)). Furthermore, one could ideally forecast out the BTC price behavior over time, such that there are verified and validated forecasts of the exogenous variables.

\subsubsection{Model Assumptions}

A few assumptions were made in this VAR model in an effort to use real market data to forecast just over six months. First, the model assumes that the relationship between the variables is static. A variety of timelines were tested accordingly in order to understand differences in behavior. The following are the timeframes selected for analysis:

Experiment A: Full timeframe: [04-01-2009, 22-11-2016], Post-boom timeframe: [10-12-2013, 22-11-2016], the Year of 2016 timeframe: [01-01-2016, 22-11-2016]. Experiment B: Full timeframe: [01-01-2011, 01-08-2020], Post-boom timeframe: [01-01-2017, 01-08-2020], the Year of 2020 timeframe: [01-01-2020, 01-08-2020]. For both Experiments A and B, the second assumption made in the model was the segregation of endogenous and exogenous variables. The decision-making process yielded a qualitative and intuitive measure for the variables.

\subsubsection{Model Validation and Verifications}

The process of validating the model was among the most difficult tasks throughout the entire process. Ultimately, the selected set of endogenous variable contained the BTC exchange rate, a variable for supply, and a variable for demand. Collectively, these variables help represent the market mechanics of Bitcoin. Based on the selected endogenous and exogenous variables, the following parameters were used:

- lag.max $=366$ - to accommodate a full year of seasonal behavior and trends;

- $\quad$ type $=$ 'both' - to evaluate the deterministic regressors.

The resulting selection of a timeframe was selected according to Akaike Information Criterion (AIC), Schwarz Criterion (SC), Hannan Quinn (HQ), and Forecast Prediction Error (FPE). This screening 
process served as a deterministic selection of the timeframe for the forecasting by encompassing summary statistics such as $p$-value and $\mathrm{R}^{2}$ to verify the accuracy of the relationship that was being estimated. Additionally, other combinations of variables were attempted with exceptionally poor results. Most of the other variables that were included as an aggregate to those used in the model projected dramatic market crashes with negative asset value.

\subsection{Bayesian Vector Autoregression (BVAR) Model}

The classical VAR model may have over-parameterization problems because of the large number of parameters and limited availability of time-series datasets (Sims 1980); alternatively, the Bayesian vector autoregression model can be used. The BVAR model applies Bayesian methods to estimate a VAR and treats the VAR model parameters as random variables. It also assigns and updates the prior probabilities of both observed and unobserved parameters based on available data (Miranda-Agrippino and Ricco 2018). The BVAR model in this paper uses the same variables of interest in the VAR model as described in Section 4.2. Let $Y_{t}$ be a list of variables used in this BVAR model, such that:

$$
Y_{t}=\{\text { MKPRU, MWNUS, TOTBC }\}
$$

As in the VAR model, the BVAR model also assumes the chosen variables have static relationships and uses several different timelines to observe forecasting outputs. The BVAR model uses the same timeframes (Experiment A and Experiment B) used in the VAR model in order to compare their forecasting abilities.

Prior Specification

In the BVAR model, the informative prior probability distribution of the VAR coefficients $\left(\beta_{t}^{\prime} s\right.$ in Equation (5)) can be assigned before observing the sample data. The Minnesota prior was introduced and developed by Robert Litterman and other researchers at the University of Minnesota (Litterman 1980), and was chosen in our BVAR model. This prior is based on the behavior of most macroeconomic variables, which is approximately a multivariate random walk model with drift. The parameters of the Minnesota prior are set as follows:

- Parameter $\lambda$ with $\max =5$ and $\min =0.0001$, to control the tightness of the prior;

- Parameter $\alpha$ with $\max =3$ and $\min =1$, to manage variance decay with increasing lag order;

- $\operatorname{var}=10,000,000$, to set the prior variance on the model's constant.

\section{Experimental Analysis}

Real datasets of the Bitcoin market in three different timeframes were used in this paper across two different time periods, Experiment A, $t_{1}=$ [04-01-2009, 22-11-2016], and Experiment B, [01-01-2011, 01-08-2020]. For Experiment B, the data were normalized using the logarithm of each return variable. Both the VAR and BVAR models were applied and tested on these datasets to forecast the Bitcoin market price. The forecasting results were analyzed to evaluate the performance of our models.

\subsection{Experimental Dataset}

The primary source of data and information was the Quandl Dataset sourced from Blockchain.com (Quandl 2020). The source contains up to 32 datasets, including the BTC market price. Each dataset contains a time series for a variable. The secondary dataset was the average OHLC (open-high-low-close) candlestick values across multiple exchanges scraped from Rbitcoincharts.com (Bitcoin Charts 2020). Additionally, any of the transforms accepted were denoted upfront before the variable. In the circumstance of the BTC simulation, the Quandl transform applied was "diff", which implied the change over time depending on the frequency (i.e., daily frequency data would be sampled as daily frequency change of that variable). The OHLC candlestick chart data (Figure 3) were sourced directly 
from Rbitcoincharts.com, consolidating the average OHLC candle according to a number of varying exchanges which trade BTC and similarly pegged altcoins. One of the major difficulties encountered upon sourcing the data was to get a consistent market price from BCHAIN, which would match the OHLC charts sourced. The difference appeared to be according to when the different data sources selected their end-of-day settlement. Rbitcoincharts.com was selected, as the close price difference was roughly around (\$1-\$2).

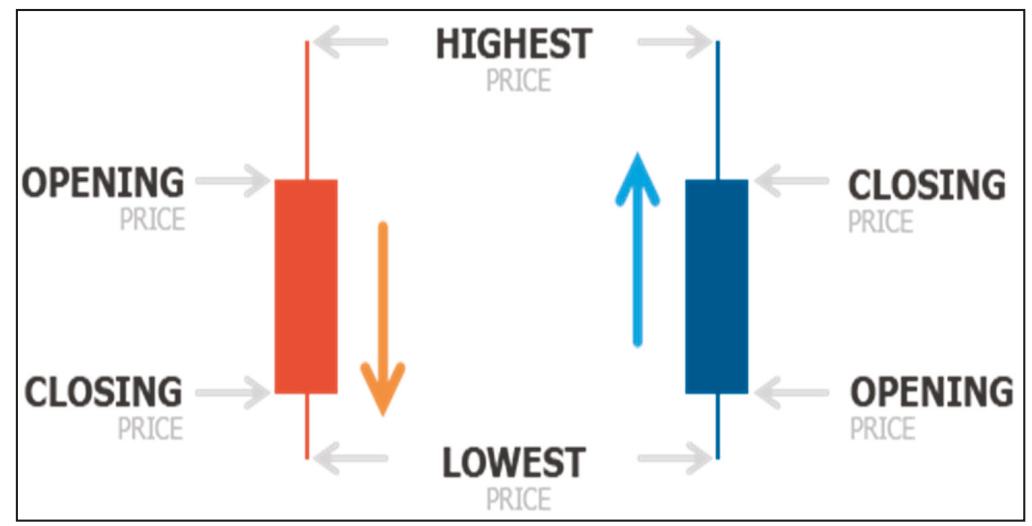

Figure 3. OHLC (open-high-low-close) candlestick.

\subsection{Forecasting Results}

Both VAR and BVAR models were tested with three timeframes in two different experiments. Experiment A: For the 2016 timeframe, values of variables described in Sections 4.2.1 and 4.2.2 between 01-01-2016 and 30-09-2016 were imported as input to the two models. For the Post-boom timeframe, data from 10-12-2013 to 30-09-2016 were imported as input. Both models forecasted the Bitcoin price in USD for the period 01-10-2016 to 30-10-2016 and compared the forecasting results with the actual Bitcoin price. For the Full timeframe, the time period selected to forecast was the last 199 days [05/08/2016-11/22/2016] to evaluate the effectiveness of these two models. Experiment B: For the 2020 timeframe, input and output variables between 01-01-2020 and 01-08-2020 were used for both the VAR and BVAR models. For the Post-boom timeframe, data from 01-01-2017 to 01-08-2020 were used. For the Full timeframe, the time period selected for forecasting was the last six months [01-02-2020, 01-08-2020] to evaluate the effectiveness of these two models.

\subsubsection{Results of the VAR Model: Experiment A}

The model selects the most suitable coefficients, where the outcome minimizes FPE. Figures 4-6, respectively show the evaluation of the Full, Post-boom, and the Year of 2016 timeframes forecasting in comparison to the BTCUSD OHLC candle from Rbitcoincharts.com, where "fcst" is the forecasted closing price, "lower" is the lower bound (95\% CI), and "upper" is the upper bound (95\% CI). The endogenous variables were simulated from the estimated VAR, as shown in Figures 7-9 for three different timeframes. The simulated exogenous variables were the real datasets taken from Quandl for the aforementioned timeframe. Ultimately, by evaluating the results of different timeframes, the full timeframe using the VAR model showed the best forecasting performance. The Full timeframe represents the most data available and incorporates the relationships over different timeframes. Although the significance of the relationship between these variables may change over time, the 7-year timeframe surely aided in modeling the market behavior. 


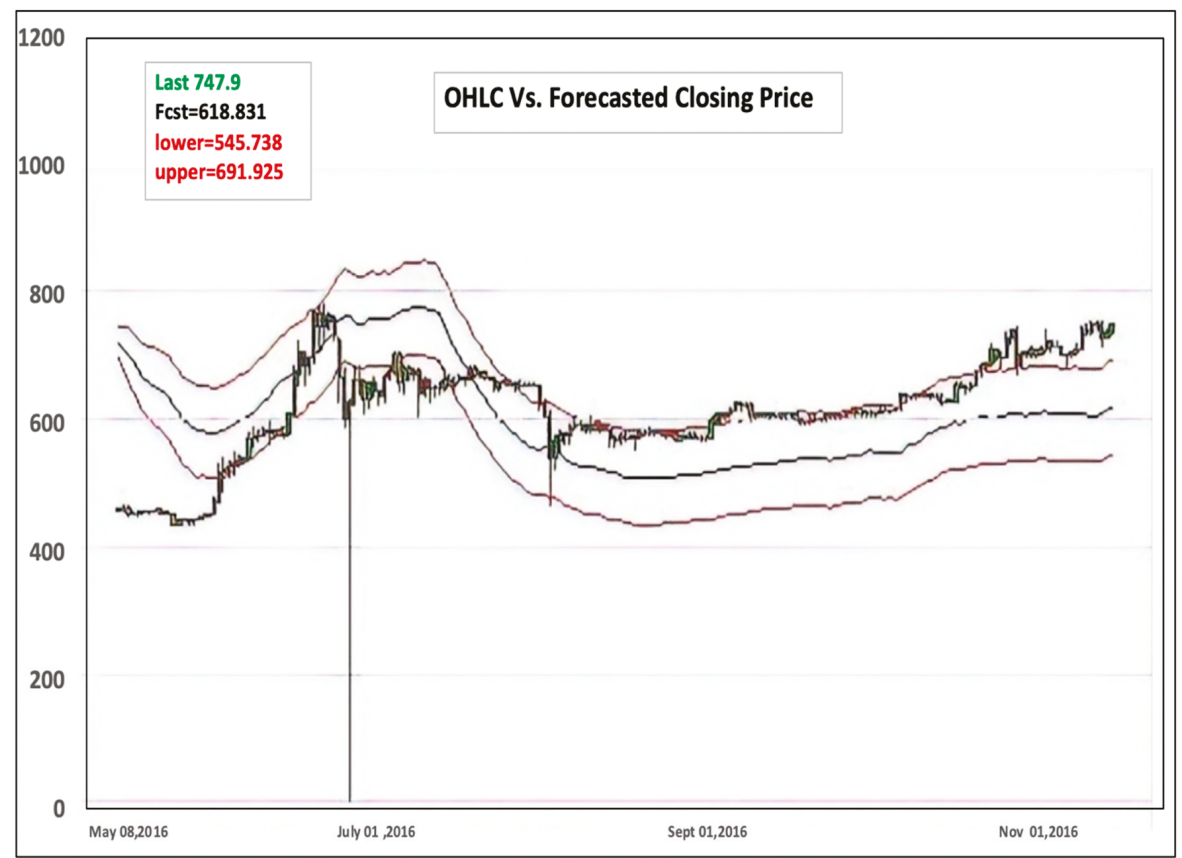

Figure 4. Forecasting Bitcoin closing price using Full timeframe. Data Vs. BTC OHLC.

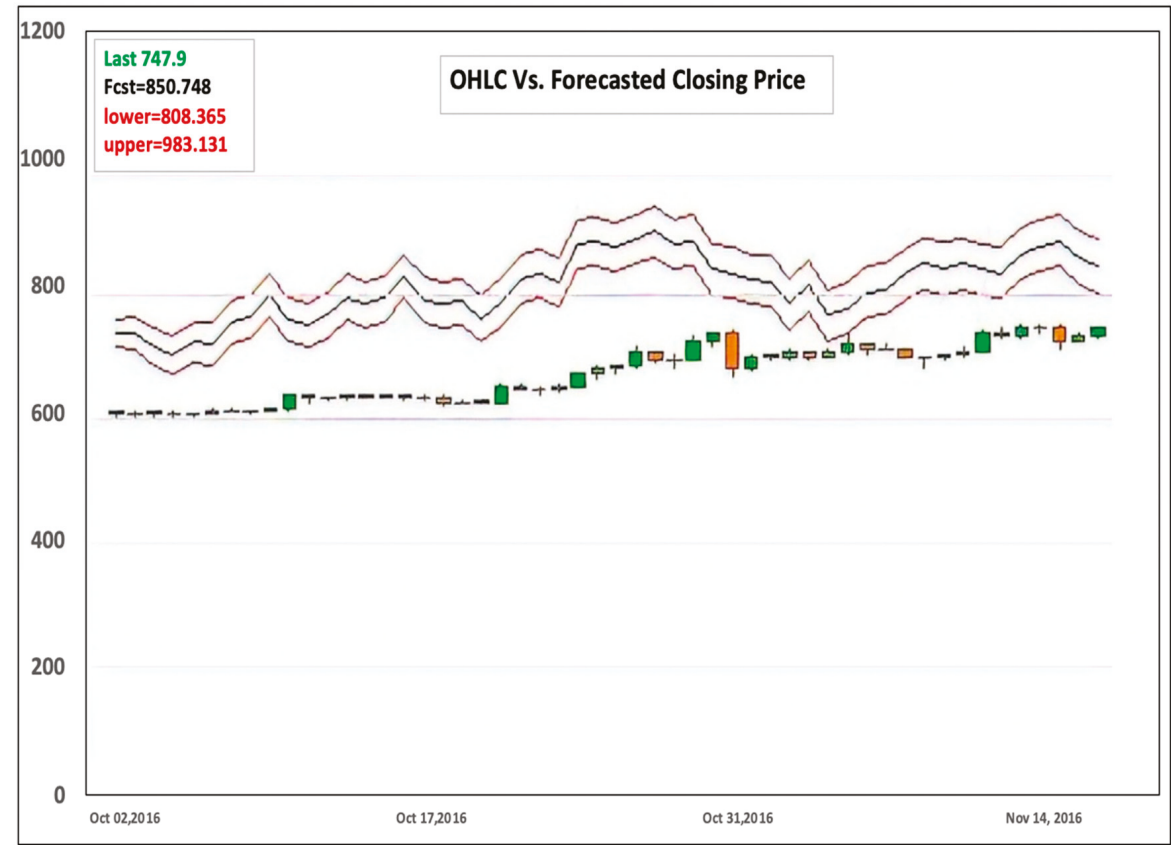

Figure 5. Forecasting Bitcoin closing price using Post-boom timeframe. Data Vs. BTC OHLC. 


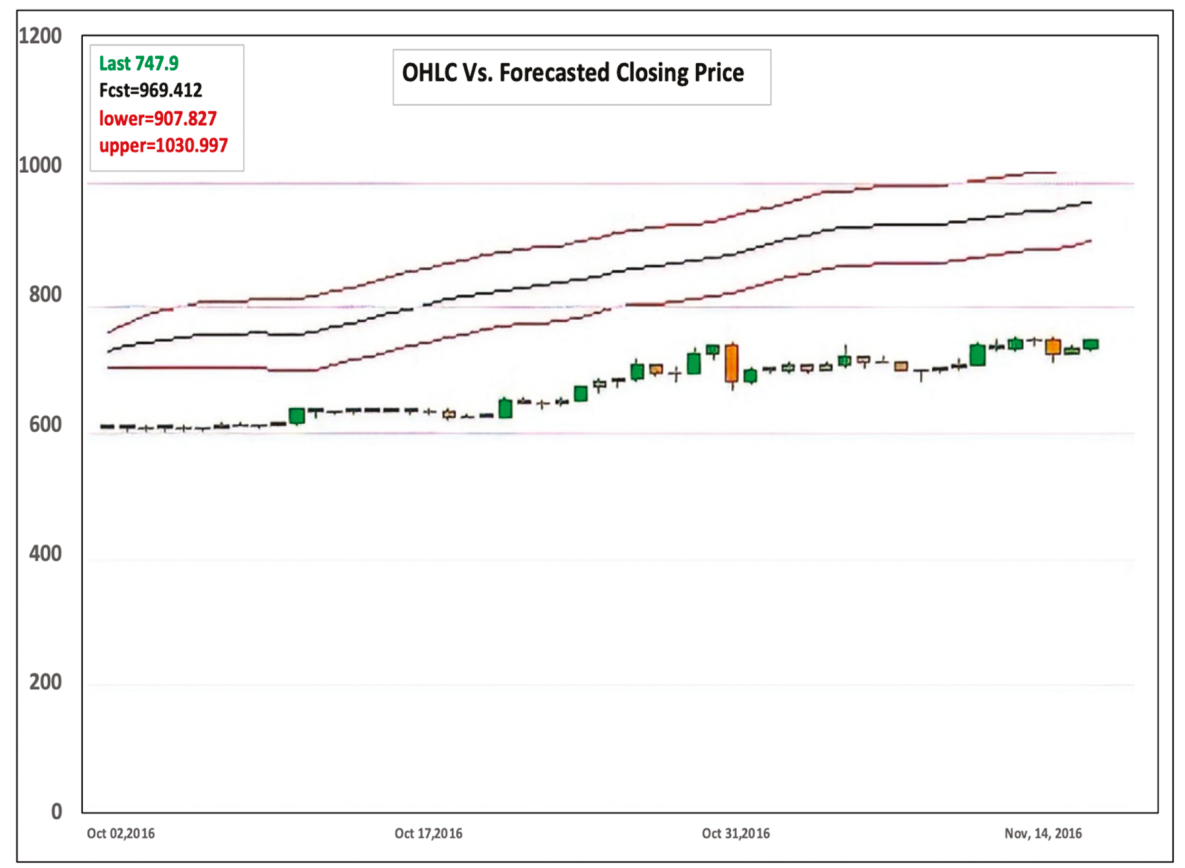

Figure 6. Forecasting Bitcoin closing price using Year of 2016 timeframe. Data vs. BTC OHLC.

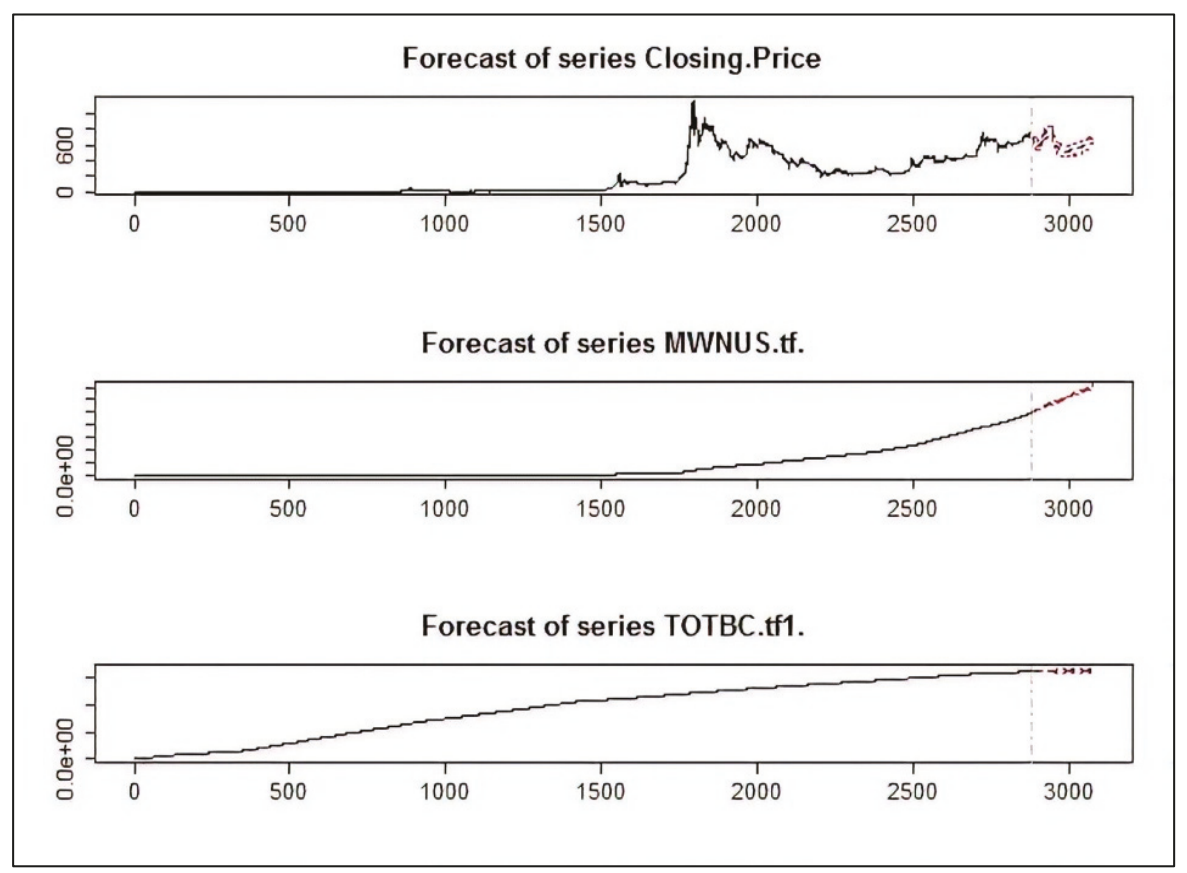

Figure 7. Forecasting the endogenous variables using Full timeframe data (VAR). 


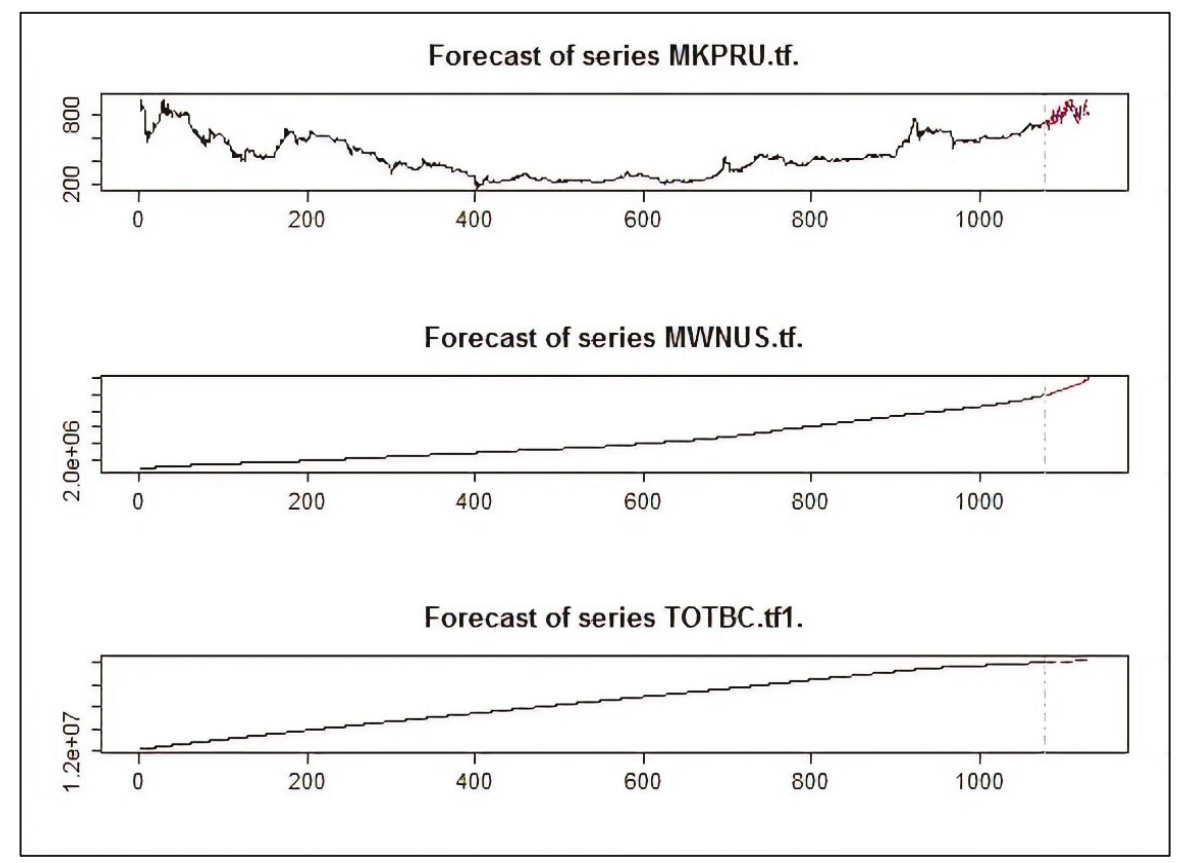

Figure 8. Forecasting the endogenous variables using Post-boom timeframe data (VAR).

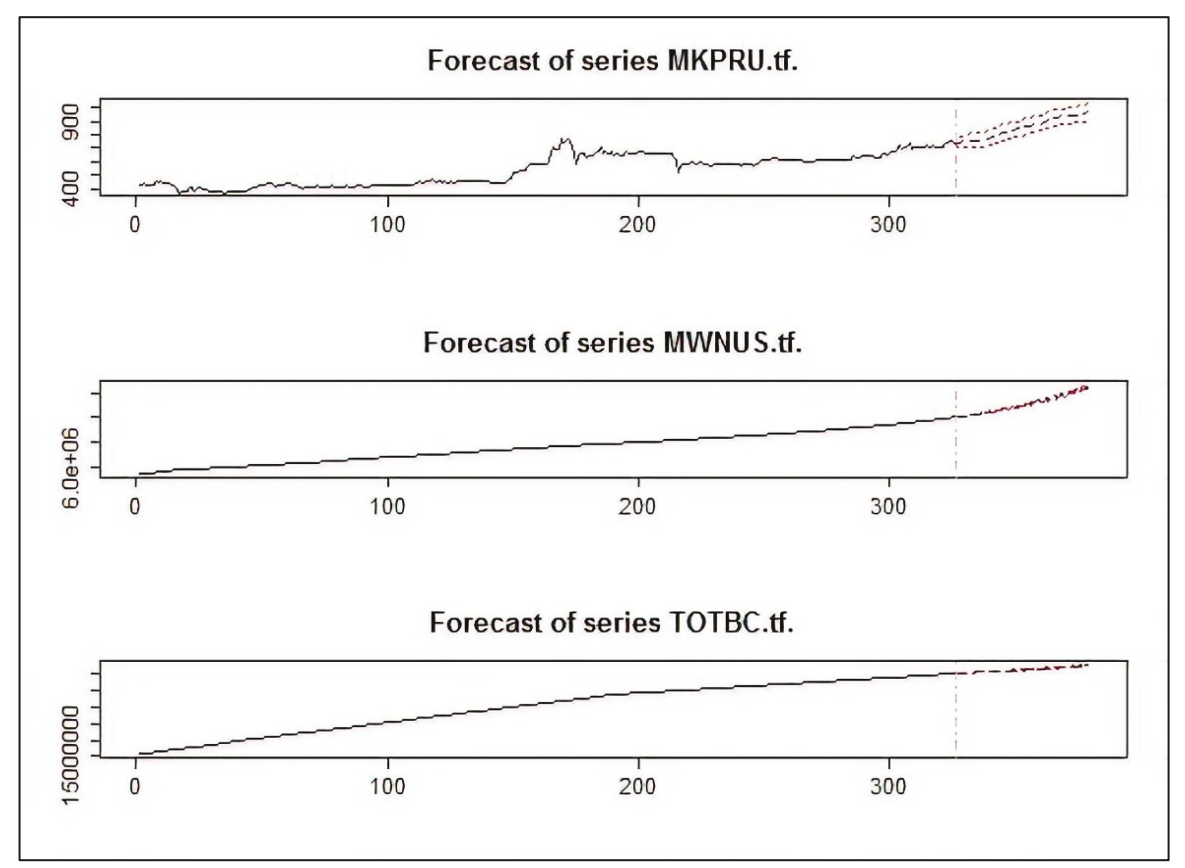

Figure 9. Forecasting the endogenous variables using Year of 2016 timeframe data (VAR). 


\subsubsection{Results of the VAR Model: Experiment B}

In this experiment, we evaluated the performance of the VAR model using the period [January 2011-August 2020] Full timeframe data, Post-boom timeframe data [January 2017-August 2020], and the Year of 2020 timeframe data [January 2020-August 2020]. We can observe that the VAR model could effectively predict the prices of the BTC using the three timeframes for the variables MKPRU, MWNUS, and TOTBC, as shown in Figures 10-13, with the best performance obtained for the Full timeframe period.

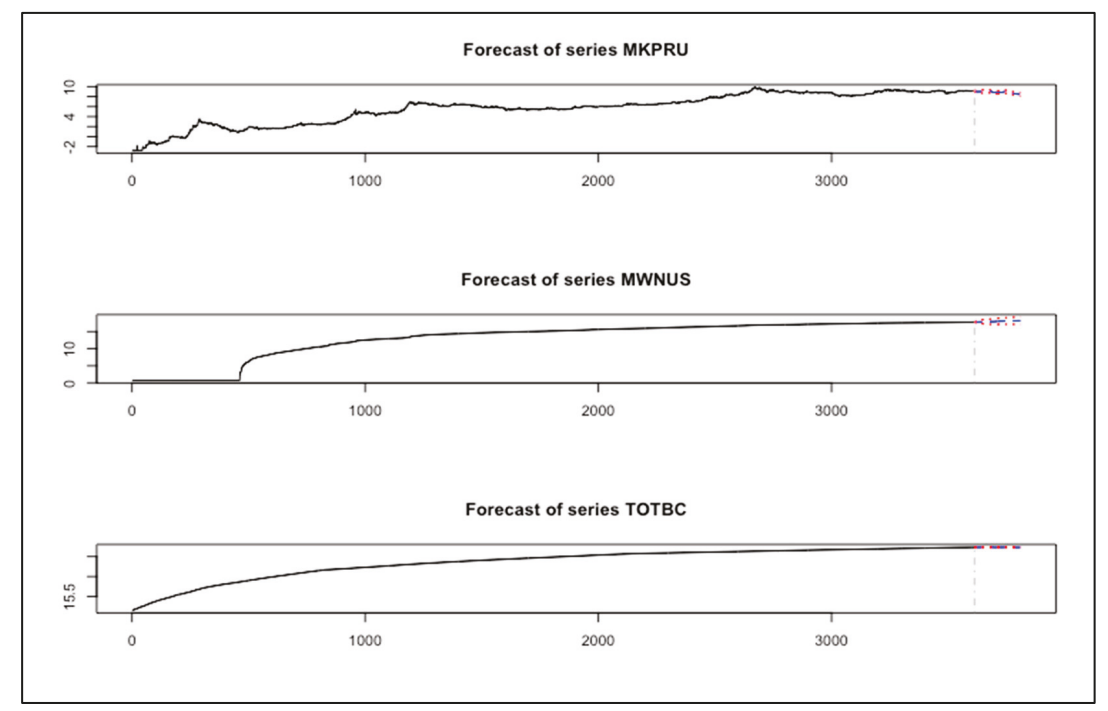

Figure 10. Forecasting the endogenous variables using Full timeframe data (VAR).

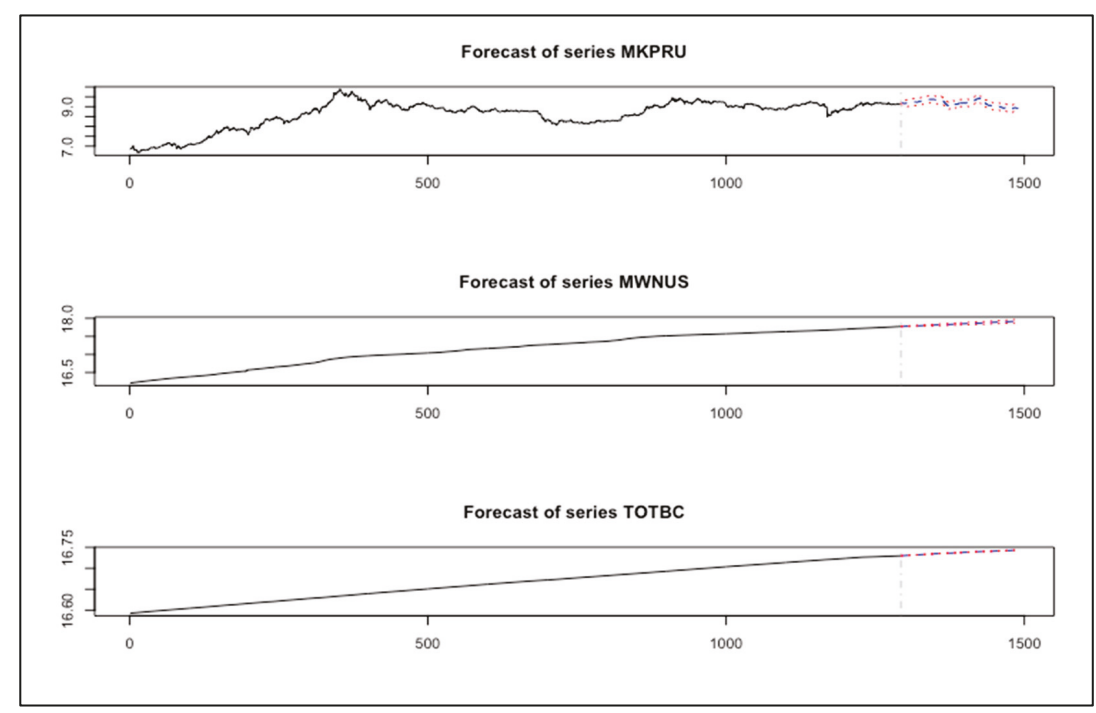

Figure 11. Forecasting the endogenous variables using Post-boom timeframe data (VAR). 


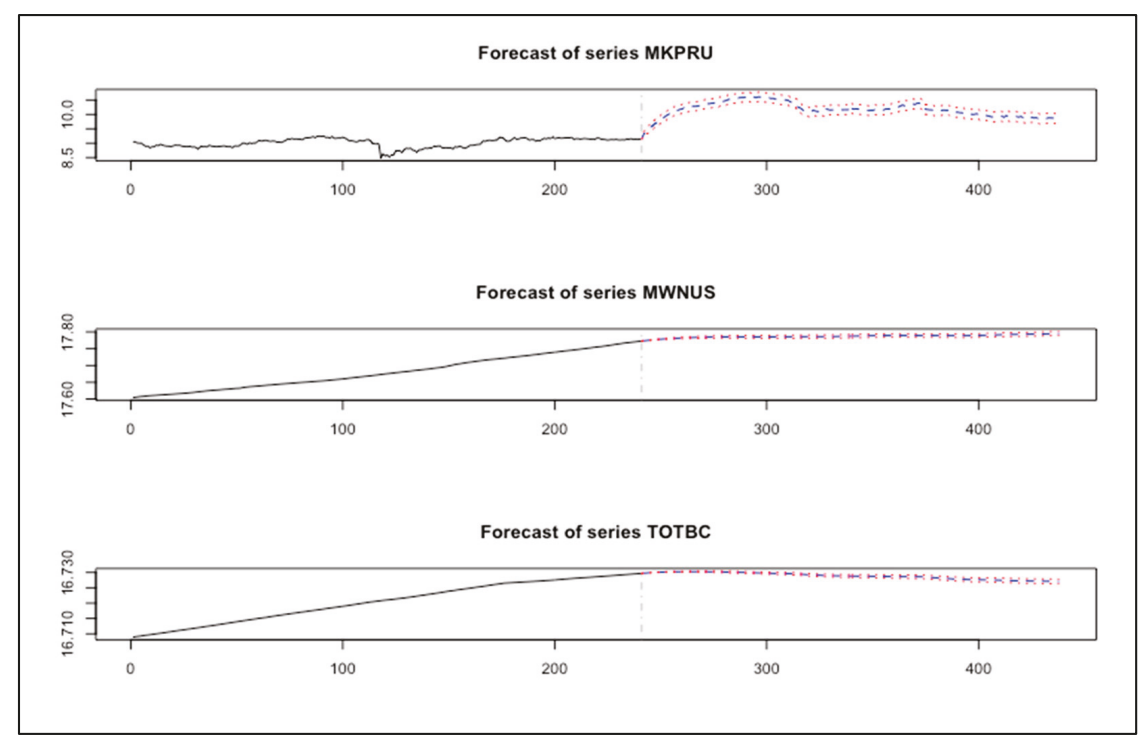

Figure 12. Forecasting the endogenous variables using Year of 2020 timeframe data (VAR).

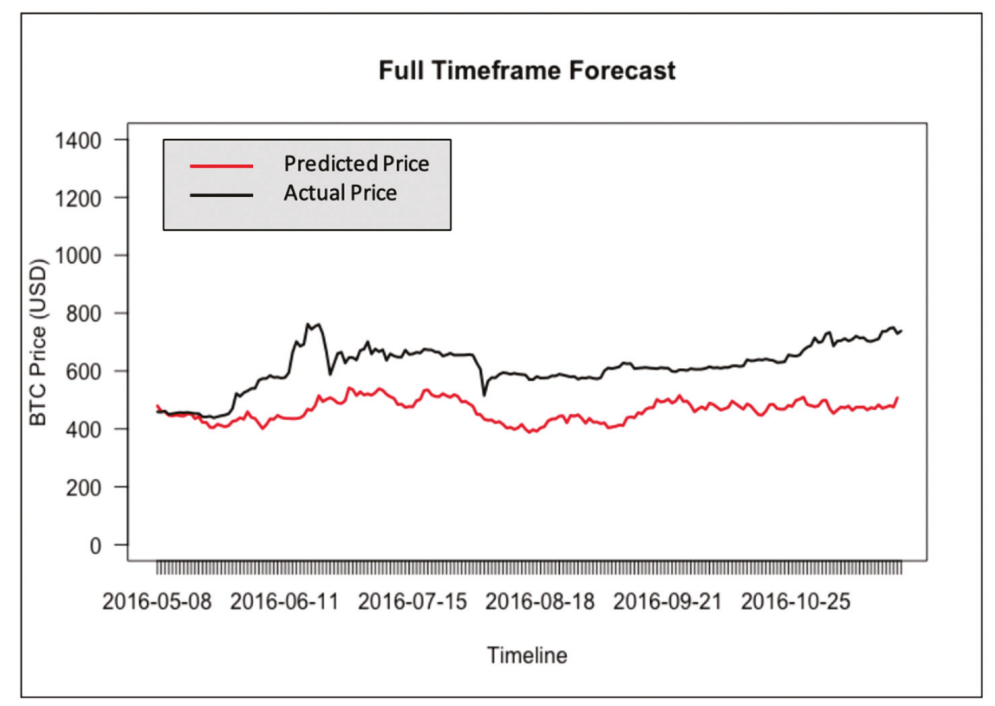

Figure 13. Forecasting Bitcoin closing price using Full timeframe data (BVAR).

\subsubsection{Results of the BVAR Model: Experiment A}

The forecasting results of Bitcoin price in USD for Full, Post-boom, and the Year of 2016 timeframes are shown in Figures 13-15, respectively. The red lines in each plot are from the BTC Market Price dataset (MKPRU) of Quandl. The mean absolute percentage error (MAPE) of each forecasting result was calculated to evaluate the model performance. The forecasting of Year of 2016 and Post-boom timeframes gave good performances, as the result of the Year of 2016 timeframe has a MAPE value of $2.38 \%$ and the MAPE value of the Post-boom timeframe result is $2.85 \%$. However, 
forecasting price using the Full timeframe resulted in the largest MAPE value, 19.88\%. The BVAR model provided high forecasting accuracy with fewer data available or shorter timeframe in the period of [January 2009-November 2016].

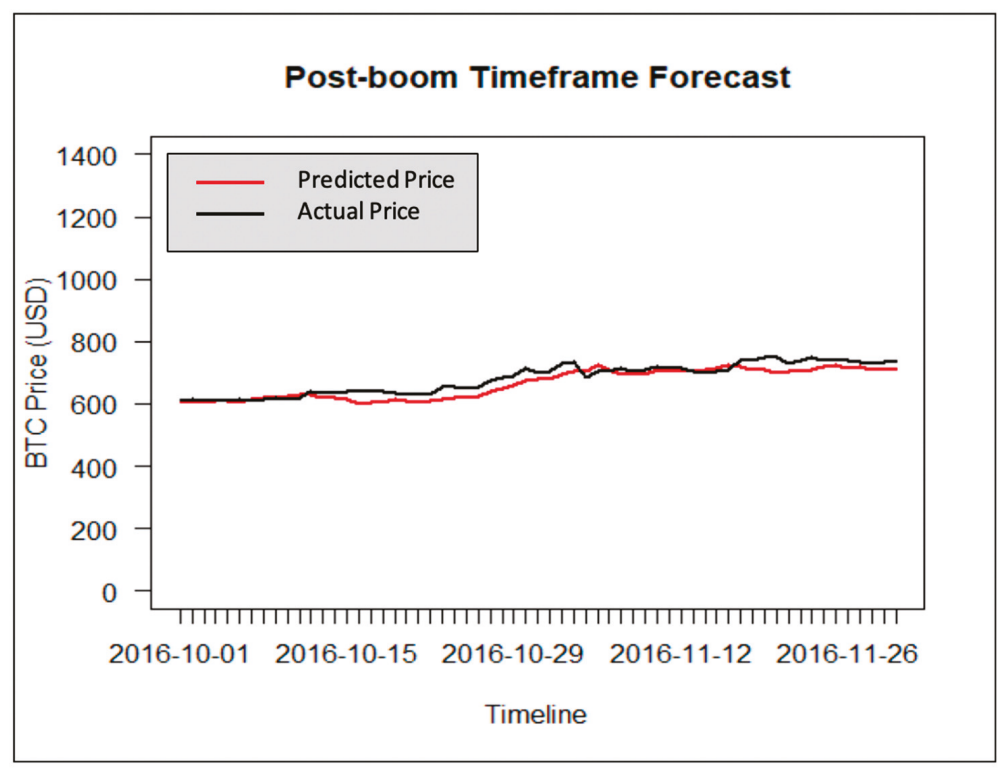

Figure 14. Forecasting Bitcoin closing price using Post-boom timeframe data (BVAR).

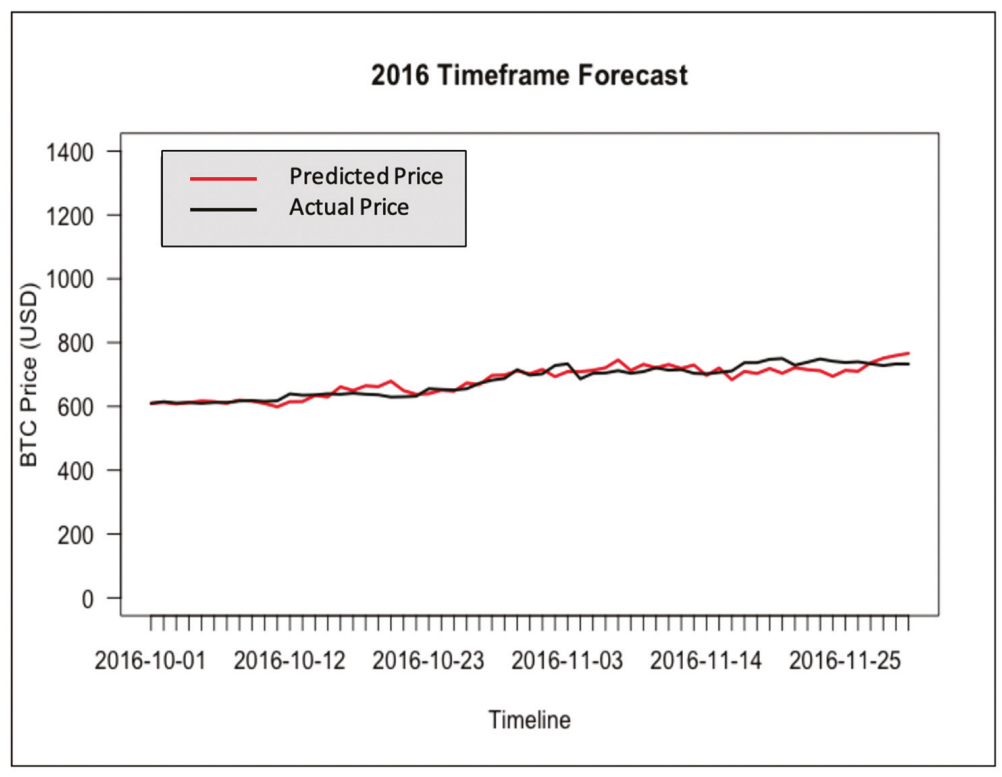

Figure 15. Forecasting Bitcoin closing price using Year of 2016 timeframe data (BVAR). 


\subsubsection{Results of the BVAR Model: Experiment B}

In this experiment, we evaluated the performance of the VAR model using the period [January 2011-August 2020] Full timeframe data, Post-boom timeframe data [January 2017-August 2020], and the Year of 2020 timeframe data [January 2020-August 2020], as shown in Figures 16-18. We can observe that the BVAR model could predict the values of the two endogenous variables (MWNUS, and TOTBC) effectively for the Post-boom period and the Year of 2020 only, while the MKPRU variable had its best prediction for the Year of 2020 alone. This experiment confirms that the BVAR model achieves better forecasting performance for short time periods.

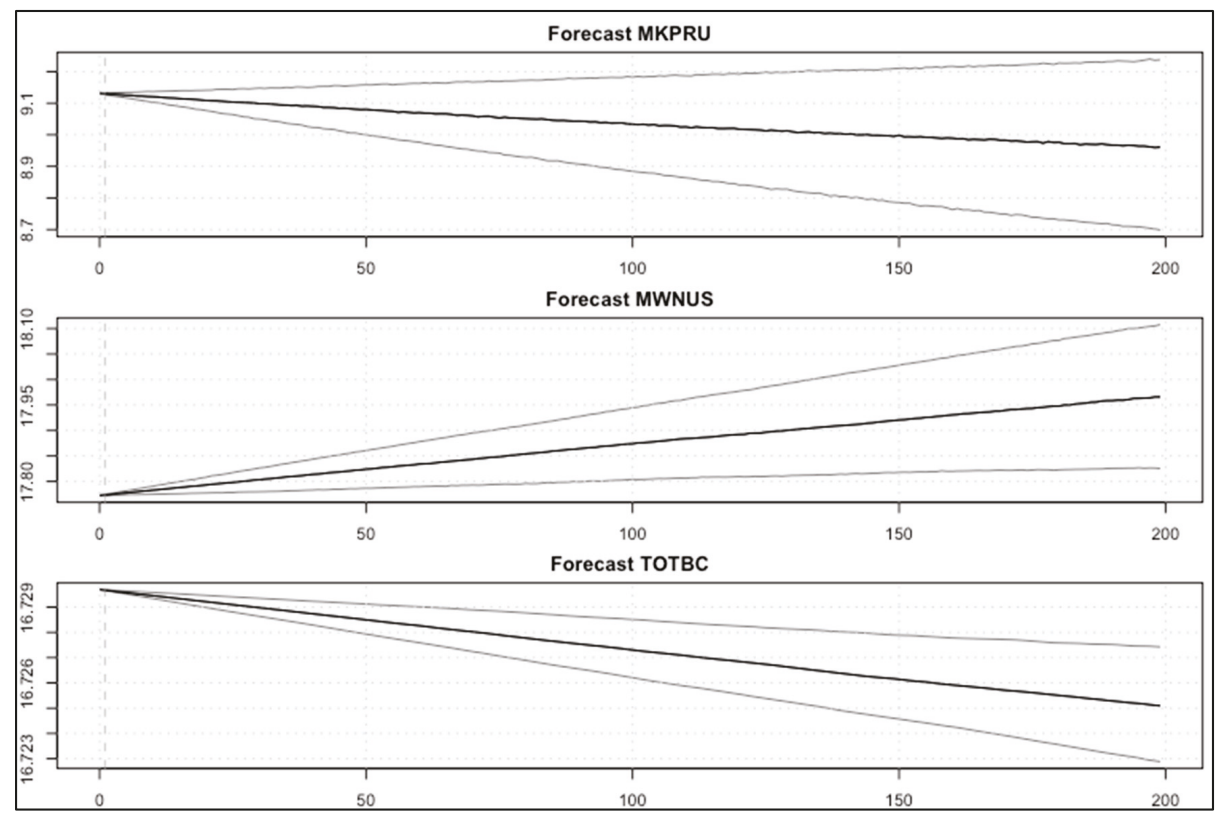

Figure 16. Forecasting the endogenous variables using Full timeframe data (BVAR). 


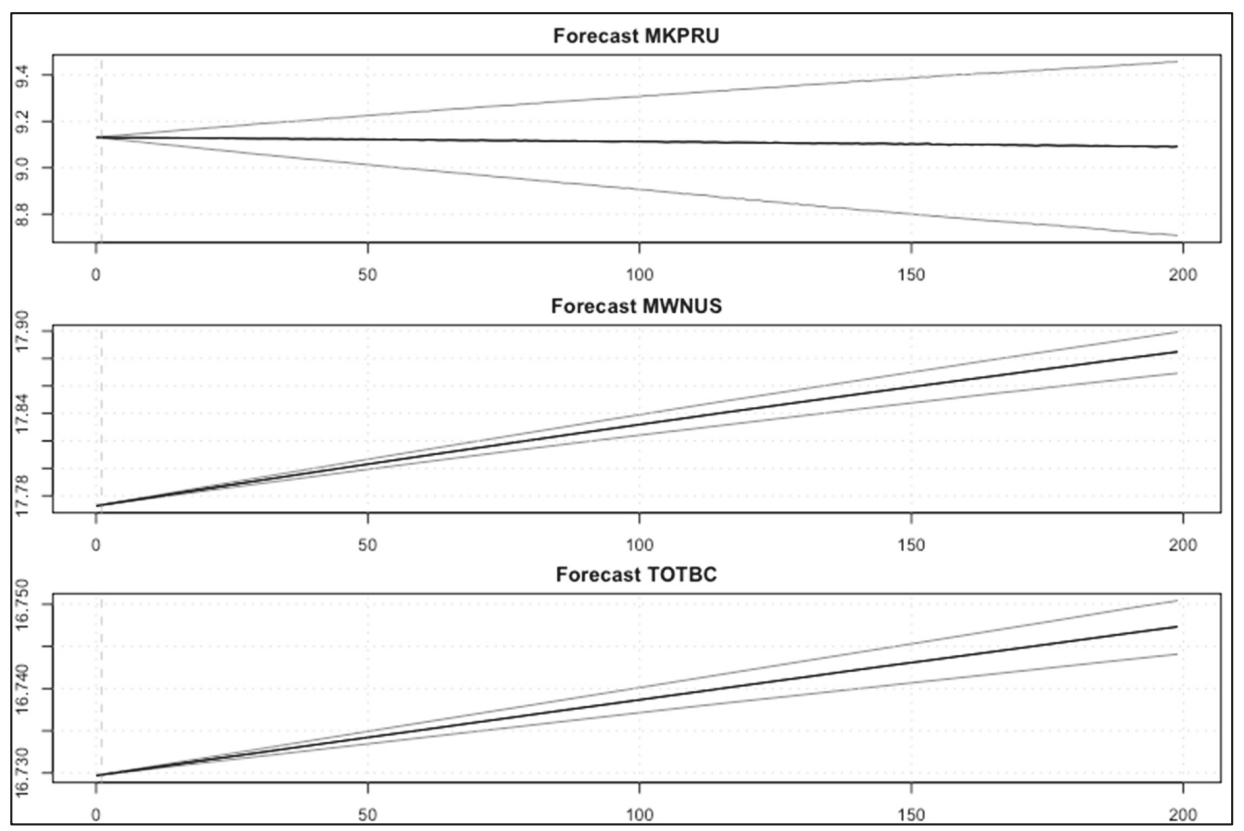

Figure 17. Forecasting the endogenous variables using Post-boom timeframe data (BVAR).

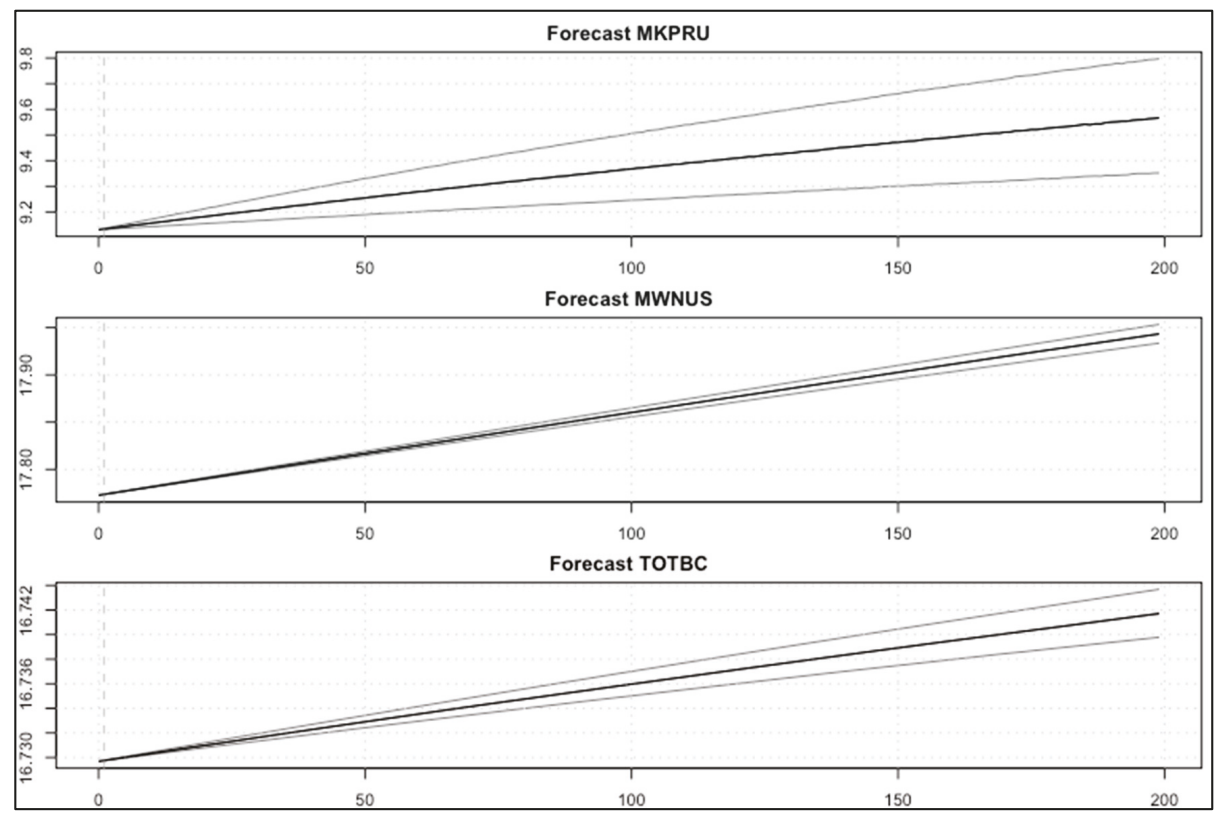

Figure 18. Forecasting the endogenous variables using Year of 2020 timeframe data (BVAR). 


\subsubsection{Analysis and Discussion of Results}

For the VAR model, the price of BTC was affected by short-term lag of itself as well as the number of MyWallet users. Surprisingly, it was not affected by the supply of BTC available on the market. One explanation for this could be that the supply of BTC is limited, and as such, this value is known by speculators beforehand as a market symmetric variable. The current BTC price was positively affected by $1,2,4,5,9,11,17$, and 20 day lags of itself. It was negatively impacted by $7,8,10,12,16$, and 18 day lags of itself, as shown in Table 1.

Table 1. Variables of significance and their effect.

\begin{tabular}{cc}
\hline Variables of Significance & Effect \\
\hline $1,2,4,5,9,11,17$, 20 day lag of BTC & + \\
$7,8,10,12,16,18$, day lag of BTC & - \\
$1,4,6,10$ day lag of MyWallet users & + \\
$2,5,12$ day lag of MyWallet users & - \\
Miner's Revenue, BTC Difficulty, Change in the Number of unique addresses & + \\
Number of Transactions per Block, Hash Rate & - \\
\hline
\end{tabular}

The effects of MyWallet users on BTC price were slightly positive overall. In terms of exogenous variables, the Miner's Revenue (+), Number of Transactions per Block (-), BTC Difficulty (+), the Change in the Number of unique addresses used $(+)$, and Hash Rate $(-)$ all played a significant part in estimating BTC. The $\mathrm{R}^{2}$ of the model was above $99 \%$, with F-Stats significant at a $99 \%$ confidence level, as shown in Table 2.

Table 2. $R^{2}$ and F-statistics.

\begin{tabular}{ccc}
\hline Variable & $\mathbf{R}^{\mathbf{2}}$ & F-Statistics \\
\hline BTC Price & $99+\%$ & $99+\%$ \\
MyWallet User & $99+\%$ & $99+\%$ \\
Total BTC & $99+\%$ & $99+\%$ \\
\hline
\end{tabular}

In addition to analyzing the individual factors of influence on Bitcoin price, the VAR model predicted a great pattern of fluctuating prices. Compared with the forecasting price curves from the VAR model, the BVAR model gave a more accurate prediction of Bitcoin price to the actual values in general. Additionally, the availability and completeness of the input data played a significant role in the performance of the VAR model, while the BVAR model achieved a great forecasting result with a low percentage error rate while using only data of the years 2016 and 2020. The results demonstrate that the BVAR model performed well for a fairly limited number of observations.

\subsection{Comparative Analysis}

In this section, we compare the performance of the VAR and BVAR models with some of the well-known autoregression and Bayesian regression algorithms, including the autoregression integrated moving average (ARIMA) (Chu et al. 2017; Hencic and Gouriéroux 2017) and Bayesian regression (BR) (Shah and Zhang 2014). ARIMA is a commonly used model to predict the price, and the model is a combination of three basic time-series models: autoregressive, moving average, and autoregressive moving average. Bayesian regression uses statistical analysis within the context of Bayesian inference rules. The comparison was made based on the values of the root mean squared Error (RMSE), the mean absolute error (MAE), and the mean absolute percentage error (MAPE) (Tan and Kashef 2019; Tobin and Kashef 2020). In this section, we focus on the data timeframe from Experiment B [January 2011-August 2020] and the variable of interest MKPRU (the equilibrium closing price of the BTC market as denominated by the US dollar). As shown in Tables 3-5, for the Full timeframe, the VAR model had the best performance. For the Post-boom timeframe, both the VAR 
and the BVAR models had the lowest RMSE, MAPE, and MAE values. Finally, for the Year of 2020, the VAR and the BVAR models had better performance than the ARIMA and BR models.

Table 3. Accuracy of forecasting models: Full Timeframe.

\begin{tabular}{cccc}
\hline & MAPE & RMSE & MAE \\
\hline VAR & 0.0249 & 0.3102 & 0.2260 \\
ARIMA $(2,2,1)$ & 0.0421 & 0.3900 & 0.3258 \\
BR & 0.0362 & 0.3554 & 0.3826 \\
BVAR & 0.0286 & 0.3375 & 0.2501 \\
\hline
\end{tabular}

Table 4. Accuracy of forecasting models: Post-boom timeframe.

\begin{tabular}{cccc}
\hline & MAPE & RMSE & MAE \\
\hline VAR & 0.0248 & 0.2708 & 0.2212 \\
ARIMA $(2,2,1)$ & 0.0421 & 0.3900 & 0.3258 \\
BR & 0.0351 & 0.3693 & 0.2776 \\
BVAR & 0.0264 & 0.2806 & 0.2286 \\
\hline
\end{tabular}

Table 5. Accuracy of forecasting models: Year of 2020 timeframe.

\begin{tabular}{cccc}
\hline & RMSE & MAE & MAPE \\
\hline VAR & 0.0123 & 0.1235 & 0.1023 \\
ARIMA $(2,2,1)$ & 0.0143 & 0.1908 & 0.1262 \\
BR & 0.0129 & 0.1418 & 0.1158 \\
BVAR & 0.0130 & 0.1273 & 0.1247 \\
\hline
\end{tabular}

\section{Conclusions and Future Directions}

In this paper, two VAR models were developed to analyze and understand the mechanics of the BTC market. The developed models were tested in predicting the endogenous variables using selected features of exogenous variables. The two models were compared with the state-of-the-art forecasting models in order to show their efficiency. This research presents a powerful way to predict Bitcoin market price and an interesting look at what factors of this BTC network can shape new innovations in blockchain and the future of digital currency. As a new currency not administered by the government, there are many interesting behaviors that can be studied. From the perspective of miners, investors, or users of BTC, these findings may be useful for understanding the movements of the price of the BTC, and could help to understand what influence each of the exogenous factors has on the price of BTC. Future experiments for BTC prices will use a non-linear or dynamic VAR, which is suitable for BTC simulation. Dynamic VAR accounts for the change in a relationship by allowing the coefficients to change over time, which makes it much more challenging to analyze. The technical indicator could be extended as an exponential moving average or volume-weighted average price. Different priors can be suggested for future directions, such as the independent normal-Wishart. Additionally, analyzing the daily market returns in order to understand the distribution of daily behavior could provide insight into the classification of upward and downward trends. Incorporating the classification would enable research to understand price action in more depth with increasingly sophisticated machine-learning or nonlinear models. Finally, further investigation combing machine-learning prediction models is recommended.

Author Contributions: Software, A.I., E.V.; Supervision, R.K.; Visualization, A.I., E.V., M.L., and E.H.; Writing-original draft, A.I.; Writing—review \& editing, A.I. and R.K.; Validation, A.I. and M.L.; Source-A.I., M.L., E.V., and E.H. All authors have read and agreed to the published version of the manuscript.

Funding: This research received no external funding.

Conflicts of Interest: The authors declare no conflict of interest. 


\section{References}

Alquist, R., L. Kilian, and R. J. Vigfusson. 2013. Forecasting the Price of Oil. Handbook of Economic Forecasting 2: 427-507.

Antonopoulos, Andreas M. 2014. Mastering Bitcoin. Unlocking Digital Crypto-Currencies. Newton: O'Reilly Media. Anupriya, and Shruti Garg. 2018. Autoregressive Integrated Moving Average Model based Prediction of Bitcoin Close Price. Paper presented at the 2018 International Conference on Smart Systems and Inventive Technology (ICSSIT), Tirunelveli, India, December 13-14.

Ariyo, Ayodele Adebiyi, Aderemi Adewumi, and Charles Ayo. 2014. Stock Price Prediction Using the ARIMA Model. Paper presented at the 2014 UKSim-AMSS 16th International Conference on Computer Modelling and Simulation, Cambridge, UK, March 26-28; pp. 106-12.

Bakar, Nashirah Abu, and Sofian Rosbi. 2017. Autoregressive integrated moving average (arima) model for forecasting cryptocurrency exchange rate in high volatility environment: A new insight of bitcoin transaction. International Journal of Advanced Engineering Research and Science 4: 130-37. [CrossRef]

Barski, Conrad, and Chris Wilmer. 2015. Bitcoin for the Befuddled. San Francisco: No Starch Press.

Bianchi, Daniele, Matteo Iacopini, and Luca Rossini. 2020. Stablecoins and Cryptocurrency Returns: Evidence from Large Bayesian Vars. SSRN Working Paper. Available online: https://ssrn.com/abstract=3605451 (accessed on 15 June 2020).

Bianchi, Daniele. Forthcoming. Cryptocurrencies as an asset class? An empirical assessment. Journal of Alternative Investment. [CrossRef]

Bitcoin Charts. 2020. Bitcoincharts. Available online: https://bitcoincharts.com/charts/ (accessed on 18 August 2020).

Bohte, Rick, and Luca Rossini. 2019. Comparing the forecasting of cryptocurrencies by bayesian time- varying volatility models. Journal of Risk and Financial Management 12: 150. [CrossRef]

Brito, Jerry. 2014. "Bitcoin: Examining the Benefits and Risks for Small Business," Statement from Jerry Brito. Available online: https://www.govinfo.gov/content/pkg/CHRG-113hhrg87403/pdf/CHRG-113hhrg87403.pdf (accessed on 2 April 2014).

Campbell, John Young, Andrew Wen-Chuan Lo, and Craig MacKinlay. 1996. The Econometrics of Financial Markets. Princeton: Princeton University Press.

Carriero, Andrea, George Kapetanios, and Massimiliano Marcellino. 2009. Forecasting exchange rates with a large Bayesian VAR. International Journal of Forecasting 25: 400-17. [CrossRef]

Catania, Leopoldo, Stefano Grassi, and Francesco Ravazzolo. 2019. Forecasting cryptocurrencies under model and parameter instability. International Journal of Forecasting 35: 485-501. [CrossRef]

Chu, Jeffrey, Stephen Chan, Saralees Nadarajah, and Joerg Osterrieder. 2017. GARCH modelling of cryptocurrencies. Journal of Risk and Financial Management 10: 17. [CrossRef]

Cocco, Luisanna, and Michele Marchesi. 2016. Modeling and Simulation of the Economics of Mining in the Bitcoin Market. PLoS ONE 11: 10. [CrossRef] [PubMed]

Felizardo, Leonardo, Roberth Oliveira, Emilio Del-Moral-Hernandez, and Fabio Cozman. 2019. Comparative study of Bitcoin price prediction using WaveNets, Recurrent Neural Networks and other Machine Learning Methods. Paper presented at 20196th International Conference on Behavioral, Economic and Socio-Cultural Computing (BESC), Beijing, China, October 28-30.

Hashish, Iman Abu, Fabio Forni, Gianluca Andreotti, Tullio Facchinetti, and Shiva Darjani. 2019. A Hybrid Model for Bitcoin Prices Prediction using Hidden Markov Models and Optimized LSTM Networks. Paper presented at the 2019 24th IEEE International Conference on Emerging Technologies and Factory Automation (ETFA), Zaragoza, Spain, September 10-13.

Hencic, Andrew, and Christian Gouriéroux. 2017. "Noncausal Autoregressive Model in Application to bitcoin/USD Exchange Rates." Econometrics of Risk. Cham: Springer, pp. 17-40.

Ito, Takatoshi, and Kiyotaka Sato. 2006. Exchange Rate Changes and Inflation in Post-Crisis Asian Economies: VAR Analysis of the Exchange Rate Pass-Through. National Bureau of Economic Research 40: 1407-38.

Koop, Gary, and Dimitris Korobilis. 2009. Bayesian Multivariate Time Series Methods for Empirical Macroeconomics. Foundations and Trends ${ }^{\circledR}$ in Econometrics 3: 267-358. [CrossRef]

Koray, Faik, and William Lastrapes. 1989. Real Exchange Rate Volatility and U.S. Bilateral Trade: A Var Approach. The Review of Economics and Statistics 71: 708. [CrossRef] 
Kuschnig, Nikolas, and Lukas Vashold. 2019. BVAR: Bayesian Vector Autoregressions with Hierarchical Prior Selection in R. Department of Economics Working Paper No. 296. Available online: https://epub.wu.ac.at/ 7216/1/WP296.pdf (accessed on 22 October 2019).

Kuschnig, Nikolas, Lukas Vashold, Michael McCracken, and Serena Ng. 2020. "Package 'BVAR,'” CRAN-Project. Available online: https://cran.r-project.org/web/packages/BVAR/BVAR.pdf (accessed on 6 May 2020).

Litterman, Robert. 1980. A Bayesian Procedure for Forecasting with Vector Autoregressions. MIT Working Paper. Cambridge: MIT.

Miranda-Agrippino, Silvia, and Giovanni Ricco. 2018. Bayesian vector autoregressions. Staff Working Paper No. 756. Available online: https://www.bankofengland.co.uk/-/media/boe/files/working-paper/2018/bayesianvector-autoregressions.pdf?la=en\&hash=1C0BC1906BDCB85150FFF8D2D4321C8CB6D43F91 (accessed on 1 September 2018).

Nakamoto, Satoshi. 2008. Bitcoin: A Peer-to-Peer Electronic Cash System (PDF). Archived (PDF) from the original on 20 March 2014. Available online: bitcoin.org (accessed on 28 April 2014).

Pagnottoni, P., and T. Dimpfl. 2019. Price discovery on Bitcoin markets. Digital Finance 1: 139-61. [CrossRef]

Quandl. 2020. quandl.com. Available online: https://www.quandl.com/data/BCHAIN (accessed on 18 August 2020).

Rane, Prachi Vivek, and Sudhir Dhage. 2019. Systematic Erudition of Bitcoin Price Prediction using Machine Learning Techniques. Paper presented at the 2019 5th International Conference on Advanced Computing \& Communication Systems (ICACCS), Coimbatore, India, March 15-16.

Roy, Shaily, Samiha Nanjiba, and Amitabha Chakrabarty. 2018. Bitcoin Price Forecasting Using Time Series Analysis. Paper presented at the 2018 21st International Conference of Computer and Information Technology (ICCIT), Dhaka, Bangladesh, December 21-23.

Shah, Devavrat, and Kang Zhang. 2014. Bayesian regression and Bitcoin. Paper presented at the 2014 52nd Annual Allerton Conference on Communication, Control, and Computing, Allerton, IL, USA, October 1-3.

Sims, Christopher. 1980. Macroeconomics and Reality. Econometrica: Journal of the Econometric Society 48: 1-48. [CrossRef]

Sims, Christopher. 1993. A Nine-Variable Probabilistic Macroeconomic Forecasting Model. In Business Cycles, Indicators and Forecasting. Chicago: University of Chicago Press, pp. 179-212.

Tan, Xue, and Rasha Kashef. 2019. Predicting the closing price of cryptocurrencies: A comparative study. Paper presented at the Second International Conference on Data Science, E-Learning and Information Systems (DATA '19), Dubai, Arab Emirates, December 2-5; New York: Association for Computing Machinery, pp. 1-5. [CrossRef]

Tandon, Sakshi, Shreya Tripathi, Pragya Saraswat, and Chetna Dabas. 2019. Bitcoin Price Forecasting using LSTM and 10-Fold Cross validation. Paper presented at the 2019 International Conference on Signal Processing and Communication (ICSC), Noida, India, March 7-9.

Tobin, Turner, and Rasha Kashef. 2020. Efficient Prediction of Gold Prices Using Hybrid Deep Learning. In Image Analysis and Recognition. ICIAR 2020. Lecture Notes in Computer Science. Edited by A. Campilho, Fakhri Karray and Z. Wang. Cham: Springer, vol. 12132. [CrossRef]

United States Securities and Exchange Commission. 2017. Annual Report Archive. Available online: http://www.annualreports.com/HostedData/AnnualReportArchive/m/AMEX_MGT_2017.pdf (accessed on 31 December 2017).

Wang, Shujuan, Shujun Ye, and Xinyang Li. 2017. The impact of real effective exchange rate volatility on economic growth in the process of renminbi internationalization an empirical study based on VAR model. Paper presented at the 2017 4th International Conference on Industrial Economics System and Industrial Security Engineering (IEIS), Kyoto, Japan, July 24-27.

Wu, Chih-Hung, Chih-Chiang Lu, Yu-Feng Ma, and Ruei-Shan Lu. 2018. A New Forecasting Framework for Bitcoin Price with LSTM. Paper presented at the 2018 IEEE International Conference on Data Mining Workshops (ICDMW), Singapore, November 17-20.

(C) 2020 by the authors. Licensee MDPI, Basel, Switzerland. This article is an open access article distributed under the terms and conditions of the Creative Commons Attribution (CC BY) license (http://creativecommons.org/licenses/by/4.0/). 

MDPI

St. Alban-Anlage 66

4052 Basel

Switzerland

Tel. +41616837734

Fax +4161302 8918

www.mdpi.com

Journal of Risk and Financial Management Editorial Office

E-mail: jrfm@mdpi.com www.mdpi.com/journal/jrfm

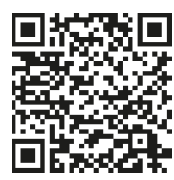



MDPI

St. Alban-Anlage 66

4052 Basel

Switzerland

Tel: +41 616837734

Fax: +41 613028918

www.mdpi.com 